\title{
Metodologia de Inspeção Visual utilizando Limiar ("Threshold") Entrópico com Aplicações na Classificação de Placas de Madeira
}

Evandro Luis Linhari Rodrigues

USP/IFSC/SBI

Tese apresentada ao Instituto de Física de São Carlos, da Universidade de São Paulo, para obtenção do título de Doutor em Ciências: "Física Aplicada sub-área Física Computacional".

Orientador: Prof. Dr. Valentin Obac Roda 
Rodrigues, Evandro Luis Linhari Rodrigues

Metodologia de Inspeção Visual utilizando Limiar ("Threshold") Entrópico com Aplicações na Classificação de Placas de Madeira/Evandro Luis Linhari Rodrigues. - São Carlos, 1998. $174 \mathrm{p}$.

Tese (Doutorado)—Instituto de Física de São Carlos, 1998.

Orientador: Prof. Dr. Valentin Obac Roda

1. Inspeção Visual. 2. Limiar Entrópico. 3. Placas de Madeira. I. Título 


\section{UNIVERSIDADE

MEMBROS DA COMISSÃO JULGADORA DA TESE DE DOUTORADO DE EVANDRO LUIS LINHARI RODRIGUES APRESENTADA AO INSTITUTO DE FÍSICA DE SÃO CARLOS, DA UNIVERSIDADE DE SÃO PAULO, EM 11 DE MAIO DE 1998.

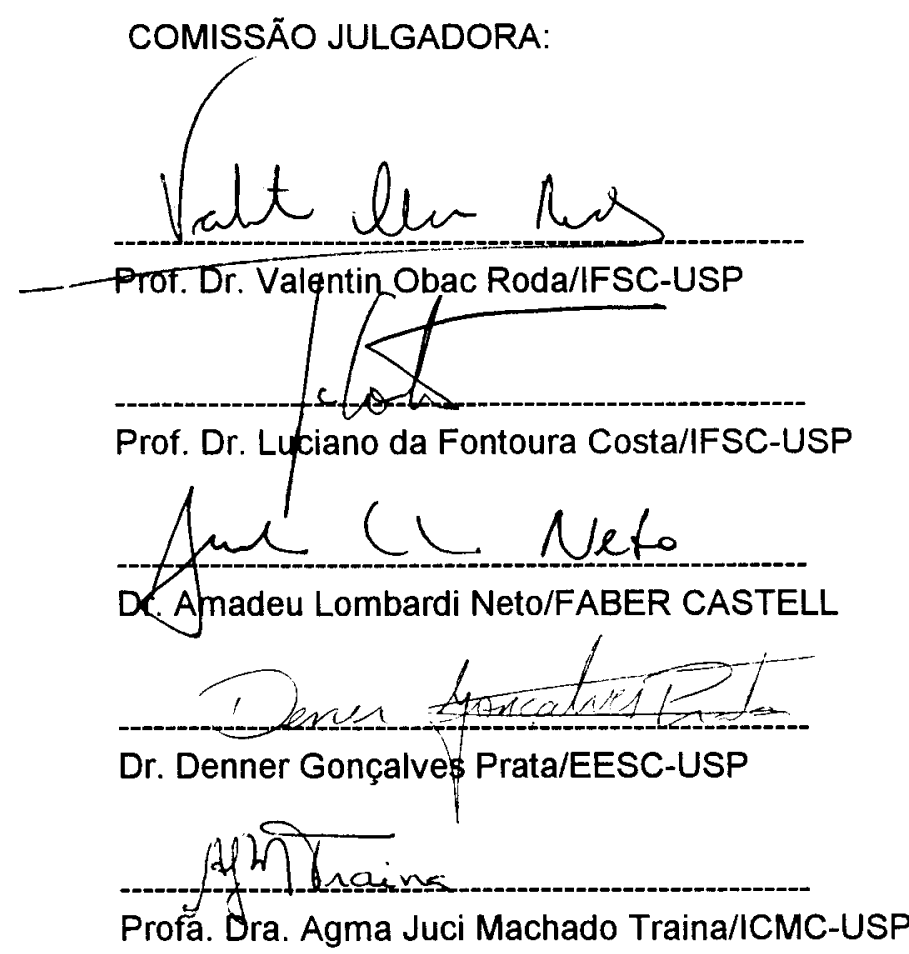


Dedico este trabalho a minha esposa Silvia, às minhas filhas Camila e Marília, pelo incentivo interminável, privações e sacrifícios. 


\section{AGRADECIMENTOS}

Gostaria de agradecer a todas as pessoas que de uma forma ou de outra, me ajudaram na realização deste trabalho.

De forma especial, gostaria de agradecer,

- Ao Prof. Dr. Valentin Obac Roda, meu orientador, que com sua imensa paciência e valiosa orientação, tornou possível a realização deste trabalho.

- Ao Prof. Dr. Adilson Gonzaga, pela inestimável colaboração nas discussões de idéias, pela amizade, pelas correções de texto, e pelo "alívio" da carga didática durante esses anos todos.

- A Prof ${ }^{\mathrm{a}}$ Dra. Maria Stela, pelo auxílio nas atividades acadêmicas.

- Ao Manoel e ao Celso, pelas discussões enriquecedoras e pelo apoio em muitas tarefas.

- Ao Ruy Bertho, pelo apoio técnico.

- Ao Dr. Eng. Amadeu Lombardi, por todo auxílio e prestatividade sem fim.

- A Eng. Eliane, pela sua colaboração.

- A Faber-Castell, pelo material de pesquisa.

Não poderia deixar de agradecer de forma especial e particular, aos meus pais Luiz e Leontina, aos meus irmãos Rose, Hamilton, Giza, Dami, Samir e Ketti, e aos meus sogros Luiz e Geni, de onde sempre tirei aquela "energia a mais" e a Deus por me permitir fazer parte dessa familia. Muito obrigado. 


\section{SUMÁRIO}

Lista de Figuras

Lista de Tabelas

Resumo

Abstract

1 - Motivação e objetivos

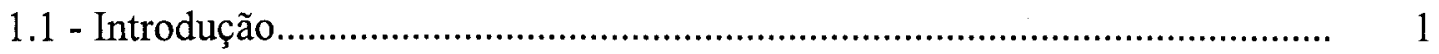

1.2 - Objetivos e justificativas...................................................................... 2

1.3 - Organização da tese........................................................................... 5

2 - Bases Teóricas

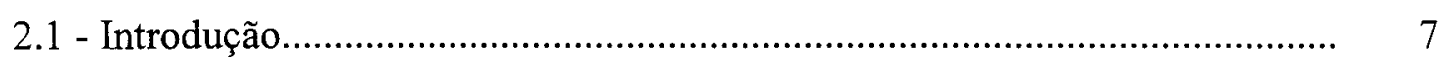

2.2 - Visão Computacional......................................................................... 7

2.3 - Inspeção Visual................................................................................... 11

2.4 - Reconhecimento de Padrões............................................................... 18

2.4.1 - Classificadores.......................................................................... 22

2.5 - Considerações finais......................................................................... 28

3 - A fabricação do lápis e a inspeção visual em madeiras

3.1 - Introdução....................................................................................... 29

3.2 - História do lápis.............................................................................. $\quad 30$

3.3 - O ciclo de produção do lápis................................................................... 33

3.4 - Inspeção visual em madeiras.................................................................. 34

3.5 - Considerações finais................................................................... 40

4 - Determinação das classes

4.1 - Introdução....................................................................................... 42

4.2 - Características básicas para definição de classes........................................ 43

4.2.1 - Composição estrutural transversal das árvores.................................... 44

4.2 .2 - Anéis de crescimento................................................................. 47 
4.3 - Definindo as classes..................................................................... 50

4.3 .1 - Placas classe A.............................................................................. 53

4.3 .2 - Placas classe B........................................................................... 53

4.3 .3 - Placas classe C..................................................................... 54

4.3 .4 - Placas classe D ............................................................................. 55

4.3.5 - Placas classe X......................................................................... 57

4.4 - Considerações finais.......................................................................... 57

\section{5 - Os Métodos Propostos}

5.1 - Introdução..................................................................................... 61

5.2 - Subdivisão das placas em regiões (janelamento).................................. 60

5.3 - Extração de características..................................................................... 61

5.3.1 - Cálculo da entropia........................................................................ 65

5.3 .2 - Algoritmo de extração dos valores-característica................................. 68

5.4 - Classificação das placas......................................................................... $\quad 70$

5.4.1 - Algoritmo de pré-classificação para cada região................................ 71

5.4.2. Classificador por redução de informação baseado em regras de combinação.................................................................................. 73

5.4 .3 - Classificador utilizando matriz de co-ocorrência................................ 79

5.5 - Considerações finais............................................................................. 83

6 - Aplicação dos métodos e discussões

6.1 - Introdução....................................................................................... 84

6.2 - O sistema de inspeção visual e seus componentes.................................. 85

6.3 - Estabelecimento e verificação dos valores limites utilizados no algoritmo de pré-classificação............................................................................ 90

6.4 - Análise dos resultados obtidos pelos algoritmos de classificação final...... 110

6.4.1 - Comparação das classificações.......................................................... 111

6.5 - Erros de classificação......................................................................... 120

6.6 - Considerações finais........................................................................ 122

7 - Contribuições, trabalhos futuros e conclusões finais

7.1 - Contribuições 
7.2 - Trabalhos futuros. 126

7.3 - Conclusões finais.

Anexo A : Limiarização

Anexo B : Tabela de classificação do conjunto de 199 placas.

Referências bibliográficas.

Apêndice 1 : Componentes e características principais utilizados na aquisição das imagens das placas. 


\section{Lista de figuras}

Figura 2.1 - Sistema classificador de padrões genérico

Figura 2.2 - Função discriminante de Bayes para problema uni-dimensional.......... 24

Figura 3.1 - Etapas do processo de produção do lápis (figura retrabalhada extraída de http://www.pencils.com/)......

Figura 4.1 - Corte transversal de uma árvore (extraída de [Hellmeister, 1972] e retrabalhada)

Figura 4.2 - Métodos de corte (ou desdobro) (extraída de [Findlay, 1975])

Figura 4.2 - Deformações em função da secagem, sofridas pela madeira em várias posições. (extraída de [Petrucci, 1975])

Figura 4.4 - Placa de madeira do tipo "lisa", desprovida de madeira dura dos anéis de crescimento.

Figura 4.5 - Placa de madeira oriunda de "corte radial"

Figura 4.6 - Placa de madeira oriunda de "corte tangencial"

Figura 4.7 - Placa da classe $B$ que apresenta poucos anéis de crescimento.

Figura 4.8 - Placa da classe $B$ apresentando vasos medulares normais à superfície e poucos anéis de crescimento.

Figura 4.9 - Placa da classe $B$ com pequenas regiões com alterações de cor.

Figura 4.10 - Placa mista de classe $A$ e classe $C$, adotada como classe $C$.

Figura 4.11 - Placa classe $D$ com número de anéis de crescimento maior que nove. 
Figura 4.12 - Placa classe $D$ com espessura da parte de madeira dura do anel maior que $1.5 \mathrm{~mm}$ e número de anéis superior a nove.

Figura 4.13 - Placa classe $D$ com pouca presença de madeira de verão.

Figura 4.14 - Placa produzida por corte tangencial pertencente à classe $X$.

Figura 5.1 - Subdivisão das placas em 36 regiões de processamento

Figura 5.2 - Entropia normalizada para o caso de duas possibilidades com probabilidades $p$ e $(1-p)$ e todas as amostras de uma distribuição qualquer com mesma probabilidade.

Figura 5.3 - (p) $\log (p)$ normalizada, com limiar encontrado (vermelho) e pico máximo (azul)

Figura 5.4 - (1-p) $\log (1-p)$ normalizada, com limiar encontrado (vermelho) e pico máximo (azul)

Figura 5.5 - Histograma da região 9 da figura 5.1

Figura 5.6 - Função densidade de probabilidade -região 9 da figura 5.1.

Figura 5.7 - Curva de Entropia - região 9 da figura 5.1

Figura 5.8 - Curva da parcial $\left(-P_{t} \log P_{t}\right)$ - região 9 da figura 5.1

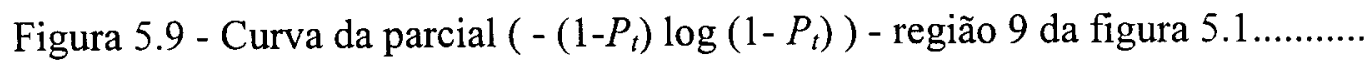

Figura 5.10 - Placa pré-classificada.

Figura 5.11 - Redução de informação por linhas

Figura 5.12 - Obtenção da classe final por redução de informação.

Figura 6.1 - Sistema de inspeção visual genérico.

Figura 6.2 - Ambiente com iluminação indireta sobre o objeto utilizado no trabalho.

Figura 6.3 - Iluminação direta sobre o objeto utilizada no trabalho

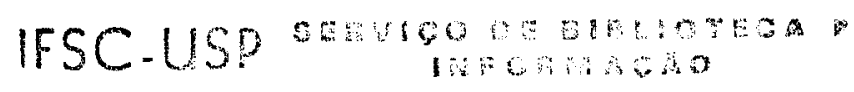


Figura 6.4 - Placa pertencente à classe desprovida de anéis de crescimento com a numeração das regiões, que gerou os valores da tabela 6.1

Figura 6.5 - Placa pertencente à classe com anéis de crescimento e proveniente de corte radial com a numeração das regiões, que gerou os valores da tabela 6.2

Figura 6.6 - Placa pertencente à classe com anéis de crescimento e proveniente de corte tangencial com a numeração das regiões, que gerou os valores da tabela 6.3

Figura 6.7 - Pré-classificação por regiões da placa da figura 6.4 com a aplicação do algoritmo do sub-item (5.4.1) sobre a tabela 6.1

Figura 6.8 - Pré-classificação por regiões da placa da figura 6.5 com a aplicação do algoritmo do sub-item (5.4.1) sobre a tabela 6.2

Figura 6.9 - Pré-classificação por regiões da placa da figura 6.6 com a aplicação do algoritmo do sub-item (5.4.1) sobre a tabela 6.3

Figura 6.10 - Distribuições normalizadas dos valores de limiar das trinta e seis regiões para as figuras $6.4,6.5$ e 6.6 com médias e desvios padrões mostrados nas duas ultimas linhas das tabelas $6.1,6.2$ e 6.3 .

Figura 6.11 - Distribuições normalizadas dos valores de Entropia das trinta e seis regiões para as figuras $6.4,6.5$ e 6.6 com médias e desvios padrões mostrados nas duas ultimas linhas das tabelas $6.1,6.2$ e 6.3

Figura 6.12 - Distribuições normalizadas dos valores de Razão de Assimetria da curva de Entropia das trinta e seis regiões para as figuras 6.4, 6.5 e 6.6, com médias e desvios padrões mostrados nas duas ultimas linhas das tabelas $6.1,6.2$ e 6.3

Figura 6.13 - Distribuições normalizadas dos valores de Diferença de Limiar tomada nos picos das Entropias parciais das trinta e seis regiões para as figuras $6.4,6.5$ e 6.6 , com médias e desvios padrões mostrados nas duas ultimas linhas das tabelas $6.1,6.2$ e 6.3

Figura 6.14 - Distribuição normalizada de Limiar para o primeiro conjunto de 
amostras (104 placas)

Figura 6.15 - Distribuição normalizada de Limiar para o segundo conjunto de amostras (199 placas)

Figura 6.16 - Distribuição normalizada dos valores de Entropia para o primeiro conjunto de amostras (104 placas)

Figura 6.17 - Distribuição normalizada dos valores de Entropia para o segundo conjunto de amostras (199 placas)

Figura 6.18 - Distribuição normalizada de Razão de assimetria da curva de Entropia para o primeiro conjunto de amostras (104 placas).

Figura 6.19 - Distribuição normalizada de Razão de assimetria da curva de Entropia para o segundo conjunto de amostras (199 placas)

Figura 6.20 - Distribuição normalizada de Diferença entre valores de Limiar tomados nos picos das equações parciais de Entropia para o primeiro conjunto de amostras (104 placas)

Figura 6.21 - Distribuição normalizada de Diferença entre valores de Limiar tomados nos picos das equações parciais de Entropia para o segundo conjunto de amostras (199 placas)

Figura 6.22 - Pré-classificação da placa número 53 do segundo conjunto

Figura 6.23- Placa 103 do segundo conjunto, mostrando a inversão de relação da área dos anéis de crescimento. 


\section{Lista de tabelas}

Tabela 5.1 - Relações entre combinações de quatro classes, soma dos códigos ASCII das combinações e as classes resultantes..

Tabela 5.2 - Relações entre combinações de três classes, soma dos códigos ASCII das combinações e a classes resultantes.

Tabela 5.3 - Matriz de co-ocorrência de vizinhança horizontal uni-direcional das regiões.

Tabela 5.4 - Matriz de porcentagem de co-ocorrências..

Tabela 5.5 - Matriz de probabilidades com somatórias de linhas e colunas

Tabela 5.6 - Combinação dos rótulos Linha-Coluna para geração das classes resultantes.

Tabela 6.1 - Valores-característica para as regiões da placa da figura 6.4 .

Tabela 6.2 - Valores-característica para as regiões da placa da figura 6.5 .

Tabela 6.3 - Valores-característica para as regiões da placa da figura 6.6.

Tabela 6.4 - Freqüências de ocorrências de classes da tabela B.1 (anexo B)

Tabela 6.5 - Freqüências observadas e esperadas das classes.

Tabela 6.6 - Coincidências de classificação entre os classificadores obtidas da tabela B.1

Tabela 6.7 - Coincidências entre os classificadores obtidas da tabela B.1 considerando as classificações de avizinhamento de classes.

Tabela B.1 - Classificação realizada no conjunto de 199 placas, pelos inspetores e pelos métodos. 


\section{Resumo}

O objetivo deste trabalho é o desenvolvimento de um método dedicado de classificação para placas de madeira utilizadas na fabricação de lápis, utilizando procedimentos de visão computacional.

$\mathrm{O}$ processo aqui proposto, foi idealizado buscando uma metodologia que pudesse ser realizada com baixa complexidade computacional, ou seja, os cálculos dos algoritmos utilizando apenas operações simples - do tipo soma, subtração, multiplicação e divisão - em imagens em níveis de cinza. A intenção em utilizar apenas as operações básicas citadas, tem o objetivo de tornar o método implementável em arquiteturas com tecnologia VLSI, notadamente em Arquiteturas Sistólicas.

O trabalho descreve o ciclo de produção do lápis localizando a etapa onde é proposta a metodologia de classificação das placas de madeira. Nesta etapa, há uma sequência de procedimentos, descritos ao longo do trabalho, que compreendem a aquisição da imagem das placas, a extração de características das imagens, o processamento dessas características e por fim os algoritmos de classificação. Na etapa de extração de características, buscou-se com a aplicação de um método de Limiar automático que utiliza a entropia de Shannon, extrair informações suficientes para classificar adequadamente as placas de madeiras em diferentes classes, fornecendo dessa forma, um sistema ágil, repetitivo e de baixo custo para aproveitamento da madeira em diferentes produtos finais. 


\section{Abstract}

The objective of this work was to develop a dedicated computer vision method for the classification of wooden plates used in pencil manufacturing.

The process here proposed was idealized looking for a low computational complexity methodology that could be accomplished in VLSI, as for instance using Systolic Computer Architectures made of logic arrays.

The pencil cycle of production is described, locating the stage where the proposed classification methodology should be used. There is a sequence of procedures, along the work, that describe the acquisition, extraction of the characteristics and the processing of the images, and finally the classification algorithms.

For the extraction of characteristics of the images, it was used an automatic method for the threshold determination, based on Shannon's entropy. The information supplied by the threshold determination method allows classifying the plates in different classes.

The analysis of the results showed that the method performs well is repetitive and efficient on the classification and its use can be extended to classify other final products. 


\section{Capítulo 1}

\section{Motivação e Objetivos}

\section{1 - INTRODUÇÃO}

A Visão de Máquina (ou Visão Computacional) de uma forma geral, consolidase cada vez mais como fundamental em diversas áreas de aplicação (engenharia, medicina, comércio, dentre outras). Ao longo das últimas três décadas a Visão Computacional vem se desenvolvendo a largos passos, beneficiando-se também de pesquisas e resultados de áreas de investigação correlacionadas como processamento de imagens, reconhecimento de padrões, psicofísica, neurociência, e também das tecnologias de hardware, dentre outras.

Nesse universo, a Inspeção Visual Automatizada tem comprovada sua grande importância em aplicações industriais, sendo possível sua atuação diretamente no controle de qualidade em todas as fases do processo de produção. Isso tem conduzido claramente a um aumento da produtividade associada à confiabilidade da qualidade final do produto.

Todo sistema automatizado de inspeção possui objetivos bem definidos, devendo apresentar baixos custos de serviço, reduzir a quantidade de material perdido, 
realizar a inspeção de forma rápida e objetiva, padronizar os processos de inspeção, permitir que sejam possíveis implementações rápidas de ações corretivas, etc...

Com estas considerações, propõe-se neste trabalho um sistema para inspeção automática de placas de madeira utilizadas na fabricação de lápis, substituindo a tarefa subjetiva e tediosa realizada por inspetores humanos.

\section{2 - OBJETIVOS E JUSTIFICATIVAS}

O objetivo deste trabalho é propor uma metodologia de inspeção visual dedicada à classificação de placas de madeira utilizadas na fabricação de lápis, que opere em alta velocidade no processo de seleção das mesmas. Não há a preocupação nesta tese em definir valores para essa "alta velocidade" (por exemplo, quantas placas por minuto), pois isso depende também do tipo de "hardware" empregado no sistema. A preocupação

sim, é propor uma metodologia inerentemente "enxuta", no tocante às tarefas necessárias para a realização das etapas de extração de características e classificação das placas ( os algoritmos propostos foram implementados utilizando MatLab).

Essa metodologia baseia-se em extração e análise de características de imagens em nivel de cinza, utilizando uma nova interpretação dos resultados obtidos através da aplicação de um método automático de limiar que utiliza a entropia de Shannon [Shannon, 1948].

O processo aqui proposto, foi idealizado na busca de uma metodologia que pudesse ser realizada com baixa complexidade computacional, com possibilidades de torná-la implementável em arquiteturas simples com tecnologia VLSI, vis!umbrando o emprego em sistemas que operem em tempo real na linha de produção de uma fábrica. 
Boa parte dos estudos iniciais da pesquisa de doutoramento, esteve voltada às arquiteturas não convencionais de computadores, especialmente as arquiteturas sistólicas [Kung, 1982]. Com base nas características particulares dessas arquiteturas, onde os algoritmos são realizados utilizando apenas operações simples sobre os dados (soma, subtração, etc...), buscou-se então a idealização de uma metodologia de classificação de placas de madeira usadas na fabricação de lápis.

A proposta de utilização de um método baseado em limiar automático, se dá devida a simplicidade do conceito que envolve o assunto.

$\mathrm{O}$ anexo A apresenta uma revisão sobre métodos de limiar, alguns automáticos outros não, que apoiam-se em variados princípios para determinar o valor, ou os valores, de limiar em imagens em nível de cinza. Salienta-se aqui que o anexo não apresenta métodos dirigidos a imagens coloridas nem tampouco métodos que utilizam redes neurais, por tratarem-se de métodos que geralmente requerem grande capacidade de processamento, e um dos objetivos deste trabalho é propor um procedimento que possua custo computacional não elevado.

Buscou-se identificar entre os métodos, aquele ou aqueles que oferecessem além do valor de limiar automaticamente (sem supervisão), também fornecessem outras informações inerentes que pudessem ser interpretadas sem muito esforço computacional, e que combinadas fossem capazes de oferecer critérios para tomadas de decisão.

Os métodos que utilizam a entropia de Shannon despertam a atenção pois possuem também suas bases na teoria de informação. Segundo Wiener apud Edwards [Edwards, 1971], a entropia de um sistema é a medida de seu grau de desorganização. Daí, surge a oportunidade de medir a "quantidade de desorganização", ou quantidade de

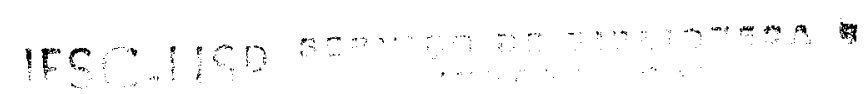


incerteza, e utilizá-la como "quantidade de informação" presente em uma imagem, para que a mesma possa servir como um critério de decisão.

A entropia de Shannon também tem sido utilizada como ferramenta importante na reconstrução de imagens com base na quantidade de incerteza de sinais [Burch, 1983] [Gull, 1984] [Skilling, 1984]. E porque não utilizar a quantidade de incerteza como quantidade de informação que os métodos de limiar entrópicos oferecem, como características de decisão em metodologias de classificação?

A partir disso, buscou-se propor um procedimento que interpretasse as informações oferecidas por um método de limiar automático entrópico simples, para classificar as placas de madeira, sem a necessidade de qualquer pré-processamento nas imagens, evitando também dessa forma um acréscimo no custo computacional.

Assim, simplificando o método de limiar automático proposto por Wong \& Sahoo [Wong, 1989], que está baseado na entropia de Shannon, e que utiliza apenas a informação do histograma uni-dimensional da imagem em níveis de cinza, procurou-se extrair características que interpretadas por algoritmos baseados em regras (classificadores), fornecessem subsídios para classificar as placas de madeira por inspeção visual.

A opção em se usar classificadores baseados em regras, reside no fato de que esse tipo de classificador não necessita de banco de dados de imagens, como é o caso dos classificadores que utilizam "template matching", pois como mostrado durante o trabalho, torna-se difícil a construção de um banco de imagens para fins de comparação, em virtude da alta variação da aparência superficial que as placas apresentam. 


\section{3 - ORGANIZAÇÃO DA TESE}

Além deste capítulo de objetivos, os seguintes capítulos são apresentados:

O capitulo 2 apresenta uma breve exposição dos conceitos que dão sustentação teórica aos tópicos utilizados nesta tese. Os campos de investigação relacionados são: visão computacional, inspeção visual, reconhecimento de padrões e classificadores.

No capítulo 3 são apresentadas informações da história do lápis, sua composição e o processo utilizado em sua fabricação, localizando em qual das etapas do processo o presente trabalho se aplica. Também são apresentadas e brevemente discutidas algumas publicações relacionadas à inspeção visual aplicada em madeiras de uma forma geral. Assim, buscou-se nas publicações identificar o tipo de procedimento utilizado no tratamento com imagens de madeira.

O capítulo 4 descreve as características visuais presentes nas placas que conduziram à determinação das classes, mostrando a relação existente com as propriedades estruturais da madeira.

Já no capítulo 5 são apresentados os algoritmos utilizados na interpretação das imagens das placas de madeira, baseados nas características determinadas no capítulo 4 . Os algoritmos são divididos em duas etapas: extração de características e classificação. Também apresenta-se neste capítulo o procedimento de interpretaç:̃o da entropia de Shannon, onde está baseada a extração das características, e os algoritmos de classificação propostos. 
O capítulo 6 descreve a aplicação dos métodos expostos no capítulo anterior (pré-classificação, redução de informações baseada em regras e redução baseada em matriz de co-ocorrência), apresentando os resultados obtidos e as discussões a respeito da forma como foi realizado todo o procedimento. São apresentados e discutidos os resultados de classificação obtidos pelos métodos, e comparados com as classificações de três inspetores especialistas.

No capítulo 7 estão descritas as conclusões finais, as contribuições e os trabalhos futuros. 


\section{Capítulo 2}

\section{BASES TEÓRICAS}

\section{1 - INTRODUÇÃO}

Este capítulo apresenta brevemente os conceitos que dão sustentação teórica aos

tópicos utilizados nesta tese. Não existe a intenção de um aprofundamento na demonstração da teoria já consolidada e sim apenas identificar as linhas de pesquisa que a presente tese se apoia, descrevendo sucintamente o objetivo de cada área e citando também algumas referências relacionadas.

Os campos de investigação referidos são: visão computacional, inspeção visual, reconhecimento de padrões e classificadores.

\section{2 - VISÃO COMPUTACIONAL}

A visão, de uma forma geral, é investigada por três diferentes escolas da comunidade científica. Os neurofisiologistas estão voltados ao entendimento do funcionamento dos mecanismos sensores e neurais dos sistemas biológicos. Os 
psicologistas perceptuais tentam entender a parte psicológica que governa as tarefas de percepção, e os cientistas de Visão Computacional tratam do envolvimento computacional e algorítmico, associados com a aquisição, processamento e interpretação de imagens.

Durante as últimas três décadas o campo da Visão Computacional testemunhou diversas fases importantes da evolução. Estas variaram entre técnicas de processamento básico de imagem digital, compreensão da física da aparência da imagem, reconhecimento automático de objetos em uma cena natural, modelamento de processos da visão biológica, etc... Nesta evolução, a Visão Computacional beneficiou-se de diferentes áreas da pesquisa como processamento de sinais, ótica, reconhecimento de padrões, psicofísica, neurociência, e também das tecnologias de hardware. Cada uma dessas disciplinas forneceu à Visão Computacional uma maneira nova de enfocar o problema da visão de máquina e, freqüentemente também surgiram novos conjuntos de problemas que enriqueceram o alcance da disciplina. Talvez igualmente importante, como a contribuição dessas ciências fundamentais, a Visão Computacional beneficiouse também significativamente dessas aplicações, pois as mesmas proporcionaram o crescimento de um grande corpo de técnicas que colocou a ciência de Visão Computacional no uso prático em engenharia, na medicina e no comércio.

Uma das forças mais importantes que tem impulsionado a Visão Computacional é a evolução da tecnologia dos computadores. Nos primeiros anos da Visão Computacional, um problema significativo era o de como adquirir imagens, como armazená-las e como processá-las nos computadores disponíveis da época. Com o corrente estado da arte em hardware de processamento de sinal em tempo real, os mecanismos de interpretação de imagem, e as facilidades de comunicação com imagens de largura de banda bem mais elevada, os profissionais e pesquisadores de Visão 
Computacional tem dirigido seus esforços para o desenvolvimento de algoritmos, diferentemente daqueles que foram utilizados a uma década.

Também, um fenômeno recente no mundo da computação é a revolução causada pela multimídia. Para os computadores anteriores, o processamento de informação implicava sempre em tratamento de números. Agora espera-se que os computadores sejam igualmente peritos no tratamento de gráficos, imagens, vídeo, e áudio como partes de informação que qualquer usuário possa adquirir, organizar, armazenar, procurar, manipular, transmitir e distribuir tão facilmente quanto as informações alfanuméricas [Ratha, 1996].

Esses avanços em computação estão forçando os cientistas da área a encarar as imagens com a mesma capacidade que encaravam as informações alfanuméricas.

O campo da Visão Computacional, ou visão de máquina, apresenta uma infindável quantidade de literatura publicada, cobrindo toda a teoria envolvida e aplicações diversas.

Por exemplo, West [West, 1983] em seu trabalho apresenta algumas utilizações para a visão de máquina, classificando-as da seguinte forma:

- Reconhecimento: determinação do formato de objetos e sua orientação apropriada em montagens.

- Identificação: usado para diferenciar entre itens que possuam o mesmo formato mas que tenham alguma característica diferente.

- Acompanhamento ("tracking"): localiza objetos e mantém o conhecimento de sua posição e orientação.

- Inspeção Visual: verificação de defeitos ou manchas em partes, posição dentro de montagens, etc... 
- Metrologia Visual: sistemas que realizam medidas de objetos através da imagem sem contato físico com as partes. Podem utilizar feixe de Laser através de telemetria ("range finder") ou por meio de iluminação estruturada.

Azriel Rosenfeld vem publicando desde 1984 uma coletânea anual de tópicos sobre Visão Computacional e assuntos correlatos, englobando artigos, conferências e livros. Tratam-se de revisões bastante amplas e que abreviam e dirigem o trabalho de pesquisa sobre $\mathrm{o}$ assunto.

Keith Price ${ }^{1}$ também disponibiliza bibliografia extensa e lista de conferências na área, via "internet", incluindo as coletâneas de Azriel Rosenfeld.

Em seu trabalho, Jean-Michel Jolion [Jolion, 1994] apresenta as metodologias utilizadas em Visão Computacional discutindo-as de uma forma filosófica, diferentemente do enfoque da maioria das publicações.

Um trabalho interessante também foi publicado por Jain \& Binford [Jain \& Binford, 1991], onde os autores colocam de forma crítica suas opiniões a respeito da pesquisa em sistemas de visão computacional. O próprio título do trabalho chama a atenção: "Ignorance, myopia, and naiveté in computer vision systems".

Como complemento interessante da literatura, Weng [Weng, 1994] analisa o desempenho de alguns algoritmos de visão computacional, enquanto Wildes [Wildes, 1996] apresenta um sistema de visão computacional para reconhecimento de iris e Zhang [Zhang, 1996] faz uma revisão dos métodos de avaliação para segmentação de imagens.

\footnotetext{
1 "Computer Vision Group" - University of Southern California - http://iris.usc.edu/ price/
} 
A obra de Young \& Fu [Young, 1986] apresenta vinte e sete capítulos de assuntos relacionados à visão como um todo. Cada capítulo é de responsabilidade de um ou mais renomados autores.

Outras obras dedicadas à Visão Computacional e que cobrem o assunto fundamentando os conhecimentos, foram escritas por de D.H.Ballard e C.M.Brown [Ballard \& Brown, 1982], Martin D. Levine [Levine, 1985], M. Sonka, V. Hlavac e R. Boyle [Sonka, 1993], R. Jain, R. Kasturi e B. G. Shunck [Jain, 1995].

Ainda, com as facilidades que a "internet" proporciona, tem-se acesso a vários centros de pesquisa dedicados à Visão Computacional, destacando-se como referência importante o "The Computer Vision Homepage" na Carnegie Mellon University², que mantém uma lista bastante grande de nomes e endereços de vários centros de Visão Computacional em todo o mundo.

\section{3 - INSPEÇÃO VISUAL}

A visão de máquina é de vital importância em muitas áreas da fabricação automatizada; não somente é necessária para grande quantidade de tarefas de robôs, mas também é de grande importância no controle de qualidade. Em 1991, E. R. Davies [Davies, 1991] estimava que $75 \%$ do potencial de aplicação de visão na indústria estava na área de inspeção automatizada.

A Inspeção Visual faz parte dos métodos de inspeção não-destrutivos, ou seja, métodos que examinam sém destruir ou nem mesmo modificar o material.

Como ilustração, abaixo são apresentados alguns t:pos de métodos de inspeção não-destrutivos:

\footnotetext{
${ }^{2}$ http://www.cs.cmu.edu/afs/cs/project/cil/www/vision.html
}

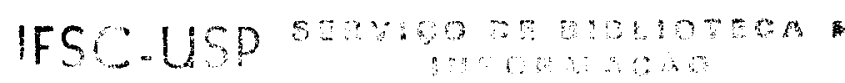


- Inspeção visual

- Radiografia

- Ultra-som

- Emissão acústica

- Inspeção por penetração de líquido

- Inspeção magnética

- etc...

Há algum tempo também a aplicação de Lasers e tecnologia de imagem (incluindo holografia, termografia, etc...) têm colocado os métodos de inspeção nãodestrutivos em lugar de significativo destaque no campo das aplicações.

Inspeção é o processo de determinar se um objeto se desvia de um dado conjunto de especificações. A inspeção usualmente envolve medidas de características de partes específicas como integridade de montagem, acabamento superficial, dimensões geométricas, etc... É uma tarefa de controle de qualidade, e é distinguida das tarefas de teste (como exemplo, análise de esforço) que envolvem examinação ativa de funções operacionais específicas do produto. Inspeção, teste e reconhecimento são tarefas distintas porém relacionadas. A inspeção deve também ser distinguida de tarefas de orientação e controle(isto é, localização). A orientação e controle consistem em medir a posição relativa do objeto para fornecer uma realimentação para um robô, por exemplo.

Tolba \& Abu-Rezeq [Tolba, 1997] enfatizam que a Inspeção Visual Automatizada vem recebendo atenção de forma crescente nos últimos anos por várias razões. Dentre elas destacam-se:

- aumento da produtividade, levando a cabo $100 \%$ de inspeção;

- baixos custos de serviço; 
- menos material perdido;

- inspeção rápida;

- inspeção objetiva;

- aumento na confiabilidade;

- padronização dos processos de inspeção;

- implementações rápidas de ações corretivas ;

- geração de banco de dados dos defeitos para análise estatística, etc...

Segundo Newman \& Jain [Newman, 1995], as técnicas de Inspeção Visual podem ser separadas em dois procedimentos gerais. $\mathrm{O}$ primeiro procedimento envolve "casar" ("template matching") um padrão de um modelo livre de defeitos (freqüentemente uma imagem sintética) com a imagem capturada do objeto a ser inspecionada. Objetos que estejam livres de defeitos "casam-se" bem com o modelo. O segundo procedimento envolve a extração de características para uma descrição ou uma lista de regras que descreva um modelo ideal. Se todas as regras são satisfeitas, o objeto é considerado livre de defeitos.

Grande quantidade dos sistemas de inspeção industrial utilizam esquemas de comparação baseados em regras. Esses sistemas tomam decisões a respeito da qualidade de um objeto de acordo com regras de classificação. O objeto é testado contra uma lista de regras de projeto, contra características que podem ser extraídas das regras de projeto ou ainda contra características extraídas do próprio objeto através da análise e/ou processamento de imagens. Como exemplo, muitos sistemas de inspeção industrial utilizam atributos como área de superfície, perímetro, razão do perímetro com a área, número de furos, área dos furos, raio máximo, raio mínimo, etc... Uma vantagem dos 
sistemas baseados em regras sobre os "template matching" é que é desnecessário manter um banco de dados de padrões. Porém, esses sistemas sofrem a desvantagem de serem menos adaptáveis a mudanças de projeto.

Chou et al. [Chou, 1997] desenvolveram um sistema de classificação automático de defeitos, que foi empregado na IBM-Burlington, atuando em etapas do processo de fabricação de circuitos integrados de semicondutores, que utiliza algoritmos baseados em regras, alcançando taxas de classificação acima de 80\%. Darwish \& Jain [Darwish \& Jain, 1988] também adotaram o procedimento baseado em regras, combinado com préprocessamento da imagem (segmentação e rotulagem usando morfologia) para inspecionar diferentes objetos em uma cena.

Chin \& Harlow [Chin, 1982] apresentaram uma revisão do assunto (Inspeção Visual) dando ênfase a inspeções do tipo: inspeção de padrões de circuito impresso, inspeção de fotomáscaras para microcircuitos, inspeção de circuito integrado e alinhamento para colagem. Citam boa quantidade de referências de artigos relacionados com Inspeção Visual em produtos têxteis, montagem de partes na indústria automobilística, na indústria de processamento de metal e imagens radiográficas na indústria. Indicam ainda várias conferências, simpósios e também vários periódicos relacionados ao tema inspeção visual.

Ainda segundo Chin \& Harlow [Chin, 1982], a tarefa mais difícil dentre os métodos de inspeção é aquela que inspeciona por aparência visual. A Inspeção Visual busca identificar tanto defeitos funcionais como os de aparência. Em muitos processos de manufatura, a inspeção visual depende principalmente de inspetores humanos, cujo desempenho é geralmente inadequado e variá:el. O sistema visual humano está adaptado para trabalhar num mundo de variedades e mudanças. $\mathrm{O}$ processo de Inspeção 
Visual, de outra maneira, necessita da observação do mesmo tipo de imagem repetidamente para detectar anormalidades.

Voltado exclusivamente para o problema de Inspeção Visual Automática, B.G.Batchelor et all [Batchelor et all 1985] faz uma varredura nos métodos, técnicas de iluminação, equipamentos disponíveis e princípios de processamento de imagens. Não discute sobre Visão ou Reconhecimento de Padrões mas fornece uma boa análise dos principais problemas solucionáveis com digitalização de imagens para posterior processamento.

Newman \& Jain [Newman, 1995] publicaram uma revisão mais recente que a de Chin \& Harlow, sobre vários sistemas de inspeção visual automatizados, cobrindo o período de 1987 a 1995.

A seguir são apresentados alguns tópicos discutidos por Newman e Jain, que cobrem o assunto Inspeção Visual em seus diversos aspectos:

\&efinição de inspeção

\$ Estágios de inspeção

Porque inspeção automatizada?

1 Benefícios gerais da inspeção automatizada

\&iabilidade da inspeção automatizada

\& Revisão da literatura de inspeção

- Sistemas de inspeção visual comerciais

- Sistemas próprios de inspeção visual industrial

- Uma taxonomia dos sistemas de inspeção

- Inspeção usando imagens binárias (circuito impresso e integrado)

- Inspeção usando imagens em níveis de cinza (circuito impresso e integrado)

- Inspeção de rotulagem e embalagem 
- Inspeção de textura

- Inspeção usando imagens coloridas

- Inspeção usando imagens em 3D

- Inspeção usando outras modalidades de sensor como:

Raio X, ultra-som, transdutor ótico-acústico, infravermelho, partículas magnéticas, líquido penetrante fluorescente combinado com UV, etc...

- "Template matching"

- Métodos baseados em regras

- Método híbridos

Inspeção baseada em CAD

- O uso de modelos CAD

- Desvantagens dos modelos CAD

O processo de formação de imagem é muito complexo e freqüentemente não modelado completamente pelo modelo CAD ou por modelo de formação de imagem suplementar. Por exemplo, algumas imagens contém reflexões especulares, complicando a tarefa de inspeção e/ou do reconhecimento.

Uma área de aplicação que recebe grande quantidade de publicações é aquela que trata da inspeção de placas de circuito impresso. Dagli \& Tsunekawa [Dagli, 1996] publicaram um artigo revisional sobre algoritmos automáticos para inspeção em placas de circuito impresso. Outro trabalho de revisão de algoritmos automáticos foi publicado por Moganti et al. [Moganti, 1996], mostrando também vários sistemas comerciais e suas características. Hara et al. [Hara, 1988] apresentaram um sistema construído com arquitetura paralela de processamento, enfatizando o processo de iluminação à base de 
luz ultravioleta. Hirata \& Tanaka [Hirata, 1983] propõem um método de inspeção automática para a indústria de semicondutores, assim como Sprague et al. [Sprague, 1991] e tantos outros, mostram procedimentos automáticos para inspeção visual voltados à indústria de circuito impresso.

Thomas et al. [ Thomas, 1995] apresentam uma revisão do estado da arte de sistemas de inspeção visual industrial em tempo real. Também mostram uma revisão dos algoritmos de visão de máquina mais utilizados assim como esquemas de iluminação para inspeção em tempo real

Outras aplicações de inspeção visual com vasta literatura incluem a inspeção para a indústria de vidro e cerâmica, a inspeção na indústria de alimentação e empacotamento, equipamentos militares, a inspeção de estradas de ferro, a inspeção da manufatura do papel e a inspeção de produtos farmacêuticos.

Futuros esforços na pesquisa em inspeção visual automatizada devem focar a construção de sistemas mais flexíveis e também em adicionar a capacidade de inspeção de superfícies de formas livres. Em aplicações de inspeção industrial, também deverá ser incrementada a exploração de modelos CAD, na medida em que o processo tornar-se mais integrado.

Os esforços imediatos em sistemas de inspeção visual automatizada deverão estar centrados em melhorar a velocidade de inspeção através do uso de melhores algoritmos de inspeção, unidades de processamento mais velozes e múltiplas unidades de processamento.

Ainda, um trabalho adicional também deverá estar voltado à melhoria da facilidade de operação e programação dos sisıəmas de inspeção visual automatizados.

Uma revisão sobre o tipo de inspeção visual aplicada em madeiras e o que se busca na inspeção de madeiras, é descrita no capítulo 3. 


\section{4 - RECONHECIMENTO DE PADRÕES}

"Reconhecimento de Padrões é uma área da ciência preocupada com a discriminação de objetos em uma base de informação disponível. Num sentido amplo, pode ser considerado como um problema de estimar funções de densidade em um alto espaço dimensional e dividir este espaço em regiões de categorias ou classes. Sua meta é clarificar os mecanismos complicados do processo de tomada de decisão e automatizar essas funções utilizando computador..." [Fukunaga, 1990].

Como Duda \& Hart [DUDA,1973] colocam, o processo de classificação de um padrão pode ser resumido da seguinte forma:

Suponha que em uma linha de produção de pranchas de madeira queira-se automatizar o processo de seleção das mesmas de acordo com o tipo de árvore de origem. Na figura abaixo, a câmera faz a aquisição da imagem das pranchas transferindo-as para um estágio denominado "extrator de características", cujo propósito é a redução de dados através da medida de certas "características" ou "propriedades". Essas características (ou seus valores) são então entregues a um estágio denominado "classificador", o qual avalia as características apresentadas e toma a decisão final.

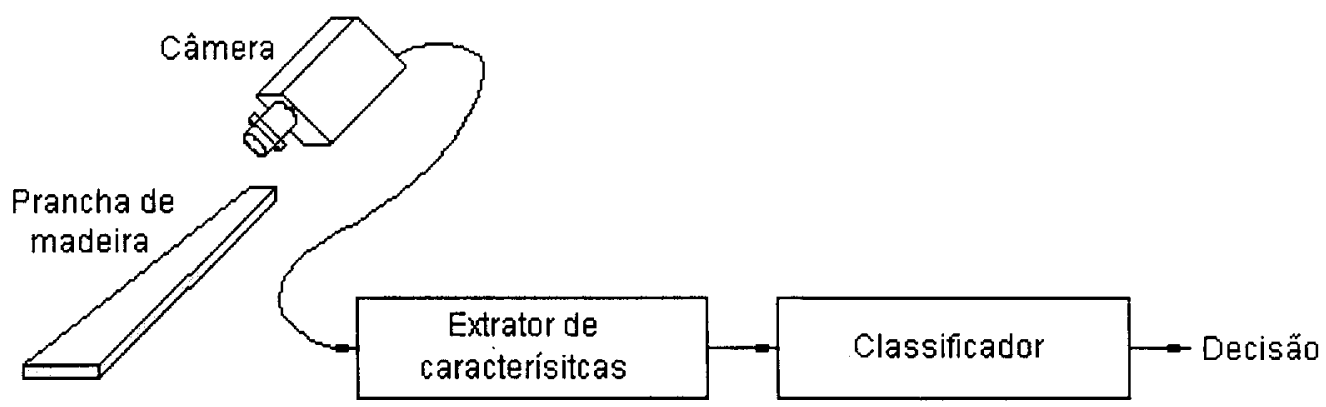

Figura 2.1 - Sistema classificador de padrões genérico 
O conjunto de dados obtidos normalmente compõe um vetor de informação num espaço com uma determinada dimensão (denominado espaço de atributos). Segundo Duda \& Hart [DUDA, 1973], a etapa de classificação reduz-se a uma partição do espaço de atributos de tal forma que, idealmente, os pontos pertencentes a uma determinada classe sejam agrupados sempre na partição correspondente. Como essa forma simplista nem sempre pode ser alcançada, deve-se estabelecer a partição minimizando algum critério; por exemplo, quando utilizada a formulação estatística do problema, critério a ser minimizado normalmente recai sobre a probabilidade de erro.

Freqüentemente as imagens contém muitas informações não essenciais, então o processo chamado de extração de características é executado para obter-se as informações adequadas que devem ser usadas na classificação. Esse processo, em alguns casos, também é utilizado para diminuir o número de características de forma a diminuir a quantidade de informações de entrada, diminuindo assim a complexidade computacional do mecanismo de reconhecimento de padrões.

\section{SELEÇÃO DE CARACTERÍSTICAS}

A seleção de características (ou atributos) é geralmente considerada um processo de mapeamento de medidas originais para atributos mais efetivos [Fukunaga, 1990]. Se o mapeamento é linear, a função mapeamento é bem definida e portanto basta encontrar os coeficientes da função linear de forma a maximizar ou minimizar algum critério.

Entretanto, em muitas aplicações de reconhecimento de padrão, existem atributos importantes os quais não são funções lineares de medidas originais, tornando o problema mais complexo.

É importante observar a escolha das características, pois como Duda \&Hart colocam [Duda, 1973] as características podem ter as seguintes limitações: 
- podem ser incapazes de distinguir diferentes classes, ou seja, podem não conter informações necessárias para separá-las;

- podem estar altamente correlacionados, e dessa forma expressarem a mesma dimensão do padrão;

- podem existir subclasses dentre as características que não foram identificadas, etc...

Com relação às propriedades que os atributos devem possuir, K.R. Castleman [Castelman, 1979] escreve:

- Discriminação: características de objetos em diferentes classes devem ter valores significativamente diferentes.

- Independência: características não devem estar fortemente correlacionados

- Confiança: características devem ter valores similares para objetos de uma mesma classe.

- Pequeno Número: Um pequeno número de características é preferido, uma vez que a complexidade do sistema de reconhecimento de padrão aumenta rapidamente com o aumento do número de atributos.

Conforme colocam Young \& Fu [Young, 1986] as aplicações mais comuns de reconhecimento de padrões e processamento de imagens incluem reconhecimento de caracteres (OCR - “Optical Caracter Recognition”), diagnósticos médicos, análise de imagens e sinais biomédicos, identificação de faces e impressões digitais humanas, reconhecimento e interpretação de voz, inspeção automática, entre outras.

Para uma visão rápida sobre as metodologias empregadas em análise e reconhecimento de imagens, algumas publicações recentes sobre aplicações de reconhecimento de padrões, são de fácil leitura e mostram o assunto com seus principais conceitos: 
Trier [Trier, 1996] apresenta uma revisão sobre métodos de extração de características para reconhecimento de caracteres. Venkateswarlu [Venkateswarlu, 1995] mostra técnicas de segmentação para análise de imagens de documentos. Wang [Wang, 1989] realizou um trabalho sobre classificação de imagens de jornais usando análise de textura. Karu \& Jain [Karu, 1996] e Ratha et al. [Ratha, 1996] publicaram seus trabalhos na área de reconhecimento de impressão digital. Já Blue [Blue, 1993] realizou um trabalho de avaliação sobre classificadores de padrão para impressões digitais e "OCR".

Poderia-se ainda também citar uma infinidade de outros artigos sobre o assunto “classificação de padrões". Contudo, este capítulo tem o objetivo de apenas apresentar a teoria, indicando algumas publicações que demonstrem as atividades na área.

Reconhecimento de Padrões e suas aplicações vem sendo estudada ao longo dos últimos 40 anos tendo crescido bastante em quantidade de publicações, sociedades dedicadas ao assunto e congressos científicos, a partir da década de 70. Livros como os editados por K.S.Fu [Fu 1974] [Fu 1976] tratam da teoria do Reconhecimento de Padrões Sintático com algumas comparações com o Estatístico, revendo a teoria formal de linguagens e a aplicação de gramáticas. Já o livro de J.T.Tou e R.C.Gonzalez [Tou, 1974] trata o assunto sob ponto de vista diverso, encarando o problema como substancialmente estatístico e reservando apenas um capítulo para a abordagem sintática.

Uma importante publicação dentro do contexto de análise de cena, ou seja, Reconhecimento de Padrões Visuais, a obra de R.O.Duda e P.E.Hart [Duda, 1973] é considerada de leitura fundamental. Está dividida em duas partes, Classificação de Padrões e Análise de Cena, fazendo uma clara exposição onde procura exploıar vários métodos e recursos sem se prender a discussões de eficiência de uma ou de outra abordagem. 
A contribuição da Inteligência Artificial pode ser observada em [Nandhakumar, 1985] e como leitura complementar adequada os artigos de M.Minsky [Minsky, 1961] e P.M.Churchland [Churchland, 1990] completam o assunto. K.Fukushima [Fukushima, 1988] mostra a aplicação de Redes Neurais em Reconhecimento de Padrões Visuais citando o desenvolvimento do Cognitron e do Neocognitron, modelos neurais para aprendizagem.

\subsection{1 - CLASSIFICADORES}

"Um tomador de decisão coleciona informações a respeito de um problema de diferentes fontes ( humano, modelo, máquina) e as combina com sua própria informação para produzir uma decisão final..." [Mostaghimi, 1997].

O objetivo do reconhecimento de padrões é o projeto de um classificador, um mecanismo o qual toma características de objetos como suas entradas e que resulta em uma classificação $\lambda$, um rótulo ou um valor indicando a que classe pertence o objeto.

Alguns métodos de classificação dividem o espaço de padrões em regiões (separando as classes) a partir de alguma medida de similaridade entre os vetores de características. Os métodos de classificação podem ser do tipo paramétrico ou nãoparamétrico. Como exemplos para o primeiro caso podem ser citadas a função discriminante de Bayes, função de máxima probabilidade [Andrews, 1972] que utilizam informações estatísticas dos dados, sua distribuição ou densidade de probabilidade. Poréin, a eficiência desses métodos é comprometida se essas informações estatísticas não forem conhecidas a priori ou forem mal estimadas. No segundo caso, uma função de distância é considerada para obtenção de um valor numérico para a similaridade 
entre os vetores de características. As funções mais comuns para este caso são: a inércia, pertinência fuzzy, distância euclidiana, distância de Mahalanobis e coeficiente de Tanimoto [Andrews, 1972] [Duda, 1973] [Fukunaga, 1990].

Tanto para os métodos paramétricos como os não-paramétricos, o que se procura é a determinação de funções discriminantes, que são superfícies de separação, ou superficies de decisão, que determinam os limites entre duas ou mais classes.

Um classificador pode ser representado matematicamente por $S: \bar{x} \rightarrow \lambda$, onde $\bar{x} \in \mathfrak{R}^{n}$ é um vetor de $n$ características e $\lambda$ é um rótulo.

O erro que um classificador comete geralmente é definido como o número ( ou porcentagem ) de objetos classificados erroneamente. Os erros podem ter uma ou duas causas: classificação errada ou sobreposição de classes: alguns valores-característica ocorrendo para mais que uma classe. Se a função densidade de probabilidade das características de classe se sobrepõem, nenhum classificador pode discriminar sem erros os objetos pertencentes à classes diferentes.

Várias funções podem ser usadas para implementação de classificadores. Alguns exemplos clássicos são:

- Classificador ótimo de Bayes

- Classificador Linear

- Classificador Quadrático

- Classificador baseado nos k-ésimos vizinhos

- Redes Neurais Artificiais 


\section{CLASSIFICADOR ÓTIMO DE BAYES}

A teoria de decisão de Bayes é um procedimento estatístico usada para o problema de classificação de padrões. Está baseado em assumir que o problema de decisão seja colocado em termos probabilísticos, e que todos os valores de probabilidade relevantes sejam conhecidos [Duda, 1973].

O classificador de Bayes é um mecanismo que minimiza o erro de classificação. Ele necessita da função densidade de probabilidade subjacente das classes. A figura 2.2 mostra isso para um problema com uma característica e duas classes.

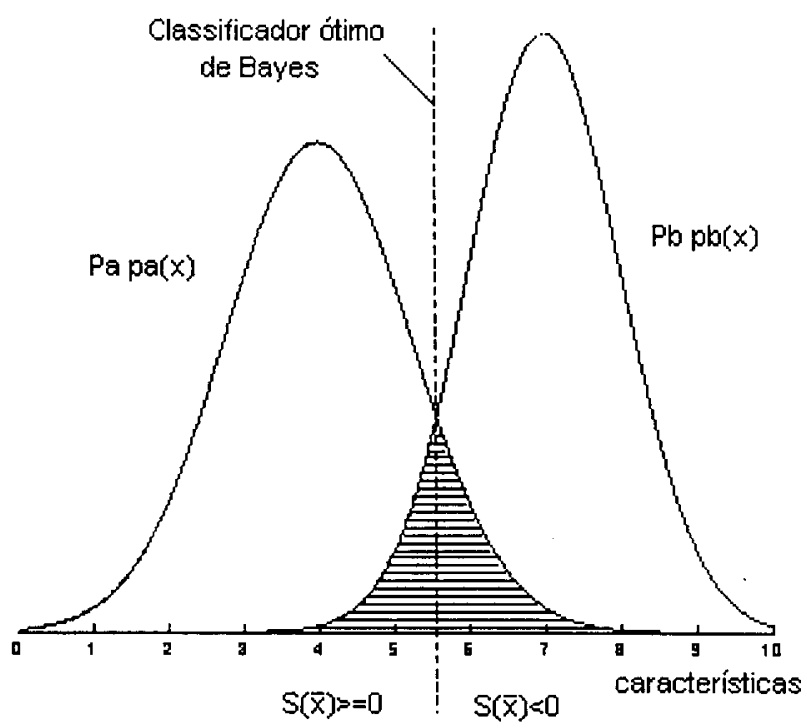

Figura 2.2 - Função discriminante de Bayes para problema uni-dimensional

A área hachurada na figura 2.2 representa o erro que a função $S(\bar{x})$ comete. Observando a figura 2.2 nota-se que qualquel deslocamento de $S(\bar{x})$ conduz a um erro maior. O erro mínimo que este classificador comete, erro de Bayes, é um mínimo teórico com relação ao erro que qualquer classificador pode cometer. 
Entretanto, em problemas práticos as informações para grande número de objetos nunca estão disponíveis, ou seja, a função densidade de probabilidade e a informação de probabilidade a priori são desconhecidas. Neste caso provavelmente o erro será maior que o erro de Bayes.

Dessa forma, a construção de classificadores está baseada em assumir que os objetos disponíveis representem a verdadeira função densidade de probabilidade, isto é, que sejam realizações de variáveis estocásticas possuindo a função distribuição verdadeira. Portanto, os classificadores serão construídos de maneira a minimizar o erro no conjunto de aprendizado na esperança que isto também minimize o erro cometido para novos objetos.

\section{CLASSIFICADOR LINEAR}

Classificadores lineares compreendem um conjunto de classificadores que implementam funções de discriminação linear. Estes classificadores estimam as matrizes de média e covariância do conjunto de objetos e supõem que as duas classes possuam matrizes de covariância iguais.

Outro classificador linear é aquele que utiliza a aproximação das médias lineares. Cada objeto é designado à classe para a qual a média seja a mais próxima no espaço de características ( no sentido Euclidiano). Esse classificador implementa uma função de discriminação linear entre as médias. 


\section{CLASSIFICADOR QUADRÁTICO}

Um classificador quadrático encontra uma função de discriminação quadrática, como um círculo, uma elipse ou uma parábola no espaço de características.

Um exemplo é o classificador quadrático baseado em densidades normais. Esse classificador é quase idêntico ao classificador linear baseado em densidades normais, porém ele calcula matrizes de covariância para cada classe individual.

\section{CLASSIFICADOR BASEADO NOS K-ÉSIMOS VIZINHOS}

Este classificador nomeia um objeto desconhecido $O$ com o rótulo da maioria dos k-ésimos vizinhos. Um vizinho é considerado o mais próximo se ele possui a menor distância, no sentido Euclidiano, no espaço de características. Para k=1, este é o rótulo do vizinho mais próximo do conjunto de aprendizagem. O método dos k-ésimos vizinhos é intuitivamente um método muito atrativo [Cover, 1967] .

A função discriminação implementada por este classificador será em geral uma função linear irregular pois ela é influenciada por cada objeto disponível no conjunto de aprendizado. Uma desvantagem deste método é a grande capacidade de computação necessária, uma vez que para classificar um objeto há que se calcular sua distância para todos os objetos do conjunto de treinamento. Observando essa deficiência muitos pesquisadores, como por exemplo Djouadi \& Bouktache [Djouadi, 1997], propuseram algoritmos rápidos para diminuir a quantidade de computação e consequentemente o tempo de processamento necessários. 


\section{CLASSIFICADOR BASEADO EM REDES NEURAIS ARTIFICIAIS}

Uma rede neural artificial pode implementar qualquer mapeamento de entradasaída se o mesmo for suficientemente complexo (isto é, tem ao menos uma camada escondida de tamanho grande). Portanto, é possível a implementação de uma função discriminante. O conjunto de aprendizado é usado para adaptar os pesos da rede; a saída de uma rede, um vetor de valores numéricos, representa uma rotulagem.

É interessante notar o fato de que o mapeamento de uma célula ou de uma camada de uma rede neural artificial é equivalente a uma função de discriminação linear. Portanto, redes neurais de duas camadas (consistindo de camada de entrada e camada de saída) podem somente atuar como classificadores lineares.

\section{REJEIÇÃO}

Um assunto final de interesse da pesquisa de reconhecimento de padrões é a rejeição. Rejeição de objetos significa recusar classificar objetos, de forma a diminuir o erro que o classificador comete. Isto pode parecer paradoxal, mas rejeitar um objeto pode "custar" menos do que classificá-lo erroneamente.

Matematicamente a rejeição pode ser vista como a definição de uma zona em torno da função de discriminação. Se a saída de um classificador cai nessa zona, o objeto é rejeitado.

Alguns autores [Woods, 1997] [Xu, 1992] [Ho, 1994] propõem métodos que combinam classificadores com a intenção de melhorar a classificação final através das 
potencialidades inerentes de cada método. [Horn, 1986] dedica um capítulo aos classificadores clássicos fazendo um bom resumo de referências.

\section{5 - CONSIDERAÇÕES FINAIS}

Este capítulo apresentou a teoria relacionada com Visão Computacional, Inspeção Visual, Reconhecimento de Padrões e Classificadores, descrevendo brevemente as idéias principais de cada tópico, assim como mesclando a bibliografia clássica com publicações recentes nas áreas.

Com base na teoria apresentada, construiu-se um sistema de Inspeção Visual dedicado a seleção de placas de madeira usadas na fabricação de lápis, que utiliza um método de classificação baseado em regras.

Como descrito neste capítulo, os classificadores baseados em regras são interessantes para aplicações industriais, pois não há a necessidade de se trabalhar com banco de dados de imagens, permitindo assim que através da extração de características adequadas das imagens, seja possível classificar os objetos em foco.

O capítulo seguinte (3), apresenta uma breve reconstrução histórica do lápis, e também uma revisão da inspeção visual em madeiras. 


\section{Capítulo 3}

\section{A FABRICAÇÃO DO LÁPIS E A INSPEÇÃO VISUAL EM MADEIRAS}

\section{1 - INTRODUÇÃO}

Este capítulo apresenta informações de como surgiram os lápis (a história do lápis), sua composição e o processo utilizado em sua fabricação, localizando em qual das etapas do processo o presente trabalho se aplica. Também são apresentadas e brevemente discutidas algumas publicações relacionadas à inspeção visual aplicada em madeiras de uma forma geral, uma vez que não foram encontradas publicações específicas para o controle de qualidade de placas de madeira para a fabricação de lápis. Assim, buscou-se nas publicações identificar o tipo de procedimento utilizado no tratamento com imagens de madeira. 


\section{2 - HISTÓRLA DO LÁPIS}

Os lápis de hoje são os descendentes dos antigos instrumentos de escrita. $\mathrm{Na}$ Roma antiga, os escribas escreviam em papiro com uma vareta fina de metal (chumbo, zinco ou prata) chamada "stylus" ou "penicillus", que deixavam uma leve marca legível.

O grafite tornou-se largamente utilizado após a descoberta de um grande depósito de grafite em Borrowdale, Cumbria, na Inglaterra em 1564. Naquela época, como pouco se conhecia de química, o grafite foi chamado de "plumbago", pois deixava marcas parecidas com as que o chumbo produzia. Em 1779, K.W. Scheele realizou uma análise química do "plumbago" que provou ser uma forma de carbono e não de chumbo, e foi em 1789 que A.G. Werner sugeriu o nome mais apropriado de grafite, vinda da palavra grega para escrita "gráfo". Hoje as minas utilizadas nos lápis são feitas de uma mistura de grafite e argila, que em função das proporções da mistura determinam sua dureza ${ }^{1}$

O grafite deixava uma marca bem mais escura que a vareta de metal, mas era tão frágil e quebradiço que necessitava de algo para estruturá-lo. Primeiramente, bastões de grafite eram embrulhados em linha ou barbante. Mais tarde, o grafite foi inserido em bastões de madeira trabalhados à mão para recebê-lo. Nascia assim o lápis com a estrutura que hoje conhecemos.

A primeira produção em massa de lápis foi feita em Nuremberg, na Alemanha em 1662, onde utilizavam como mina uma mistura de grafite, enxofre e antimônio, pois os alemães não tinham acesso ao grafite da Inglaterra. Nos Estados Unidos, coube a William Monroe em Concord, Massachusetts, fabricar o primeiro lápis de madeira em 1812. Até então os lápis eram importados da Europa.

${ }^{1}$ http://www.perkolator.com/2_pencil.html 
Os primeiros lápis produzidos em massa não eram pintados, para mostrar a alta qualidade da madeira empregada. Entretanto, por volta de 1890, muitos fabricantes começaram a pintar seus lápis atribuindo a eles marcas comerciais.

Há uma história interessante com relação à cor amarela dos lápis comuns ${ }^{2}$ : Durante o século dezenove, o melhor grafite do mundo vinha da china. Os fabricantes de lápis dos Estados Unidos queriam encontrar uma forma de mostrar aos usuários que seus lápis continham grafite chinês. $\mathrm{Na}$ China, a cor amarela está associada com realeza e respeito. Os fabricantes americanos de lápis começaram então a pintar externamente seus lápis de amarelo claro para comunicar este sentimento régio e a associação com a China. Ainda hoje, $75 \%$ dos lápis vendidos nos Estados Unidos são pintados de amarelo.

Os primeiros lápis americanos eram feitos de "Eastern Red Cedar", uma madeira forte e resistente ao estilhaçamento que crescia no estado do Tennessee e em outras partes do sudeste dos Estados Unidos. Por volta de 1900, os fabricantes de lápis necessitaram de fontes adicionais de madeira, indo encontrá-las nas montanhas de Sierra Nevada na California. Lá encontraram a madeira "Incense-cedar", uma espécie que crescia em abundância e gerava lápis superiores. Rapidamente essa madeira tornou-se a preferida pelos fabricantes de todo o mundo. Para assegurar a contínua disponibilidade de "Incense-cedar", foi necessário criar uma forma sustentada de colheita da madeira de tal modo que o crescimento anual da floresta fosse maior que a quantidade de árvores retiradas no mesmo período.

Os lápis feitos de "Incense-cedar" possuem uma cor marrom-avermelhada com uma costura visivel suave e de fina granulação. Eles tambérn tem o familiar aroma de cedro quando apontados, daí o nome "Incense" (incenso, resina aromática).

\footnotetext{
${ }^{2}$ http://www.pencils.com/
} 
Hoje também encontramos lápis feitos de plástico, os quais possuem uma cor rosada sem granulação ou costura, pois são extrudados por máquinas. Eles entortam facilmente, e estalam claramente quando quebrados.

Já os lápis feitos de madeira de florestas tropicais tem uma cor amarronzada com pequenas manchas marrom-escuras ou vermelhas. É muito difícil observar a granulação e possuem um leve aroma.

Mais de dois bilhões de lápis são usados nos EUA todo ano, e somente como curiosidade, a maioria deles possui borracha para correção, diferentemente da Europa onde a grande maioria não a tem.

Segundo Mandang ${ }^{3}$, a madeira utilizada na fabricação de lápis deve possuir as seguintes propriedades: densidade baixa e uniforme, granulação uniforme, textura fina, cor avermelhada ou amarronzada, facilidade para ser descascada com apontadores rotatórios mas suficientemente firme para manter a mina de grafite. A madeira mais utilizada para esse propósito na Indonésia hoje é denominada “Jelutung" (Dyero spp. Apocynacene)...

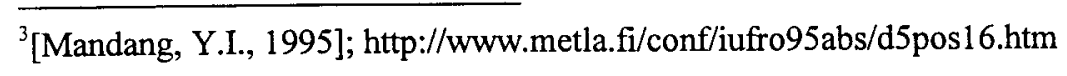




\section{3 - O CICLO DE PRODUÇÃO DO LÁPIS}

As empresas fabricantes de lápis contam com fontes renováveis de madeira (reflorestamentos). As árvores utilizadas apresentam além das características ideais para a fabricação do lápis como descrito anteriormente, também o rápido crescimento das mesmas, comparado à outras espécies utilizadas no passado.

O processo completo da produção do lápis é mostrado na figura 3.1 e comentado a seguir ${ }^{4}$
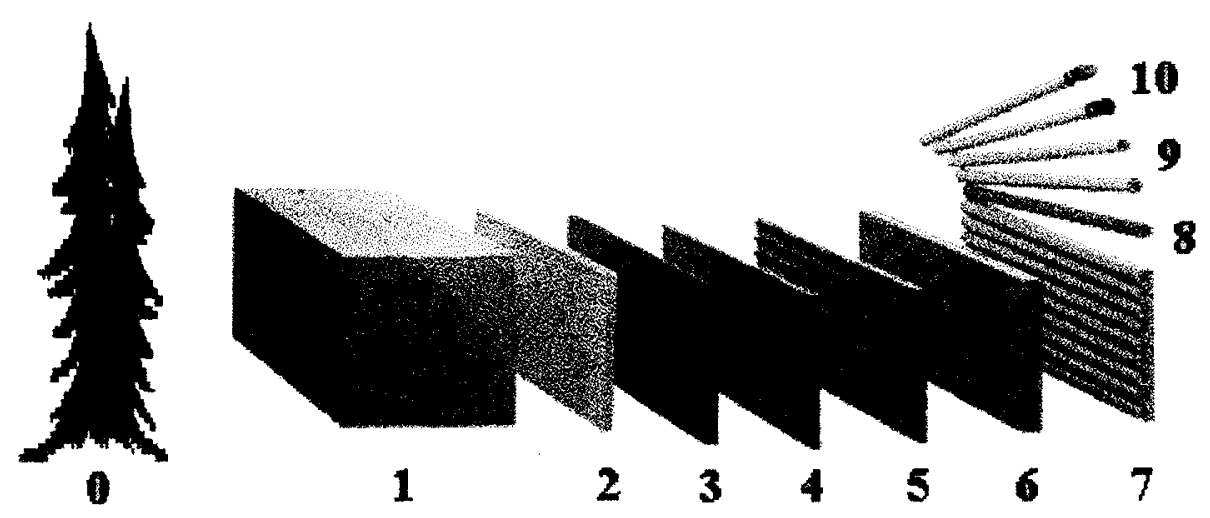

Figura 3.1 - Etapas do processo de produção do lápis

(figura retrabalhada extraída de http://www.pencils.com/)

0. Matéria prima - Plantações renováveis de "Incense-cedar" e Pinus;

1. Toras de madeira são cortadas em blocos;

2. Os blocos são cortados em pequenas placas;

3. As placas são tratadas ( cera e tintura ) e secas;

- O procedimento de seleção das placas apresentado neste trabalho, se aplica neste estágio do processo, após as placas receberem a cera e a tintura.

\footnotetext{
${ }^{4}$ http://www.pencils.com/
} 
4. São feitas ranhuras nas placas onde serão alojadas as minas de grafite;

5. As minas são distribuídas nas ranhuras;

6. Uma segunda placa ranhurada é colada com a primeira - fazendo um sanduíche;

7. O sanduíche é processado por máquinas que o deixa em formato de lápis;

8. Os lápis individuais são cortados do sanduíche e são submetidos à processos de acabamento;

9. Cada lápis é pintado;

10. Em alguns modelos, há ainda a colocação da borracha de correção.

\section{4-INSPEÇÃO VISUAL EM MADEIRAS}

A literatura de inspeção visual em madeira, em sua grande maioria, apresenta obras que centram atenção na detecção de defeitos de madeira para indústria de móveis e outros produtos construídos com madeira. As soluções buscam identificar e classificar, ou selecionar, defeitos mais comuns como: nós (cariado, vazado, firme de quina, etc...), tingimento azul, rachaduras, podridão, empenamento, torcimento, bolsas de resina, casca, esmoado, encanoamento, furos de inseto, encrustação mineral, etc... (as especificações dos defeitos podem ser encontradas em [ABPM, 1985]).

Dentro dessa linha, muitos autores propuseram os mais variados tipos de solução, tanto para a identificação seguida de aceitação/rejeição, quanto para combinação com técnicas de corte automatizadas nas indústrias produtoras de madeira serrada.

Observando-se o ciclo de produção do lápis mostrado na figura 3.1 , a grande maioria dos trabalhos publicados poderiam ser aplicados nos estágios 1 e 2 , onde a 
madeira é selecionada/classificada pela presença de defeitos como nós, furos de inseto, incrustação mineral, etc...

A seguir são apresentados breves resumos de algumas publicações sobre o assunto "detecção de defeitos em madeira".

Conners et al. [Conners, 1983] e [Conners, 1984] apresentam em seus trabalhos um sistema de processamento de pranchas de madeira automatizado (para indústria de móveis e outros produtos construídos com madeira), o qual denominaram ALPS (do inglês "Automated Lumber Processing System"). No primeiro estágio, a madeira bruta é rastreada por tomografia de modo a localizar nós internos e estabelecer a geometria de corte a ser empregada. Grande parte das pranchas resultantes ainda contém defeitos superficiais (nós, manchas, furos de insetos, etc...), muitos dos quais não podem ser detectados pelo processo tomográfico (Wagner et. al. [Wagner, 1991] e Funt \& Bryant [Funt \& Bryant, 1987] também utilizam-se do processo tomográfico para gerar imagens bi e tri-dimensionais para detecção de defeitos no interior de toras de madeira). Depois de secas, as pranchas são submetidas a um segundo estágio, que realiza a aquisição e o processamento das imagens das duas faces das pranchas, informando as coordenadas dos defeitos para a geração de um padrão de corte ótimo, utilizando Laser. Na análise das imagens, em alguns casos os autores utilizam medidas estatísticas dos níveis de cinza como média, variância, assimetria e curtose, porém os autores esclarecem que essas medidas não são suficientes para a variedade de situações encontradas. Aplicam também estatística de segunda ordem (matriz de co-ocorrência) para determinação de textura de regiões das pranchas, utilizando algumas medidas propostas por Haralick et al. [Haralick, 1973], como inércia, importância de agrupamento, homogeneidade local, entropia e energia. Os autores apresentam os resultados mostrando que as medidas 
realizadas com estatística de primeira ordem atingiram uma porcentagem média de acertos de $63.13 \%$ e, que com os métodos de estatística de segunda ordem alcançaram média de $75.96 \%$. Com a combinação dos dois métodos conseguiram a média de $88.33 \%$ de acertos. Reconhecem, entretanto, que mesmo conseguindo uma melhora com o segundo método, os resultados podem não ser suficientes para todas as aplicações industriais.

Continuando o trabalho retrocitado de Conners, Klinkhachorn et al. [Klinkhachorn, 1988] propõem melhoramentos no algoritmo que estabelece as regiões de corte das pranchas de madeira, fornecendo informações mais precisas ao sistema de corte a Laser empregado na indústria de móveis.

Koivo \& Kim [Koivo, 1989] apresentaram um trabalho de classificação de defeitos em pranchas de carvalho. Foram consideradas nove classes, sendo uma classe para madeira livre de defeitos e oito para os tipos de defeitos: nó, furo, traços minerais, casca, decomposição, esmoado, rachadura e tingimento. Como características para classificação, foram utilizadas as estatísticas de primeira ordem clássicas dos níveis de cinza das imagens como média, variância, mediana e, também os valores de nível de cinza máximo e mínimo. Mostram dois experimentos de classificação utilizando funções discriminantes lineares e árvore de decisão como classificadores. Nos experimentos apresentados, o primeiro compara duas características e o segundo três. Não foi esclarecido como e de que forma atuaria o classificador quando as nove classes fossem consideradas.

Szymani \& McDonald [Szymani, 1981] publicaram um trabalho sobre o estado da arte na detecção de defeitos em madeira, onde apresentam além dos tipos de defeitos clássicos encontrados em madeiras, também discutem as características de vários métodos de detecção de defeitos, mostrando as propriedades medidas, tipo de defeito 
detectado, vantagens e limitações. Os métodos são baseados em vários princípios: ótico, ultra-som, micro-ondas, raio-X e radiografia com neutron. Apresentam bibliografia selecionada por métodos.

No trabalho apresentado por Andersson \& Walter [Andersson, 1995], os autores aplicam um método supervisionado (não completamente automático, pois o operador escolhe 12 pontos de treinamento para cada tipo de madeira) que analisa imagens coloridas de discos de madeira com o intuito de classificar madeira de compressão. Como exposto no artigo, a madeira de compressão é responsável pelo empenamento das pranchas serradas, e para aplicar o algoritmo de decisão, a madeira é classificada em três espécies: madeira normal, compressão moderada e compressão severa. Foi utilizada uma plataforma para o processamento das imagens desenvolvida no "Center for Image Analysis- Swedish University of Agri, Sweden". O algoritmo processa a quantidade de madeira de compressão severa e moderada, o ângulo da medula até o centróide de diferentes tipos de madeira e o diâmetro médio dos discos de madeira. Segue um processamento convencional utilizando um classificador de máxima semelhança, baseado em valores estatísticos como média e desvio padrão, aplicando a função de decisão de Bayes. Concluem o trabalho comparando os resultados com quatro classificações feitas por inspetores, reconhecendo que o método aplicado opera bem para compressão moderada, mas para compressão severa apresentou grandes erros de estimativa.

Butler et al. [Butler, 1993] mostraram um refinamento de um algoritmo (ISM Image Sweep-and-Mark) que identifica áreas de madeira sem defeito em imagens coloridas. Esse algoritmos dividem em retângulos as sı'perfícies de madeira em análise, buscando identificar as regiões com e sem defeitos. Operam com estatística de primeira ordem (média e variância) de intensidades transformadas do sistema RGB, e cor dos 
"pixels". Processam esses valores em um procedimento que utiliza histogramas e valores de limiar das características, para classificar regiões com cinco tipos de defeito: furos, nós livres, nós firmes, listras e madeira limpa.

Steele et al. [Steele, 1991] analisam a inclinação dos grãos da madeira para determinar qual o tipo de defeito presente em uma determinada região da imagem, através de um mapeamento das características dielétricas da madeira, baseados no trabalho de McLauchlan et al. [McLauchlan, 1973], no sentido de otimizar e automatizar o processo de corte de madeira em indústrias que fornecem matéria prima para móveis.

Clauson \& Wilson [Clauson \& Wilson, 1991] fizeram uma comparação entre dois métodos para medir densidade da madeira e características dos anéis de crescimento (tipo de madeira: Douglas-fir). Um método utiliza imagens coloridas que são representadas em variáveis de intensidades simples e outro utiliza um densitômetro a raio-X (Hoag \& McKimmy [Hoag \& McKimmy] também utilizam densitometria com raio-X para análise da secção de madeiras). Clauson \& Wilson retiram uma "fatia" apenas das imagens para análise (depois de re-escalonadas em intensidades e dimensões, para garantir a validade da comparação) e através da verificação da variação de intensidade dos "pixels" com relação a uma varredura longitudinal nas imagens, realizam três comparações estatísticas entre os dois métodos: variação de densidade como função da localização na varredura; a distribuição de densidades por porcentagem de varredura e a variação de densidade determinada somente pela consideração dos valores altos e baixos da própria densidade.

A publicação de trabalhos de investigação envolvendo madeira para fabricação de lápis e seus resultados, é rara. Compreende-se tal fato, pois os resultados de estudos 
e pesquisas sobre o assunto, que certamente são realizados pelos fabricantes de lápis do mundo todo, tratam-se de informações de importância industrial. O nível de informação que é publicado, pode ser medido pelos dois artigos comentados abaixo, ou seja, não são informações que quando reveladas auxiliam decisivamente os fabricantes concorrentes.

Packianather [Packianather, 1997] apresentou em seu trabalho de doutoramento um classificador utilizando redes neurais para um sistema automático de inspeção visual para madeira compensada. O sistema foi proposto para descriminar doze tipos de defeitos e também madeira "limpa". São extraídas dezessete características de imagem para realizar o processo. Para diminuir o número de características, o autor propõe um método de identificação de redundância de características.

Um trabalho relativo à placas de madeira para fabricação de lápis, foi realizado por Rhemrev et al. [Rhemrev, 1991], porém não trata da inspeção visual de defeitos mas sim de um procedimento para medir o "quanto" uma placa de madeira está seca, medindo três diferentes formas da presença de água: água livre, água confinada e vapor de água. Os autores apresentam um método de teste não-destrutivo utilizando uma relação entre o conteúdo da mistura e uma constante dielétrica, através da aplicação de um campo elétrico no corpo de prova. Concluem o artigo dizendo que o processo provou ser útil no auxílio do controle de qualidade de secagem das placas, mostrando os resultados através de gráficos do conteúdo da mistura.

Dois anos mais tarde, Rhemrev et al. [Rhemrev, 1993] apresentaram um método para medir deformação de empenamento e torção em placas de madeira para fabricação de lápis baseado em varredura a Laser (600 placas por minuto). Não utilizam interpretação de imagens mas sim uma combinação de informações de medidas 
realizadas por um emissor Laser com um fotodiodo sensor acoplados, determinando se as três linhas dos feixes Laser produzidas na superfície das placas de madeira pelos emissores, desviam-se ou não dos padrões estabelecidos, rejeitando ou não as placas de madeira.

Outro trabalho voltado à madeira para fabricação de lápis [Andrade, 1998], apresenta um levantamento do comportamento das características físicas da madeira para fabricação de lápis, dando sustentação à determinação das classes utilizadas nesta tese e que estão descritas no próximo capítulo.

\section{5 - CONSIDERAÇÕES FINAIS}

Este capítulo mostrou em forma resumida a história e o processo de fabricação do lápis, localizando a etapa em que os algoritmos propostos nesta tese se aplicam. Também mostrou-se através da análise de publicações voltadas à automatização do processamento de madeira, que a preocupação dos autores está centrada na detecção/classificação dos "defeitos" em madeira, localizando também em que etapa poderiam ser utilizados na produção de lápis.

As placas de madeira utilizadas na fabricação de lápis quando atingem o estágio número 3 da figura 3.1 , não contém os defeitos clássicos citados neste capítulo, como nós, furos, etc..., pois foram excluídos na fase anterior (fase 2).

Este trabalho vem dessa forma, propor métodos de classificação que atuem diretamente na etapa número 3 da figura 3.1 , onde são selecionadas as placas para os diversos tipos de produtos finais, desde placas para fabricação de lápis mais "finos", até placas de madeira para fabricação de lápis que tolerem bem a presença de madeira mais dura (exemplo: lápis de carpinteiro). 
A classificação não ocorre portanto com base em defeitos, mas sim em características que apresentam comportamentos altamente aleatórios. Essas características são descritas no próximo capítulo.

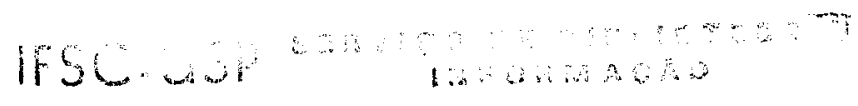




\section{Capítulo 4}

\section{DETERMINAÇÃO DAS CLASSES}

\section{1 - INTRODUÇÃO}

"Quando temos duas ou mais classes, a extração de características consiste na escolha das que são mais efetivas na preservação da separabilidade... A separabilidade depende não somente das distribuições das classes mas também do classificador a ser usado ...'[Fukunaga, 1990].

"Idealmente, espera-se uma função que meça cada ponto no espaço de padrões ou de características e atribua a cada ponto um valor, como por exemplo seu grau de pertinência para uma dada classe. Tais funções tem sido chamadas de funções características no contexto da teoria dos conjuntos "fuzzy" [Zadeh, 1965], funções 
discriminantes no contexto de reconhecimento de padrões e funções densidade de probabilidade em teoria de decisão estatística..." [Andrews, 1972].

A escolha de uma determinada espécie de madeira para fins industriais só deve ser realizada com conhecimento preciso de suas qualidades físicas e mecânicas. Este conhecimento somente pode ser adquirido por meio de estudos sistemáticos, através de ensaios em laboratórios e este não é o objetivo deste trabalho. Portanto, neste capítulo são descritas as características visuais presentes nas placas que conduziram à determinação das classes.

Devido a inexistência de literatura específica que baseie as definições utilizadas, pois tratam-se de informações técnicas da indústria de fabricação de lápis, seguiu-se a orientação recebida de técnicos especializados no assunto.

\section{2 - CARACTERISTICAS BÁSICAS PARA DEFINIÇÃO DE CLASSES}

A madeira utilizada na fabricação de lápis, quase em sua totalidade, provém de reflorestamentos de variedades de pinus, pertencentes à família das coníferas, também chamadas de resinosas ou gimnospermas. São árvores que apresentam rápido crescimento, se comparadas a outras potenciais espécies para a fabricação de lápis, e também possuem características interessantes para a finalidade, como o lenho de madeira branda e com anatomia simples, constituído de dois elementos principais: os traqueídes e os raios medulares. Os traqueídes possuem dupla função: resistência, ou sustentação, e a condução da seiva. Os raios medulares também apresentam basicamente as mesmas funções dos traqueídes, e estão melhor descritos mais a frente. 
As placas de madeira tratadas neste trabalho provém da espécie Pinus caribaea variedade hondurensis, cuja densidade varia entre 0.35 e $0.50 \mathrm{~g} / \mathrm{cm}^{3}$ e é a variedade que apresenta maior crescimento dentro da espécie (Bertolani apud Bortoletto) ${ }^{1}$.

Além do crescimento diferenciado, também outras características são importantes e o que se deseja de uma placa de madeira ideal para que a mesma possa ser utilizada na fabricação de lápis, é que possua as seguintes características principais:

- seja livre de defeitos biológicos, como furos de insetos, incrustações minerais, ataque de fungos, etc...,

- livre de nós e de bolsas de resina,

- livre ou pequena presença nos anéis de crescimento da madeira de verão ${ }^{2}$.

Como as amostras de placas utilizadas neste trabalho foram pré-selecionadas em uma etapa anterior do processo produtivo, eliminando os defeitos biológicos e nós, a determinação das classes baseia-se quase que exclusivamente na presença, forma e distribuição dos anéis de crescimento presentes.

\subsection{1 - COMPOSIÇÃO ESTRUTURAL TRANSVERSAL DAS ÁRVORES}

A figura 4.1, extraída do trabalho de Hellmeister [Hellmeister, 1972] e retrabalhada, mostra a seção transversal do tronco de uma árvore, onde é possível distinguir suas partes bem caracterizadas:

\footnotetext{
${ }^{1}$ Bertolani, F. ; As experiências com pinus no Brasil.In: Encontro Nacional de Reflorestadores, 4 1978, Campo Grande. Anais. São Paulo: UNIPRESS, 1978, p. 33-36

${ }^{2}$ Para seguir a literatura, trata-se por madeira de verão, a madeira formada em estações do ano com indice de chuva reduzido.
} 


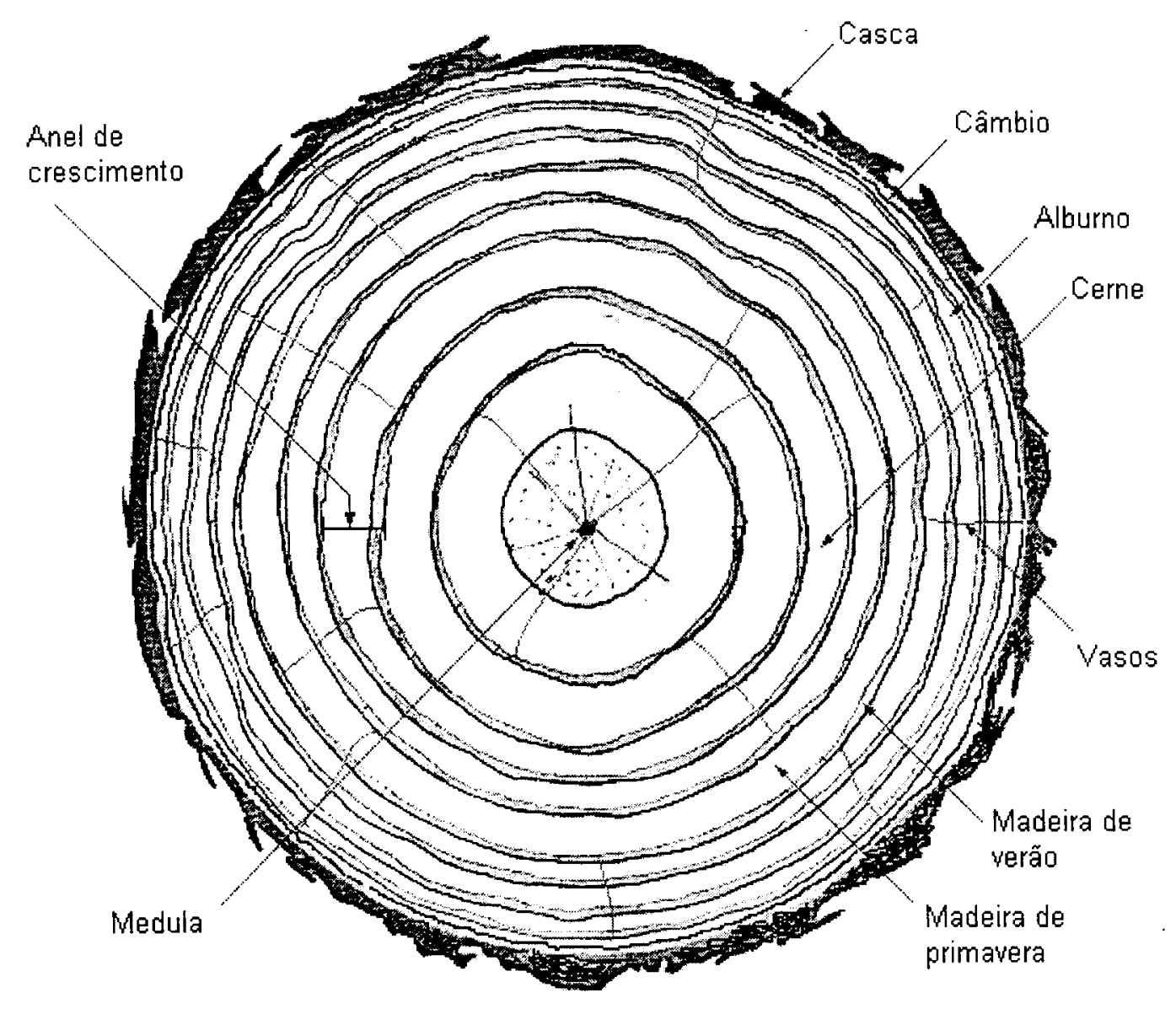

Figura 4.1 - Corte transversal de uma árvore

(extraída de [Hellmeister, 1972] e retrabalhada)

Casca: Protege a árvore contra agentes externos. Nela encontra-se uma parte externa, denominada camada cortical a qual é formada por tecidos mortos e uma camada interna constituída de tecido vivo, mole e úmido que é veículo da seiva elaborada.

Câmbio: Camada invisível a olho nu, situada entre a casca e o lenho, formada de tecido meristemático ${ }^{3}$.

\footnotetext{
${ }^{3}$ Meristema: tecido caracterizado pela ativa divisão de suas células, e que produz as novas células necessárias ao crescimento da planta.[Ferreira-1975]
} 
Lenho: Constitui a parte resistente das árvores, compreendendo o cerne, formado por células mortas, que tem como função resistir aos esforços externos que solicitam a árvore, e o alburno, formado pelas camadas externas mais novas, que contém células vivas, geralmente menos resistente mecanicamente e é também veículo da seiva bruta, que é transportada das raízes às folhas. É a alteração do alburno que vai ampliando e formando o cerne. Durante esta alteração, as paredes das células se impregnam mais ou menos, conforme a espécie, por taninos ${ }^{4}$, resinas e materiais corantes que obstruem os vasos e conferem ao cerne uma cor mais forte.

Medula: Miolo central, constituído de tecido mole e esponjoso de cor escura. Não possui resistência mecânica, nem durabilidade.

Raios Medulares: Ligam as diferentes camadas entre si e tem a função de transportar e armazenar a seiva. Pelo seu efeito de amarração transversal, inibem em parte a retratilidade devida a variações de umidade. São constituídos de células parenquimáticas ${ }^{5}$ dirigidas da medula para a periferia e podem apresentar-se uni ou multisseriados. As coníferas apresentam raios medulares unisseriados, com uma só fiada de células.

Toda madeira apresenta em sua anatomia uma microestrutura celular. O tecido lenhoso está constituído por células de dimensões, formas e agrupamentos diferentes

\footnotetext{
${ }^{4}$ Taninos: classe de substâncias limitantes encontradas em certos vegetais.
} 
com funções como resistência, condução de sucos vitais e armazenamento de reservas nutritivas necessárias. A disposição variável dos elementos constituintes, resulta em particularidades de espécies para espécies tanto na anisotropia e heterogeneidade do material em geral, como diferenças nas características físicas e mecânicas.

As células são formadas por paredes de membranas celulósicas permeáveis, chamadas de paredes primárias, que aos poucos vão se cobrindo de lignina, e a parede secundária, que deixa falhas permeáveis e pontuações. A celulose constitui a estrutura de sustentação das paredes celulares. A lignina é o material aglomerante que liga as células umas às outras. Estes dois componentes são os responsáveis por todas as propriedades da madeira, tais como higroscopicidade, resistência à corrosão, etc... A composição química da madeira apresenta em termos médios, $60 \%$ de celulose, $28 \%$ de lignina e quantidades menores de outras substâncias. Segundo Hellmeister [Hellmeister, 1972], a rigidez e a dureza da madeira podem ser atribuídas à lignina, pois quanto maior porcentagem de lignina menor é a absorção de água e também maior é a estabilidade dimensional. Ele a compara ao "cimento" do concreto.

Portanto, como a madeira utilizada para fabricação de lápis deve ser suave e mole, quanto menos lignina ela contiver melhor será o produto final.

\subsection{2 - ANÉIS DE CRESCIMENTO}

O crescimento das árvores acontece diametralmente, pela adição de novas camadas provenientes da diferenciação do câmbio. Cada camada de tecido formada anualmente constitui um anel de crescimento, com duas partes distintas: uma de cor

\footnotetext{
5 Parênquima: conjunto de células que se assemelham às fibras, lignificadas, dispostas longitudinal e transversalmente ao lenho, com reservas nutritivas.
}

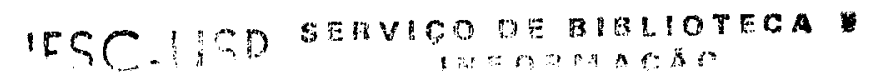


clara, tecido brando e células de paredes finas, formada na primavera e uma segunda, de cor escura, com células pequenas e tecido compacto, que corresponde à madeira formada no verão. A contagem destes anéis permite a avaliação, com bastante aproximação, da idade de uma árvore. Se por qualquer motivo, seca ou ataque de insetos, for interrompido o desenvolvimento normal da árvore, podem formar-se na mesma estação dois ou mais anéis: são os falsos anéis de crescimento [Petrucci, 1975].

Os anéis de crescimento permitem caracterizar as três direções diferenciais da anisotropia do material: axial, segundo o eixo da árvore; tangencial, tangente aos anéis de crescimento e radial, normal aos mesmos.

Nas placas em estudo, o posicionamento de corte de onde as mesmas são extraídas com relação aos anéis de crescimento, caracteriza-se como elemento determinante na classificação, pois a maneira com que os anéis de crescimento se apresentam visualmente nas placas, acaba por estabelecer a classe das mesmas.

Findlay [Findlay, 1975] mostra que o corte, ou desdobro, de toras de madeira, determina diretamente como os anéis de crescimento estão dispostos nas pranchas produzidas pelos cortes tangenciais (planos), e cortes radiais (em quadrantes), como mostrado na figura 4.2 . 


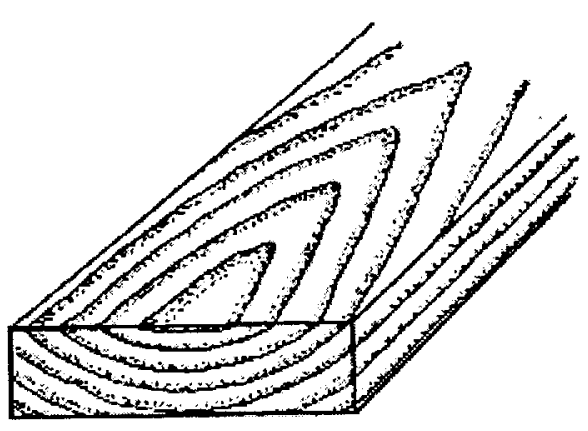

Placa produzida por corte tangencial

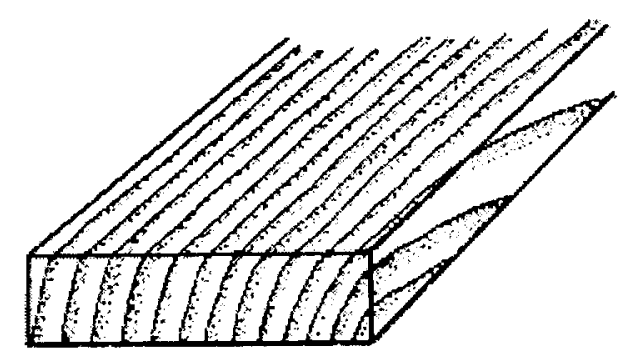

Placa produzida por corte radial

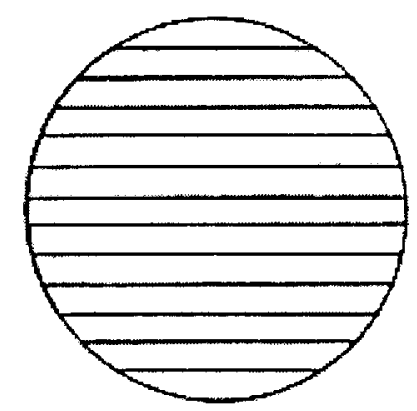

Método de corte que produz placas tangenciais

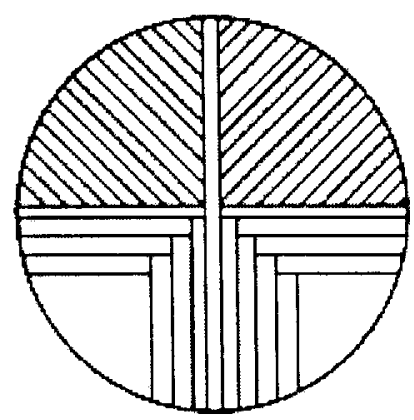

Método de corte que produz placas radiais

Figura 4.2 - Métodos de corte (ou desdobro)

(extraída de [Findlay, 1975])

O método de corte tangencial é mais simples de ser executado, porém as placas provenientes deste processo estão mais sujeitas, quando secas, a apresentarem empenamento e rachaduras, além de possuirem percentualmente mais madeira dura, madeira de veıão do anel de crescimento, do que as placas obtidas com o corte radial. Estas características não são toleradas na fabricação do lápis, pois atuam como elementos determinantes da qualidade final do mesmo. Um lápis que possa empenar ou rachar, não interessa à indústria fabricante de lápis, assim como também não interessa um lápis que apresente dificuldade ao ser apontado, pela excessiva presença de madeira de verão do anel de crescimento. 
A figura 4.3 mostra as deformações sofridas pela madeira com a secagem, relacionadas com a posição de corte em uma árvore.

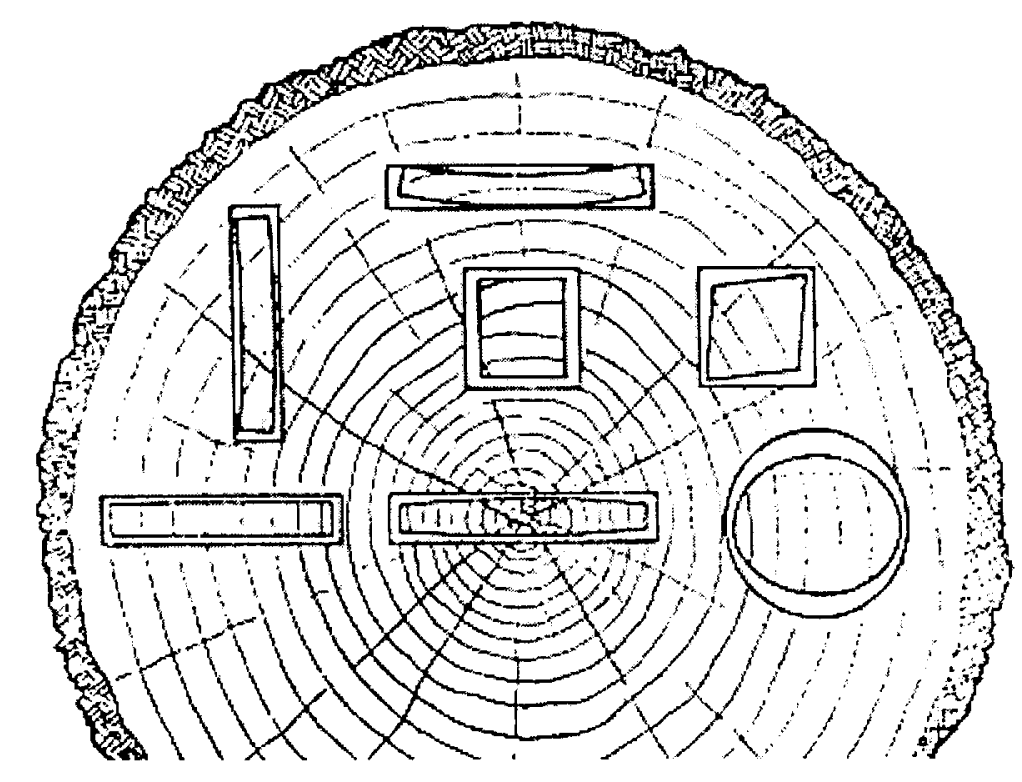

Figura 4.3 - Deformações em função da secagem, sofridas pela madeira em várias posições.

(extraida de [Petrucci, 1975])

\section{3 - DEFININDO AS CLASSES}

Como o objetivo deste trabalho é classificar as placas de madeira através de inspeção visual, procurou-se com o auxílio das características descritas anteriormente agrupá-las em um número de classes as quais pudessem estar bem caracterizadas.

Em primeira análise, as placas apresentam-se em uma seqüência de três categorias básicas: as desprovidas de madeira dura dos anéis de crescimento que representam a melhor classe, chamadas de "lisas" daqui por diante; aquelas provenientes do corte radial, onde a madeira dura dos anéis de crescimento aparece em forma de 
listras escuras em uma distribuição regular e não muito densa; e as que são produto do corte tangencial, possuidoras de maior quantidade de madeira de verão (madeira dura) do que as anteriores, e de cor mais escura com distribuição superficial aleatória.

As figuras 4.4, 4.5 e 4.6 mostram os tipos descritos.

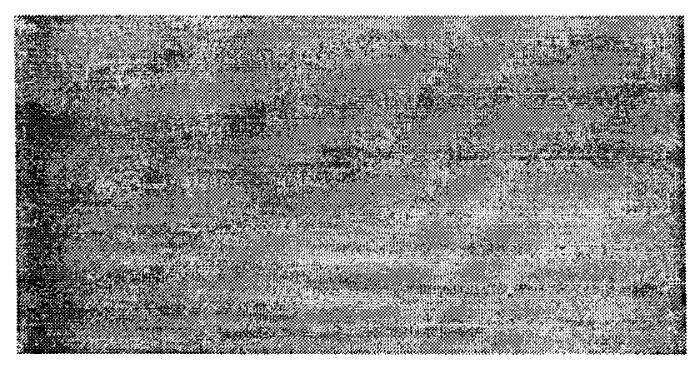

Figura 4.4 - Placa de madeira do tipo "lisa", desprovida de madeira dura dos anéis de crescimento.

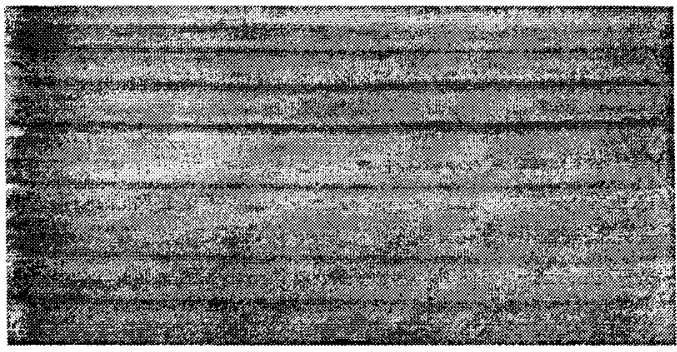

Figura 4.5 - Placa de madeira oriunda de "corte radial"

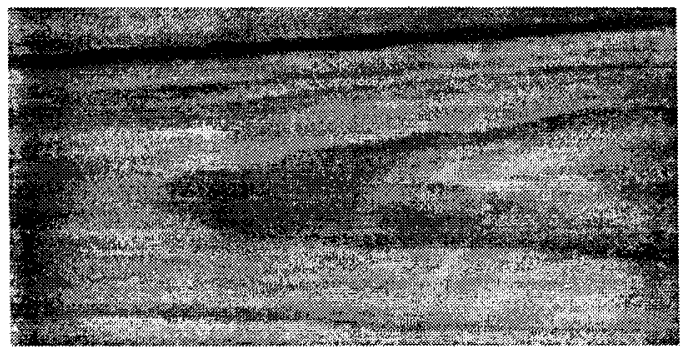

Figura 4.6 - Placa de madeira oriunda de "corte tangencial" 
Embora a proposta das três classes citadas acima possa ser aceitável, ou seja, estão perfeitamente caracterizadas as classes "lisa", "corte radial" e "corte tangencial", o comportamento dos padrões das superfícies das placas é altamente aleatório e diverso. Buscando uma classificação com certo rigor, um sistema de seleção baseado somente nas três classes, proporciona resultados, que de certa forma, podem ser considerados insatisfatórios. As possibilidades de interpretações ambíguas surgem com relativa freqüência, pois as características que definem as classes não geram uma fronteira exata entre as mesmas, havendo sim o que podemos chamar de uma região de fronteira de transição, onde estão localizadas as placas com características marcantes de transição entre duas classes e que podem gerar ambigüidade na interpretação.

No sentido de minimizar a ocorrência de interpretações ambíguas, propôs-se a criação de mais duas classes, localizadas exatamente sobre as regiões de fronteira entre as classes. Esse procedimento agrupa as placas com características que apresentam nitidamente um comportamento de transição entre duas classes vizinhas, considerando que a classe "lisa" é vizinha da "corte radial" ( e vice-versa) e a classe "corte tangencial" também é vizinha da "corte radial" (e vice-versa) mas não se avizinha com a "lisa".

Portanto, foram estabelecidas e denominadas as cinco classes:

- $A$ - Placas "lisas" - (melhor classe)

- $\boldsymbol{B}$ - Placas de transição entre "lisas" e "corte radial"

- C - Placas provenientes de "corte radial"

- D - Placas de transição entre "corte radial" e "corte tangencial"

- $X$ - Placas provenientes de "corte tangencial" 


\subsection{1 - PLACAS CLASSE A}

As placas dessa classe caracterizam-se pela homogeneidade superficial e ausência da madeira dura dos anéis de crescimento, manchas escuras, acículas, etc..., ou seja, são as chamadas placas "lisas" (figura 4.4) e representam a melhor classe.

\subsection{2 - PLACAS CLASSE B}

As placas da classe $B$, devem possuir a maior parte de sua área classificável como $A$, tolerando a presença de poucos anéis de crescimento bem separados uns dos outros, com superfícies de madeira de verão estreitas o suficiente apenas para serem notadas e de cor ligeiramente mais escura que a madeira de primavera da placa; tolerar a presença, com baixa concentração, de acículas normais à superfície das placas (ocorrem com mais intensidade quando as mesmas são extraídas próximas da medula); e ainda tolerar a presença espalhada de pequenas regiões com alterações de cor.

As figuras $4.7,4.8$ e 4.9 mostram placas pertencentes à classe $B$ com as características descritas.

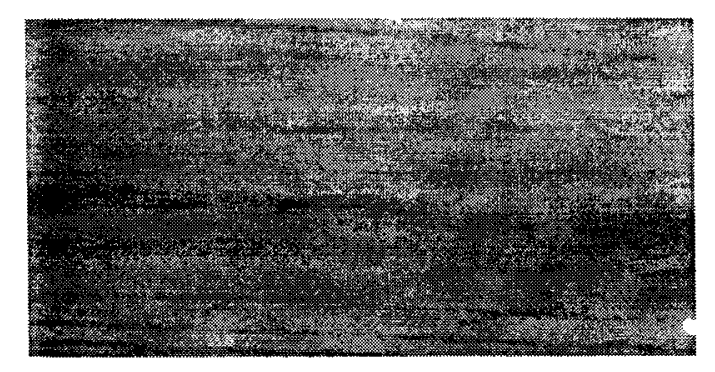

Figura 4.7 - Placa da classe $B$ que apresenta poucos anéis de crescimento 


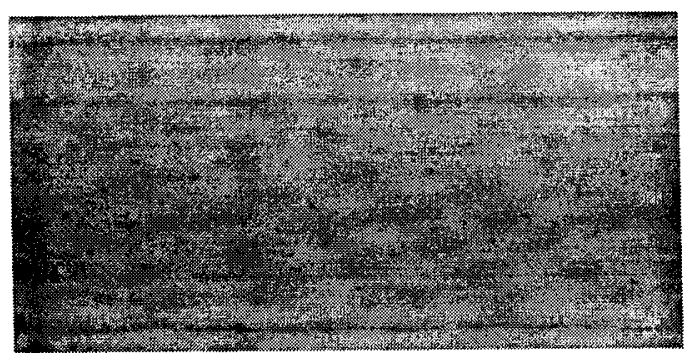

Figura 4.8 - Placa da classe $B$ apresentando acículas normais à superfície e poucos anéis de crescimento.

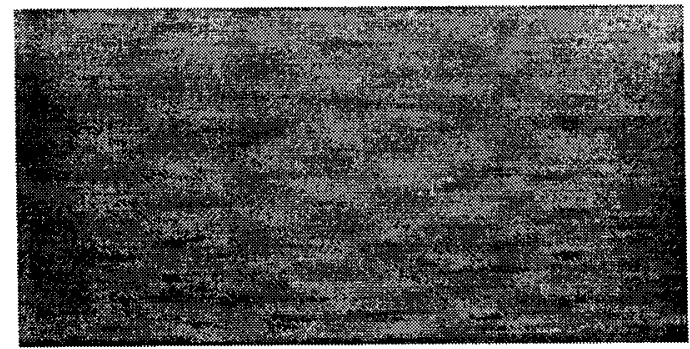

Figura 4.9 - Placa da classe $B$ com pequenas regiões com alterações de cor.

\subsection{3 - PLACAS CLASSE C}

Provenientes do corte radial, são placas que possuem a parte da madeira de verão dos anéis de crescimento bem caracterizada, com espaçamento regular, apresentando-se com variações de baixa a média concentração por placa ( de 5 a 9 anéis por largura de placa - estes limites foram sugeridos por técnicos especializados, considerando a utilização no processo produtivo); tonalidade da madeira dura do anel no máximo 25 niveis de cinza mais escuro que a parte da madeira de primavera, tolerando dentre os presentes na placa, um ou dois anéis com madeira dura que apresente diferença superior a esse máximo; e com espessura da parte de madeira dura perfeitamente caracterizada $=$ $1.5 \mathrm{~mm}$, conforme exemplo da classe mostrado na figura 4.5. Nesta classe também estão presentes placas com características mistas das classes $\boldsymbol{A}$ e $\boldsymbol{C}$, e define-se como 
regra, selecioná-las sempre na pior classe. A figura 4.10 mostra um exemplo desse caso, onde metade da placa tem comportamento de classe $C$ e metade de classe $A$.

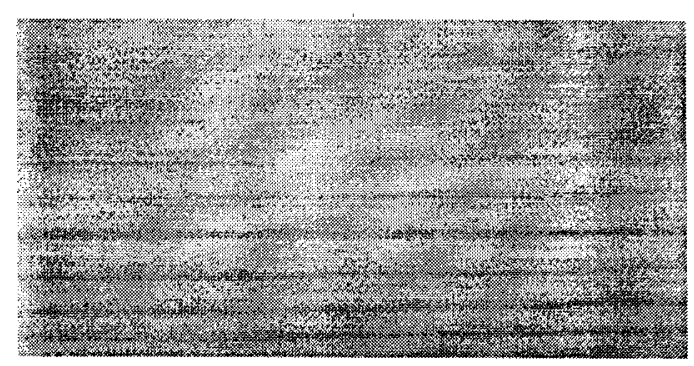

Figura 4.10 - Placa mista de classe $A$ e classe $C$, adotada como classe $C$

\subsection{4-PLACAS CLASSE D}

Como as placas da classe $D$ pertencem à região de transição entre as classes $C$ e $X$, as mesmas podem possuir características de ambas, porém não simultâneamente, pois como adotado para a classe mista entre as classes $\boldsymbol{A}$ e $\boldsymbol{C}$, a regra seleciona sempre pela pior classe; nesse caso a classe $X$.

Quando uma placa com características da classe $C$ ultrapassa os limites estabelecidos para aquela classe, como na figura 4.11, onde o número de anéis por placa é maior que 9, ou a espessura da parte de madeira dura do anel é maior que $1.5 \mathrm{~mm}$, como na figura 4.12, ou ainda quando a diferença de tonalidade da madeira de verão com a madeira de primavera é maior que 25 níveis de cinza (nas duas figuras 4.11 e 4.12 isso também ocorre), então a placa é selecionada como classe D.

Ainda, quando nas flacas provenientes de corte transversal a quantidade de madeira de verão apresenta-se como na figura 4.13, ou seja, existe anel de crescimento 
atingido pelo corte de maneira transversal, porém a presença desse tipo de madeira se dá em pequena escala, também essas são selecionadas como classe $D$.

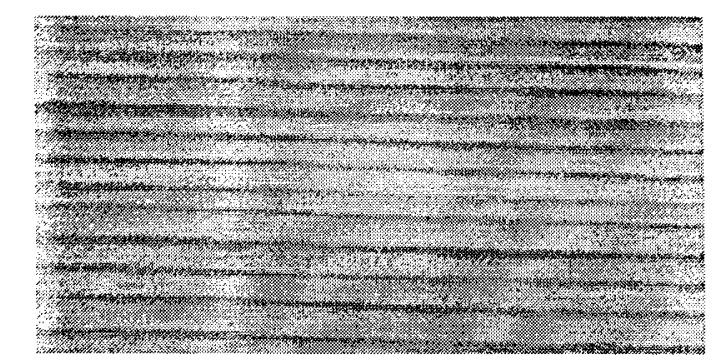

Figura 4.11 - Placa classe $D$ com número de anéis de crescimento maior que nove

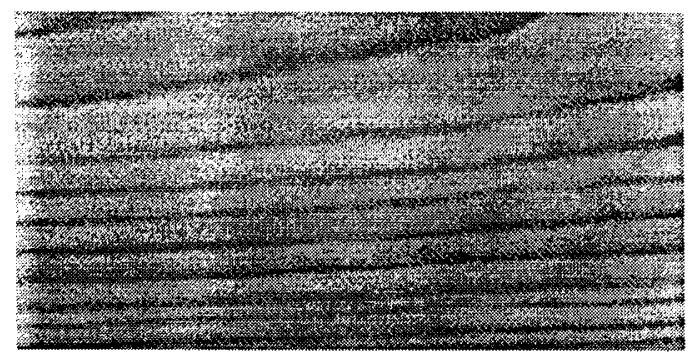

Figura 4.12 - Placa classe $D$ com espessura da parte de madeira dura do anel maior que $1.5 \mathrm{~mm}$ e número de anéis superior a nove

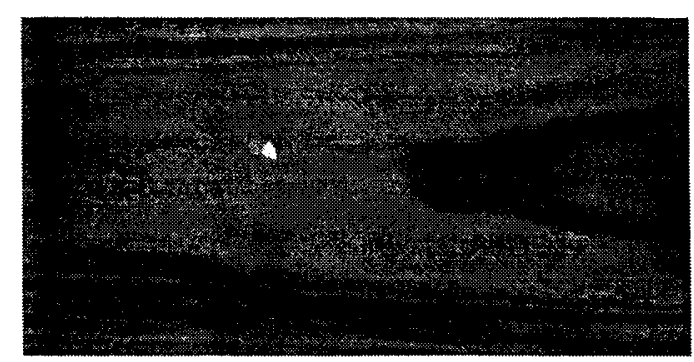

Figura 4.13 - Placa classe $D$ com pouca presença de madeira de verão 


\subsection{5 - PLACAS CLASSE $X$}

Provenientes do corte tangencial, representam a pior classe, onde são encontradas as maiores áreas e as mais diversas distribuições da parte de madeira dura dos anéis de crescimento.

A figura 4.6 (página 8) e a figura 4.13 a seguir, mostram exemplos de cortes tangenciais que geraram placas da classe $X$.

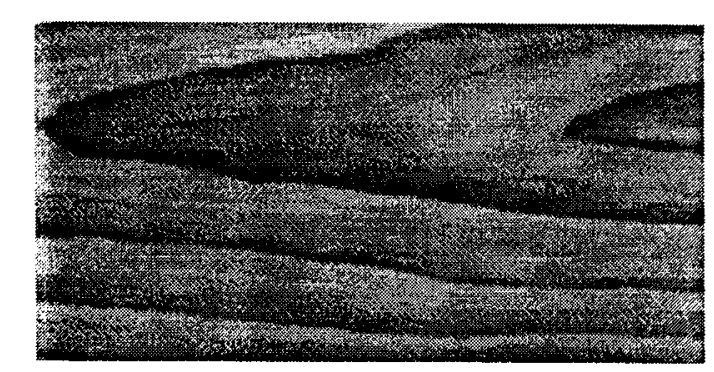

Figura 4.14 - Placa produzida por corte tangencial pertencente à classe $X$.

\section{4 - CONSIDERAÇÕES FINAIS}

Neste capítulo foram estabelecidas as classes que servirão para nortear a seleção das placas de madeira. O estabelecimento dessas classes seguiu orientações recebidas de técnicos em madeira para fabricação de lápis e baseia-se fundamentalmente na forma com que os anéis de crescimento se apresentam na superfície das placas. Discutiu-sc também a relação direta existente entre a apresentação desses anéis e a posição de corte que origina suas diversas distribuições superficiais. As cinco classes propostas 
(denominadas neste trabalho : $A, B, C, D$ e $X$ ) cobrem de maneira bastante satisfatória todas as superficies encontradas nas amostras tratadas, embora reconhecendo que outras classes pudessem ser propostas, dependendo do grau de refinamento de decisão que se desejasse obter. O procedimento de aumentar ou diminuir o número de classes reflete diretamente na qualidade do produto final.

Para que outras classes fossem propostas, o estágio de extração das características do método proposto descrito no próximo capítulo, necessitaria de outros valores-característica além dos lá descritos, o que certamente acarretaria um acréscimo no tempo para a extração e consequentemente um incremento na complexidade dos algoritmos de classificação, necessitando também de tempo adicional para a conclusão da tarefa.

No próximo capítulo descreve-se a proposta do método de extração das características e também métodos de classificação baseados em regras. 


\section{Capítulo 5}

\section{OS MÉTODOS PROPOSTOS}

\section{1 - INTRODUÇÃO}

Neste capítulo são apresentados os algoritmos utilizados na interpretação das imagens das placas de madeira, estando divididos em duas etapas: extração de características e classificação.

"Se uma distribuição de probabilidade qualquer é conhecida, podemos medir o conteúdo de informação da imagem usando a entropia" [Sonka, 1993].

"O princípio da máxima entropia serve como um critério para selecionar uma distribuição de probabilidade a priori quando muito pouco ou nada é conhecido. Isto estabelece que, para uma dada quantidade de informação, a distribuição de probabilidade que melhor descreve nosso conhecimento, é aquela que maximiza a 
entropia de Shannon [Shannon, 1948] com relação a dadas evidências como restrições" [Wong, 1989].

Apoiados nas afirmações acima, o algoritmo para extração de características utiliza o conceito de entropia, buscando medir a quantidade de informação presente nas imagens através da análise de método de limiar ("threshold") entrópico automático.

\section{2 - SUBDIVISÃO DAS PLACAS EM REGIÕES (JANELAMENTO)}

Realizando processamento global nas placas, ou seja, considerando-as como uma única região, torna-se difícil, senão impossível, separá-las adequadamente utilizando apenas algoritmos baseados em limiar, pois embora seja possível observar valores ligeiramente agrupados em diferentes faixas, o alto desvio padrão presente nos grupos dificulta uma classificação efetiva e sem ambigüidades.

Assim sendo, optou-se pelo processamento local subdividindo-as (as placas) em um número fixo de regiões que favorecesse uma interpretação baseada em conhecimentos prévios.

Disso surge a questão: - Qual o número de linhas e colunas que seriam mais adequados à subdivisão das placas?

Resposta: - Partindo-se das dimensões das placas e observando-se que, de cada placa é possível confeccionar até nove lápis, pareceu-nos lógico subdividi-las em nove linhas, possibilitando assim atribuir também uma classificação parcial às placas. Como exemplo, se apenas uma, duas ou três linhas laterais das placas (linhas que comportem um lápis) fossem classificadas como ruins e as demais não, este procedimento de subdivisão possibilitaria uma decisão de envio desse tipo de placa a um estágio de 
reprocesso, onde, excluindo as linhas ruins, placas com esse comportamento poderiam ter aproveitamento parcial em uma classe superior. Com relação ao número ideal de colunas, determinou-se heuristicamente o melhor número de subdivisões, aquele que menos erro cometesse ao classificar as regiões. Este procedimento envolveu ajustes dos níveis de decisão para cada número de colunas escolhido, mostrando que de quatro a seis colunas os resultados são semelhantes e altamente satisfatórios. Optou-se então por quatro colunas pois significa um menor número de células para processamento, já que temos nove linhas, perfazendo então trinta e seis células, ou regiões de processamento.

As placas foram então mapeadas em regiões conforme a figura 5.1 abaixo.

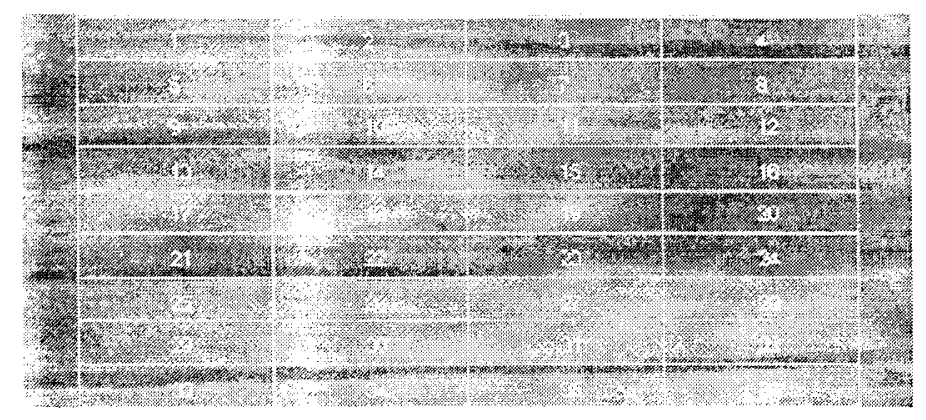

Figura 5.1 - Subdivisão das placas em 36 regiões de processamento

\section{3 - EXTRAÇÃO DE CARACTERÍSTICAS}

Certamente um dos aspectos mais importantes em reconhecimento de padrões é a seleção de características. Realizando esta seleção adequada e eficientemente, tanto os algoritmos de classificação sofisticados quanto os simples podem ser implementados devido a grande redução de dimensionalidade fornecida pelo processo de extração de 
características, simplificando assim o custo computacional envolvido necessário à classificação [Andrews, 1972].

Fukunaga [Fukunaga, 1990] deduz que somente $(L-l)$ características são necessárias para a classificação de $L$ classes, e que um aumento nesse número certamente acarreta em redundância de informações.

O algoritmo utilizado para a extração de características das placas de madeira foi desenvolvido baseado no método de limiar automático, que utiliza a maximização da entropia de Shannon [Shannon, 1948] para determinar o valor ótimo de limiar.

Além do valor de limiar automático foi explorada a extração de outros valorescaracterística, intrínsecos ao método, que serviram ao algoritmo de pré-classificação.

O método está baseado no nível de limiar que maximiza a equação:

$$
H=-\sum_{i=1}^{n} p_{i} \log p_{i}+\left(1-p_{i}\right) \log \left(1-p_{i}\right)
$$

a qual apresenta duas possibilidades de probabilidades que são $p$ e $(1-p)$, tomadas para exprimir a probabilidade de fundo e a probabilidade de qualquer estrutura presente não pertencente ao fundo.

Observando a equação 5.1 acima, quando todas as amostras de uma distribuição qualquer possuem a mesma probabilidade, a equação apresenta o comportamento da figura 5.2. 


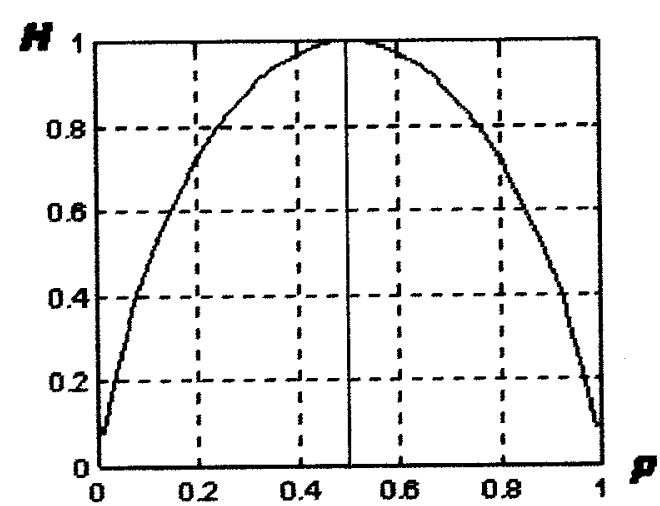

Figura 5.2 - Entropia normalizada para o caso de duas possibilidades com probabilidades $p$ e (1-p) e todas as amostras de uma distribuição qualquer com mesma probabilidade

O método de limiar automático encontra o valor de limiar para cada região da placa, quando a entropia da mesma é máxima, e como pode-se observar na figura $\mathbf{5 . 2}$ isso ocorre quando $p=0.5$. Além do valor do nível de limiar, são ainda extraídos dessa curva outros dois valores-característica que são a entropia total e a razão de assimetria apresentada pela curva. A entropia total, que é a integral da curva da figura 5.2, é um indicativo importante da quantidade de informação presente na região, ou seja, quanto maior o seu valor, maior também a presença de formas não pertencentes ao fundo, indicando assim região não uniforme. Com a razão de assimetria ocorre que quanto mais afastada da unidade, esta indica a presença de alterações de padrão, também em alterações que ocupam pequenas áreas, mas de significativo contraste na região. Valores menores que a unidade indicam regiões de contraste de áreas e com área escura predominante, e conseqüentemente valores maiores que a unidade apontam a presença de regiões com maior quantidade de área mais clara. Apenas relembrando que a curva apresentada acima na figura 5.2 não apresenta assimetria pois pertence a uma distribuição que possui amostras com probabilidades iguais, o quê não ocorre nas regiões das placas. 
Como outro valor-característica, observou-se ainda que o comportamento das duas parcelas da equação $5.1, p \log (p)$ e $(1-p) \log (1-p)$ contra a probabilidade (figuras 5.3 e 5.4), apresentam outra informação importante que é a diferença absoluta entre os valores de nível de cinza tomados nos picos das duas parcelas. Valores elevados dessa diferença indicam presença de grandes áreas contrastantes na região.

As figuras 5.3 e 5.4 mostram os afastamentos entre o local de limiar encontrado no método automático e os picos máximos de cada parcela.

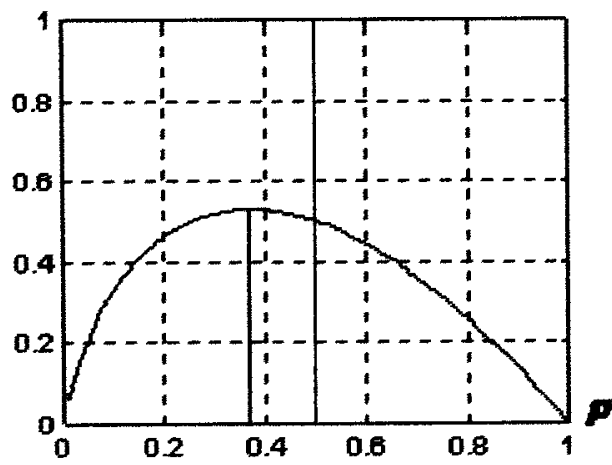

Figura 5.3 - (p) $\log (p)$ normalizada, com limiar encontrado (vermelho) e pico máximo (azul)

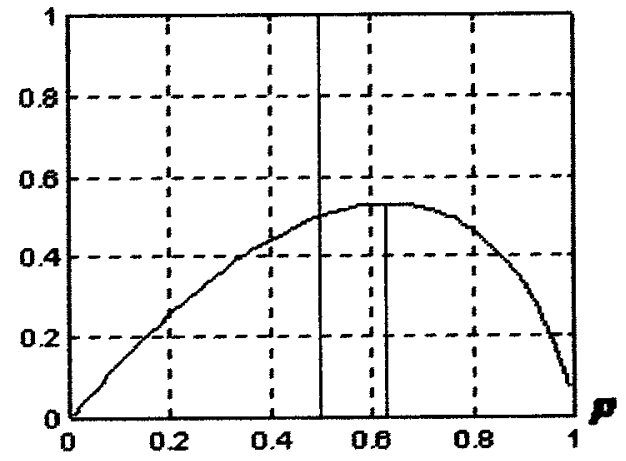

Figura 5.4 - (1-p) $\log (1-p)$ normalizada, com limiar encontrado (vermelho) e pico máximo (azul)

Somado aos quatro valores-característica apresentados, toma-se ainda como mais um elemento de decisão, a razão entre o valor de limiar encontrado na região e o valor de limiar médio da placa, representando assim o último valor-característica do conjunto utilizado. Essa razão é importante pois a região toda pode fazer parte de uma grande estrutura indesejada e não ser detectada pelos outros valores-característica, pois, pode tratar-se de uma região bastante uniforme porém com nível de cinza de limiar bem 
abaixo ou bem acima da média das outras regiões, o que realmente a descaracteriza como região livre de alterações.

\subsection{1 - CÁLCULO DA ENTROPIA}

O algoritmo apresentado a seguir é calculado para todas as regiões das placas, fornecendo assim a estratégia de extração dos valores-característica utilizados no algoritmo de pré-classificação(descrito mais a frente).

Como definições básicas temos:

$p_{i}$ - probabilidade de um nível de cinza $i$ ocorrer em uma região: $p_{i}=\frac{f_{i}}{N_{0}}(\mathbf{5 . 2 )}$

$f_{i}$ - frequência dos níveis de cinza

$$
N_{0}-\text { número total de pixels na região : } \quad N_{0}=\sum_{i=0}^{l-1} f_{i} \quad i=0,1, \ldots, l-1
$$

Aplicando-se um limiar $t$ em uma imagem, obtém-se uma imagem em dois níveis. A probabilidade a posteriori dos pixels com valores de cinza menores que $t$ é dada por:

$$
P_{t}=\sum_{i=0}^{t} p_{i}
$$

Similarmente, a probabilidade a posteriori de todos os pixels com valores maiores ou iguais a $t$ é $1-P_{t}$. Daí a entropia de Shannon de uma imagem em dois níveis é:

$$
H\left(P_{t}\right)=-\sum_{i=1}^{t} P_{t} \log P_{t}+\left(1-P_{t}\right) \log \left(1-P_{t}\right)
$$

onde (zerox $\log$ (zero)) é assumido como zero. Se nada mais é conhecido com relação à imagem, maximizando a equação 5.5 obtém-se o valor ótimo de limiar para a imagem. 
No trabalho de Wong \& Sahoo [Wong, 1989], os autores afirmam que: "Uma maximização irrestrita da equação 5.5 com respeito a $P_{t}$, produz $P_{t}=0.5$. Se nada mais é conhecido, então o princípio da máxima entropia sugere que deve-se escolher o valor de limiar de maneira que a porcentagem de pixels brancos e pretos sejam iguais. Este é precisamente o caso se um histograma é bimodal, com mesmas contribuições de cada moda. Entretanto, o histograma de uma imagem não é sempre bimodal, e nesses casos, outras considerações de informações da imagem devem ser incorporadas ao método."

No presente trabalho, o tratamento com as placas de madeira, cuja incidência de regiões com histogramas unimodais não é fato raro, mostrou entretanto que a maximização irrestrita da equação 5.5 , produziu excelentes valores de limiar também para as regiões com histogramas unimodais, e que combinados com os outros valorescaracterística, permitiram a atribuição das classes às regiões sem a necessidade da incorporação de outras considerações de informação para a obtenção dos valores de limiar.

Na aplicação do método, como primeiro passo é necessário o levantamento do histograma da região, onde obtém-se a distribuição de freqüências dos pixels presentes.

A figura 5.5 apresenta, como exemplo, o histograma da região 9 da figura 5.1 . 


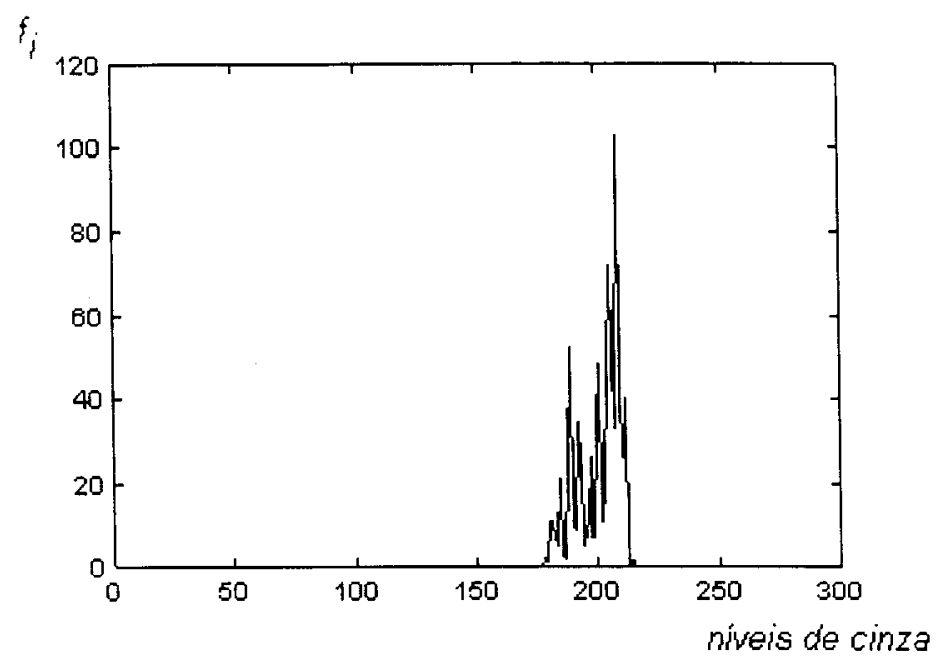

Figura 5.5 - Histograma da região 9 da figura 5.1

Conhecendo-se então a distribuição de freqüências da região, ou seja, seu histograma, sabendo-se também sua dimensão, é possível calcular-se a função densidade de probabilidade, mostrada na figura 5.6.

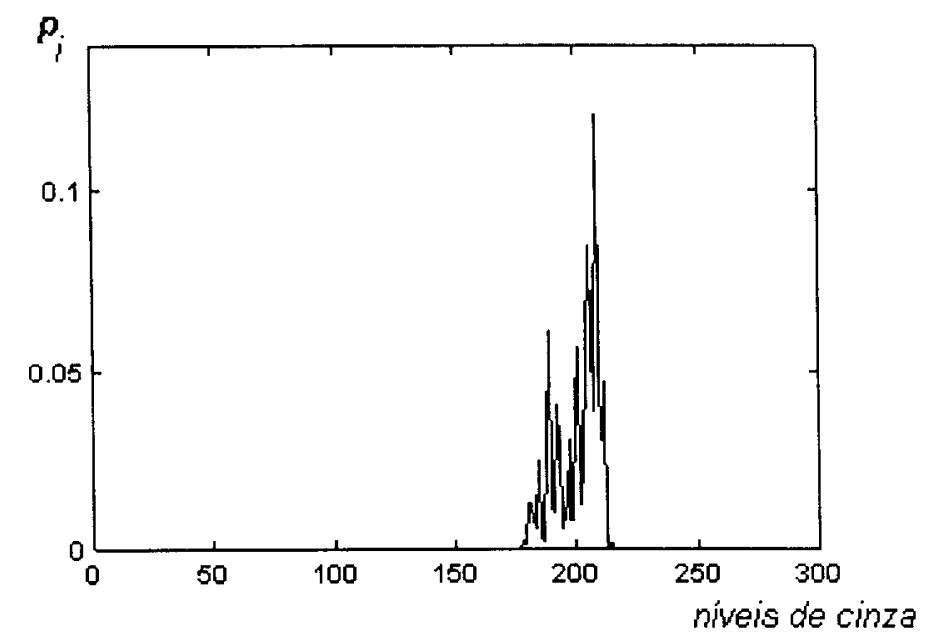

Figura 5.6 - Função densidade de probabilidade -região 9 da figura 5.1

De posse da função densidade de probabilidade, calcula-se a equação 5.5 para cada valor de limiar atribuído, ou seja, variando-se $t$ de 1 a 256, buscando assim a extração dos valores-característica. 


\subsection{2 - ALGORITMO DE EXTRAÇÃO DOS VALORES-CARACTERÍSTICA}

A seguir apresenta-se o algoritmo que executa a extração dos valorescaracterística.

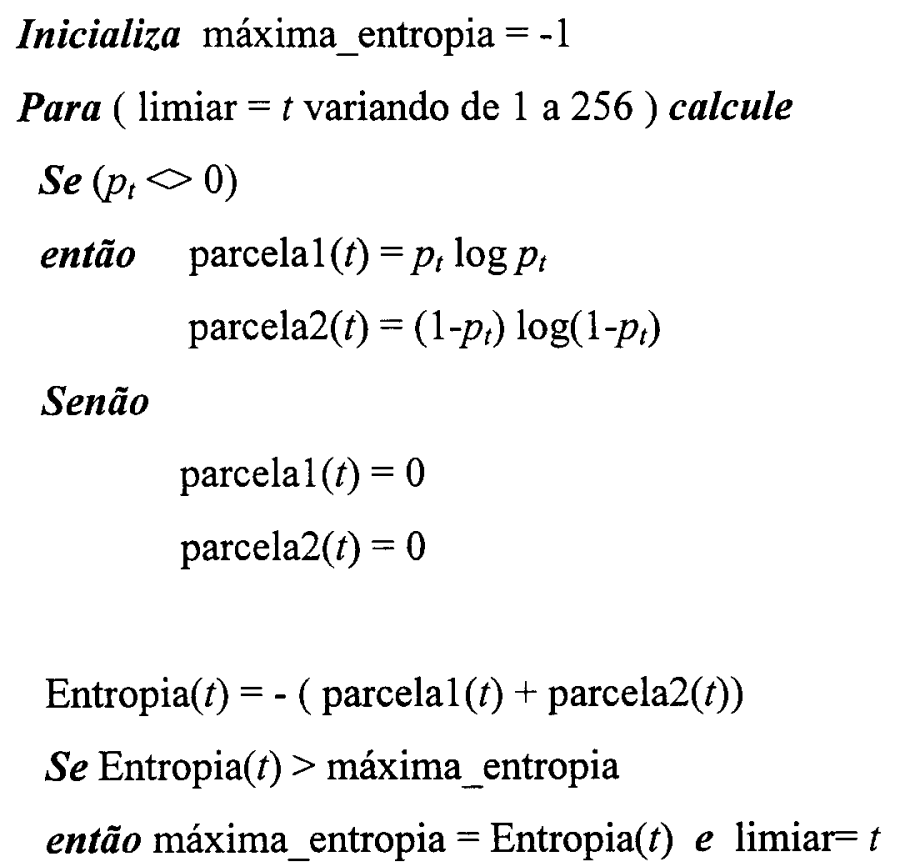

Pode-se observar o comportamento das curvas da Entropia da região, assim como também o comportamento das parcelas da equação 5.5 nas figuras $5.7,5.8$ e 5.9 , respectivamente. Para melhor visualização do posicionamento do nível de limiar encontrado e dos picos das parcelas da equação 5.5, as figuras estão dispostas com o eixo das abcissas em função dos níveis de cinza e não em função da densidade de probabilidade como nas figuras 5.2, 5.3 e 5.4 . 


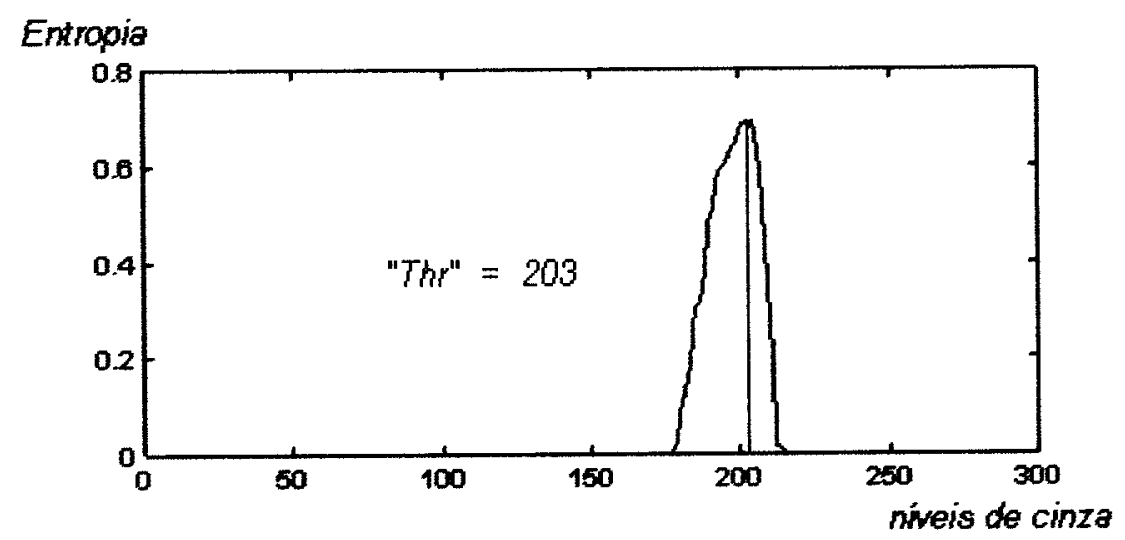

Figura 5.7 - Curva de Entropia - região 9 da figura 5.1

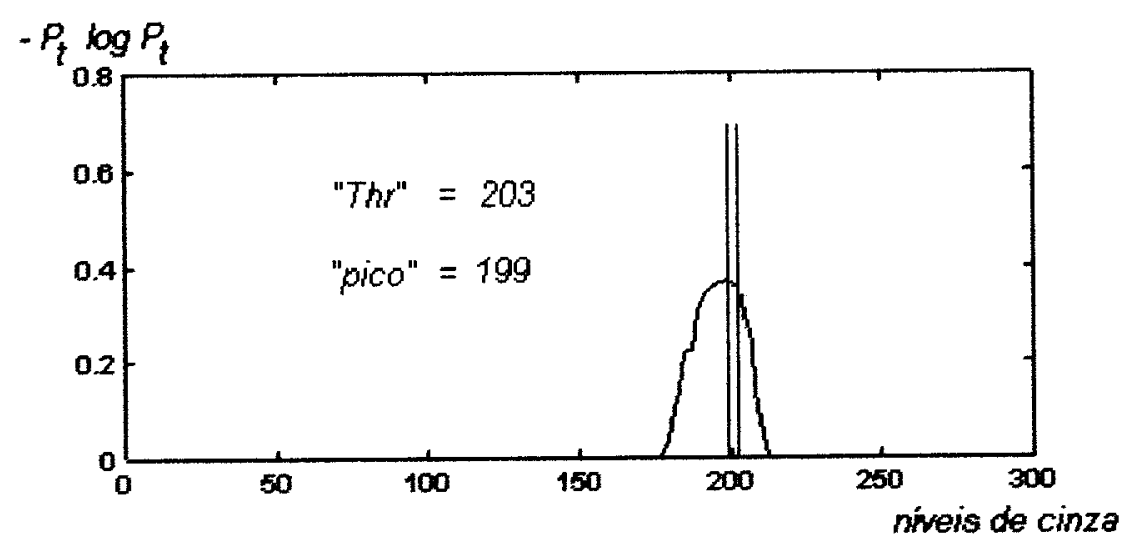

Figura 5.8 - Curva da parcial $\left(-P_{t} \log P_{t}\right)$ - região 9 da figura 5.1

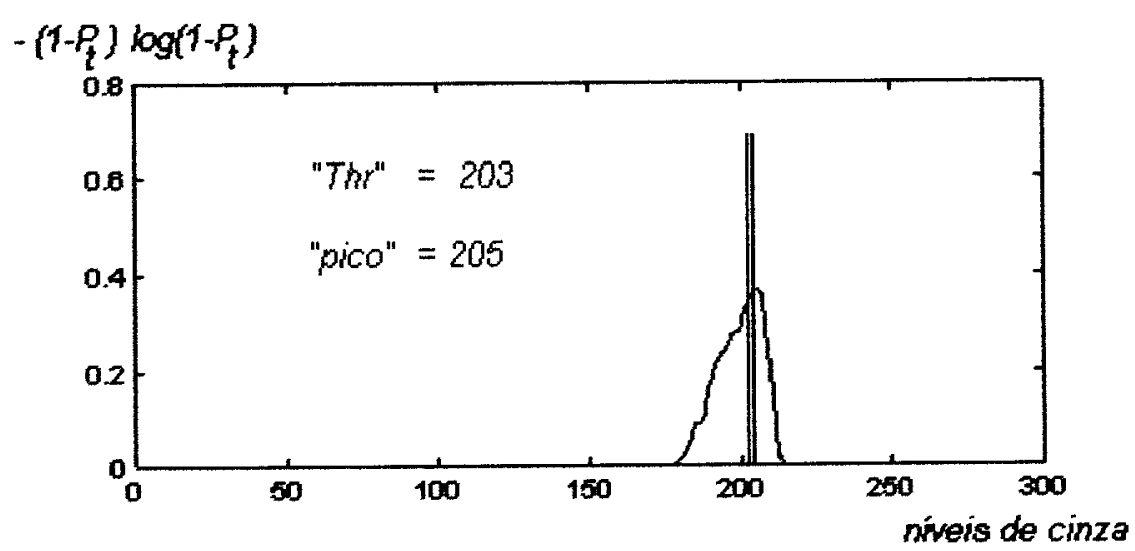

Figura 5.9 - Curva da parcial $\left(-\left(1-P_{t}\right) \log \left(1-P_{t}\right)\right)$ - região 9 da figura 5.1 


\section{4 - CLASSIFICAÇÃO DAS PLACAS}

Após a fase de aquisição dos valores-característica, estes são submetidos a uma combinação com diferentes valores de limiar; alguns valores são interpretados com decisão tipo passa-faixa e outros simplesmente com decisão de fronteira, ou seja, acima ou abaixo de certo valor será ou não aprovado com relação àquele critério. Os limites foram estabelecidos após ensaios de observação, que combinados definem então quatro classes $(A, B, C$ e $X)$ que serão atribuídas às regiões, onde a combinação de todas é que definirá a classe final.

Cabe aqui ressaltar que embora pareça haver discrepâncias nas definições, pois como discutido no capítulo 4 , as classes foram definidas como sendo um total de cinco e aqui tratam-se de apenas quatro; isso não acontece em virtude do tratamento de préclassificação operar sobre regiões das placas (ou janelas de processamento) e somente na parte final do método é que reaparecem as cinco classes, com as quais selecionam-se as placas como rotuladas no capítulo $4:$ : $A, B, C, D$ e $X$ ", onde " $A$ " representa a melhor classe e $X$ a pior. As letras $(A, B, C \mathrm{e} X)$ foram mantidas com relação à definição do capitulo 4 , apenas para guardar o grau de hierarquia de qualidade na classificação da região, pois não é possível em uma região apenas, encontrar-se por exemplo, todas as características globais que definem uma placa de classe $X$. 
A seguir é apresentado o algoritmo de decisão baseado em regras de fronteiras que atua no estágio do método denominado pré-classificação, atribuindo um rótulo de classe a cada região (os níveis de decisão estão detalhados na seção 6.3).

Se $\quad($ entropia total $)<10.0$

e (diferença entre níveis de cinza dos picos nas parciais ) $<9$

$e \quad$ (razão limiar da região pelo limiar médio) $>=0.94$

e $\quad 0.6<=$ (razão de assimetria da curva de entropia) $<2$

então atribuir à classe o rótulo $A$

\section{Senão}

Se (entropia total) $<12.5$

$e \quad$ (diferença entre níveis de cinza dos picos nas parciais ) $<8$

$e \quad$ (razão limiar da região pelo limiar médio) $>=0.94$

$e \quad 0.7<=$ (razão de assimetria da curva de entropia $)<1.8$

então atribuir à classe o rótulo $\boldsymbol{B}$

\section{Senão}

Se $\quad($ entropia total $)<18.0$

e (diferença entre níveis de cinza dos picos nas parciais ) $<7$

$e \quad$ (razão limiar da região pelo limiar médio) $>=0.92$

e $\quad 0.65<=($ razão de assimetria da curva de entropia $)<2.5$

então atribuir à classe o rótulo $\quad C$

Senão atribuir à classe o rótulo $X$ 
O algoritmo acima sempre estabelece uma classe à região, desconsiderando assim a opção de rejeição. A opção de não rejeitar, acarreta em algumas situações em um aumento no erro de classificação em alguma classe, todavia esse aumento mostrouse aceitável no geral.

Um exemplo do resultado dessa pré-classificação pode ser visto na figura $\mathbf{5 . 1 0 ,}$ onde estão atribuídos os rótulos para cada região.

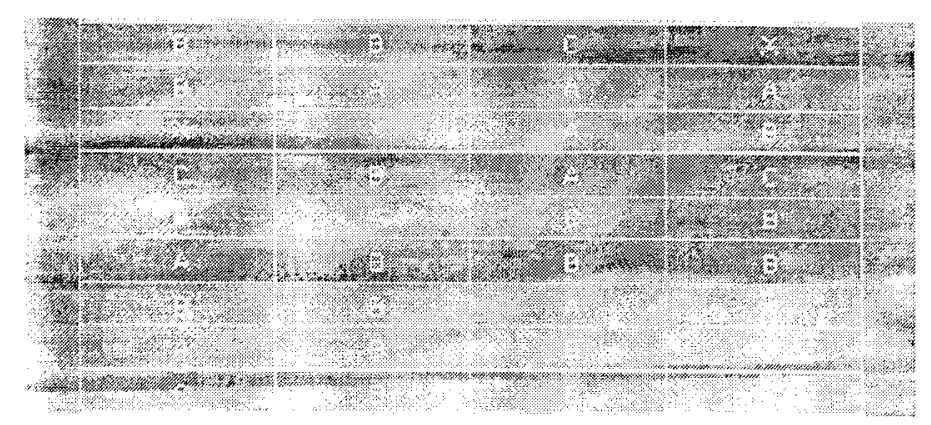

Figura 5.10 - Placa pré-classificada

A partir da pré-classificação acima, um operador treinado facilmente finalizaria o processo de classificação atribuindo uma classe à placa em exemplo, pois o ser humano em sua interpretação é capaz de ponderar que a distribuição de regiões apresentada possui informações do tipo: posição de aglomeração de regiões de mesma classe, quantidade aproximada de regiões pertencentes a cada classe, tipo de regiões presentes, ou seja, uma noção bastante próxima do comportamento do conjunto. Isso não descarta a hipótese de que diferentes operadores, com o mesmo grau de treinamento, ocasionalmente discordem a respeito da classificação, e passem a produzir resultados finais distintos, pois a tarefa tem a tendência de se tornar tediosa e subjetiva, o que naturalmente indica que há alguma sobreposição entre as classes ou mesmo incerteza em sua definição. 
Como Sonka et. al. [Sonka, 1993] e tantos outros autores analizam, a visão de máquina consiste de níveis baixos e altos de processamento, e certamente o entendimento contextual final dessa imagem pré-classificada necessita de um nível maior de processamento, levando-nos à utilização de classificadores.

Apresenta-se então neste trabalho, como proposta para solução, dois métodos que finalizam a classificação das placas.

\subsection{2 - CLASSIFICADOR POR REDUÇÃO DE INFORMAÇÃO BASEADO EM REGRAS DE COMBINAÇÃO}

Este classificador está baseado em redução de informação através do conhecimento prévio de combinação de classes. Na primeira etapa utiliza-se o conceito de combinar quatro regiões para gerar apenas uma. Para isso, foi construída uma tabela de equivalências entre as combinações e suas classes resultantes (tabela 5.1). No sentido de diminuir o número final de possibilidades de combinações, foram desconsideradas as permutações dentro de uma mesma combinação; por exemplo, as combinações " $A A A B$ ", " $A A B A "$, " $A B A A$ " e " $B A A A "$, possuem a mesma classe resultante " $A$ ", isso por entender que em uma linha qualquer das placas as permutações dos elementos não prejudicam a classificação resultante. Também, o número de combinações possíveis num arranjo de quatro posições com quatro variáveis, resulta em 256 combinações, e a tabela 5.1 mostra que desconsiderando aquelas permutações, houve uma redução de dez vezes no número final de classe resultante. Assim, utilizando a soma dos códigos ASCII das letras que compõem a combinação, torna-se transparente para o $\epsilon$ stágio de interpretação o posicionamento das letras dentro da sequiência e facilita a tomada de decisão, pois ao 
observar a tabela podemos notar sequiências e limites bem definidos, salvo em uma situação ou outra que carece de um critério suplementar para tomada de decisão.

Tabela 5.1 - Relações entre combinações de quatro classes, soma dos códigos ASCII das combinações e as classes resultantes

\begin{tabular}{|c|c|c||c|c|c|}
\hline Combinação & Soma dos & Classe & Combinação de & Soma dos & Classe \\
de Classes & Códigos ASCII & Resultante & Classes & Códigos ASCII & Resultante \\
\hline \hline AAAA & 260 & A & CCCC & 268 & C \\
\hline AAAB & 261 & A & AAAX & 283 & C \\
\hline AABB & 262 & A & AABX & 284 & C \\
\hline AAAC & 262 & A & BBAX & 285 & C \\
\hline AABC & 263 & B & ABCX & 286 & C \\
\hline BBBA & 263 & B & BBBX & 286 & C \\
\hline AACC & 264 & B & BBCX & 287 & C \\
\hline BBAC & 264 & B & CCAX & 287 & C \\
\hline BBBB & 264 & B & CCBX & 288 & C \\
\hline BBBC & 265 & B & CCCX & 289 & C \\
\hline CCAB & 265 & C & XX? & $>=306$ & X \\
\hline CCCA & 266 & C & XXX? & $>=329$ & X \\
\hline CCCB & 267 & C & XXXX & 352 & X \\
\hline
\end{tabular}

Combinando-se então os quatro rótulos atribuídos a cada linha, gera-se apenas um rótulo por linha, culminando em um vetor-coluna de resultados que obedecem a combinação da tabela 5.1, como mostrado na figura 5.11 .

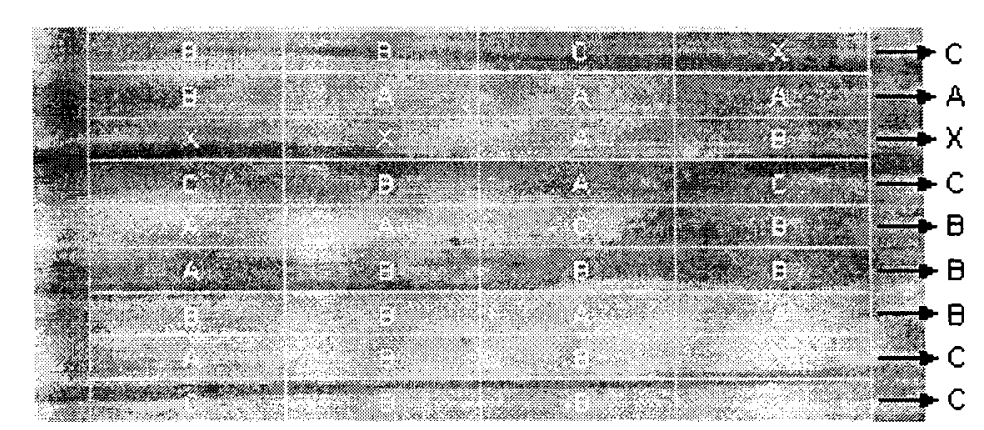

Figura 5.11 - Redução de informação por linhas 


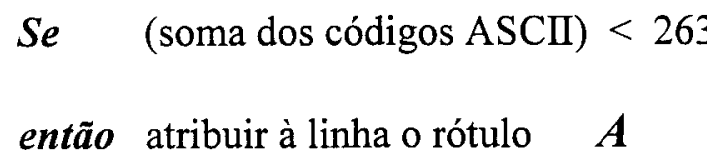

\section{Senão}

$$
\begin{aligned}
& \text { Se } \quad \text { (soma dos códigos ASCII) }<265 \\
& \text { então atribuir à linha o rótulo } \boldsymbol{B} \\
& \text { Se } \quad \text { (soma dos códigos ASCII) }=265 \\
& e \quad \text { (todas as letras) } \quad>\text { "A" } \\
& \text { então atribuir à linha o rótulo } \boldsymbol{B}
\end{aligned}
$$

\section{Senão}

Senão

Se $\quad$ (soma dos códigos ASCII) $<290$

então atribuir à linha o rótulo C

Senão atribuir à linha o rótulo $X$

Chega-se assim a um vetor-coluna que transporta agora uma informação já reduzida da distribuição das classes por linhas, restando a extração final da informação de classe da placa.

Uma análise exata do vetor-coluna para chegar-se à classificação final, resulta em uma decisão entre 262144 possibilidades da combinação de nove posições com quatro variáveis.

Assim sendo, a segunda etapa executa um processo de redução do vetor-coluna gerado pela etapa anterior, combinando três a três os rótulos e a cada combinação 
gerando apenas um. A tarefa de redução total até alcançar um único rótulo toma quatro estágios de combinação, como mostrado na figura 5.12, onde então finalmente estabelece-se a classificação final. Da mesma forma que o algoritmo anterior, optou-se pela adoção das mesmas considerações quanto a permutação dentro das combinações, agora de três elementos.

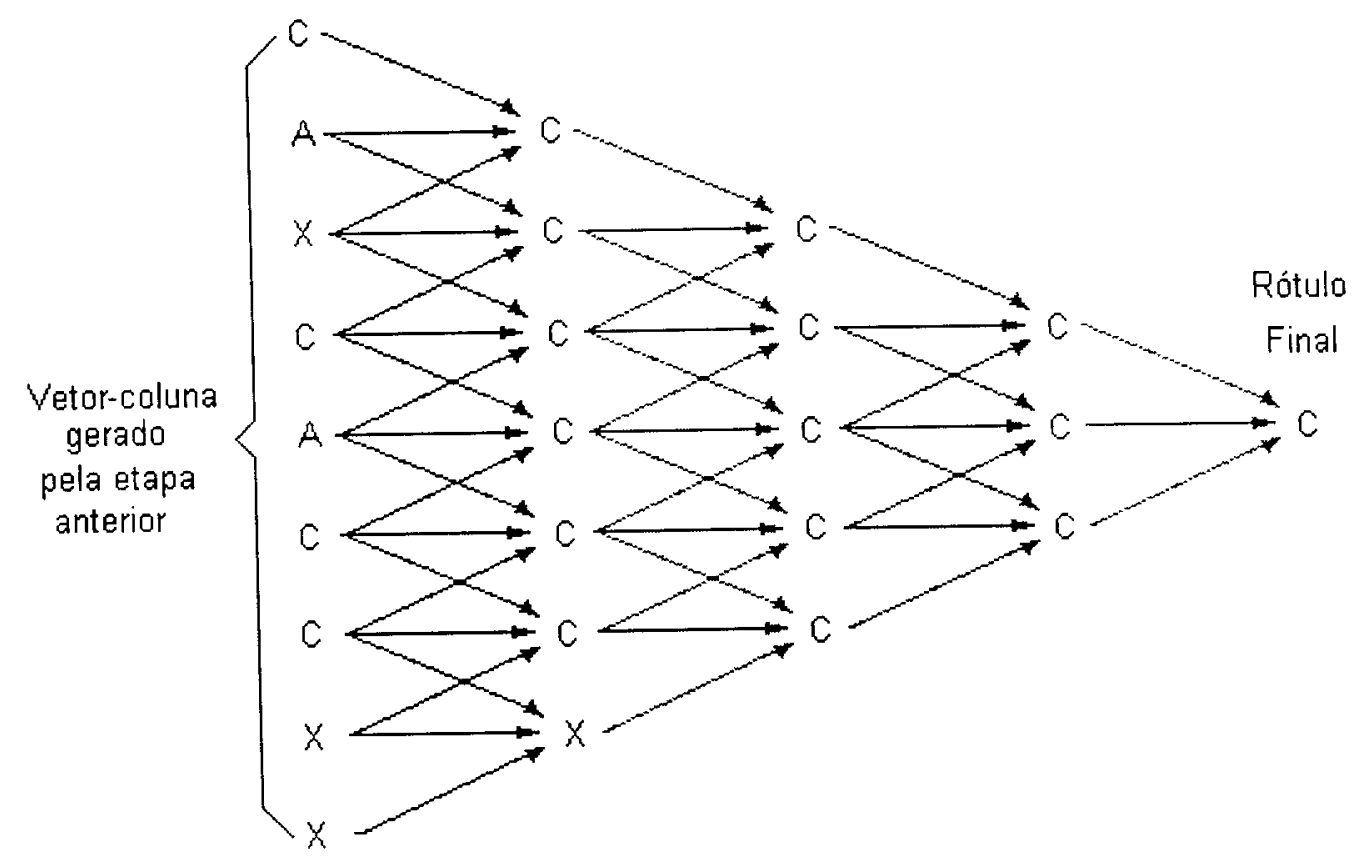

Figura 5.12 - Obtenção da classe final por redução de informação

Após as combinações mostradas no exemplo da figura 5.12, chega-se então à atribuição final de uma classe. Os desvios ou erros gerados pelo processo de redução são discutidos no capítulo 6. 
Tabela 5.2 - Relações entre combinações de três classes, soma dos códigos ASCII das combinações e a classes resultantes

\begin{tabular}{|c|c|c||c|c|c|}
\hline $\begin{array}{c}\text { Combinação } \\
\text { de Classes }\end{array}$ & $\begin{array}{c}\text { Soma dos } \\
\text { Códigos ASCII }\end{array}$ & Resultante & Classes & Códigos ASCII & Resultante \\
\hline \hline AAA & 195 & A & ADD & 201 & D \\
\hline AAB & 196 & A & CCD & 202 & C \\
\hline AAC & 197 & B & BDD & 202 & D \\
\hline BBA & 197 & B & CDD & 203 & D \\
\hline AAD & 197 & B & AAX & 218 & B \\
\hline ABC & 198 & B & ABX & 219 & C \\
\hline BBB & 198 & B & ACX & 220 & C \\
\hline ABD & 199 & B & BBX & 220 & C \\
\hline BBC & 199 & B & ADX & 221 & D \\
\hline ACC & 199 & C & BCX & 221 & D \\
\hline ACD & 200 & C & BDX & 222 & D \\
\hline BBD & 200 & C & CCX & 222 & D \\
\hline CCB & 200 & C & CDX & 223 & D \\
\hline BCD & 201 & C & DDD & 204 & D \\
\hline CCC & 201 & C & XX? & $>=241$ & X \\
\hline
\end{tabular}

\section{ALGORITMO DA SEGUNDA ETAPA}

Se $\quad$ (soma dos três códigos ASCII) $<197$

então atribuir à combinação o rótulo $\boldsymbol{A}$

\section{Señ̃o}

Se (soma dos três códigos ASCII) $<199$

então atribuir à combinação o rótulo $\boldsymbol{B}$

\section{Senão}

Se $\quad$ (soma dos três códigos ASCII) $=199$

e (alguma das três letras) = "B"

então atribuir à combinação o rótulo $B$

Senão

$\mathrm{Se} \quad$ (soma dos três códigos ASCII) $=199$

$e$ (alguma das três letras) = "C"

então atribuir à combinação o rótulo $C$

Senão 


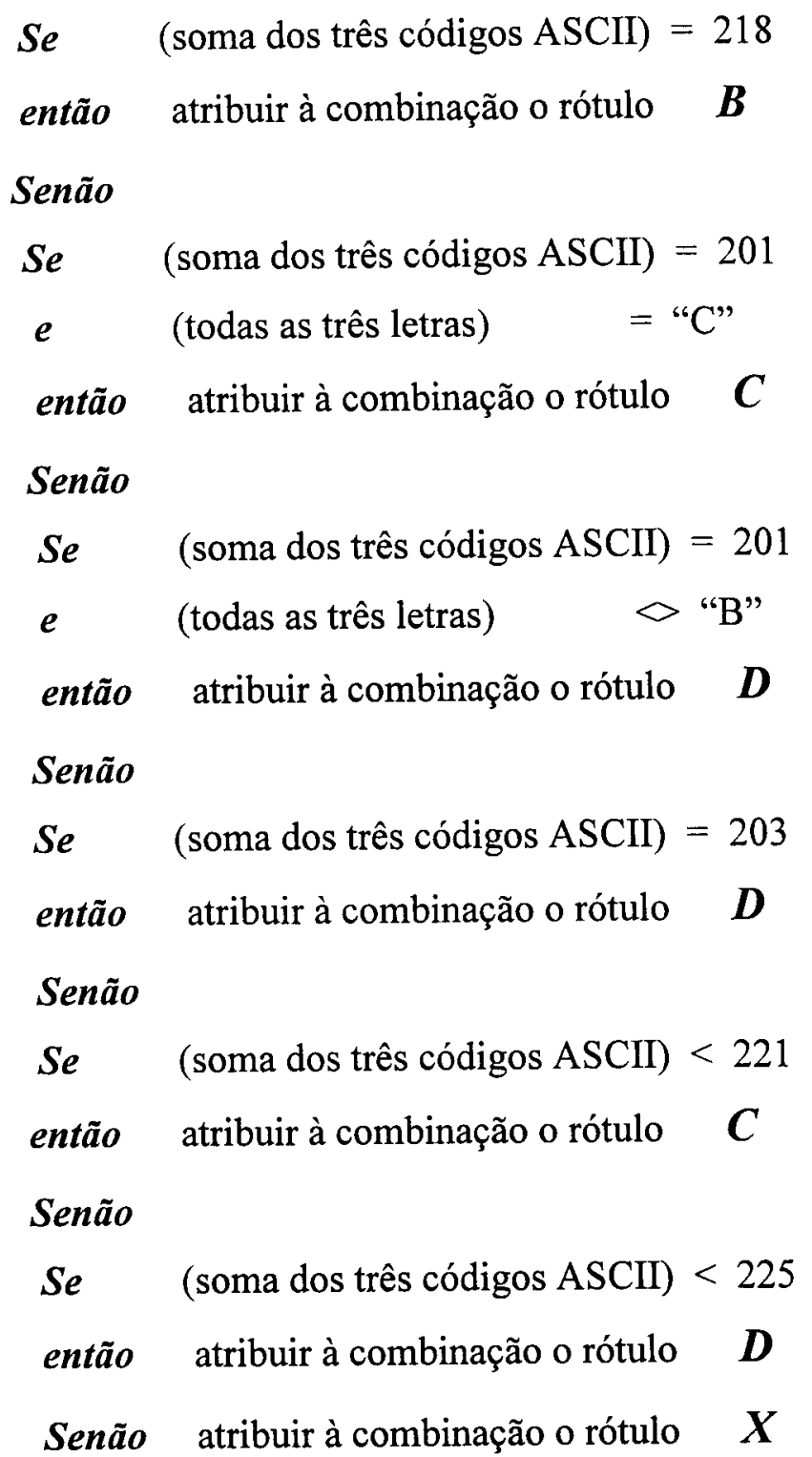

É importante salientar que nesse algoritmo de redução composto por duas etapas (denominadas etapa 1 e 2), somente na segunda é que aparecem combinações que geram a classe $D$ (ver tabelas 5.1 e 5.2). Isso ocorre porque na primeira etapa a inclusão ou não dessa classe, como fruto de uma redução de combinação de quatro classes, não mostrou influência significativa nos resultados finais, por isso ela foi suprimida na primeira etapa. 


\subsection{3 - CLASSIFICADOR UTILIZANDO MATRIZ DE CO-OCORRÊNCIA}

O segundo classificador proposto, parte do resultado da pré-classificação e está baseado na matriz de co-ocorrência de vizinhança horizontal uni-direcional das regiões, ou seja, leva-se em conta apenas o vizinho à direita da região em questão. Isso é feito considerando a direção de fabricação do lápis em apenas um sentido. Essa é uma maneira simples de reduzir a quantidade de cálculos, uma vez que a inclusão de outras direções no cálculo como propõem Haralick et al. [Haralick, 1973] e [Gotlieb, 1990], não mostraram contribuição que pudesse ser considerada como imprescindível. É realizada uma varredura no resultado da pré-classificação para cada classe e a cada coocorrência, acrescenta-se uma unidade à célula correspondente. Como são quatro classes, a matriz de co-ocorrência gerada possui dimensão $4 \times 4$.

Seguindo o exemplo da figura 5.11, a matriz gerada fica:

Tabela 5.3 - Matriz de co-ocorrência de vizinhança horizontal uni-direcional das regiões

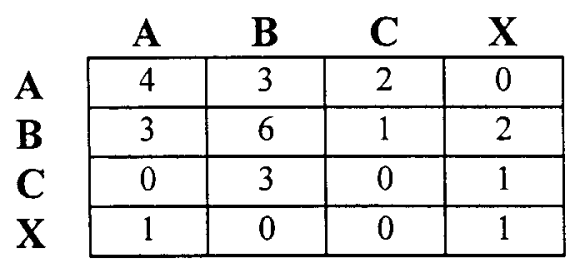

Uma maneira de melhor expressar o comportamento da matriz acima, possibilitando uma melhor visualização dos resultados e também permitir uma melhor tomada de decisões, é representá-la como uma de matriz de porcentagem de coocorrência, ou seja, quanto cada célula participa percentualmente da descrição de vizinhança horizontal de cada placa, como mostrado na tabela 5.4. 
Tabela 5.4 - Matriz de porcentagem de co-ocorrências

\begin{tabular}{|c|c|c|c|}
\hline A & B & C & $\mathrm{X}$ \\
\hline 0.1481 & 0.1111 & 0.0741 & 0 \\
\hline 0.1111 & 0.2222 & 0.0370 & 0.0741 \\
\hline $\mathbf{C}$ & 0.1111 & 0 & 0.0370 \\
\hline 0.0370 & 0 & 0 & 0.0370 \\
\hline
\end{tabular}

O que se obtém até aqui é uma outra matriz, que representa como as regiões estão avizinhadas na horizontal, e não o resultado final de classificação.

Para interpretar essa matriz de informações percentuais simplificando a solução, adotou-se o procedimento de realizar uma somatória de linhas e colunas para que fosse possivel observar o comportamento por avizinhamento das classes. Dessa forma, chegase a dois vetores de resultados que representam a somatória horizontal por linhas de classe e a somatória vertical por colunas de classe, como mostrado abaixo:

Tabela 5.5 - Matriz de porcetagens com somatórias de linhas e colunas

\begin{tabular}{|c|c|c|c|c|c|c|}
\hline & $\mathbf{A}$ & B & $\mathrm{C}$ & $\mathbf{X}$ & Somatória & Índice de \\
\hline $\mathbf{A}$ & 0.1481 & 0.1111 & 0.0741 & 0 & 0.3333 & {$[1]$} \\
\hline B & 0.1111 & 0.2222 & 0.0370 & 0.0741 & 0.4444 & [2] \\
\hline $\mathrm{C}$ & 0 & 0.1111 & 0 & 0.0370 & 0.1481 & [3] \\
\hline $\mathbf{X}$ & 0.0370 & 0 & 0 & 0.0370 & 0.0741 & [4] \\
\hline Somatória & 0.2963 & 0.4444 & 0.1111 & 0.1481 & & \\
\hline $\begin{array}{l}\text { Índice de } \\
\text { coluna }\end{array}$ & [1] & [2] & [3] & [4] & & \\
\hline
\end{tabular}

De poss: dessas informações, aplica-se um algoritmo baseado em decisão por níveis de fronteira, classificando o vetor-coluna e o vetor-linha. $\mathrm{O}$ algoritmo é o mesmo para os dois vetores, por isso é apresentado apenas o algoritmo para solução do vetorlinha. 


\section{ALGORITMO DE DECISÃO PARA O VETOR-LINHA}

Identificar qual é o maior elemento no vetor

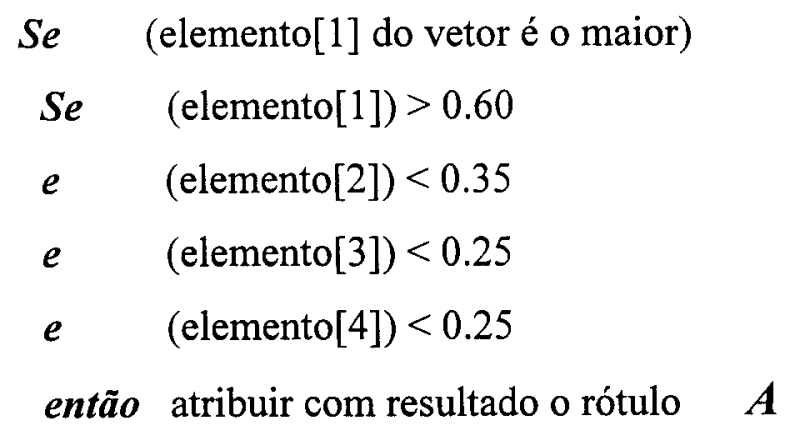

\section{Senão}

Se (elemento[1]) $>0.35$

e $\quad(($ elemento[4] $)<0.20$ ou $\quad($ elemento[2] $)>0.30)$

então atribuir como resultado o rótulo $\boldsymbol{B}$

Senão atribuir como resultado o rótulo $C$

\section{Senão}

Se (elemento[2] do vetor é o maior)

$\mathrm{Se} \quad($ elemento[2]) $>0.40$

ou (elemento[1]) $>0.3$

então atribuir como resultado o rótulo

B

\section{Senão}

Se $\quad($ elemento[3] $)<0.35$

então atribuir como resultado o rótulo $C$

\section{Senão}

Se $\quad($ elemento[4] $)>0.25$

então atribuir como resultado o rótulo $D$

Senão atribuir como resultado o rótulo $\boldsymbol{B}$

\section{Senão}

$\mathrm{Se}$ (elemento[3] do vetor é o maior)

Se (elemento[3]) $>0.45$

e $\quad(($ elemento[4] $)<0.2$ ou $($ elemento[2] $)>0.3)$

então atribuir como resultado o rótulo $C$ 


\section{Senão}

$\mathrm{Se} \quad($ elemento[4] $)>0.2$

então atribuir como resultado o rótulo

Senão atribuir como resultado o rótulo

\section{Senão}

Se (elemento[4]) $>=0.45$

$e \quad($ elemento[3] $)<0.3$

então atribuir como resultado o rótulo $\boldsymbol{X}$

\section{Senão}

Se (elemento[4]) $>=0.35$

$\boldsymbol{e} \quad($ elemento[3]) $>=0.3$

então atribuir como resultado o rótulo $D$

Senão atribuir como resultado o rótulo $X$

Realizando o mesmo procedimento para o vetor-coluna, obtém-se dois rótulos, que combinados através das regras mostradas na tabela 5.6, chega-se à classificação final com as cinco possíveis classes resultantes, " $A, B, C, D$ e $X$ ".

Somente para completar o exemplo de placa adotado, a mesma receberia classificação $B$ com relação à essa face.

Tabela 5.6 - Combinação dos rótulos Linha-Coluna para geração das classes resultantes

\begin{tabular}{|c|c||c|c|}
\hline $\begin{array}{c}\text { Combinação } \\
\text { Linha } \\
\text { Coluna }\end{array}$ & $\begin{array}{c}\text { Classe } \\
\text { Resultante }\end{array}$ & $\begin{array}{c}\text { Combinação } \\
\text { Linha } \\
\text { Coluna }\end{array}$ & $\begin{array}{c}\text { Classe } \\
\text { Resultante }\end{array}$ \\
\hline \hline $\mathrm{AA}$ & $\mathrm{A}$ & $\mathrm{CD}$ & $\mathrm{D}$ \\
\hline $\mathrm{AB}$ & $\mathrm{A}$ & $\mathrm{DD}$ & $\mathrm{D}$ \\
\hline $\mathrm{BB}$ & $\mathrm{B}$ & $\mathrm{AX}$ & $\mathrm{D}$ \\
\hline $\mathrm{AC}$ & $\mathrm{B}$ & $\mathrm{BX}$ & $\mathrm{D}$ \\
\hline $\mathrm{AD}$ & $\mathrm{C}$ & $\mathrm{CX}$ & $\mathrm{X}$ \\
\hline $\mathrm{BC}$ & $\mathrm{C}$ & $\mathrm{DX}$ & $\mathrm{X}$ \\
\hline $\mathrm{BD}$ & $\mathrm{C}$ & $\mathrm{XX}$ & $\mathrm{X}$ \\
\hline $\mathrm{CC}$ & $\mathrm{C}$ & - & - \\
\hline
\end{tabular}

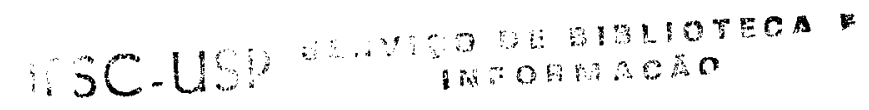




\section{5 - CONSIDERAÇÕES FINAIS}

Neste capítulo descreveu-se a proposta do método de extração das características e também dos métodos de classificação baseados em regras. Foi exposta em detalhes, a nova interpretação dos resultados obtidos através da aplicação de um método automático de limiar que utiliza a entropia de Shannon [Shannon, 1948], o que proporcionou a extração dos valores-característica. De posse desses valores, propôs-se como solução para classificação, um procedimento baseado em regras que pode ser descrito em duas partes. A primeira parte realiza uma pré-classificação, distribuindo rótulos de classe à todas as regiões da placa, com base nos valores-característica extraídos. Na segunda parte do procedimento são propostas duas soluções, uma por redução de informação, utilizando regras de combinação entre as classes e outra utilizando matriz de co-ocorrência uni-direcional, também combinada com regras propostas, para encontrar a solução final.

A aplicação desses procedimentos com apresentação dos resultados, é discutida no próximo capítulo. 


\section{Capítulo 6}

\section{APLICAÇÃO DOS MÉTODOS E DISCUSSÕES}

\section{1 - INTRODUÇÃO}

Este capítulo descreve a aplicação dos métodos expostos no capítulo anterior (pré-classificação, redução de informações baseada em regras e redução baseada em matriz de co-ocorrência), apresentando os resultados obtidos e as discussões a respeito da forma como foi realizado todo o procedimento.

O trabalho de aplicação dos métodos foi desenvolvido utilizando dois conjuntos de placas de madeira. Um conjunto com cento e quatro placas previamente classificadas (muitas vezes referenciado no texto como primeiro conjunto), foi utilizado no estabelecimento dos níveis de decisão dos valores-característica, ou seja, no estágio de treinamento do algoritmo de pré-classificação. O outro conjunto, com cento e noventa e nove placas sem classificação prévia (muitas vezes referenciado no texto como segundo conjunto), onde os algoritmos foram testados. Esse segundo conjunto foi classificado por três técnicos especialistas, posteriormente à classificação das placas feita pelos algoritmos, e os resultados obtidos com os algoritmos foram então comparados a essas classificações. 


\section{2 - O SISTEMA DE INSPEÇÃO VISUAL E SEUS COMPONENTES}

Um sistema de inspeção visual industrial genérico, para o tipo do problema tratado neste trabalho, ou seja, inspeção de superficies, basicamente constitui-se de sensores de imagens (usualmente câmeras), placas de conversão dos sinais dos sensores (geralmente "frame grabbers" acopladas a microcomputadores), esteiras ou quaisquer outros dispositivos mecânicos que transportam as placas através do campo de visão dos sensores e um estágio (eletro-mecânico, eletro-pneumático, etc..) comandado pelo "software" interpretador/classificador que atua como separador de classes, como mostrado na figura 6.1 .

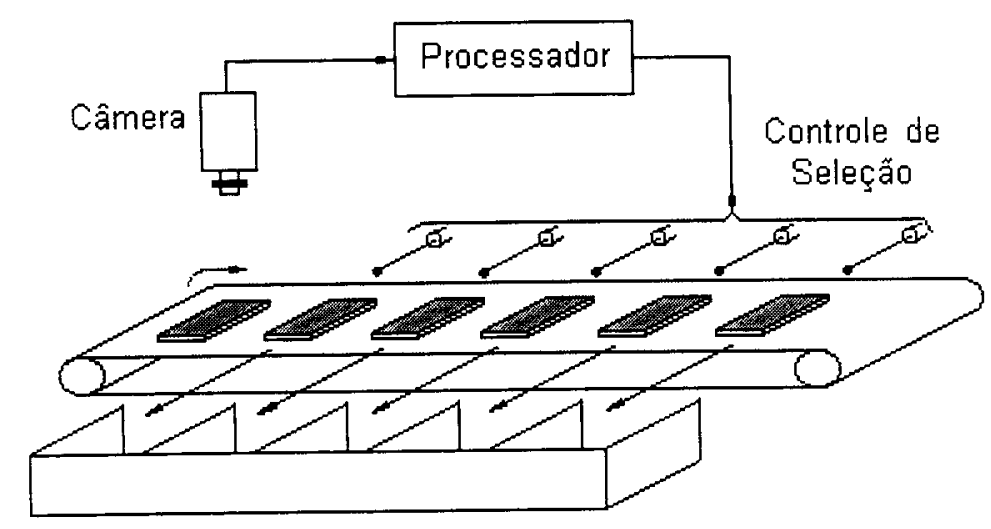

Figura 6.1 - Sistema de inspeção visual industrial genérico

Existem inúmeros sistemas de inspeção visuais propostos para os mais variados fins, pois de acordo com a aplicação de inspeção em questão, são necessários cuidados particulares para cada caso. Esses cuidados devem ser tomados, por exemplo, com o tipo de iluminação a ser empregada, com o tipo de sistema ótico utilizado, com o sistema de processamento necessário, etc... Um livro bastante amplo no assunto foi escrito por Batchelor [Batchelor, 1985], sendo uma obra dedicada especificamente aos 
sistemas de inspeção visual, onde são propostos grande quantidade de arranjos óticos para diversos tipos de aplicação e diversas discussões sobre o assunto inspeção visual automatizada. Eltoft [Eltoft, 1995] também apresenta um trabalho interessante sobre controle de iluminação como meio de realçar características em imagens.

Nesta tese não houve a preocupação com os mecanismos de transporte e mecanismos de seleção das placas, pois não é objetivo deste trabalho.

As imagens das placas foram capturadas no Laboratório de Visão Computacional do Departamento de Engenharia Elétrica EESC/USP, por um sistema que utiliza uma câmera com tecnologia CCD (em níveis de cinza), uma placa "frame grabber" acoplada a um microcomputador (PC-compatível) e um "software" desenvolvido em linguagem $\mathrm{C}$, que comanda a captura das imagens das placas e as transformam em arquivos. Dessa forma, buscou-se com a utilização de componentes comerciais de uso genérico (câmera CCD, "frame grabber" "e software" de captura) em conjunto com os métodos propostos, construir um sistema com capacidade de ser aplicado industrialmente.

No apêndice 1 estão descritos os componentes utilizados na captura das imagens assim como suas características principais.

De todos os elementos envolvidos no processo de aquisição das imagens, somente a iluminação obteve atenção especial, pois, para que as imagens fossem capturadas de forma a assegurar as mesmas quantidades de lux (neste trabalho utilizouse nível de iluminação entre 1600 e 1700 lux $)^{1}$ em toda a região da placa e para todas as placas. Utilizou-se um ambiente com iluminação controlada, sendo esta proveniente de

${ }^{1}$ O Manual de Iluminação Philips, Eindhoven, Holanda, 1986, recomenda por exemplo 1500 lux para ambientes de montagem de peças de ultraprecisão, ambientes de trabalho muito fino que operem em medição e inspeção de pequenas peças, montagem de instrumentos de precisão, etc... 
lâmpadas fluorescentes alimentadas por reatores eletrônicos com alta freqüência de chaveamento. As diferenças de iluminação podem ocorrer em virtude da freqüência da tensão de alimentação das lâmpadas. Variando-se a intensidade de iluminação, atua-se diretamente na qualidade da imagem capturada, pois essa ação modifica a informação de contraste entre as regiões claras e escuras das placas, o que provoca a perda de padrão na aquisição das imagens. Como o método proposto para extração de atributos faz uso da característica de contraste, alterá-la significa modificar de forma decisiva o resultado final de classificação das imagens das placas.

Segundo Batchelor [Batchelor, 1985], existem poucos princípios gerais para o objetivo iluminação, mas um bom projetista deve considerar alguns aspectos como:

- O nível de saída de luz das lâmpadas

- A estabilidade temporal desse nível de luz

- O espectro de radiação iluminando o objeto sob consideração

- A resposta espectral dos componentes óticos utilizados (como lentes, espelhos, filtros, etc...)

- A refletividade do objeto como função do comprimento de onda (sua cor)

- A resposta espectral do sensor de imagem utilizado

- A distribuição espacial de luz, isto é, verificar se deve ser uniforme, sombreada, pontual, etc...

- A distribuição temporal, ou seja, se necessita ser estável, piscar periodicamente, etc...

- A polarização da luz

- Considerar o ambiente de operação (em atmosfera empoeirada há dificuldade em manter os componentes limpos) 
- A magnificação do sistema ótico

- Observar se qualquer benefício pode ser obtido pela omissão ou interpretação diferente de alguma característica envolvida (pode funcionar como um filtro de pré-processamento)

- Verificar a presença de luz ambiente, especialmente a luz do sol e aquelas provenientes de luz fluorescente de $50 / 60 \mathrm{~Hz}$

- Vibração do ambiente

- Fixação do sistema de iluminação

- A necessidade do controle automático ou manual do nível de iluminação

- Escolha do tipo de alimentação das lâmpadas: comum $(50 / 60 \mathrm{~Hz})$, contínua, alta frequiência, com toda a potência, com potência reduzida, etc...

Foram montados dois sistemas de iluminação, onde no primeiro (figura 6.2), as placas recebem iluminação indireta através da reflexão da luz nas paredes de superfícies Lambertianas $^{2}$ de uma cúpula (esse sistema é mais apropriado para ser utilizado em linha de produção) e no segundo (figura 6.3), as placas recebem iluminação direta das lâmpadas, sem a interferência de qualquer outra fonte de iluminação. Ambos os sistemas funcionaram a contento.

Para este trabalho optou-se pelo segundo sistema em virtude da facilidade de manipulação das placas quando da aquisição das imagens.

\footnotetext{
2 "São superficies que refletem a luz de forma totalmente difusa. Quando a luminância é constante em uma dada superficie, qualquer que seja a direção de observação, esta satisfaz as leis de Lambert e por isso é dita superficie Lambertiana, ou ainda, um difusor perfeito. Estas leis também são conhecidas como leis da incidência..." Guerrini apud [Gonzaga, 1991]
} 


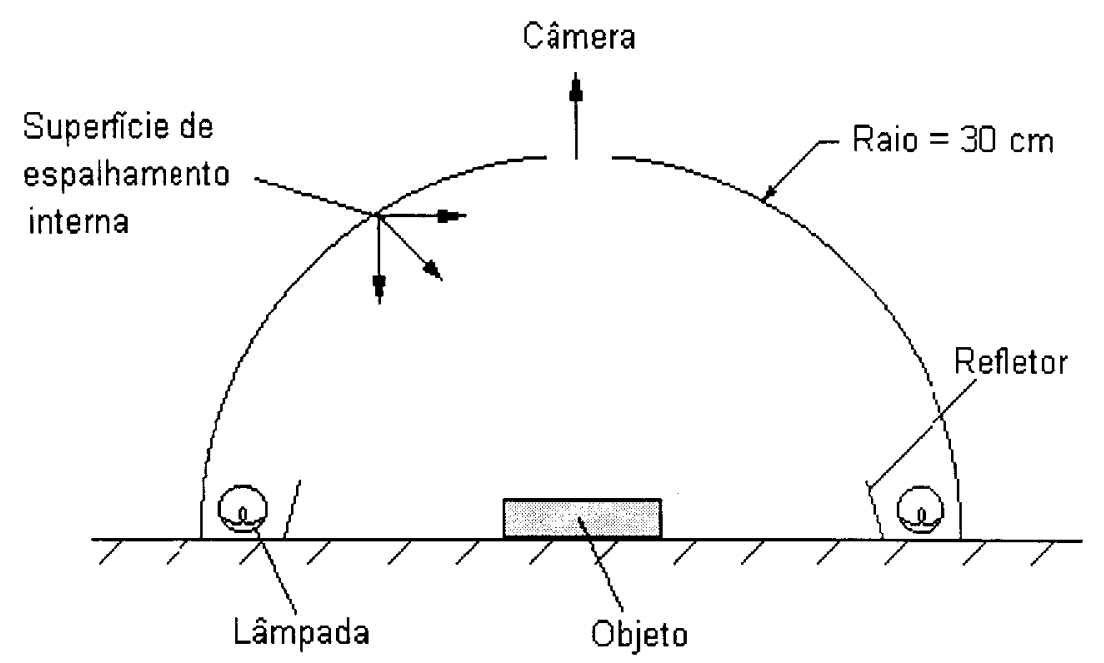

Figura 6.2 - Ambiente com iluminação indireta sobre o objeto utilizado no trabalho

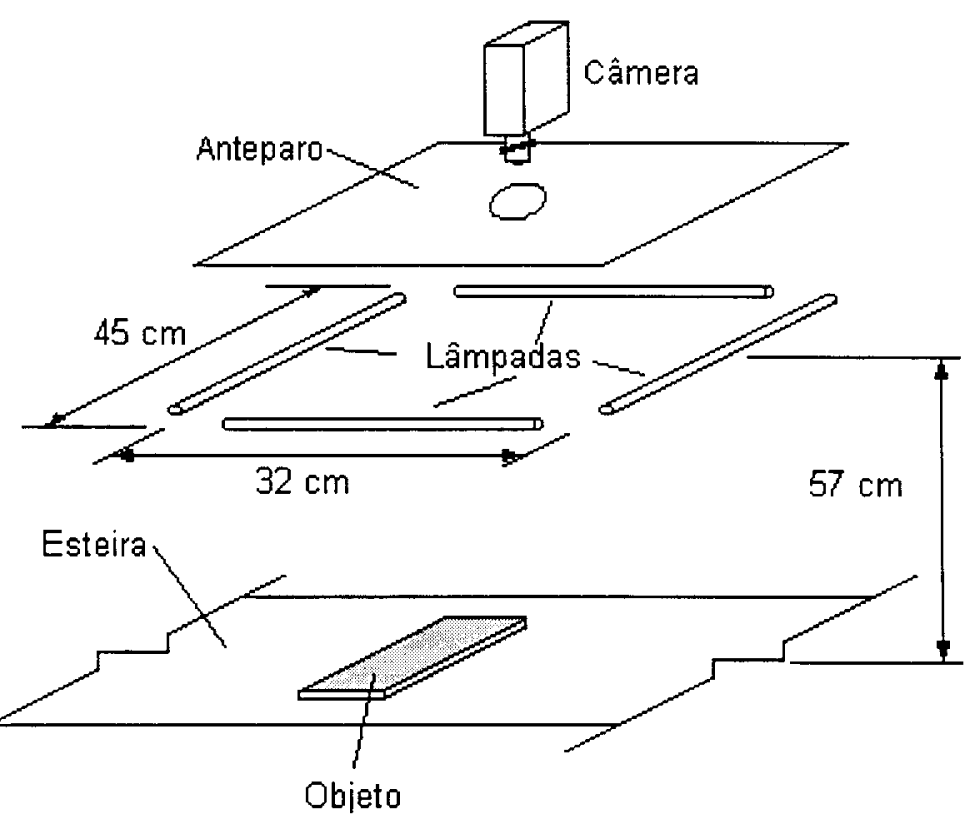

Figura 6.3 - Iluminação direta sobre o objeto utilizada no trabalho

Capturando-se as imagens das duas faces das placas de madeira com a utilização do sistema de iluminação da figura 6.3 , montou-se um banco de imagens de onde extraem-se as características para classificação, completando assim o sistema de inspeção visual para seleção das placas de madeira. 


\section{3 - ESTABELECIMENTO E VERIFICAÇÃO DOS VALORES LIMITES UTILIZADOS NO ALGORITMO DE PRÉ-CLASSIFICAÇÃO}

O estabelecimento dos limites que são aplicados aos valores-característica no algoritmo de pré-classificação, baseou-se inicialmente na observação das características apresentadas do primeiro conjunto (104 placas), o qual foi previamente classificado por técnicos especialistas em três categorias: placas desprovidas de anéis de crescimento, com anéis e provenientes de corte radial, e aquelas também com anéis mas fruto de corte tangencial.

Procedeu-se então, a aplicação do algoritmo de extração das características utilizadas, montando-se arquivos de dados dos valores-característica das regiões (do conjunto todo), onde foram analisadas as variações dos mesmos em função do comportamento superficial visual de cada região. Dessa forma, foram estabelecidos os primeiros limites para os valores-característica, que posteriormente sofreram ajustes no decorrer do trabalho, cujos valores limites finais também estão descritos no algoritmo do sub-ítem 5.4.1 do capítulo anterior .

Como exemplo dos arquivos de dados gerados e analisados; tomam-se três imagens de placas pertencentes às classes descritas anteriormente ("lisa", corte radial e corte tangencial). A tabela 6.1 apresenta os valores-característica (descritos no capítulo 5, sub-item 5.3) para as trinta e seis regiões da placa mostrada na figura 6.4, que pertence à classe desprovida de anéis de crescimento; a tabela 6.2 apresenta os valorescaracterística para a placa da figura 6.5 , que pertence à classe com anéis de crescimento e proveniente de corte radial, e a tabela 6.3 upresenta os valores-característica para a placa da figura 6.6, que pertence à classe com anéis de crescimento e proveniente de corte tangencial. 


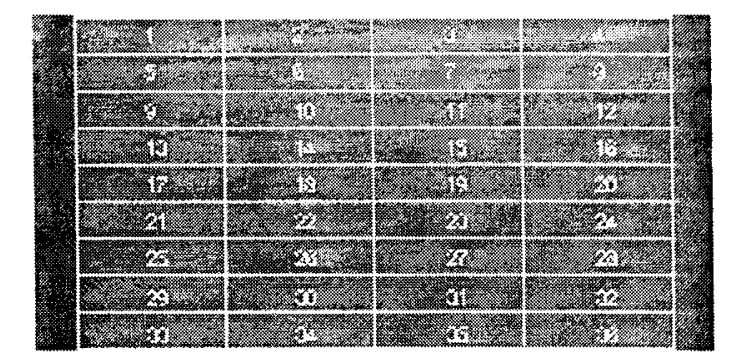

Figura 6.4 - Placa pertencente à classe desprovida de anéis de crescimento com a numeração das regiões, que gerou os valores da tabela 6.1

Tabela 6.1 - Valores-característica para as regiões da placa da figura 6.4

\begin{tabular}{|c|c|c|c|c|c|}
\hline Região & $\begin{array}{l}\text { Valor de } \\
\text { Limiar }\end{array}$ & Entropia & $\begin{array}{c}\text { Razão de } \\
\text { assimetria }\end{array}$ & $\begin{array}{c}\text { Diferença } \\
\text { tomada nos } \\
\text { picos } \\
\end{array}$ & $\begin{array}{l}\text { Razão-Limiar } \\
\text { da Região pelo } \\
\text { Limiar médio } \\
\end{array}$ \\
\hline 1 & 152 & 8,18683 & 1,32178 & 3 & 0,99401 \\
\hline 2 & 158 & 6,2681 & 1,71369 & 3 & 1,03324 \\
\hline 3 & 159 & 6,30388 & 1,26341 & 2 & 1,03978 \\
\hline 4 & 155 & 10,79141 & 2,1137 & 4 & 1,01362 \\
\hline 5 & 153 & 10,42466 & 1,71727 & 4 & 1,00054 \\
\hline 6 & 159 & 6,49325 & 1,32666 & 2 & 1,03978 \\
\hline 7 & 161 & 6,96776 & 1,9769 & 2 & 1,05286 \\
\hline 8 & 157 & 9,79248 & 2,28496 & 4 & 1,0267 \\
\hline 9 & 154 & 10,80165 & 2,21624 & 3 & 1,00708 \\
\hline 10 & 159 & 5,74049 & 1,19167 & 2 & 1,03978 \\
\hline 11 & 158 & 5,66996 & 0,96632 & 2 & 1,03324 \\
\hline 12 & 155 & 8,50427 & 2,38272 & 3 & 1,01362 \\
\hline 13 & 152 & 7,91665 & 1,6115 & 2 & 0,99401 \\
\hline 14 & 157 & 5,29761 & 1,19713 & 2 & 1,0267 \\
\hline 15 & 157 & 5,04817 & 1,6257 & 2 & 1,0267 \\
\hline 16 & 155 & 7,14169 & 1,78084 & 3 & 1,01362 \\
\hline 17 & 149 & 7,35543 & 1,30607 & 3 & 0,97439 \\
\hline 18 & 155 & 5,97925 & 1,32381 & 2 & 1,01362 \\
\hline 19 & 156 & 4,31924 & 1,27927 & 2 & 1,02016 \\
\hline 20 & 155 & 7,59513 & 1,60197 & 3 & 1,01362 \\
\hline 21 & 147 & 8,38553 & 1,34704 & 3 & 0,96131 \\
\hline 22 & 153 & 6,22391 & 1,5003 & 2 & 1,00054 \\
\hline 23 & 154 & 5,20833 & 1,24055 & 2 & 1,00708 \\
\hline 24 & 151 & 6,68173 & 1,47164 & 2 & 0,98747 \\
\hline 25 & 146 & 7,11672 & 1,97482 & 3 & 0,95477 \\
\hline 26 & 152 & 5,43785 & 1,18358 & 2 & 0,99401 \\
\hline 27 & 153 & 5,6065 & 1,3291 & 2 & 1,00054 \\
\hline 28 & 149 & 6,67238 & 1,4344 & 2 & 0,97439 \\
\hline 29 & 144 & 6,91746 & 1,6569 & 2 & 0,94169 \\
\hline 30 & 150 & 5,23869 & 1,83911 & 2 & 0,98093 \\
\hline 31 & 150 & 4,61731 & 1,11879 & 2 & 0,98093 \\
\hline 32 & 147 & 6,92598 & 1,66694 & 2 & 0,96131 \\
\hline 33 & 145 & 7,10843 & 3,15101 & 2 & 0,94823 \\
\hline 34 & 149 & 5,03109 & 2,10582 & 3 & 0,97439 \\
\hline 35 & 150 & 3,99621 & 1,97616 & 1 & 0,98093 \\
\hline 36 & 149 & 6,84709 & 1,68795 & 2 & 0,97439 \\
\hline Média & 152,91667 & 6,79481 & 1,63571 & 2,41667 & 1 \\
\hline Desvio padrão & 4,35808 & 1,71949 & 0,44352 & 0,69179 & $0,02 \times 5$ \\
\hline
\end{tabular}




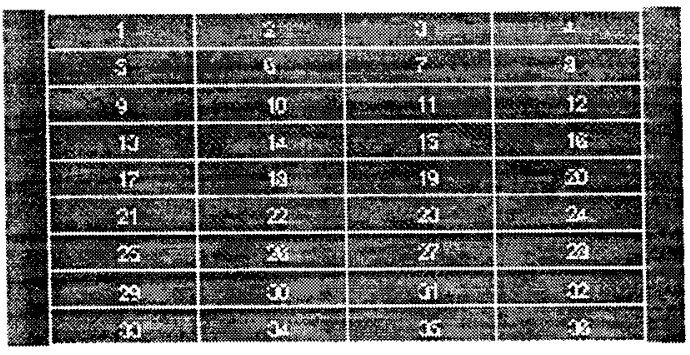

Figura 6.5 - Placa pertencente à classe com anéis de crescimento e proveniente de corte radial com a numeração das regiões, que gerou os valores da tabela 6.2

Tabela 6.2 - Valores-característica para as regiões da placa da figura 6.5

\begin{tabular}{|c|c|c|c|c|c|}
\hline Região & $\begin{array}{c}\text { Valor de } \\
\text { Limiar }\end{array}$ & Entropia & $\begin{array}{c}\text { Razão de } \\
\text { assimetria }\end{array}$ & $\begin{array}{c}\text { Diferença } \\
\text { tomada nos } \\
\text { picos } \\
\end{array}$ & $\begin{array}{l}\text { Razão-Limiar } \\
\text { da Região pelo } \\
\text { Limiar médio } \\
\end{array}$ \\
\hline 1 & 138 & 8,07554 & 1,55893 & 4 & 0,99261 \\
\hline 2 & 142 & 9,51998 & 1,74642 & 4 & 1,02138 \\
\hline 3 & 144 & 10,38027 & 2,99826 & 3 & 1,03576 \\
\hline 4 & 140 & 10,49149 & 0,9927 & 5 & 1,00699 \\
\hline 5 & 138 & 8,69972 & 2,64027 & 3 & 0,99261 \\
\hline 6 & 142 & 10,09858 & 1,84991 & 4 & 1,02138 \\
\hline 7 & 143 & 7,64555 & 2,50779 & 3 & 1,02857 \\
\hline 8 & 141 & 7,24044 & 1,9674 & 3 & 1,01419 \\
\hline 9 & 136 & 9,10678 & 1,53776 & 4 & 0,97822 \\
\hline 10 & 139 & 8,81973 & 1,93855 & 4 & 0,9998 \\
\hline 11 & 140 & 8,47233 & 1,91058 & 3 & 1,00699 \\
\hline 12 & 137 & 9,03805 & 1,90729 & 4 & 0,98541 \\
\hline 13 & 137 & 5,95354 & 1,99377 & 3 & 0,98541 \\
\hline 14 & 139 & 5,54456 & 1,05739 & 2 & 0,9998 \\
\hline 15 & 139 & 4,29179 & 1,61313 & 1 & 0,9998 \\
\hline 16 & 138 & 5,61672 & 2,2553 & 2 & 0,99261 \\
\hline 17 & 137 & 9,67632 & 1,76077 & 3 & 0,98541 \\
\hline 18 & 139 & 10,02215 & 2,1691 & 4 & 0,9998 \\
\hline 19 & 138 & 8,57116 & 1,93772 & 3 & 0,99261 \\
\hline 20 & 137 & 8,89897 & 2,52235 & 3 & 0,98541 \\
\hline 21 & 138 & 10,01677 & 2,28838 & 3 & 0,99261 \\
\hline 22 & 141 & 9,55466 & 2,3607 & 4 & 1,01419 \\
\hline 23 & 141 & 7,94468 & 2,38131 & 2 & 1,01419 \\
\hline 24 & 137 & 11,59892 & 2,10458 & 4 & 0,98541 \\
\hline 25 & 135 & 10,95308 & 2,20113 & 3 & 0,97103 \\
\hline 26 & 139 & 10,71885 & 2,85281 & 4 & 0,9998 \\
\hline 27 & 140 & 10,90213 & 2,42436 & 4 & 1,00699 \\
\hline 28 & 136 & 13,524 & 1,94688 & 6 & 0,97822 \\
\hline 29 & 135 & 11,31621 & 1,75833 & 4 & 0,97103 \\
\hline 30 & 140 & 11,91747 & 1,75642 & 5 & 1,00699 \\
\hline 31 & 141 & 12,73392 & 1,90765 & 6 & 1,01419 \\
\hline 32 & 136 & 14,66728 & 1,29667 & 5 & 0,97822 \\
\hline 33 & 137 & 11,64777 & 1,54141 & 4 & 0,98541 \\
\hline 34 & 142 & 10,60711 & 1,71035 & 4 & 1,02138 \\
\hline 35 & 143 & 10,23273 & 1,95133 & 4 & 1,02857 \\
\hline 36 & 140 & 10,94204 & 2,22116 & 4 & 1,00699 \\
\hline Média & 139,02778 & 9,59559 & 1,98802 & 3,63889 & 1 \\
\hline Desvio padrão & 2,34808 & 2,20682 & 0,44538 & 1,04616 & 0,01689 \\
\hline
\end{tabular}


Figura 6.6 - Placa pertencente à classe com anéis de crescimento e proveniente de corte tangencial com a numeração das regiões, que gerou os valores da tabela 6.3

Tabela 6.3 - Valores-característica para as regiões da placa da figura 6.6

\begin{tabular}{|c|c|c|c|c|c|}
\hline Região & $\begin{array}{l}\text { Valor de } \\
\text { Limiar }\end{array}$ & Entropia & $\begin{array}{c}\text { Razão de } \\
\text { assimetria } \\
\end{array}$ & $\begin{array}{c}\text { Diferença } \\
\text { tomada nos } \\
\text { picos }\end{array}$ & $\begin{array}{l}\text { Razão-Limiar } \\
\text { da Região pelo } \\
\text { Limiar médio }\end{array}$ \\
\hline 1 & 137 & 11,64055 & 2,18499 & 5 & 1,01922 \\
\hline 2 & 131 & 24,31395 & 1,84868 & 12 & 0,97458 \\
\hline 3 & 120 & 27,06294 & 1,89704 & 14 & 0,89275 \\
\hline 4 & 114 & 26,80473 & 1,19183 & 12 & 0,84811 \\
\hline 5 & 122 & 26,66939 & 1,55536 & 14 & 0,90763 \\
\hline 6 & 134 & 27,75105 & 4,12593 & 10 & 0,9969 \\
\hline 7 & 136 & 13,63383 & 2,54442 & 4 & 1,01178 \\
\hline 8 & 131 & 11,40863 & 1,24318 & 4 & 0,97458 \\
\hline 9 & 128 & 12,55656 & 1,12281 & 6 & 0,95226 \\
\hline 10 & 139 & 13,58977 & 1,57943 & 5 & 1,0341 \\
\hline 11 & 141 & 8,78951 & 1,18716 & 4 & 1,04898 \\
\hline 12 & 131 & 15,90414 & 2,40635 & 6 & 0,97458 \\
\hline 13 & 141 & 13,97101 & 1,95286 & 6 & 1,04898 \\
\hline 14 & 145 & 14,08732 & 2,93599 & 3 & 1,07874 \\
\hline 15 & 133 & 18,33096 & 1,73856 & 12 & 0,98946 \\
\hline 16 & 131 & 17,24467 & 1,56487 & 7 & 0,97458 \\
\hline 17 & 139 & 16,26598 & 2,94918 & 4 & 1,0341 \\
\hline 18 & 118 & 21,64618 & 0,42917 & 6 & 0,87787 \\
\hline 19 & 134 & 17,19584 & 1,16661 & 6 & 0,9969 \\
\hline 20 & 141 & 20,81539 & 4,5202 & 8 & 1,04898 \\
\hline 21 & 141 & 12,77896 & 3,29562 & 3 & 1,04898 \\
\hline 22 & 117 & 14,89111 & 0,77427 & 7 & 0,87043 \\
\hline 23 & 125 & 16,10586 & 1,19737 & 7 & 0,92994 \\
\hline 24 & 130 & 14,19014 & 1,22952 & 4 & 0,96714 \\
\hline 25 & 142 & 8,11598 & 1,86698 & 2 & 1,05642 \\
\hline 26 & 144 & 19,20374 & 5,29629 & 4 & 1,0713 \\
\hline 27 & 136 & 25,36293 & 3,00414 & 22 & 1,01178 \\
\hline 28 & 118 & 25,01377 & 0,63244 & 19 & 0,87787 \\
\hline 29 & 145 & 13,66271 & 2,30028 & 5 & 1,07874 \\
\hline 30 & 147 & 7,84201 & 2,08123 & 2 & 1,09361 \\
\hline 31 & 144 & 7,16025 & 0,98313 & 3 & 1,0713 \\
\hline 32 & 140 & 9,47764 & 2,55488 & 2 & 1,04154 \\
\hline 33 & 141 & 17,2001 & 1,79118 & 7 & 1,04898 \\
\hline 34 & 144 & 15,68539 & 1,87342 & 9 & 1,0713 \\
\hline 35 & 141 & 13,51378 & 1,98958 & 5 & 1,04898 \\
\hline 36 & 138 & 12,00004 & 1,80582 & 5 & 1,02666 \\
\hline Média & 134,41667 & 16,4413 & 2,0228 & 7,05556 & $\overline{1}$ \\
\hline Desvio padrão & 9,0912 & $5,885 / 8$ & 1,06003 & 4,65338 & 0,06764 \\
\hline
\end{tabular}


Nas primeiras observações notou-se a possibilidade, e também a necessidade, de poder-se contar com mais classes do que as três propostas inicialmente pelos técnicos, pois as variações visuais percebidas na superfície das placas são numerosas e altamente aleatórias. Essa constatação foi aceita prontamente pelos técnicos.

Nesse estágio de pré-classificação, os resultados mostraram que o acréscimo de uma classe fornece informações suficientes para o estágio de classificação final. Incorporou-se dessa forma, uma classe intermediária entre a classe das placas desprovidas de anéis de crescimento e a classe daquelas com anéis e oriundas de corte radial. Isso porque as placas geralmente também apresentam alterações não pertencentes aos anéis de crescimento, como pequenas manchas de coloração, presença de vestígios de acículas, etc..., o que não caracteriza efetivamente a presença de madeira dura (madeira de verão dos anéis de crescimento) que é decisiva na distribuição dos rótulos de classe na pré-classificação.

Disso resultou a denominação das quatro classes utilizadas na pré-classificação, já descritas no capítulo 5:

- $\boldsymbol{A}$ - Placas desprovidas de anéis de crescimento ou "lisas" - (melhor classe)

- $\boldsymbol{B}$ - Placas de transição entre "lisas" e "corte radial"

- $C$ - Placas provenientes de "corte radial" (com anéis de crescimento)

- $X$ - Placas provenientes de "corte tangencial" (com anéis de crescimento)

Aplicando o algoritmo de pré-classificação do capítulo 5 ( sub-ítem 5.4.1) utilizando os valores das três tabelas $(6.1,6.2$ e 6.3), obtém-se a pré-classificação das placas das figuras $6.4,6.5$ e 6.6 , como pode-se observar nas figuras $6.7,6.8$ e 6.9 respectivamente. 


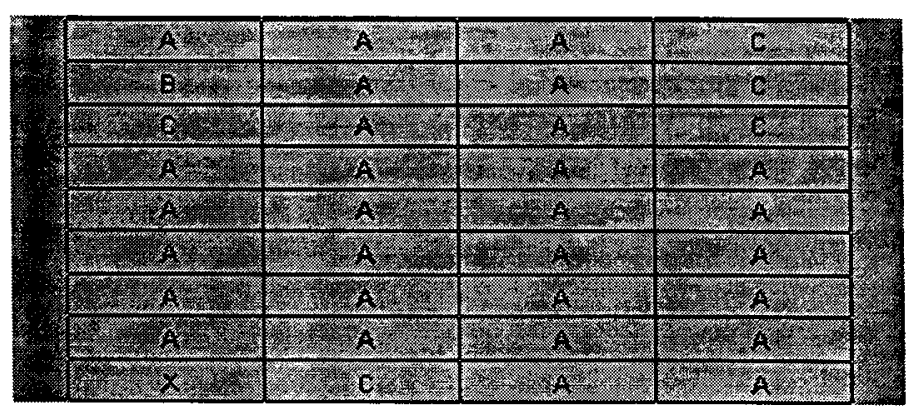

Figura 6.7 - Pré-classificação por regiões da placa da figura 6.4 com a aplicação do algoritmo do subitem (5.4.1) sobre a tabela 6.1

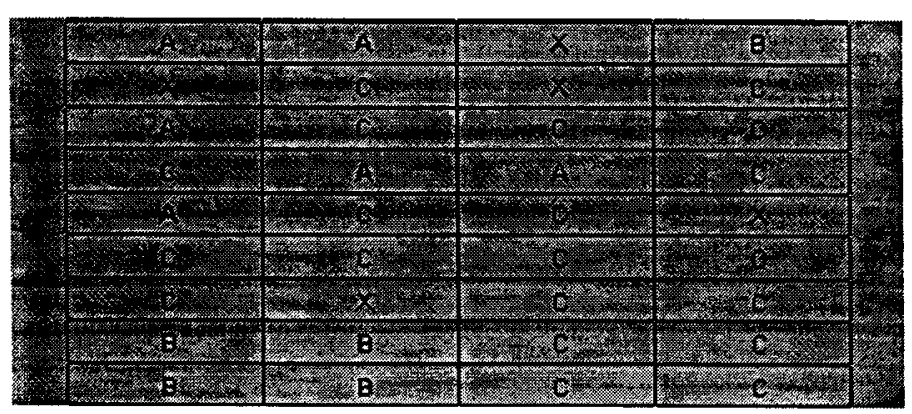

Figura 6.8 - Pré-classificação por regiões da placa da figura 6.5 com a aplicação do algoritmo do subitem (5.4.1) sobre a tabela 6.2

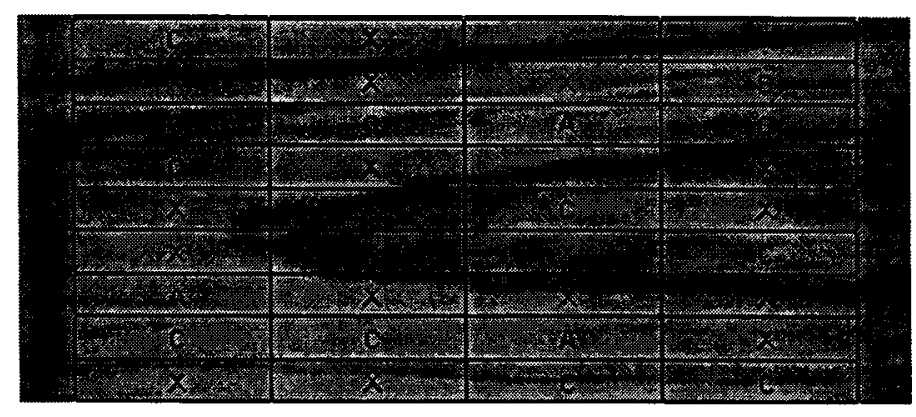

Figura 6.9 - Pré-classificação por regiões da placa da figura 6.6 com a aplicação do algoritmo do subitem (5.4.1) sobre a tabela 6.3 
Analisando os resultados obtidos nessa fase de pré-classificação, na figura 6.7 , apenas sete regiões da placa (das trinta e seis) não foram rotuladas como classe $A$, mostrando que a mesma possui superfície altamente regular e desprovida de quaisquer estruturas visuais que pudessem colocá-la em outras classes (somente como observação, esse tipo de placa, sem imperfeições visuais, não ocorre com muita freqüência nas amostras tratadas neste trabalho). As sete regiões que não receberam o rótulo de classe $A$, como pode ser verificado na figura 6.7 , localizam-se em regiões de periferia e, para essa placa, apresentam maior concentração de tintura que as demais, embora visualmente isso não seja tão marcante a ponto de influir em uma decisão de classificação. Para o algoritmo que interpreta as imagens, isso significa um acréscimo na população de níveis de cinza mais escuros na região, de tal modo que produz valorescaracterística ligeiramente mais elevados nessas regiões comparado às outras. Em virtude disso, são incrementados os valores de razões de assimetria, entropia e diferença tomada nos picos (ver tabela 6.1), proporcionando assim classificações com rótulos diferentes dos esperados para essas regiões. Contudo, como a grande maioria das regiões pertencem à classe $A$, certamente os dois algoritmos finais de classificação devem atribuir a categoria de classe $A$ para este tipo de placa.

Observando os rótulos de classe distribuídos na figura 6.8, nota-se a presença de todas as classes, com predominância da classe $C$ com 20 regiões, seguida da classe $A$ com 6 regiões, e as classes $B$ e $X$ com 5 regiões cada. Das regiões rotuladas como classe $A$, as regiões 9 e 17 (ver figura 6.5 e 6.8) chamam a atenção, pois visualmente pode-se concluir que deveriam receber rótulo $\mathrm{C}$ (ou no mínimo $\mathrm{B}$ ), em virtude de possuírem madeira dura em suas respectivas áreas. Porém a madeira dura ali encontrada apresenta níveis de cinza com intensidades que proporcionam baixo contraste em relação ao 
restante da área dessas regiões. Isso faz com que os valores-característica (ver tabela 6.2) não sejam tão elevados como esperaria-se que fossem, de forma que ao serem interpretados pelo algoritmo de pré-classificação, recebem rotulação de classe $A$. Por outro lado, analisando os valores-característica da tabela 6.2 para as regiões que receberam rótulos de classe $X$, verifica-se que o fator decisivo para que as mesmas fossem classificadas como tal, está atribuído à razão de assimetria da curva de entropia, cujos valores excedem os limites para as classes anteriores. Nessas regiões, os níveis de cinza relacionados com a presença de madeira dura, atuam de maneira contrária ao comportamento descrito para as regiões rotuladas como classe $A$, ou seja, apresentam alto contraste em relação ao restante da área das regiões em análise, influindo diretamente na razão de assimetria da curva de entropia fazendo com que as mesmas recebam rótulo de classe $X$. Mesmo assim, como na análise da figura 6.7 realizada acima, a presença dessas classes nessas proporções não alteram o resultado da classificação final da placa.

Para a figura 6.9 , a forma de constatação da efetividade da pré-classificação é a mesma realizada para as figuras 6.7 e 6.8 , ou seja, verifica-se a presença marcante de regiões de classe $X$ com algumas regiões pertencentes a outras classes que não interferem decisivamente no resultado de classificação final.

Pode-se concluir, com base na análise realizada para as três amostras anteriores, considerando também que o algoritmo de pré-classificação comportou-se de maneira similar para o restante das placas, que a estratégia adotada para mapear suas superfícies é um procedimento simples e prático que fornece informações mais claras a respeito da aparência visual que cada placa apresenta, pois como Ġscrito anteriormente, o comportamento visual das superficies das placas é altamente aleatório e por vezes não muito bem definido. Conners et al. [Conners, 1983] e Darwish \& Jain [Darwish, 1988] 
também utilizam em seus trabalhos o procedimento de divisão da superfície em investigação.

Para melhor visualizar o comportamento dos valores-característica, recorre-se aqui à estatística clássica, onde define-se que amostras com população maior que 30 elementos podem ser representadas pela curva normal, cuja distribuição é totalmente determinada por intermédio de dois parâmetros: a média $(\mu)$ e o desvio padrão $(s)$. A equação que descreve a curva normal pode ser escrita sob a forma da equação 6.1 [Beiguelman, 1996].

$$
y=\frac{1}{\sigma \sqrt{2 \pi}} e^{-\frac{z^{2}}{2}}
$$

onde $y$ é a ordenada da curva normal padrão, s é o seu desvio padrão e $z$ é a razão (x $\mu) / s$.

Os três exemplos de pré-classificação mostrados (figuras 6.7, 6.8 e 6.9), possuem médias dos valores-característica bem caracterizadas e aparentemente distintas, definindo as três classes propostas pelos técnicos especialistas. Entretanto, as figuras $6.10,6.11,6.12$ e 6.13 mostram o comportamento dos valores-característica, utilizando a equação 6.1 , com valores de média e desvio padrão mostrados nas últimas duas linhas das tabelas $6.1,6.2$ e 6.3, apresentando sobreposições que comprometem a utilização individual de qualquer valor-característica como elemento de decisão. 


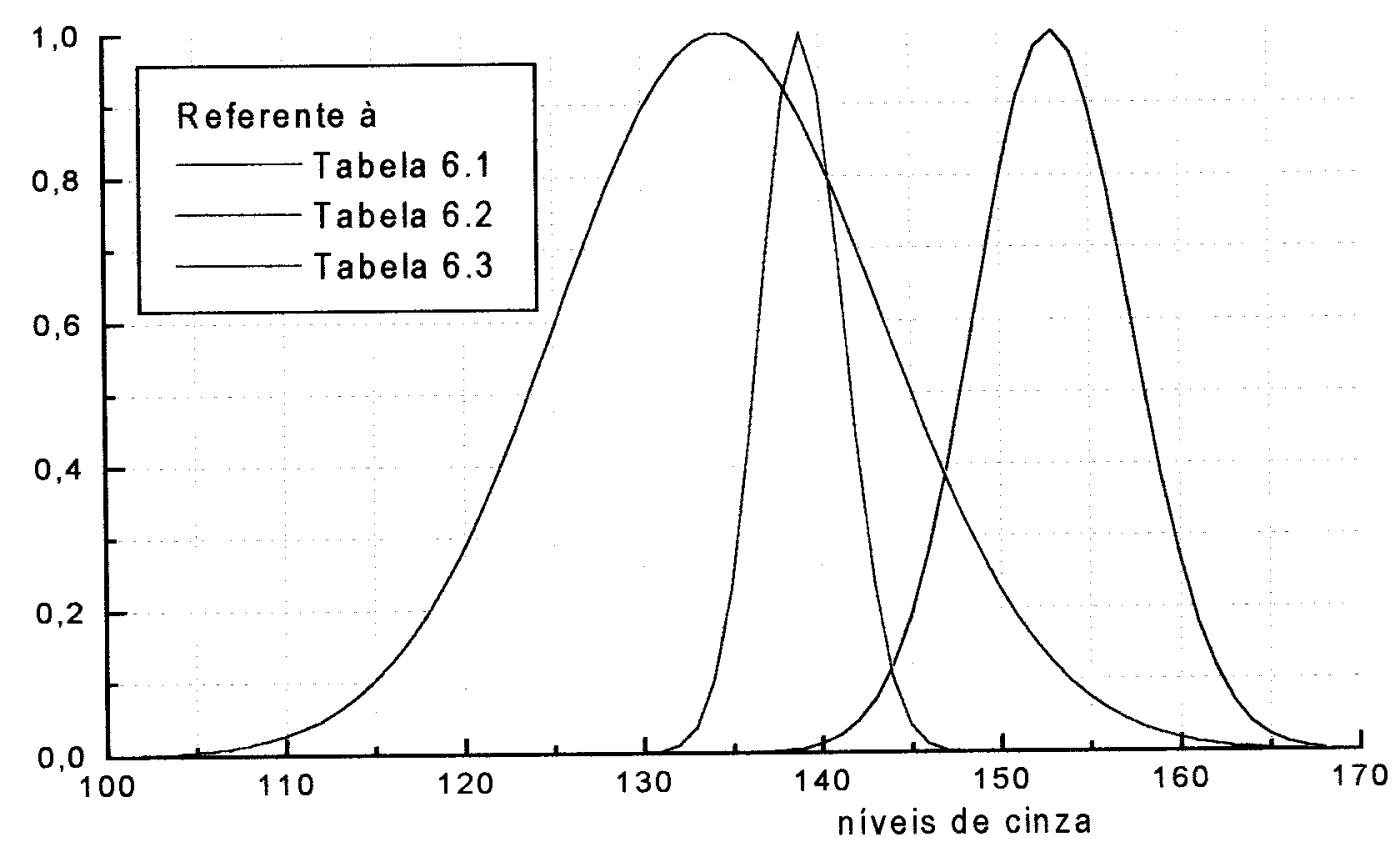

Figura 6.10 - Distribuições normalizadas dos valores de limiar das trinta e seis regiões para as figuras $6.4,6.5$ e 6.6 com médias e desvios padrões mostrados nas duas últimas linhas das tabelas $6.1,6.2$ e 6.3

Na figura 6.10 pode-se observar graficamente o comportamento dos niveis de Limiar mostrados nas tabela 6.1,6.2 e 6.3, onde verifica-se que as médias de Limiar das três placas exemplo estão distribuídas separadamente, porém os desvios padrões impedem que somente com esse valor-característica sejam tomadas quaisquer decisões de classificação. 


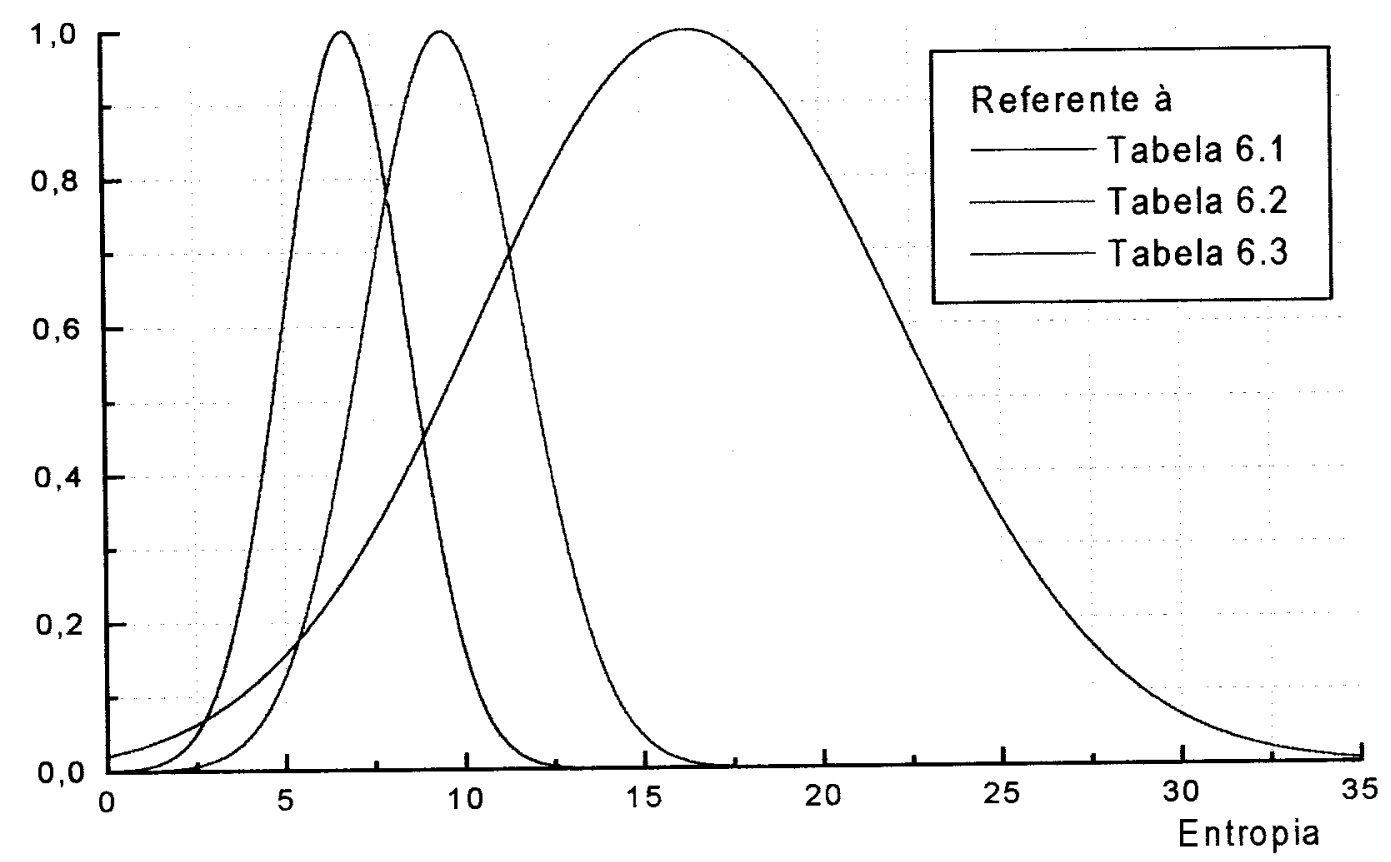

Figura 6.11 - Distribuições normalizadas dos valores de Entropia das trinta e seis regiões para as figuras $6.4,6.5$ e 6.6 com médias e desvios padrões mostrados nas duas últimas linhas das tabelas $6.1,6.2$ e 6.3

A figura 6.11 apresenta o comportamento bem definido dos valores de Entropia mostrados nas tabela $6.1,6.2$ e 6.3, onde também as médias dos valores das três placas exemplo estão distribuídos separadamente, porém novamente os desvios padrões impedem que somente com esse valor-característica sejam tomadas quaisquer decisões de classificação 


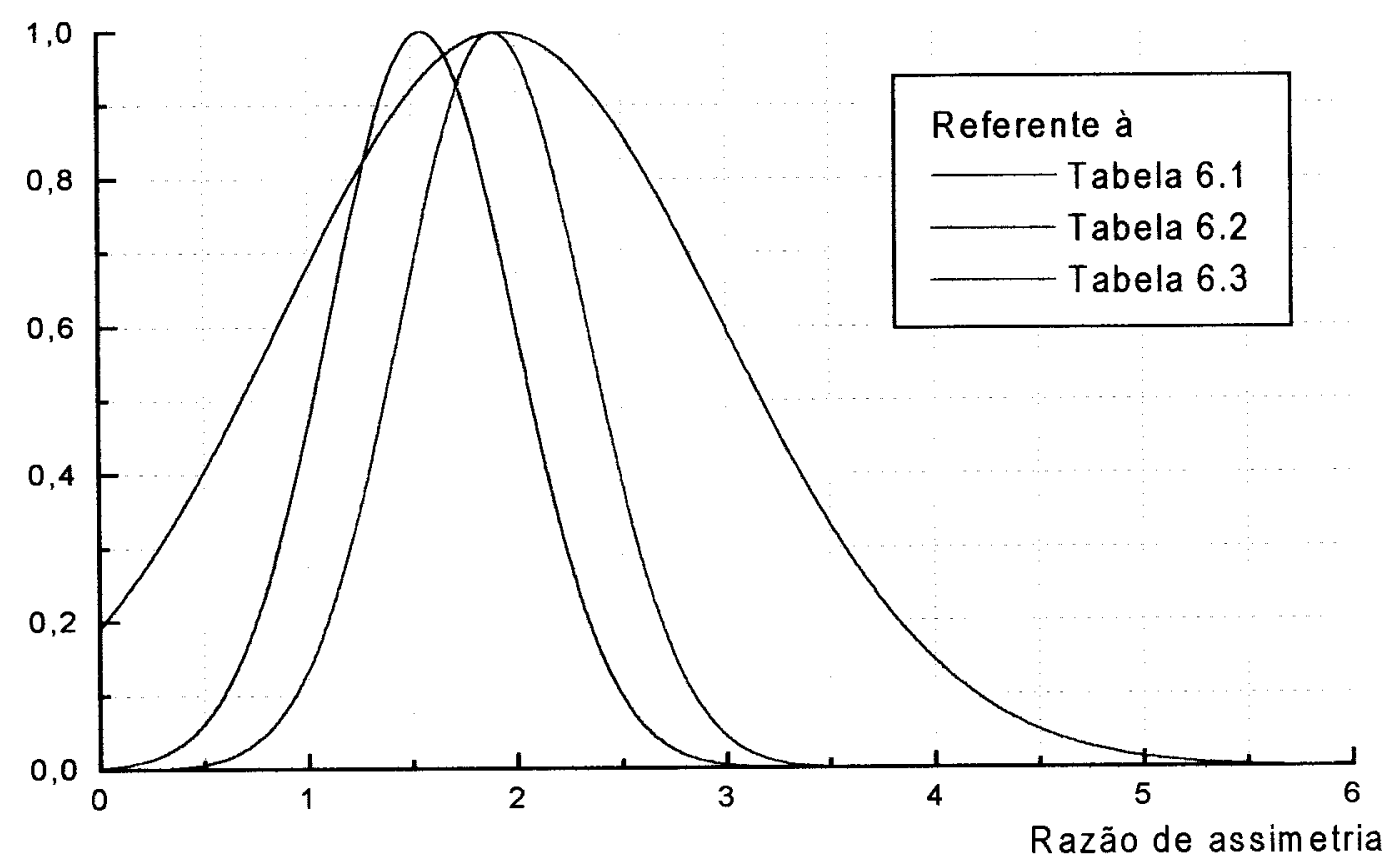

Figura 6.12 - Distribuições normalizadas dos valores de Razão de Assimetria da curva de Entropia das trinta e seis regiões para as figuras 6.4, 6.5 e 6.6, com médias e desvios padrões mostrados nas duas últimas linhas das tabelas $6.1,6.2$ e 6.3

Na figura 6.12 apresenta-se a distribuição dos valores de Razão de assimetria da curva de Entropia onde pode-se observar o comportamento relativo às três placas exemplo. Mais uma vez, o alto desvio padrão do valor-característica em análise, principalmente aquele que corresponde à figura 6.6 (dados na tabela 6.3), impede que esse critério seja capaz de sozinho fornecer informações suficientes para o estágio de classificação final

E assim o processo se repete também com o valor-característica "Diferença de Limiar tomada nos picos das Entropias parciais" (figura 6.13), onde verificam-se distribuições com médias distintas porém com grandes valores de desvio padrão, o que impossibilita qualquer decisão apoiada somente nesse valor-característica.

Com relação ao valor-característica "Razão entre Limiar da Região e Limiar médio da placa", ele só participa do algoritmo para detectar regiões muito claras ou 
muito escuras, e por isso também não pode ser utilizado sozinho para decisões de classificação.

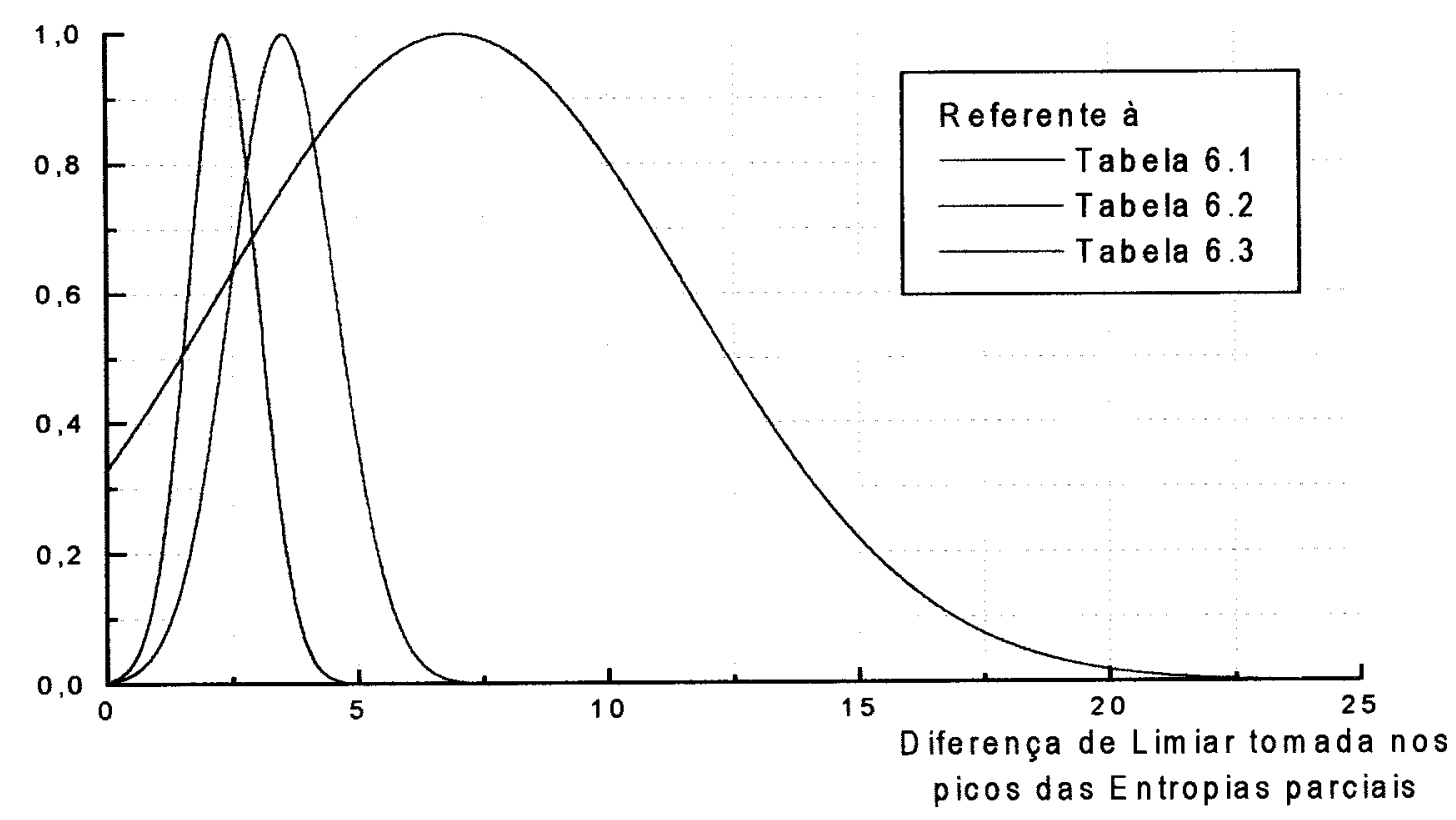

Figura 6.13 - Distribuições normalizadas dos valores de Diferença de Limiar tomada nos picos das Entropias parciais das trinta e seis regiões para as figuras $6.4,6.5$ e 6.6, com médias e desvios padrões mostrados nas duas últimas linhas das tabelas $6.1,6.2$ e 6.3

As três placas utilizadas como exemplo para analisar os valores-característica, estão perfeitamente caracterizadas como padrões bem definidos em suas classes. Como já descrito anteriormente, as variações visuais percebidas na superfície das placas são numerosas e altamente aleatórias, fazendo com que na análise geral das placas tratadas neste trabalho os valores-característica apresentem um comportamento global menos definido se comparados às três classes ideais mostradas.

Aplicando-se o algoritmo de extração dos valores-característica para todas as placas dos dois conjuntos de amostras, obtém-se o comportamento geral das regiões do conjunto das placas apresentado a seguir nas figuras 6.14 a 6.21 . 


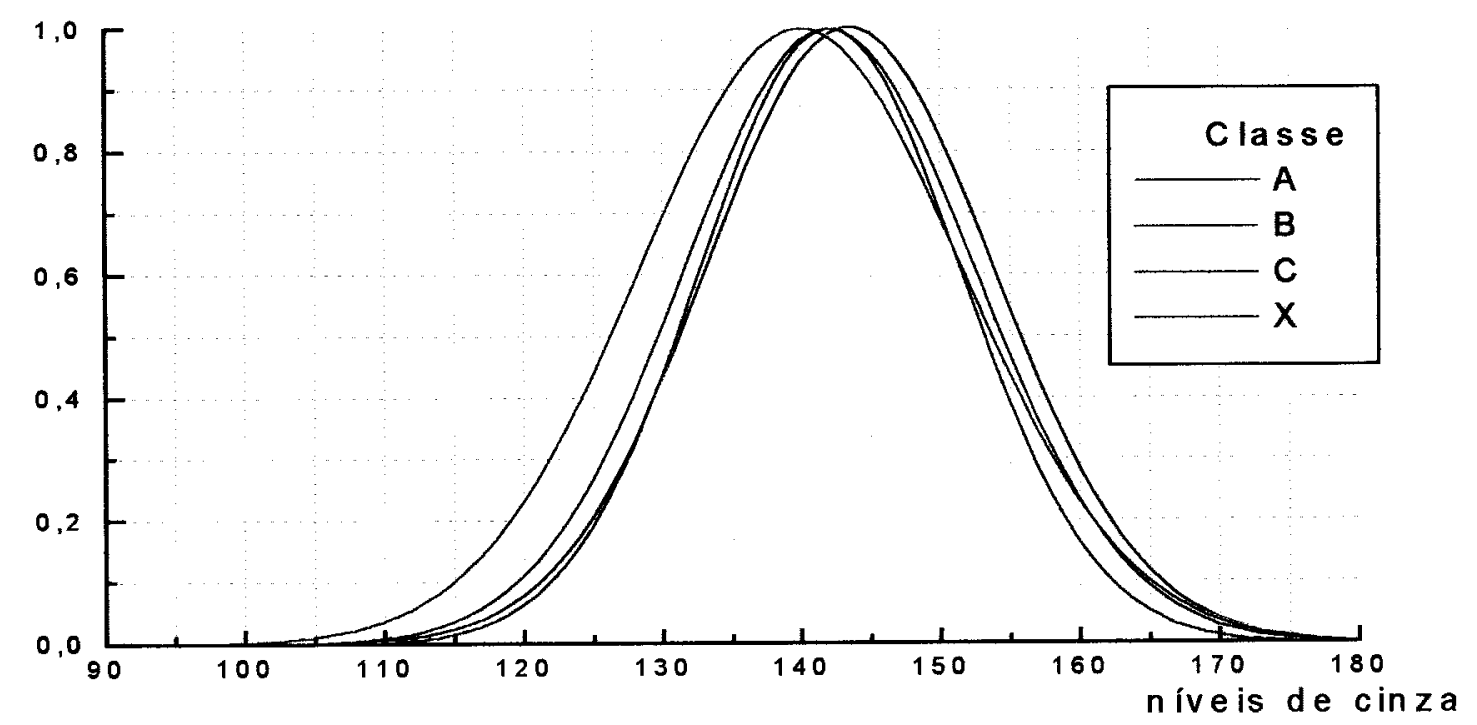

Figura 6.14 - Distribuição normalizada de Limiar para o primeiro conjunto de amostras (104 placas)

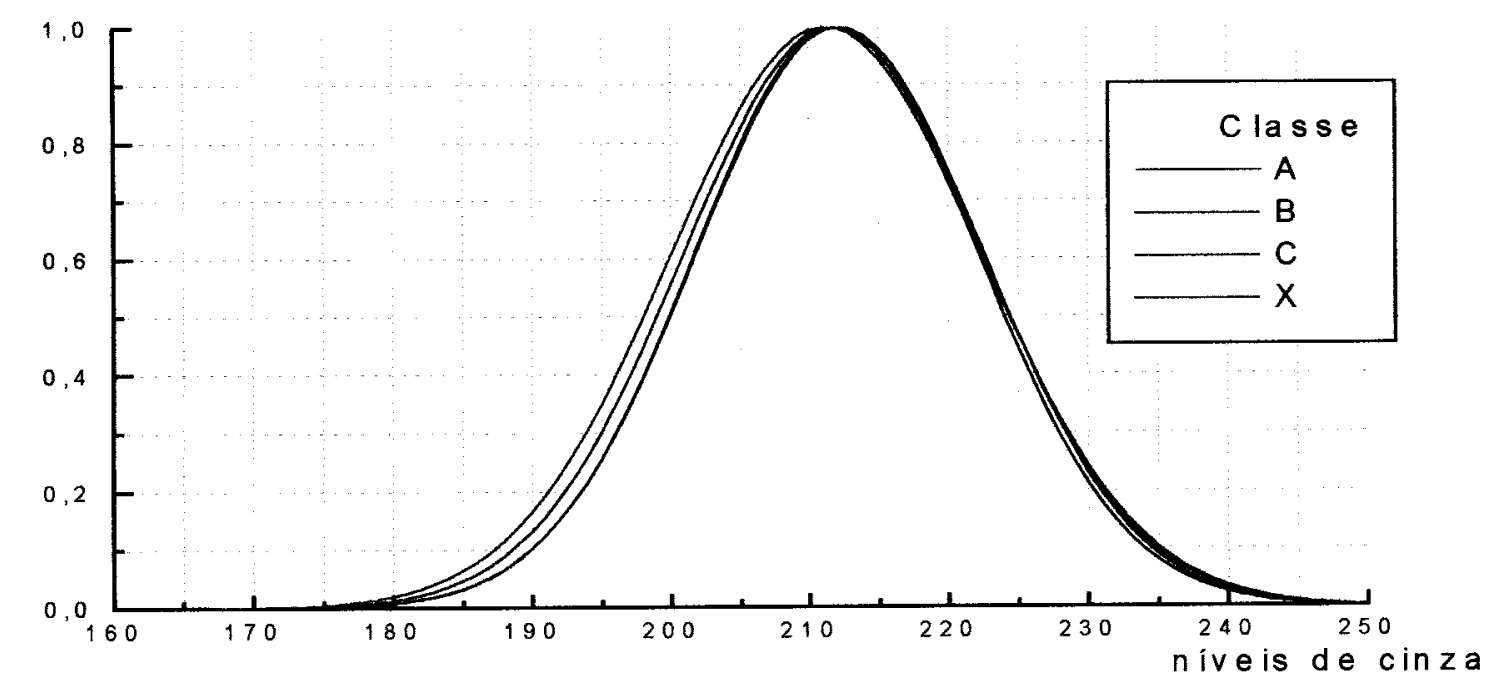

Figura 6.15 - Distribuição normalizada de Limiar para o segundo conjunto de amostras (199 placas) 


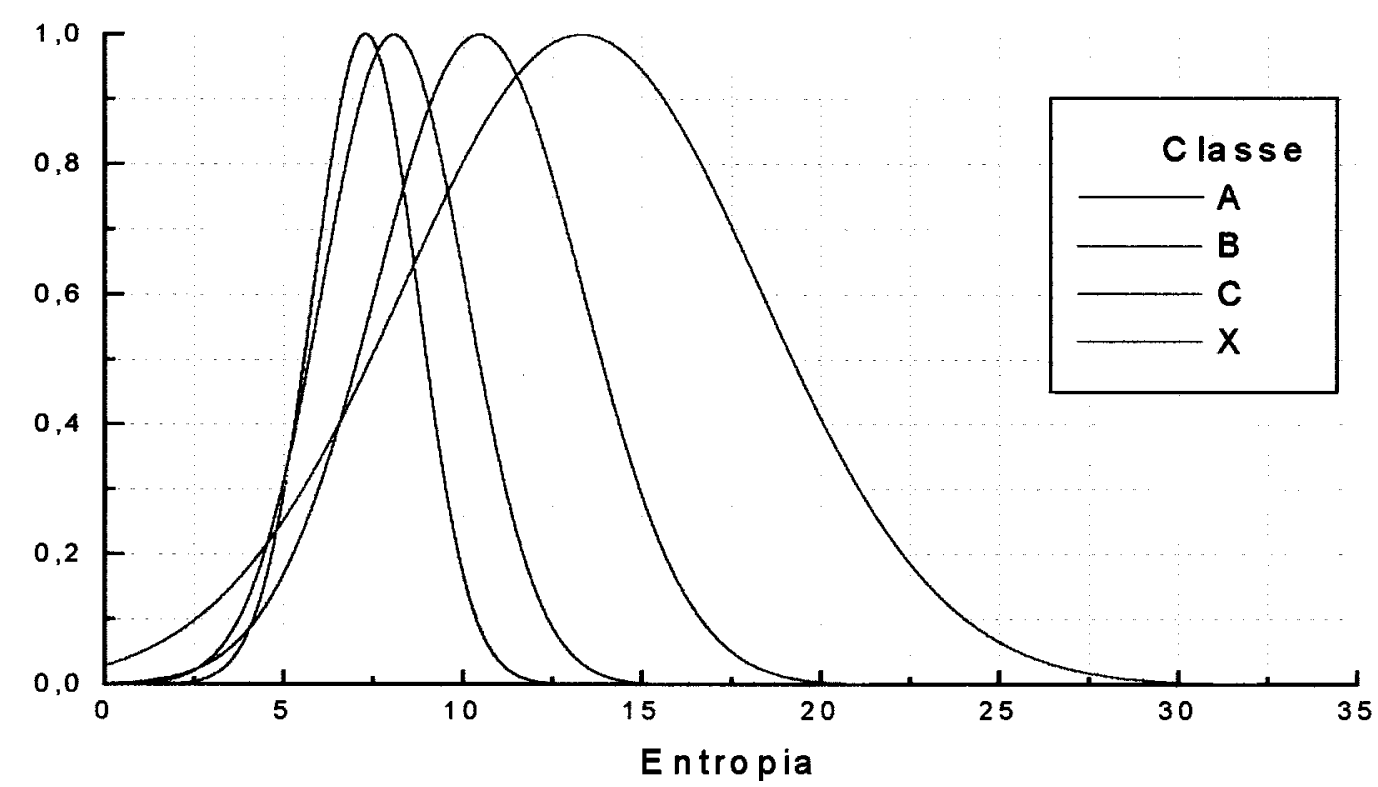

Figura 6.16 - Distribuição normalizada dos valores de Entropia para o primeiro conjunto de amostras (104 placas)

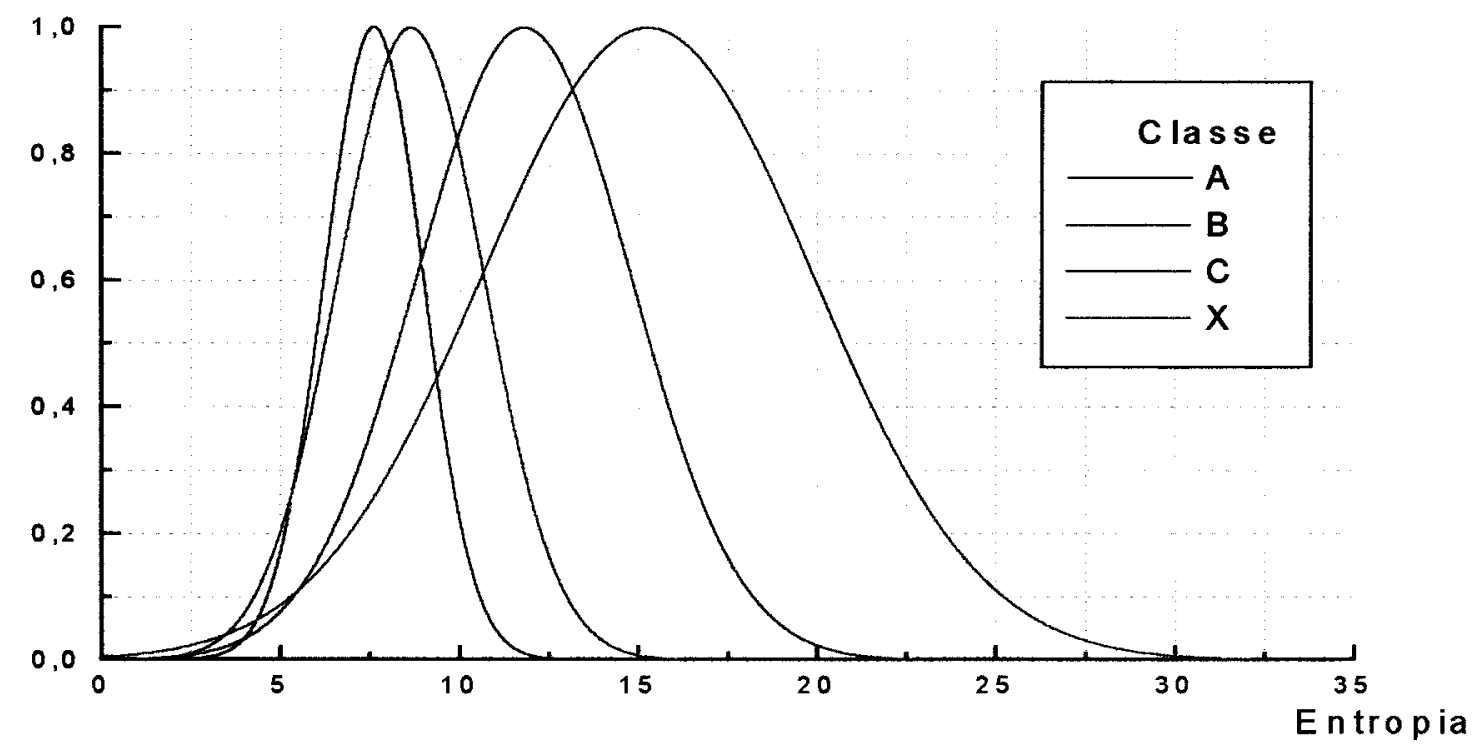

Figura 6.17 - Distribuição normalizada dos valores de Entropia para o segundo conjunto de amostras (199 placas) 


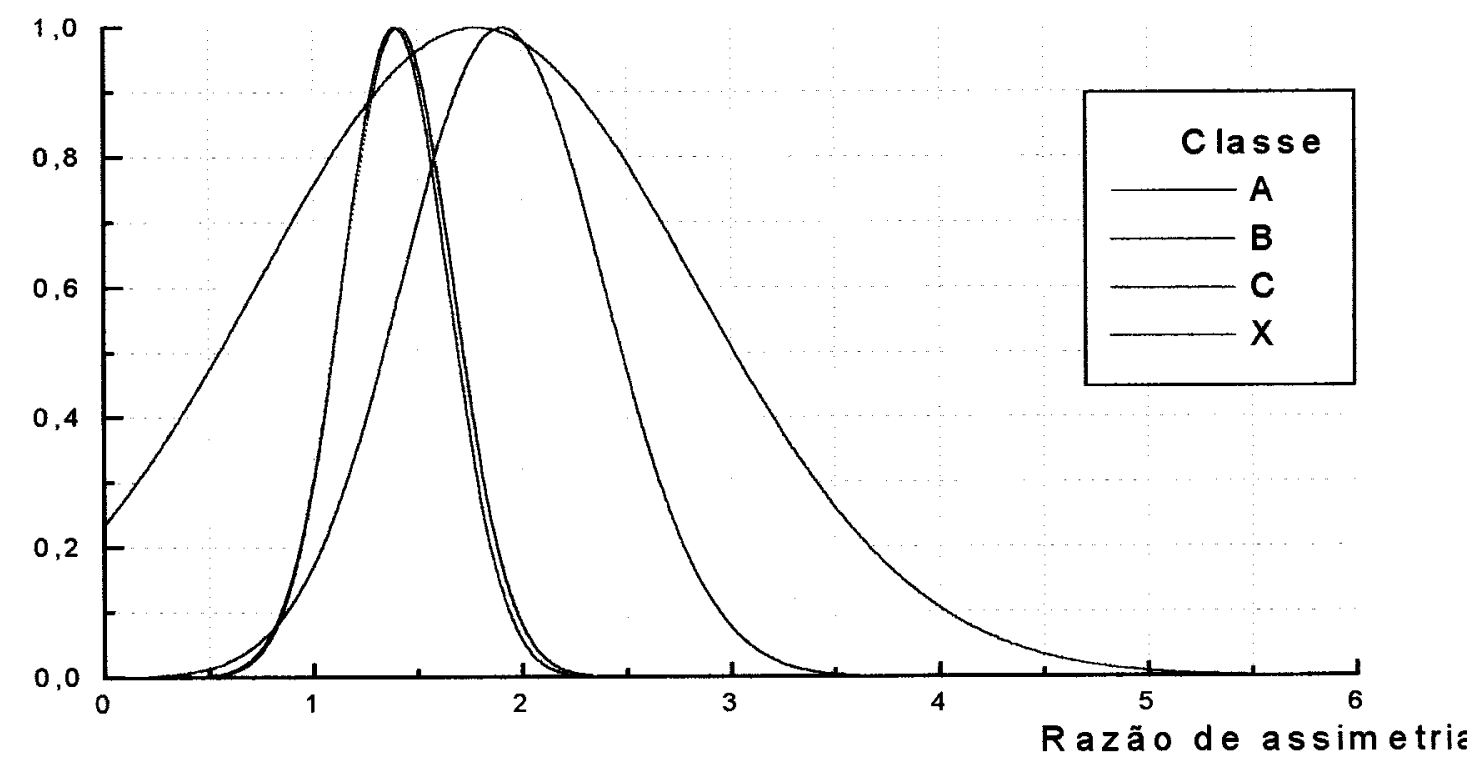

Figura 6.18 - Distribuição normalizada de Razão de assimetria da curva de Entropia para o primeiro conjunto de amostras (104 placas)

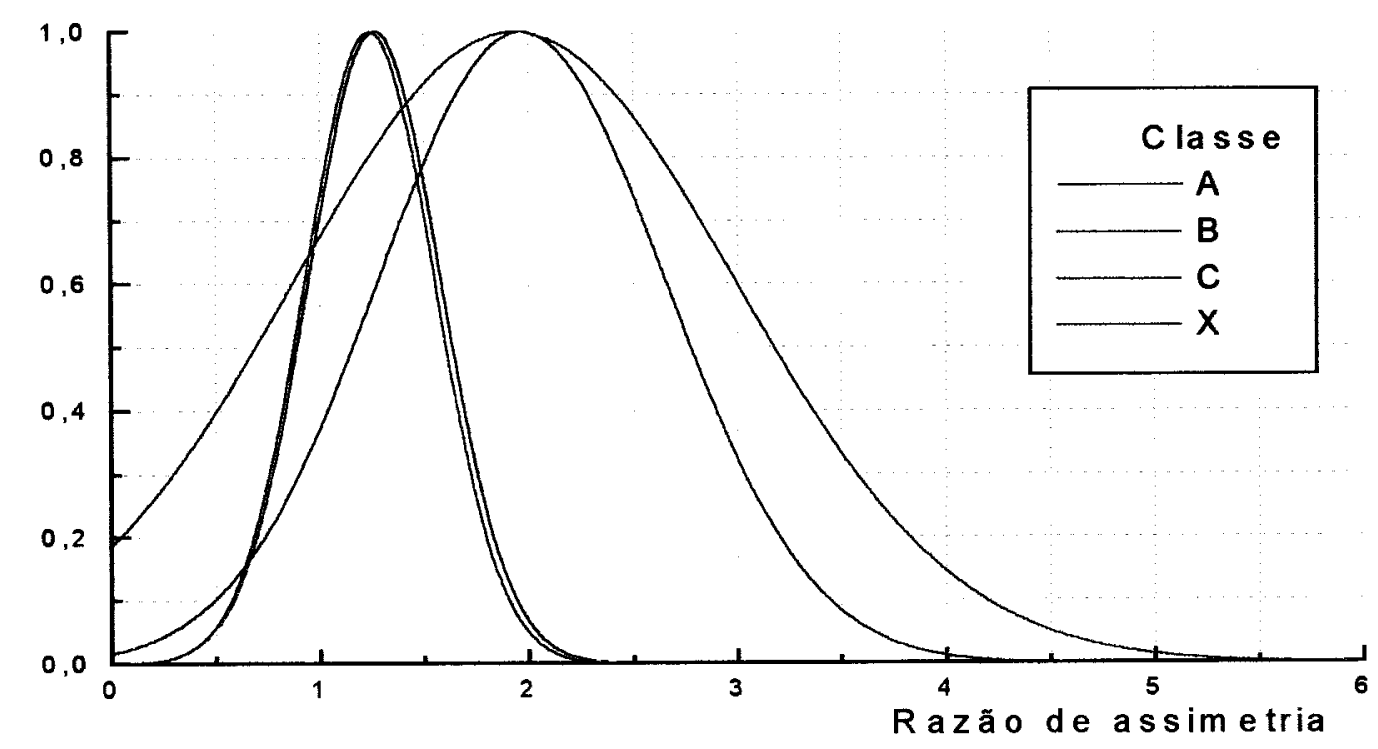

Figura 6.19 - Distribuição normalizada de Razão de assimetria da curva de Entropia para o segundo conjunto de amostras (199 placas) 


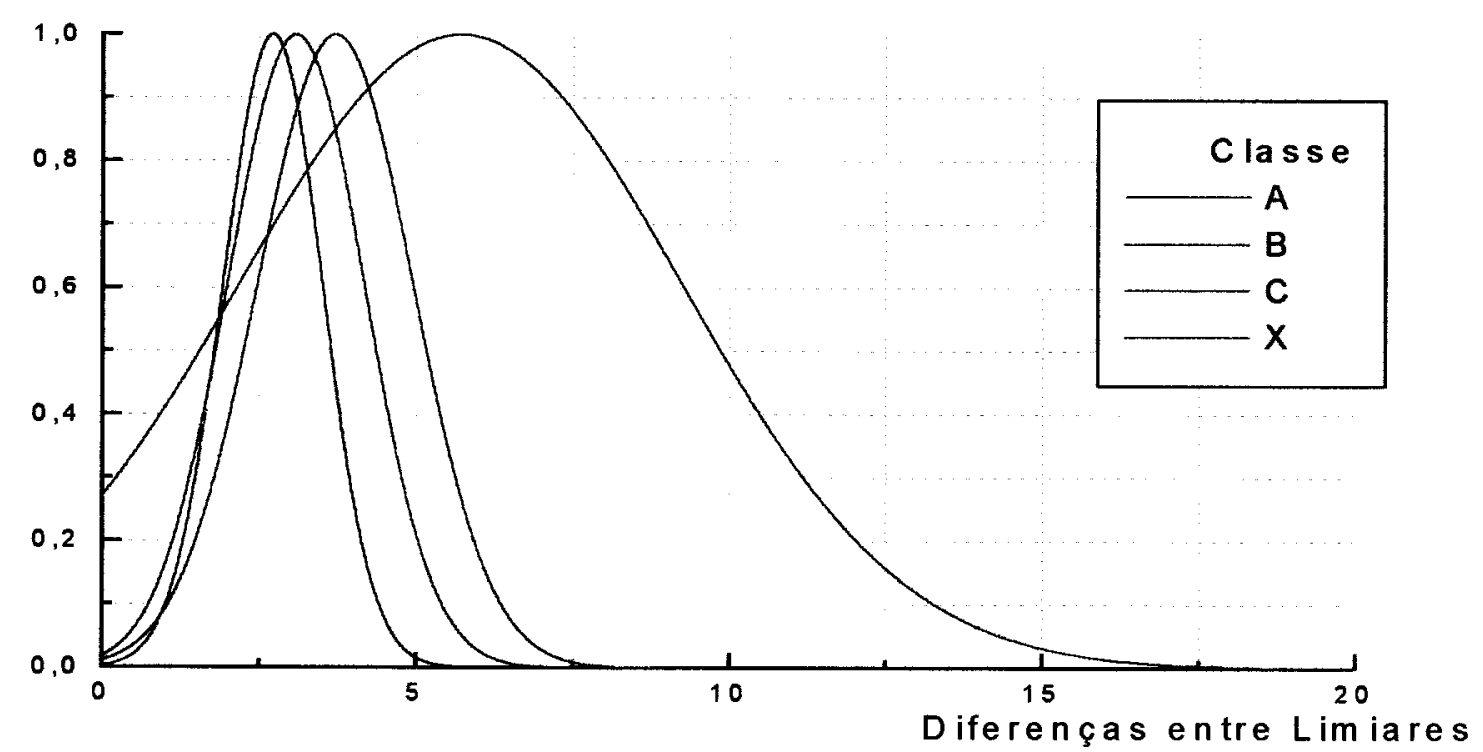

Figura 6.20 - Distribuição normalizada de Diferença entre valores de Limiar tomados nos picos das equações parciais de Entropia para o primeiro conjunto de amostras (104 placas)

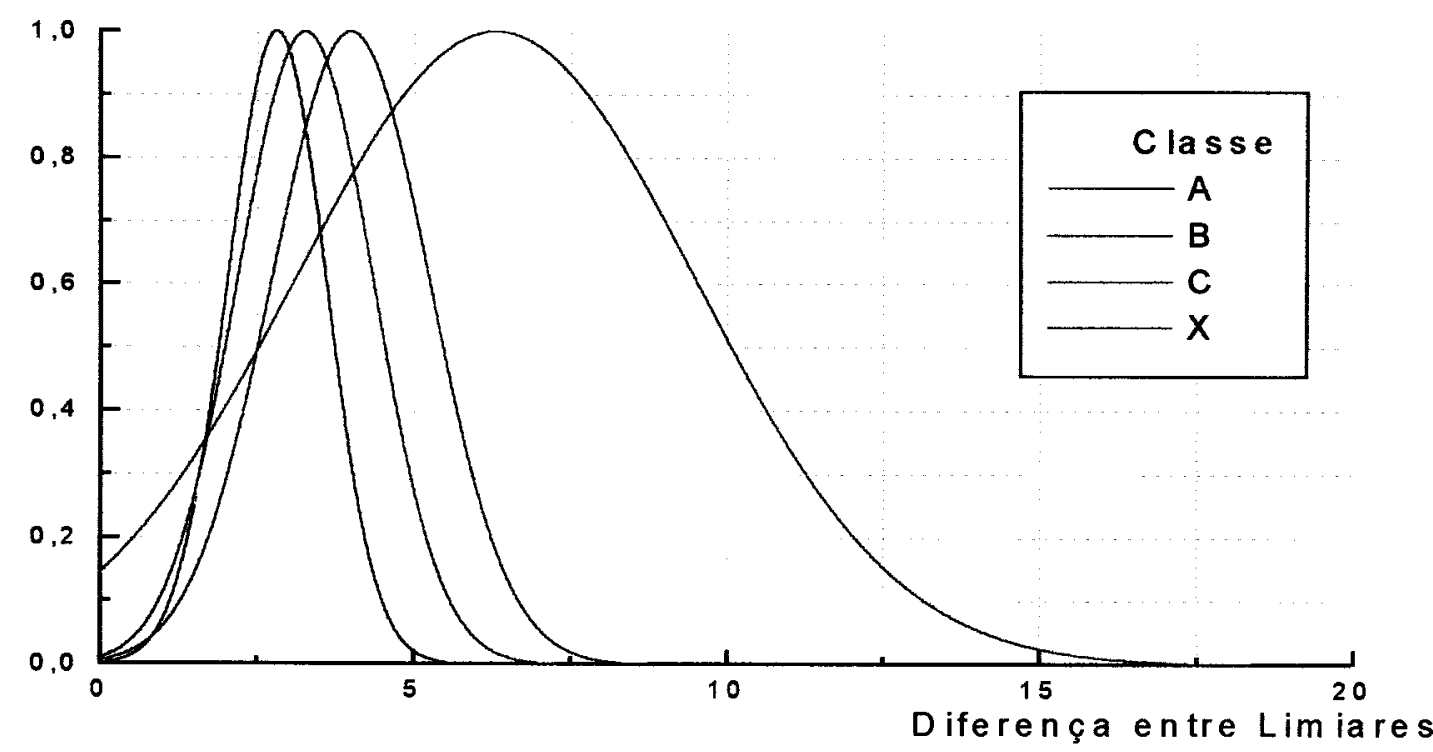

Figura 6.21 - Distribuição normalizada de Diferença entre valores de Limiar tomados nos picos das equações parciais de Entropia para o segundo conjunto de amostras (199 placas) 
Observando-se as figuras 6.14 a 6.21 , pode-se notar que as diferenças de comportamento entre os valores-característica dos dois conjuntos de amostras, em média são pequenas. Uma diferença considerável apresentada entre eles, encontra-se no valor-característica Limiar (figuras 6.14 e 6.15 ), onde o primeiro conjunto de amostras apresenta médias de Limiar bem abaixo dos valores das médias do segundo conjunto. Isso acontece porque na captura das imagens que compõem o segundo conjunto de amostras, buscou-se eliminar, ou atenuar o máximo possível, a presença de certas características (podem ser chamadas de características secundárias, como por exemplo manchas, acículas, etc...) que não transportam informações capazes de contribuir na análise em qualquer estágio dos algoritmos propostos.

A estratégia, que podemos chamar de filtragem de informações indesejadas, foi conseguida variando-se a abertura da lente da câmera, até que o nível de luminosidade percebido fosse tal que as imagens capturadas contivessem o mínimo possível de informações secundárias, sem contudo interferir na qualidade das características principais, ou seja, as formas de interesse que são as partes de madeira dura dos anéis de crescimento foram conservadas. Por isso, os valores de Limiar do segundo conjunto de amostras têm média de nível de cinza em torno de 211 e o primeiro conjunto em torno de 141.

Com as figuras 6.10 a 6.21 mostrando o comportamento dos valorescaracterística utilizados, o algoritmo descrito no capítulo 5, sub-ítem 5.4.1, utiliza-se de combinações de faixas desses valores para determinar a que classe pertence cada uma das trinta e seis regiões das placas, realizando assim á tarefa de pré-classificação das mesmas. 
Todos os valores-característica foram determinados observando $o$ comportamento visual das quatro classes empregadas na rotulagem de região, confrontando com os valores das tabelas de dados (como nas tabelas 6.1, 6.2 e 6.3) de todas as placas.

Assim, a rotulagem de região obedece às seguintes regras:

\section{Classe $A$ deve possuir}

- Entropia total $<10.0$

- Diferença entre níveis de cinza dos picos nas parciais $<9$

- Razão Limiar da região pelo Limiar médio da placa $>=0.94$

- $0.6<=$ Razão de assimetria da curva de entropia $<2$

Classe $B$ deve possuir

- $10.0<=$ Entropia total $<12.5$

- Diferença entre níveis de cinza dos picos nas parciais $<8$

- Razão Limiar da região pelo Limiar médio $>=0.94$

- $0.7<=$ Razão de assimetria da curva de entropia $<1.8$

\section{Classe $C$ deve possuir}

- $12.5<=$ Entropia total $<18.0$

- Diferença entre níveis de cinza dos picos nas parciais $<7$

- Razão Limiar da região pelo Limiar médio $>=0.92$

- $0.65<=$ Razão de assimetria da curva de entropia $<2.5$ 
Classe $X$ deve possuir

- Qualquer valor de Entropia $>=18.0$

(Independentemente dos outros valores-característica)

- Qualquer outro valor-característica também é decisivo quando exceder os limites para as classes anteriores

Para atribuir uma classe final às placas conhecendo-se a pré-classificação, poderia-se agora atuar com algoritmos clássicos para classificação de texturas, pois após a fase de pré-classificação as superfícies em análise podem ser interpretadas com um comportamento mais definido com relação à textura.

Oferece-se dessa forma, a oportunidade da aplicação de algoritmos clássicos para classificação de texturas, como por exemplo os propostos por Haralick et al. [Haralick, 1973] e tantos outros expostos na maioria dos livros correlatos ao assunto como [Marr, 1982], [Gonzales \& Woods, 1993], [Ballard \& Brown, 1982], [Low, 1991], [Russ, 1995], etc..., ou mesmo um algoritmo que determinasse exatamente a qual classe pertence tal distribuição de pré-classificação, pela comparação direta em um banco de dados com todas as combinações das regiões, não fosse o elevado número de combinações possiveis que geram as quatro classes em trinta e seis regiões (um total de $\sim 4.72 \times 10^{21}$ possibilidades).

Como um dos objetivos deste trabalho é propor um procedimento completo de classificação, simples e veloz, os algoritmos de finalização descritos no capítulo anterior nos sub-ítens 5.4.2 e 5.4.3, que buscam apresentar em poucos passos a solução para a distribuição da pré-classificação, produziram resultados que são analisados a seguir. 


\section{CLASSIFICAÇÃO FINAL}

Depois de pré-classificadas, as placas foram submetidas aos dois algoritmos de classificação final, cujos desempenhos são analisados e comparados com classificações realizadas por técnicos especialistas em placas de madeira para a fabricação de lápis, que assimilaram a inclusão de duas classes a mais na classificação final.

Mesmo considerando a capacidade técnica de discernimento dos inspetores, a presença de desvios na classificação realizada por operadores humanos é fato que não pode ser ignorado [Newman \& Jain, 1995] [Chin \& Harlow, 1982].

Considerando-se que aumentando o número de classes propicia-se também um aumento na probabilidade de classificações discordantes na tarefa realizada por humanos, incorporou-se uma classificação alternativa para as placas classificadas pelos técnicos especialistas. Nas placas onde não existe uma presença marcante de características que determinem de forma definitiva uma classe, aquelas que permitem interpretações dúbias, é oferecida além da classificação "mais provável", também uma classificação suplementar no sentido de minimizar os desvios de classificação que porventura possam ser cometidos pelos inspetores.

A tabela B.1 do anexo B apresenta os resultados de classificação do segundo conjunto de placas (199 placas que não foram previamente classificadas) realizada pelos três técnicos (identificados na tabela B.1 por Inspetor 1,2 e 3) e pelos dois algoritmos de classificação final. Identifica-se na tabela B.1 for Redução o algoritmo que utiliza redução de informação baseado em regras (sub-ítem 5.4.2) e por Co-ocorrência o algoritmo que utiliza matriz de co-ocorrência (sub-ítem 5.4.3). 
Não existem colunas de classificações alternativas para os dois algoritmos, pois o procedimento adotado para os mesmos admite somente uma classe final para as placas.

\subsection{1 - COMPARAÇÃO DAS CLASSIFICAÇÕES}

Observando-se os resultados de classificação apresentados na tabela B.1 do anexo $\mathrm{B}$, podem ser notadas pequenas diferenças entre as classes atribuídas às placas pelos inspetores e também pelos métodos. Essas diferenças podem ser atribuídas aos casos onde as características presentes nas placas não permitem uma interpretação precisa, exata e indiscutível das mesmas.

Para visualização das diferenças existentes, a tabela 6.4 mostra as quantidades encontradas, por classes, nas cinco classificações obtidas (três inspetores e os dois métodos).

Tabela 6.4 - Freqüências de ocorrências de classes da tabela B.1 (anexo B)

\begin{tabular}{|c||c|c|c|c|c||c|}
\hline & Classe A & Classe B & Classe C & Classe D & Classe X & Total \\
\hline \hline Inspetor 1 & 12 & 33 & 49 & 49 & 56 & 199 \\
\hline Inspetor 2 & 16 & 30 & 52 & 52 & 49 & 199 \\
\hline Inspetor 3 & 14 & 37 & 43 & 54 & 51 & 199 \\
\hline Co-ocorrência & 15 & 37 & 49 & 51 & 47 & 199 \\
\hline Redução & 14 & 42 & 53 & 45 & 45 & 199 \\
\hline \hline Total & 71 & 179 & 246 & 251 & 248 & 995 \\
\hline
\end{tabular}

Considerando-se cada uma das classificações realizadas pelos inspetores ou pelos métodos como uma amostra, percebe-se que quando há discordância de atribuição de classes entre as cinco amostras, isso se dá em sua grande maioria entre classes 
vizinhas, ou seja, não existem classificações discrepantes a ponto de observar-se por exemplo, uma amostra atribuindo classe $A$ a uma placa e outra atribuindo classe $D$ à mesma placa, ou , uma amostra atribuindo classe $B$ a uma placa e outra amostra atribuindo classe $X$ à mesma placa. Existem poucas classificações que não se avizinham totalmente, como por exemplo, uma amostra atribuindo classe $B$ e outra atribuindo classe $D$. Esses acontecimentos são analisados mais adiante.

Diante desse fato, e considerando que as classificações alternativas feitas pelos inspetores amenizam esses acontecimentos, pode-se dizer que não existem diferenças significativas no número de placas classificadas em cada uma das cinco classes $(A, B, C$, $D$ e $X$ ) pelas cinco amostras de classificação da tabela B.1.

Para pôr à prova e determinar a significância dessas diferenças analisou-se as amostras de classificação do Inspetor 1, Inspetor 2, Inspetor 3, Co-ocorrência e Redução como cinco amostras independentes, onde são confrontadas as quantidades de placas que cada amostra determina em cada uma das cinco classes, através da utilização do método estatístico não-paramétrico do $\chi^{2}$ (qui-quadrado) [Spiegel, 1985] [Beiguelman, 1996].

Por que utilizar o método do $\chi^{2}$ ?

"Quando os dados de uma pesquisa consistem de frequiências em categorias discretas, pode-se usar a prova do $\chi^{2}$ para determinar a significância das diferenças entre $k$ grupos independentes..." [Siegel, 1977]. 
Define-se na estatística o teste do $\chi^{2}$ como o somatório das razões do quadrado da diferença entre freqüências observadas e esperadas pela freqüência observada, ou seja:

$$
\chi^{2}=\sum_{j=1}^{k} \frac{\left(o_{j}-e_{j}\right)^{2}}{e_{j}}
$$

A tabela 6.4 representa a distribuição de freqüências observadas das classes para as cinco amostras. A hipótese nula $\left(H_{0}\right)$ admitida é a de que as amostras não diferem entre si e a hipótese alternativa é a de que isso não é verdadeiro.

De acordo com Siegel [Siegel, 1977], a aplicação do método do $\chi^{2}$ para a tabela de contingências 6.4 , deve seguir a aplicação da equação 6.3 , com grau de liberdade expresso por $(k-1)(r-1)$, onde $k$ é o número de colunas e $r$ o número de linhas da tabela.

$$
\chi^{2}=\sum_{i=1}^{r} \sum_{j=1}^{k} \frac{\left(o_{i j}-e_{i j}\right)^{2}}{e_{i j}}
$$

sendo $o_{i j}=$ número de casos observados classificados na linha $i$ da coluna $j$;

$e_{i j}=$ número de casos esperados, sob $H_{0}$, na linha $i$ da coluna $j$;

$\sum_{i=1}^{r} \sum_{j=1}^{k}$ indica somatório sobre todas as células

Beiguelman [Beiguelman, 1996] enfatiza que em estatística, um resultado com probabilidade de ocorrência igual ou inferior a $5 \%$ é considerado como tendo pouca probabilidade de acontecer. Com base nisso, o risco que se corre em rejeitar uma hipótese verdadeira, que é denominado nível de significância $(\alpha)$, foi estabelecido conforme usualmente adotado pela literatura em $5 \%$. O valor do $\chi^{2}$ ao nível de significância estabelecido é denominado qui-quadrado crítico e simbolizado por $\chi_{c}^{2}$.

Quando usar a prova do $\chi^{2} ?$ 
"A prova do $\chi^{2}$ exige que as freqüências esperadas em cada célula não sejam muito pequenas. Quando tal exigência não é satisfeita, os resultados da prova não são válidos. Cochran $(1954)^{3}$ recomenda que, quando $k$ ou $r$ são maiores que 2 , ou seja, no caso de provas de $\chi^{2}$ com graus de liberdade superior a 1 , a prova do $\chi^{2}$ só deve ser aplicada quando menos de 20 por cento das células possuirem freqüência esperada inferior a 5 , e quando nenhuma célula possuir freqüência esperada inferior a $1 . . . "$ [Siegel, 1977].

Como as condições estão plenamente satisfeitas, pode-se empregar o método do $\chi^{2}$ para a verificação da significância das diferenças apresentadas pelas cinco amostras de classificação.

A tabela 6.4 apresenta somente as freqüências observadas $(o)$ e de acordo com Beiguelman [Beiguelman, 1996], como não existe nenhuma teoria que permita o cálculo da proporção esperada em cada uma de suas vinte e cinco células, ele sugere o raciocínio de que se a hipótese nula $H_{0}$ fosse verdadeira, as cinco amostras deveriam apresentar as mesmas proporções de classes $A, B, C, D$ e $X$. Tudo se passaria então como se tivéssemos apenas uma amostra constituída por 995 placas (199 placas por amostra). Sendo assim, a razão 71/995 estimaria a probabilidade de uma placa pertencer a classe $A$, pois 71 é o total de placas naquela classe com as cinco amostras de classificação reunidas e 995 é o número total de placas também das cinco amostras. Da mesma forma o procedimento segue-se para as outras classes estimando assim a probabilidade de todas elas.

${ }^{3}$ Cochran, W. G., 1954. Some methods for strengthening the common $\chi^{2}$ tests. Biometrics, $10,417-451$ 
Baseando-se nessas probabilidades, pode-se calcular a proporção esperada de placas das cinco classes $(A, B, C, D$ e $X)$ nas cinco amostras de classificação. Como as amostras possuem o mesmo tamanho (199 placas), as proporções são calculadas por classes como:

$$
\begin{aligned}
& \text { Classe A }-199 *(71 / 995)=14.2 \\
& \text { Classe B }-199^{*}(179 / 995)=35.8 \\
& \text { Classe C }-199 *(246 / 995)=49.2 \\
& \text { Classe D }-199 *(251 / 995)=50.2 \\
& \text { Classe X }-199 *(248 / 995)=49.6
\end{aligned}
$$

Para melhor visualização, a tabela 6.5 apresenta os valores observados (o) juntamente com os esperados (e).

Tabela 6.5 - Frequiências observadas e esperadas das classes

\begin{tabular}{|c|ccc|c|c|c|c|c|c||c||c|}
\hline & \multicolumn{2}{|c|}{ Classe A } & \multicolumn{2}{|c|}{ Classe B } & \multicolumn{2}{|c|}{ Classe C } & \multicolumn{2}{|c||}{ Classe D } & \multicolumn{2}{|c|}{ Classe X } & Total \\
& $o$ & $e$ & $o$ & $e$ & $o$ & $e$ & $o$ & $e$ & $o$ & $e$ & linhas \\
\hline Inspetor 1 & 12 & 14.2 & 33 & 35.8 & 49 & 49.2 & 49 & 50.2 & 56 & 49.6 & 199 \\
\hline Inspetor 2 & 16 & 14.2 & 30 & 35.8 & 52 & 49.2 & 52 & 50.2 & 49 & 49.6 & 199 \\
\hline Inspetor 3 & 14 & 14.2 & 37 & 35.8 & 43 & 49.2 & 54 & 50.2 & 51 & 49.6 & 199 \\
\hline Co-ocorrência & 15 & 14.2 & 37 & 35.8 & 49 & 49.2 & 51 & 50.2 & 47 & 49.6 & 199 \\
\hline Redução & 14 & 14.2 & 42 & 35.8 & 53 & 49.2 & 45 & 50.2 & 45 & 49.6 & 199 \\
\hline $\begin{array}{c}\text { Total } \\
\text { colunas }\end{array}$ & 71 & 71.0 & 179 & 179.0 & 246 & 246.0 & 251 & 251.0 & 248 & 248.0 & 995 \\
\hline
\end{tabular}

De posse dos valores observados e esperados pode-se calcular o valor $\frac{(o-e)^{2}}{e}$ correspondente a cada célula e, após somar os vinte e cinco valores, obtém-se o valor do $\chi^{2}=6.5361$ para a tabela 6.5 
O número de graus de liberdade calculado por $(k-1)(r-1)$, onde $k=5$ e $r=5$, é igual

a 16. Como assumido anteriormente, o nível de significância é $\alpha=0.05$, obtém-se dessa forma através de consulta na tabela de valores para o qui-quadrado, o qui-quadrado crítico $\chi_{c}^{2}=26.296$.

Tendo em vista que o resultado encontrado de $\chi^{2}=6.5361$ é menor que o $\chi_{c}^{2}=26.296$, pode-se aceitar a hipótese nula de que as amostras não diferem entre si quanto às proporções observadas para cada classe, isso equivalendo a dizer que as cinco amostras de classificações poderiam ser reunidas para compor uma única.

Consultando-se também a tabela do $\chi^{2}$, essa afirmação pode ser resumida pela expressão:

$$
\chi_{(16)}^{2}=6.5361 ; \quad 0.98<p<0.99
$$

onde $p$ indica a probabilidade de aceitar-se que de $98 \%$ a $99 \%$ de classificações similares às da tabela B.1, pode-se considerar como classificações que não diferem significativamente.

O resultado alcançado com o teste do qui-quadrado mostra uma análise realizada com quantidades de placas encontradas por classes pelos cinco classificadores (três inspetores e dois métodos).

Embora as defuições das características que determinam cada classe, mostradas no capítulo 4, sejam definições que forneçam sustentação para a classificação, seus limites, tênues por natureza, permitem que apareçam divergências de concordâncias nas classificações, quando observadas as cnincidências reais de classificação alcançadas pelos cinco classificadores. 
A tabela 6.6 foi construída extraindo-se da tabela B.1 do anexo B, as coincidências reais de classificação estabelecidas entre os inspetores, entre os métodos e entre os inspetores e métodos, mostrando as quantidades encontradas por classe, a quantidade total e a porcentagem total de coincidências.

Tabela 6.6 - Coincidências de classificação entre os classificadores obtidas da tabela B.1

\begin{tabular}{|c|c|c|c|c|c|c|c|}
\hline Coincidências & Classe A & Classe B & Classe C & Classe D & Classe X & $\begin{array}{c}\text { Total de } \\
\text { coincidências }\end{array}$ & $\%$ \\
\hline $\begin{array}{l}\text { Inspetor } 1 \\
\text { Inspetor } 2\end{array}$ & 7 & 16 & 34 & 36 & $\overline{446}$ & 139 & 69.85 \\
\hline $\begin{array}{l}\text { Inspetor } 1 \\
\text { Inspetor } 3\end{array}$ & 8 & 22 & 31 & 38 & 47 & 146 & 73.37 \\
\hline $\begin{array}{c}\text { Inspetor } 1 \\
\text { Co-ocorrência }\end{array}$ & 7 & 23 & 30 & 25 & 36 & 121 & 60.80 \\
\hline $\begin{array}{l}\text { Inspetor } 1 \\
\text { Redução }\end{array}$ & 7 & 24 & 33 & 26 & 37 & 127 & 63.83 \\
\hline $\begin{array}{l}\text { Inspetor } 2 \\
\text { Inspetor } 3\end{array}$ & 12 & 23 & 31 & 37 & 43 & 146 & 73.37 \\
\hline $\begin{array}{c}\text { Inspetor } 2 \\
\text { Co-ocorrência }\end{array}$ & 10 & 15 & 27 & 27 & 33 & 112 & 56.28 \\
\hline $\begin{array}{c}\text { Inspetor } 2 \\
\text { Redução }\end{array}$ & 8 & 18 & 32 & 26 & 34 & 118 & 59.30 \\
\hline $\begin{array}{c}\text { Inspetor } 3 \\
\text { Co-ocorrência }\end{array}$ & 10 & 25 & 25 & 28 & 36 & 124 & 62.31 \\
\hline $\begin{array}{l}\text { Inspetor } 3 \\
\text { Redução }\end{array}$ & 9 & 26 & 28 & 27 & 35 & 125 & 62.81 \\
\hline $\begin{array}{l}\text { Co-ocorrência } \\
\text { Redução }\end{array}$ & 12 & 32 & 38 & 29 & 36 & 147 & 73.87 \\
\hline
\end{tabular}

A tabela 6.6 mostra que a porcentagem de coincidências de classificação entre os inspetores varia no intervalo de $69 \%$ a $73 \%$, enquanto entre os métodos esse valor chega a quase $74 \%$ de coincidências, considerando todas as classes. Quando são observadas as coincidências entre os inspetores e os métodos, os valores de coincidência diminuem ligeiramente indo de $56 \%$ a $62 \%$ para o método que utiliza matriz de co- 
ocorrência e de $59 \%$ a $63 \%$ para o método baseado em redução por combinação de informações.

Os índices de coincidências reais entre os inspetores apresentados na tabela 6.6, mostram o grau de dificuldade existente nas atribuições exatas de classes às placas.

Considerando que quando um inspetor executa uma classificação ele o faz com base em seu conhecimento e em uma quantidade de informações visuais muito superior à quantidade de informações que os métodos propostos utilizam, os índices de coincidências entre os inspetores não são muito superiores aos níveis de coincidências entre os inspetores e os métodos. Esses índices ratificam o bom desempenho de resultados de classificação dos dois métodos, com ligeira superioridade para o método baseado em redução por combinação de informações.

Somente para observação do nível dessa superioridade, calculando-se a média das porcentagens de coincidências entre os métodos e os inspetores, obtém-se $59.8 \%$ de média de coincidências para o método baseado em matriz de co-ocorrência e $61.98 \%$ para o método baseado em redução por combinação de informações, o que permite considerar que ambos possuem o mesmo desempenho na classificação final das placas.

Uma outra forma de análise dos resultados de classificação da tabela B.1 do anexo $\mathrm{B}$, apoia-se nas considerações de que existem poucas classificações que não se avizinham, ou seja, não existem muitas situações em que um classificador qualquer, por exemplo, atribua classe $A$ a uma placa e outro atribua classe $D$ à mesma placa.

Também, considerando que há uma classificação alternativa para os inspetores, com o objetivo de reduzir o valor de discordância que algumas interpretações 
produzem, a tabela 6.7 apresenta os níveis de concordância entre os classificadores quando as análises são feitas considerando-se as vizinhanças de classe.

Tomando-se dois classificadores quaisquer (inspetores e/ou métodos), considerase como classificação coincidente se as classes atribuídas por ambos para a mesma placa corresponderem-se da seguinte forma:

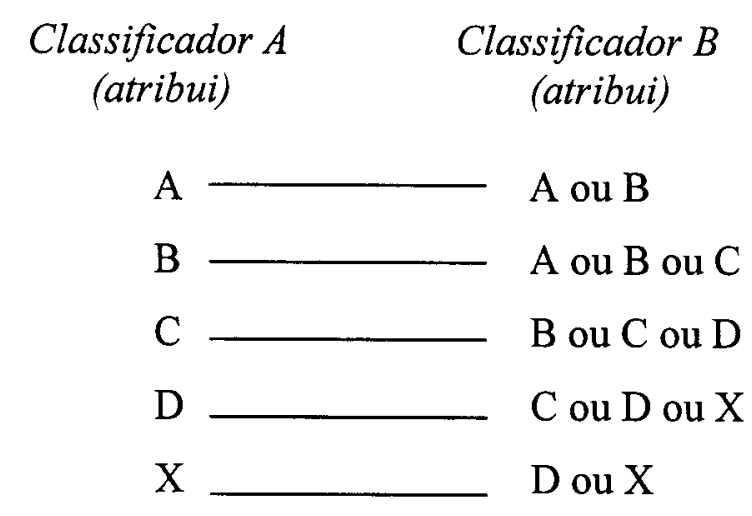

Tabela 6.7 - Coincidências entre os classificadores obtidas da tabela B.1 considerando as classificações de avizinhamento de classes

\begin{tabular}{|c|c|c|c|c|c|c|c|}
\hline Coincidências & Classe A & Classe B & Classe C & Classe D & Classe X & $\begin{array}{c}\text { Total de } \\
\text { coincidências }\end{array}$ & $\%$ \\
\hline $\begin{array}{l}\text { Inspetor } 1 \\
\text { Inspetor } 2\end{array}$ & 12 & 32 & 49 & 49 & 55 & 197 & 99.00 \\
\hline $\begin{array}{l}\text { Inspetor } 1 \\
\text { Inspetor } 3\end{array}$ & 12 & 33 & 49 & 49 & 56 & 199 & 100.00 \\
\hline $\begin{array}{c}\text { Inspetor I } \\
\text { Co-ocorrência }\end{array}$ & 14 & 37 & 45 & 50 & 47 & 193 & 96.99 \\
\hline $\begin{array}{l}\text { Inspetor } 1 \\
\text { Redução }\end{array}$ & 13 & 41 & 50 & 45 & 45 & 194 & 97.49 \\
\hline $\begin{array}{l}\text { Inspetor } 2 \\
\text { Inspetor } 3\end{array}$ & 16 & 30 & 52 & 52 & 49 & 199 & 100.00 \\
\hline $\begin{array}{c}\text { Inspetor } 2 \\
\text { Co-ocorrência }\end{array}$ & 15 & 35 & 46 & 50 & 46 & 192 & 96.48 \\
\hline $\begin{array}{l}\text { Inspetor } 2 \\
\text { Redução }\end{array}$ & 13 & 39 & 51 & 45 & 45 & 193 & 97.00 \\
\hline $\begin{array}{c}\text { Inspetor } 3 \\
\text { Co-ocorrência }\end{array}$ & 15 & 37 & 46 & 50 & 47 & 195 & 98.00 \\
\hline $\begin{array}{l}\text { Inspetor } 3 \\
\text { Redução }\end{array}$ & 14 & 42 & 51 & 45 & 45 & 197 & 99.00 \\
\hline $\begin{array}{l}\text { Co-ocorrência } \\
\text { Redução }\end{array}$ & 15 & 37 & 49 & 50 & 47 & 198 & 99.50 \\
\hline
\end{tabular}


Na tabela 6.7 pode-se observar os altos índices de coincidências de classificação, considerando as relações de avizinhamento de classes entre dois classificadores (inspetores e/ou métodos).

Isso mostra que eliminando-se as subjetividades de interpretação, os inspetores concordam entre si e também com as classificações apresentadas pelos dois métodos propostos nesta tese, reforçando assim o resultado encontrado pelo método estatístico aplicado às quantidades de placas encontradas por classes da tabela 6.4.

\section{5 - ERROS DE CLASSIFICAÇÃO}

Os principais fatores que atuaram de modo a não permitir $100 \%$ de coincidências entre os métodos e entre os métodos e inspetores, foram a qualidade da imagem analisada e as próprias limitações dos métodos impostas pelas combinações de valores em cada método.

Com relação às imagens, em determinadas placas ou regiões de placas, as informações presentes que servem para definir a classificação de uma região, foram de certa forma atenuadas em excesso pelo processo de abertura da lente da câmera, no estágio de captura das imagens, fazendo com que os valores-característica fossem extraídos com valores atenuados das regiões afetadas. Com esses valores alterados, os algoritmos tornam-se em determinados casos incapazes de atribuir classes que sejam pelo menos "vizinhas" daquelas atribuídas pelos inspetores. Contudo, como pode-se observar pelos resulıados da tabela 6.7, a quantidade de imagens afetadas por esse processo é bastante reduzida, validando assim o processo estabelecido na captura das imagens. 
Em outras poucas placas, o fator decisivo foi o erro inerente que os dois métodos possuem. Como ambos operam baseados na redução por combinação de informações, um na combinação de classes e outro na informação simplificada de co-ocorrência de vizinhança de classes, ocorrem situações não desejadas.

Como exemplo de erro do método baseado em redução, observando-se a figura 6.22, que corresponde à placa 53 do segundo conjunto, esta encontra-se pré-classificada e com a primeira fase do algoritmo final realizada gerando o vetor-coluna [CBCCXBBCA]. Tanto por observação visual da pré-classificação quanto pela observação do vetor-coluna, esperaria-se uma atribuição de classe $C$ a essa face da placa, pois possui em seu vetor-coluna maior quantidade de classes $C$. Entretanto, a presença da classe X na posição central do vetor-coluna, interfere de maneira decisiva culminando em uma atribuição de classe $D$, como pode-se ver a seguir.

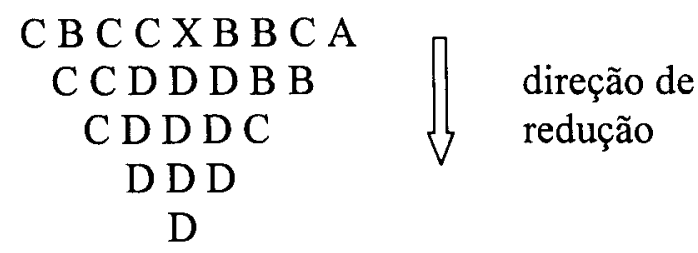

\begin{tabular}{|c|c|c|c|}
\hline $8 \div 4$ & $x$ & त C ? & C \\
\hline $\bar{A}$ & B & A & c \\
\hline 3.8 & A & 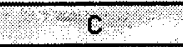 & $\mathrm{c}$ \\
\hline 1. C C & 3. c & $x$ & $\mathrm{C}$ \\
\hline 8 & c & $x$ & $x$ \\
\hline A & $\mathbf{B}$ & 19 & 2 \\
\hline $\mathrm{C}$ & $\mathrm{B}$ & 日. & $.4 \mathrm{~B}$ \\
\hline 7.7. & B.?:? & D. & $\sqrt{\mathrm{c}}$ \\
\hline $\mathbf{A}$ & Wrol A & A. & $\frac{\mathrm{c}}{1.0}$ \\
\hline
\end{tabular}

Figura 6.22 - Pré-classificação da placa número 53 do segundo conjunto

Outro erro que ocorre, para ambos os métodos, deve-se à inversão de comportamento dos anéis de crescimento em algumas placas. Normalmente os anéis apresentam uma relação de presença de madeira mole e de madeira dura (mais escura) 
com predominância da madeira mole. Eventualmente surgem placas com essa relação invertida, ou seja, há maior presença de madeira dura do que madeira mole, como pode ser visto na figura 6.23 que mostra a placa 103 do segundo conjunto.

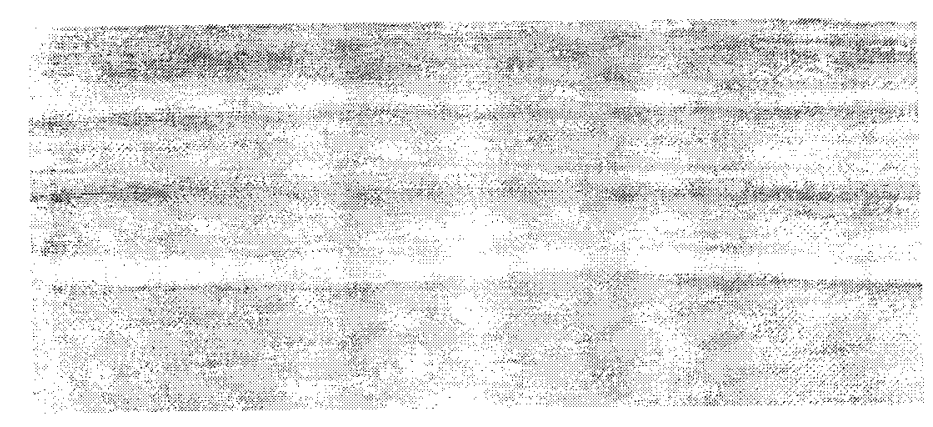

Figura 6.23 - Placa 103 do segundo conjunto, mostrando a inversão de relação da área dos anéis de crescimento

Como a quantidade de madeira dura é que basicamente determina a classe a ser atribuída, a placa da figura 6.23 deve ser considerada como pertencente à classe $X$, pois possui grande quantidade de madeira dura, entretanto, ambos os métodos atribuem classe C à mesma em função dos valores-característica encontrados na placa apresentarem o mesmo comportamento de uma placa de classe C, ou seja, uma placa que corresponda ao "negativo" da placa da figura 6.23.

\section{6 - CONSIDERAÇÕES FINAIS}

Neste capitulo apresentou-se a forma como os limites de decisão utilizados nos algoritmos foram extraídos, assim como, mostrou-se também o comportamento dos valores-característica para os dois conjuntos de placas de madeira utilizados neste trabalho.

Os critérios utilizados na combinação dos valores-característica no estágio de pré-classificação, como também os próprios valores, mostraram-se suficientemente 
capazes de atribuir classes às regiões das placas de uma forma consistente, traduzindo com bastante fidelidade a aparência visual das superfícies das mesmas.

Foram mostrados também neste capítulo, os resultados da aplicação dos dois métodos de classificação final, comparando-os através do teste estatístico nãoparamétrico $\chi^{2}$, com classificações realizadas por técnicos especialistas no assunto.

O teste de significância das diferenças apresentado, mostrou que mesmo com as pequenas discordâncias de classificação observadas na tabela B.1 do anexo B, as classificações dos métodos podem ser aceitas dentro de uma margem de acerto bastante segura.

Outra razão da existência das discordâncias dos resultados dos métodos, é que os mesmos tomam uma combinação entre as classes atribuídas às duas faces da placa como resultado final de classificação, admitindo sempre a pior das duas classificações como classe resultante, não permitindo uma interpretação mais maleável como ocorre com os inspetores.

Os erros de classificação inerentes aos métodos mostraram-se bastante reduzidos, conforme pode-se observar nas análises de coincidências de classificação, concentrando-se apenas nos exemplos citados no item 6.5 . 


\section{Capítulo 7}

\section{Contribuições, trabalhos futuros e conclusões finais}

\subsection{CONTRIBUIÇÕES}

Apresenta-se como uma das contribuições deste trabalho, a metodologia de extração e análise de características de imagens em nível de cinza. Está baseada em uma nova interpretação dos resultados obtidos através da aplicação de um método automático de limiar que utiliza a entropia de Shannon [Shannon, 1948]. Nessa interpretação, o valor da entropia total do método de limiar automático empregado, combinado com seu comportamento amostral e também com o valor de limiar encontrado onde a entropia é máxima, mostrou ser eficiente como critério de decisão.

Como outra contribuição que este trabalho traz, a sugestão de classificação apresentada no capítulo 4 deve ser observada, pois através da interpretação das características visuais das placas de madeira, analisando a relação direta existente entre a apresentação dos anéis de crescimento e a posição de corte que origina suas diversas 
distribuições superficiais, foi possível definir as cinco classes propostas, denominadas $A, B, C, D$ e $X$

A divisão das placas em regiões, como descrita no trabalho, oferece possibilidades de interpretações particulares para cada placa, pois como as regiões são rotuladas, é possivel estabelecer algoritmos que realizem interpretações em cada linha que represente a região de um lápis. Por exemplo, uma placa que apresente uma, duas ou três linhas nas extremidades da placa com excesso de madeira dura, e o restante das linhas não, pode ser classificada como placa aproveitável após reprocesso, e ser assim posteriormente selecionada em classes que não possuam madeira dura.

Contribuição também se apresenta na proposta do procedimento simples de classificação baseado em regras, descrita em duas partes. A primeira parte realiza uma pré-classificação, distribuindo rótulos de classe à todas as regiões da placa, com base nos valores-característica extraídos. $\mathrm{Na}$ segunda parte do procedimento foram propostas duas soluções que se equipararam quanto aos resultados de classificação. Uma por redução de informação, utilizando regras de combinação entre as classes e outra utilizando regras de simplificação sobre a matriz de co-ocorrência uni-direcional, para que uma classe final fosse atribuída às placas.

Como combinação dessas contribuições, apresentou-se uma metodologia completa e original, para classificação de placas de madeira utilizadas na fabricação de lápis, com todo o procedimento idealizado objetivando sua implementação em arquiteturas sistólicas. 


\subsection{TRABALHOS FUTUROS}

Com a proposta da metodologia apresentada neste trabalho, surgem oportunidades para a continuação das pesquisas.

Uma delas é o trabalho com imagens coloridas das placas. Como o presente trabalho baseou-se em imagens em níveis de cinza, abre-se a oportunidade de confrontação dos resultados obtidos por ambos.

Se o objetivo for melhorar os índices de coincidências apresentados pela metodologia deste trabalho, talvez abandonando ligeiramente o objetivo "velocidade", poderia-se incluir estágios de extração de outras características, por exemplo algumas das propostas por Haralick et al. [Haralick, 1973].

Outro trabalho futuro, que o autor deste trabalho pretende realizar, é a implementação em hardware da metodologia proposta, retomando os trabalhos do início do doutoramento. O avanço da tecnologia de "hardware" para processamento em geral ( sinais, imagens, voz, etc...), oferece cada vez mais a oportunidade da construção de sistemas dedicados altamente velozes. Explorando adequadamente as características inerentes em cada área de atuação e combinando com as novas tecnologias em "hardware" (como por exemplo as FPGAs - "Field Programmable Gate Arrays"), a literatura tem mostrado ser possível a confecção de sistemas eficientes e rápidos. Um exemplo dessa combinação pode ser visto em Rodrigues \& Roda [Rodrigues, 1996], onde o tempo de processamento de um sistema de determinação de limiar dinâmico por avaliação de bordas em imagens, é reduzido significativamente através da exploração da combinação do paralelismo intrínseco às imagens e a tendência natural em ser veloz que os arranjos sistólicos apresentam. Ainda, quando é possível a implementação de 
algoritmos simples para solucionar o problema em questão, atinge-se a situação ideal para a realização de sistemas que operem em tempo real. Dessa forma, utilizando "hardware" adequado a alta velocidade de processamento (FPGAs e DSPs -"Digital Signal Processing"), o objetivo "velocidade" (quantas placas por minuto) poderá ser explorado efetivamente.

\subsection{CONCLUSÕES FINAIS}

O sistema de inspeção visual proposto neste trabalho, alcançou resultados altamente satisfatórios, considerando as restrições impostas a ele: operar com imagens em níveis de cinza adquiridas com sistema comercial comum e basear-se somente nas características extraídas do método de limiar entrópico.

A metodologia apresentada neste trabalho, propôs uma classificação que atua diretamente na etapa número 3 da figura 3.1 (capítulo 3 - processo de produção do lápis), onde são selecionadas as placas para os diversos tipos de produtos finais, desde placas para fabricação de lápis mais "finos", até placas de madeira para fabricação de lápis que tolerem bem a presença de madeira mais dura, ou seja, lápis mais "rústicos".

Mostrou-se através da análise de publicações voltadas à automatização do processamento de madeira, que a preocupação de grande parte dos autores está centrada na detecção/classificação dos "defeitos" em madeira (não propriamente madeira para fabricação de lápis), localizando também em que etapa poderiam ser utilizados na produção de lápis. 
Também procurou-se esclarecer durante o trabalho que a classificação não ocorre com base em defeitos, mas sim em caracteristicas que apresentam comportamentos altamente aleatórios (presença e disposição dos anéis de crescimento).

Deve-se ressaltar a relevância deste trabalho, pois a metodologia aqui proposta atuaria com eficiência nas empresas produtoras de lápis. Comprovou-se pelos resultados de comparação apresentados no capítulo 6, que os métodos propostos operam de forma semelhante aos inspetores humanos, com vantagens indiscutíveis como repetibilidade, padronização de produto, estabelecimento de critérios mais sólidos para o controle de qualidade, etc...

Enfatizando a aplicabilidade que esta metodologia encontra, só como ilustração, uma empresa do porte da Faber Castell - São Carlos, tem sua produção diária estimada em alguns milhões de lápis por dia, demandando boa quantidade de inspetores para a realização das tarefas de inspeção, sujeitos às complicações de saúde que toda tarefa repetitiva oferece. 


\section{Anexo A}

\section{Limiarização \\ ("Thresholding")}

Este apêndice apresenta um levantamento bastante amplo de técnicas de limiarização, atualizando o trabalho anterior de Sahoo et al. [Sahoo, 1988], através da citação de novos métodos e a retirada de alguns, que foram incorporados por outros métodos ou mesmo caíram na obsolescência.

Não fazem parte deste apêndice os métodos de limiarização que operam em imagens coloridas e também aqueles que utilizam redes neurais. O motivo disso é que esses métodos normalmente consomem mais tempo por possuirem algoritmos mais complexos.

\section{A.1. Introdução}

Em processamento de imagens, freqüentemente é necessário extrair objetos de uma imagem e representá-los eficientemente. $O$ método mais utilizado para identificar regiões homogêneas diferentes de uma imagem, é o método de limiarização em níveis de cinza (também conhecido como binarização). Os resultados podem ser aplicados em reconhecimento automático de alvo, realce de texto, aplicações industriais de visão computacional, análise de imagens biomédicas, etc... De maneira a avaliar os valores de limiar, vários métodos vem sendo propostos, tanto paramétricos quanto nãoparamétricos. No procedimento paramétrico, a complexidade computacional é elevada, e além disso, o desvio entre o histograma de uma imagem e do modelo assumido, geralmente leva a resultados com baixos desempenhos. Já nos procedimentos nãoparamétricos, os valores de limiar são determinados de uma forma ótima e baseados em algum dado critério, e tem-se mostrado nos resultados que são mais robustos e mais precisos que os paramétricos.

Uma desvantagem da técnica de limiarização é que não existe um método simples que possa ser universalmente aplicado de modo a produzir bons resultados para toda as situações, portanto, é necessário determinar qual algoritmo é apropriado para os dados a serem analisados, sendo freqüentemente necessário utilizar e comparar um bom número desses métodos antes da escolha do melhor para o caso particular. 
Tomemos $N$ como o conjunto dos números naturais, $(x, y)$ como coordenadas espaciais de uma imagem digitalizada, e $G=\{0,1, \ldots, l-1\}$ o conjunto dos inteiros positivos representando os níveis de cinza. Então, uma função imagem pode ser definida como o mapeamento $f: N \times N \rightarrow G$. O brilho (isto é, o nível de cinza) de um "pixel" com coordenadas $(x, y)$ é denotado como $f(x, y)$.

Façamos $t \in G$ ser um limiar e $B=\left\{b_{0}, b_{1}\right\}$ ser um par de níveis de cinza binário e $b_{0}, b_{1} \in G$. O resultado de aplicar um limiar em uma função imagem $f(x, y)$ a um nível $t$ é uma função imagem binária $f_{t}: N \times N \rightarrow B$, tal que

$$
f(x, y)=\left\{\begin{array}{l}
b_{0} s e(x, y)\langle t \\
b_{1} \operatorname{sef}(x, y) \geq t
\end{array}\right.
$$

Para que a apresentação dos métodos se faça com certa ordem, abaixo temos algumas definições que são aceitas pela maioria, se não pela totalidade, dos autores de artigos relacionados com limiarização, segmentação, reconstrução, etc...

Em geral, um método de limiarização é aquele que determina o valor $t^{*}$ (valor ótimo) de $t$ baseado em algum critério. Se $t^{*}$ é determinado somente do nível de cinza de cada "pixel", então o método de limiarização é dito dependente de ponto (ou pontodependente). Se $t^{*}$ é determinado das propriedades locais de vizinhança (isto é, da distribuição local dos níveis de cinza), então o método de limiarização é dito dependente de região (ou região-dependente). Técnica de limiarização global é aquela que aplica um único valor de limiar para toda a imagem, ao passo que a técnica de limiarização local é aquela que particiona uma dada imagem em sub-imagens e determina um valor de limiar para cada uma destas sub-imagens.

Com isso posto, os métodos serão apresentados agrupados conforme as definições acima descritas, com exceção feita aos métodos entrópicos, os quais serão agrupados no final.

Seja $n_{i}$ o número de "pixels" com nível de cinza $i$. Então o número total de "pixels" em uma dada imagem é:

$$
n=\sum_{i=0}^{l-1} n_{i}
$$

A probabilidade de ocorrência do nível de cinza $i$ é definida como:

$$
p_{i}=\frac{n_{i}}{n}
$$

\section{A.2. LIMIARIZAÇÃO GLOBAL : TÉCNICAS PONTO-DEPENDENTES}

\section{A.2.1. Método p-tile}

Trata-se de um dos métodos mais antigos de limiarização. Assumindo que uma imagem contenha objeto escuro sobre um fundo branco e que uma porcentagem da área do objeto seja conhecida, o limiar é definido como o maior nível de cinza que mapeie ao menos $(100-p) \%$ de "pixels" do objeto na imagem binarizada. Por exemplo, suponha que um objeto ocupe $20 \%$ de uma imagem, então a imagem deverá ser submetida a um 
valor de limiar que represente o nível de cinza mais alto de modo a permitir que pelo menos $20 \%$ dos "pixels" sejam mapeados no objeto. Claramente este método não pode ser aplicado em imagens onde a área do objeto é desconhecida, tratando-se então de um método pouco utilizado.

\section{A.2.2. Método de Otsu}

Este método é baseado em análise discriminante, como proposto em [Otsu, 1979]. Neste método, a operação de limiar é considerada como o particionamento dos "pixels" de uma imagem em duas classes $C_{0}$ e $C_{I}$ (isto é, objeto e fundo) a um nível de cinza $t$, onde $C_{0}=\{0,1, \ldots, t\}$ e $C_{I}=\{t+1, t+2, \ldots, l-1\}$. Tomam-se $\sigma_{w}^{2}, \sigma_{B}^{2}$ e $\sigma_{T}^{2}$ como variância dentro da classe, variância entre classes e variância total, respectivamente. $O$ valor de limiar ótimo pode ser determinado pela minimização de uma das seguintes funções critério (são equivalentes) com relação a $t$ :

$$
\lambda=\frac{\sigma_{B}^{2}}{\sigma_{W}^{2}}, \quad \eta=\frac{\sigma_{B}^{2}}{\sigma_{T}^{2}} \quad \text { e } \quad k=\frac{\sigma_{T}^{2}}{\sigma_{W}^{2}}
$$

Das três funções critério acima, $\eta$ é a mais simples. Daí, o limiar ótimo $t^{*}$ é:

$$
t^{*}=\arg \underset{t \in G}{\operatorname{Min}} \eta
$$

onde

$$
\begin{aligned}
& \sigma_{T}^{2}=\sum_{i=0}^{l-1}\left(i-\mu_{T}\right)^{2} p_{i}, \quad \mu_{T}=\sum_{i=0}^{l-1} i p_{i}, \\
& \sigma_{B}^{2}=\omega_{0} \omega_{1}\left(\mu_{0} \mu_{1}\right)^{2}, \quad \omega_{0}=\sum_{i=0}^{t} p_{i}, \quad \omega_{1}=1-\omega_{0}, \\
& \mu_{1}=\frac{\mu_{T}-\mu_{t}}{1-\omega_{0}}, \quad \mu_{0}=\frac{\mu_{t}}{\omega_{0}}, \quad \mu_{t}=\sum_{i=0}^{t} i p_{i}
\end{aligned}
$$

\section{A.2.3. Método da análise de concavidade em histogramas}

Para imagens com objeto e fundo distintos é possível selecionar o valor de limiar do histograma de níveis de cinza utilizando o método da moda. Para algumas imagens onde os vales não podem ser encontrados em seu histograma, freqüentemente é possível definir um bom limiar no "ombro" do mesmo, pois este "ombro" também corresponde à concavidade no histograma [Rosenfeld, 1983].

Tomemos $H S$ como um histograma definido sobre um conjunto de níveis de cinza $g_{0}, g_{1}, \ldots, g_{l-1}$, e a altura do histograma nestes níveis de cinza como $h\left(g_{0}\right), h\left(g_{1}\right), \ldots$, $h\left(g_{l-1}\right)$, onde $h\left(g_{i}\right) \neq 0$ para todo $i$. Daí, $H S$ pode ser considerado como uma região bidimensional.

Para determinar a concavidade de $H S$, é construída sua "casca convexa". É o menor polígono convexo $\overrightarrow{H S}$ que contém $H S$. As concavidades de $H S$ são determinadas de um conjunto teórico diferença $H S-\overline{H S}$. Tomemos $\bar{h}\left(g_{i}\right)$ como a altura de $\overline{H S}$ no nível de cinza $g_{i}$. Possíveis valores de limiar são níveis de cinza aos quais $\bar{h}\left(g_{i}\right)$ $h\left(g_{i}\right)$ possui um máximo local. Entretanto, nem todos esses máximos locais são bons 
candidatos para limiarização porque largas concavidades podem ser também introduzidas por picos formados por ruídos. Rosenfeld \& De La Torre [Rosenfeld, 1983], chamaram estas concavidades de "espúrias". De maneira a eliminar máximos causados por concavidades espúrias, uma medida de balanço é introduzida:

$$
E_{i}=\left\{\sum_{j=g_{0}}^{g_{i-1}} h(j)\right\}\left\{\sum_{j=g_{i}}^{g_{l-1}} h(j)\right\}
$$

$E_{i}$ mede o balanço do histograma com respeito ao nível de cinza $g_{i}$. Para concavidades espúrias, as quais usualmente consistem somente em um lado do histograma, o valor de $E_{i}$ será pequeno. Daí, concavidades espúrias podem ser eliminadas ignorando máximos de $\bar{h}$ - $h$ quando $E_{i}$ é pequeno. Os máximos restantes indicam possíveis locais para limiarização, mas eles podem não ser ótimos. Outros níveis de cinza próximos a estes máximos também podem ser considerados para possíveis melhoramentos.

\section{A.2.4. Método de preservação de momento}

Neste método [Tsai, 1985], os valores de limiar são computados deterministicamente de tal modo que os momentos de uma imagem a ser submetida a um valor de limiar são preservados na imagem de saída (binária). O i-ésimo momento $m_{i}$ é calculado como:

$$
m_{i}=\frac{1}{n} \sum_{g=0}^{l-1} g^{i} h(g), \quad i=1,2,3,
$$

onde $n$ é o número total de "pixels" na imagem. O valor de limiar $t^{*}$ é obtido do histograma de níveis de cinza da imagem escolhendo-se $t^{*}$ como o " $p_{0}$-tile", onde $p_{0}$ é dado por:

$$
p_{0}=\frac{z-m_{1}}{\left(c_{1}^{2}-4 c_{0}\right)^{1 / 2}}
$$

e

$$
\begin{gathered}
c_{0}=\frac{m_{1} m_{3}-m_{2}^{2}}{m_{2}-m_{1}^{2}}, \quad c_{1}=\frac{m_{1} m_{2}-m_{3}}{m_{2}-m_{1}^{2}}, \\
z=\frac{1}{2}\left\{\left(c_{1}^{2}-4 c_{0}\right)^{1 / 2}-c_{1}\right\} .
\end{gathered}
$$

\section{A.2.5. Método do erro mínimo}

No método do erro mínimo [Kittler, 1986], o histograma de níveis de cinza é visto como uma estimativa da função densidade de probabilidade $p(g)$, da mistura de população compreendida de níveis de cinza dos "pixels" de objeto e fundo. Assume-se normalmente que cada um dos dois componentes $p(g / i)$ da mistura, é normalmente distribuído com média $\mu_{\mathrm{i}}$, desvio padrão $\sigma_{\mathrm{i}}$ e probabilidade a priori $\mathrm{P}_{\mathrm{i}}$, isto é:

$$
p(g)=\sum_{i=1}^{2} P_{i} p(g / i),
$$

onde 


$$
p(g / i)=\frac{1}{\sqrt{2 \pi} \sigma_{i}} \exp \left(-\frac{\left(g-\mu_{i}\right)}{2 \sigma_{i}^{2}}\right)
$$

O valor de limiar pode ser selecionado através da solução da equação quadrática:

$$
\frac{\left(g-\mu_{i}\right)^{2}}{\sigma_{1}^{2}}+\log _{e} \sigma_{1}^{2}-2 \log _{e} P_{1}=\frac{\left(g-\mu_{2}\right)^{2}}{\sigma_{2}^{2}}+\log _{e} \sigma_{2}^{2}-2 \log _{e} P_{2}
$$

Entretanto, os parâmetros $\mu_{i}, \sigma_{i}^{2}$ e $P_{i}(i=1,2)$ da densidade de mistura $p(g)$ associada a uma imagem a ser submetida a um valor de limiar, não são usualmente conhecidos. Para superar esta dificuldade de estimativa destes parâmetros desconhecidos, Kittler \& Illingworth [Kittler, 1986] introduziram uma função critério $J(t)$, a qual é dada por:

$$
J(t)=1+2\left\{P_{1}(t) \log _{e} \sigma_{1}(t)+P_{2}(t) \log _{e} \sigma_{2}(t)\right\}-2\left\{P_{1}(t) \log _{e} P_{1}(t)+P_{2}(t) \log _{e} P_{2}(t)\right\}
$$

onde

$$
\begin{aligned}
& P_{1}(t)=\sum_{g=0}^{t} h(g), \quad P_{2}(t)=\sum_{g=t+1}^{l-1} h(g), \\
& \mu_{1}(t)=\frac{\left\{\sum_{g=0}^{t} h(g) g\right\}}{P_{1}(t)}, \quad \mu_{2}(t)=\frac{\left\{\sum_{g=t+1}^{l-1} h(g) g\right\}}{P_{1}(t)}, \\
& \sigma_{1}^{2}(t)=\frac{\left\{\sum_{g=0}^{t}\left(g-\mu_{1}(t)\right)^{2} h(g)\right\}}{P_{1}(t)} \quad \mathrm{e} \quad \sigma_{2}^{2}(t)=\frac{\left\{\sum_{g=t+1}^{l-1}\left(g-\mu_{2}(t)\right)^{2} h(g)\right\}}{P_{1}(t)}
\end{aligned}
$$

O limiar ótimo é obtido pela minimização de $J(t)$, ou seja, encontrando:

$$
t^{*}=\arg \underset{t \in G}{\operatorname{Min}} J(t)
$$

\section{A.3. LIMIARIZAÇÃO GLOBAL : TÉCNICAS REGIÃO-DEPENDENTES}

\section{A.3.1. Métodos de transformação de histograma}

Os métodos descritos aqui não selecionam um limiar diretamente. Antes, eles transformam o histograma de níveis de cinza de uma imagem em histogramas com vales profundos e picos salientes, de maneira que a busca passa a ser pelo nível de cinza de menor freqüência dentro do vale, para então ser determinado o valor de limiar. Também, este método assume que cada uma das imagens consideradas consistem de objeto e fundo, ambos possuindo uma distribuição de níveis de cinza unimodal. 
Mason et al. apud [Kapur, 1985] propuseram o uso de um operador de bordas (Laplaciano, Robert, etc...) para pesagem. De acordo com seu método, os valores de um operador de bordas são pequenos para "pixels" em regiões homogêneas e estes "pixels" são dados com mais peso. Entretanto, os valores de um operador de bordas são grandes para "pixels" na vizinhança de uma borda e estes "pixels" são dados com menor peso. $\mathrm{O}$ peso pode ser computado como $1 /\left(1+\Delta^{2}\right)$, onde $\Delta$ é o valor de borda em um dado "pixel". Como um resultado deste processo de pesagem, o novo histograma de níveis de cinza possuirá picos agudos e vales profundos.

Katz apud [Kapur, 1985] mostrou que desde que os "pixels" na vizinhança de uma borda possuem altos valores de borda, o histograma de níveis de cinza para estes "pixels" devem possuir um simples pico localizado no nível de cinza entre os níveis de cinza do objeto e do fundo. Este nível de cinza é portanto, uma escolha adequada para um valor de limiar.

\section{A.3.2. Métodos baseados em estatísticas de níveis de cinza de segunda ordem}

Uma das desvantagens dos métodos de limiarização ponto-dependentes, é que eles dependem somente da estatística dos níveis de cinza de primeira ordem (dos histogramas) da imagem. Os métodos que serão descritos aqui são baseados em estatísticas de níveis de cinza de segunda ordem.

\section{A.3.2.1. Método da matriz de co-ocorrência}

A matriz de co-ocorrência foi introduzida por Haralick et al. [Haralick, 1973] para análise de textura. Em geral, uma matriz de co-ocorrência $M_{(d, \phi)}$ é aquela cujas entradas são freqüências relativas para dois "pixels" vizinhos com níveis de cinza $i$ e $j$, separados por uma distância $d$ e com orientação $\phi$. Obviamente, o número de matrizes pode ser grande, dependendo da escolha de $d$ e de $\phi$. Ahuja \& Rosenfeld [Ahuja, 1978], definiram a matriz de co-ocorrência como:

$$
M=M_{(1,0)}+M_{(1, \pi / 2)}+M_{(1, \pi)}+M_{(1,3 \pi / 2)}
$$

isto é, o elemento $(i, j)$ de $M$ é a freqüência que ocorre o nível de cinza $i$ considerando vizinhança de quatro do nível de cinza $j$.

Devido à homogeneidade, os "pixels" do interior do objeto ou do fundo devem contribuir principalmente para as entrajas próximas à diagonal de $M$. Também, "pixels" próximos a uma borda devem contribuir principalmente para as entradas fora da diagonal de $M$ devido à mudança do nível de cinza próximo a uma borda. Portanto, a matriz $M$ pode ser usada para definir dois novos histogramas:

a - Um histograma baseado nas entradas próximas à diagonal de $M$. Este deve possuir um vale profundo entre os níveis de objeto e fundo.

b - Um histograma baseado nas entradas fore da diagonal de $M$. Este deve possuir um pico pronunciado entre os níveis de cinza do objeto e fundo.

Um valor de limiar para a imagem pode então ser escolhido em uma faixa de níveis de cinza na qual o vale em (a) sobreponha-se ao pico em (b). 


\section{A.3.3. Método de Deravi e Pal}

Neste método [Deravi, 1983], matrizes de transição similares à matriz de coocorrência são utilizadas para definir duas "medidas de interação" para seleção de limiar. O valor de limiar ótimo é determinado pela minimização dessas medidas de interação.

Tomando a mesma notação usada para o método da matriz de co-ocorrência, as matrizes de transição definidas em [Deravi, 1983] podem ser escritas como:

$$
\begin{aligned}
& T_{h}=M_{(1,0)} \\
& T_{v}=M_{(1,3 \pi / 2)} \\
& T_{v h}=T_{v}+T_{h}
\end{aligned}
$$

Qualquer das matrizes de transição acima podem ser utilizadas na seleção de limiar. Os resultados obtidos com diferentes matrizes de transição não diferem significativamente.

Tomemos $T_{i j}$ como a entrada $(i, j)$ de $T$ e $t$ como o valor de limiar que divide o conjunto de níveis de cinza em duas classes: $C_{0}=\{0,1, \ldots, t\}$ e $C_{1}=\{t+1, t+2, \ldots, l-1\}$. Então $T$ pode ser particionado em quatro regiões definidas pelos seguintes parâmetros:

$$
\begin{array}{ll}
a=\sum_{i=0}^{t} \sum_{j=0}^{t} T_{i j} & b=\sum_{i=t+1}^{l-1} \sum_{j=t+1}^{l-1} T_{i j} \\
c=\sum_{i=0}^{t} \sum_{j=t+1}^{l-1} T_{i j} & d=\sum_{i=t+1}^{l-1} \sum_{j=0}^{t} T_{i j}
\end{array}
$$

Deste modo $a, b, c$ e $d$ representam o número total de transições dentro de $C_{0}$, dentro de $C_{1}$, de $C_{0}$ para $C_{1}$ e de $C_{1}$ para $C_{0}$, respectivamente. As probabilidades de associação e condicional da transição entre $C_{0}$ e $C_{1}$ podem ser estimadas por:

$$
\begin{aligned}
& P_{j}(t)=\frac{c+d}{a+b+c+d} \\
& P_{c}(t)=\frac{1}{2}\left\{\frac{c}{a+c}+\frac{d}{b+d}\right\}
\end{aligned}
$$

Deravi \& Pal [Deravi, 1983] chamaram $P_{j}(t)$ e $P_{c}(t)$ como medidas de interação. Eles também apontaram que $P_{j}(t)$ é similar a "medida de negócios" em [Weszka, 1978] e que $P_{c}(t)$ não depende diretamente do histograma. $O$ valor ótimo de limiar, $t^{*}$, é obtido pela maximização de uma das medidas de interação descritas.

\section{A.3.4. Método de relaxamento de gradiente}

Em relaxamento de gradiente, o esquema de rotulação ótimo é determinado pela maximização de uma função critério com otimização de gradiente.

Tomando-se $\lambda_{1}$ e $\lambda_{2}$ como os rótulos das classes de "pixels" claros e escuros, $\left\{\left[p_{i}\left(\lambda_{1}\right), p_{i}\left(\lambda_{2}\right)\right]^{\mathrm{T}}, i=0,1, \ldots, l-1\right\}$ como o conjunto de vetores probabilidade associado com os níveis de cinza e $\left\{\left[q_{i}\left(\lambda_{1}\right), q_{i}\left(\lambda_{2}\right)\right]^{\mathrm{T}}, i=0,1, \ldots, l-1\right\}$ como o conjunto de vetores 
probabilidade, onde $q_{i}\left(\lambda_{k}\right)=\frac{1}{8} \sum_{x_{j} \in N_{i}} p_{j}\left(\lambda_{k}\right), N_{i}$ são os 8 vizinhos do "pixel" $x_{i}$. Bhanu \&

Feugeras [Bhanu, 1982] sugeriram que o esquema de rotulação ótima para imagem com distribuição de níveis de cinza unimodal pode ser determinado pela maximização de:

$$
\begin{gathered}
C(p)=\sum_{i=0}^{l-1} p_{i}^{T}(\lambda) q_{i}(\lambda), \text { sujeito a } \\
p_{i}(\lambda) \in K=\left\{p(\lambda)=\left(p\left(\lambda_{1}\right), p\left(\lambda_{2}\right)\right) \mid p\left(\lambda_{j}\right) \geq 0, \sum_{j=1}^{2} p\left(\lambda_{j}\right)=1\right\}
\end{gathered}
$$

Eles concluíram que a maximização de $C(p)$ é equivalente a redução de inconsistência e ambigüidade da rotulação de "pixel".

É sugerido um método similar que usa uma função critério diferente, derivada da teoria de informação. Neste método o esquema de rotulação ótima é determinado pela maximização de:

$$
\begin{aligned}
& \Psi(p)=\sum_{i=0}^{l-1} I\left(p_{i}, q_{i}\right), \text { sujeito a } \\
& p_{i} \in K .
\end{aligned}
$$

A quantidade $I\left(p_{i}, q_{i}\right)$ é definida como:

$$
I\left(p_{i}, q_{i}\right)=\sum_{j=1}^{2} p_{i}\left(\lambda_{j}\right) \log _{e}\left(\frac{p_{i}\left(\lambda_{j}\right)}{q_{i}\left(\lambda_{j}\right)}\right)
$$

\section{A.3.5. Método baseado em características de fronteira}

Gonzales \& Woods [Gonzales, 1993] descrevem este método o qual faz a seleção de limiar baseado em características de fronteira. Um procedimento para melhorar a forma dos histogramas é considerar somente aqueles "pixels" que pertencem ou estão próximos à fronteira entre objeto e fundo. Os histogramas devem ser menos dependentes dos tamanhos relativos do objeto e do fundo.

Analisando um histograma de intensidades de uma imagem composta por uma área de fundo grande e um objeto pequeno, o mesmo seria dominado por um grande pico devido à alta concentração de "pixels" do fundo. Mas, se somente os "pixels" próximos à fronteira entre objeto e fundo forem utilizados, o histograma resultante possuirá picos com alturas aproximadas. Ainda, a probabilidade desses "pixels" pertencerem ao objeto é a mesma deles pertencerem ao fundo, melhorando portanto a simetria do histograma. Finalmente, utilizando "pixels" que satisfaçam algumas medidas simples baseadas em operadores gradiente e Laplaciano, a tendência é que o vale entre picos no histograma seja aprofundado.

$O$ problema principal desse procedimento, é que seria necessário o conhecimento prévio da localização das fronteiras entre objeto e fundo, e isso é exatamente o que se espera que um método de segmentação encontre. Entretanto, a informação de que se um "pixel" pertence a uma borda, pode ser obtida computando-se seu gradiente. Somado a isso, o uso do Laplaciano pode fornecer informação se um dado "pixel" pertence ao lado escuro (fundo) ou ao lado claro (objeto) de uma borda. Como o valor médio do Laplaciano é 0 (zero) na transição de uma borda, na prática pode-se esperar que os vales dos histogramas formados dos "pixels" selecionados por um critério gradiente/Laplaciano sejam pouco populosos. 
O gradiente $\nabla f$ em qualquer ponto $(\mathrm{x}, \mathrm{y})$ em uma imagem é dado por:

$$
\begin{aligned}
& \nabla f=\operatorname{mag}(\nabla f)=\left[G_{x}^{2}+G_{y}^{2}\right]^{1 / 2} \\
& \nabla f \approx\left|G_{x}\right|+\left|G_{y}\right|
\end{aligned}
$$

Considerando uma implementação em uma região $3 \times 3$, a forma mais encontrada do Laplaciano $\nabla^{2} f$ é dado por:

$$
\nabla^{2} f=4 z_{5}-\left(z_{2}+z_{4}+z_{6}+z_{8}\right)
$$

conforme a distribuição posicional abaixo:

\begin{tabular}{|l|l|l|}
\hline$z_{1}$ & $z_{2}$ & $z_{3}$ \\
\hline$z_{4}$ & $z_{5}$ & $z_{6}$ \\
\hline$z_{7}$ & $z_{8}$ & $z_{9}$ \\
\hline
\end{tabular}

Das duas equações acima, é definido então um critério para estabelecer um valor de limiar para cada ponto $(\mathrm{x}, \mathrm{y})$ que pode ocupar três níveis:

$$
s(x, y)=\left\{\begin{array}{lllll}
0 & \text { se } & \nabla f<T \\
+ & \text { se } & \nabla f \geq T & \text { e } & \nabla^{2} f \geq 0 \\
- & \text { se } & \nabla f \geq T & \text { e } & \nabla^{2} f<0
\end{array}\right.
$$

onde os símbolos " $0,+\mathrm{e}$-" representam quaisquer três níveis de cinza distintos.

\section{A.3.6. Método baseado em avaliação local e global de bordas}

Venkatesh \& Rosin [Venkatesh, 1995] apresentaram um trabalho utilizando o método de avaliação de bordas, cujo procedimento baseia-se na coerência de bordas locais, incorporando os critérios Continuidade e Espessura de borda. Este método leva em consideração o contexto de espaço em que um determinado "pixel" se encontra. Com a maximização dos resultados da medida de avaliação, torna-se possível a determinação de valores de limiar ótimos por região, pois o resultado produzido pela avaliação é uma matriz de coeficientes que combinam os dois critérios citados anteriormente, em valores que vão de zero, para bordas mal formadas, até 1 para aquelas bem formadas. Para calcular a Continuidade, são tomadas duas funções , $L(k)$ e $R(k)$, as quais medem a continuidade do "pixel" em avaliação, com seus vizinhos à esquerda e direita respectivamente.

$$
\begin{aligned}
& L(k)=\left\{\begin{array}{l}
A(d c, d k) \times A\left(\frac{\pi k}{4}, d c+\frac{\pi}{2}\right), \text { se o vizinho k e' pixel de borda } \\
0, \text { de outra forma }
\end{array}\right. \\
& R(k)=\left\{\begin{array}{l}
A(d c, d k) \times A\left(\frac{\pi k}{4}, d c-\frac{\pi}{2}\right), \text { se o vizinho ke' pixel de borda } \\
0, \text { de ourra forma }
\end{array}\right.
\end{aligned}
$$

sendo $d c$ a direção gradiente do "pixel" central e $d k$ a direção gradiente dos "pixels" vizinhos, e ainda a discrepância angular dada por $A(\alpha, \beta)=(\pi-|\alpha-\beta|) / \pi$ que mede a diferença absoluta entre dois ângulos $\alpha$ e $\beta$, variando de zero até $\pi$.

A medida de continuidade de toda a vizinhança é calculada por:

$$
C=\frac{1}{2}(\max \{L(i)\}+\max \{R(i)\})
$$


A Espessura ( $\mathrm{T}$ ) é calculada como a fração dos "pixels" restantes, os quais não são "pixels" de borda.

Por fim, a medida de avaliação de borda é computada usando uma combinação linear dos dois critérios conforme a equação:

$$
E=\gamma C+(1-\gamma) T
$$

Também apresentaram um método para limiar automático, utilizando uma avaliação global de bordas, a qual está baseada na avaliação de listas de bordas conectadas. São analisadas curvas considerando um espaço bi-dimensional, tendo como dimensões a média das magnitudes e o comprimento das lista de bordas. Estas curvas, representam distribuições as quais são analisadas pelo teorema do limite central, através da média, variância e desvios absolutos médios (MAD) que é análogo ao desvio padrão de uma distribuição Gaussiana. Como a maioria da população em uma distribuição Gaussiana reside dentro de $3 \sigma$, este equivalente não-paramétrico deve valer $\alpha \mathrm{MAD}$, com $\alpha=6$ de maneira que $\alpha$ MAD seja aproximadamente equivalente a $4 \sigma$.

Então, com auxílio de análise gráfica, considerando que o comprimento é denotado por $(l$ e $L)$ e a magnitude por ( $m$ e $M)$, chegaram a duas equações de decisão, que são equivalentes:

$$
\begin{aligned}
& \text { "limiar } r_{1}(1, \mathrm{~m})=\left\{\begin{array}{lc}
\text { aceita }- \text { se } & m-M_{M}+a M A D_{M}\left(\frac{1}{M_{M}+a M A D_{M}}-1\right)>0 \\
\text { rejeita }- & \text { de outra maneira }
\end{array}\right. \\
& \text { "limiar }_{2} "(1, \mathrm{~m})=\left\{\begin{array}{lc}
\text { aceita }- \text { se } & m-M_{M}+a M A D_{M}\left(\frac{1}{2\left(M_{L}+a M A D_{L}\right)}-1\right)>0 \\
\text { rejeita }- & \text { de outra maneira }
\end{array}\right.
\end{aligned}
$$

\section{A.3.7. Outros Métodos}

Técnicas de limiarização para sistemas de reconhecimento ótico de caracteres tem também recebido muita atenção. Devido a grande faixa de distorção de qualidade de impressão sobre um documento simples, é freqüentemente utilizada uma combinação de operadores de limiar, com cada operador sensivel a um diferente tipo de distorção.

Ullmann [Ullman, 1974], seleciona o limiar de "pixel" $X$ baseado nos níveis de cinza em uma janela $5 \times 5, W$, de $X$. Somente os "pixels" que estão rotulados com $n$ contribuem para a decisão de limiar. 


\begin{tabular}{|l|l|l|l|l|}
\hline$o$ & $n$ & $n$ & $n$ & $o$ \\
\hline$n$ & $n$ & $o$ & $n$ & $n$ \\
\hline$n$ & $o$ & $X$ & $o$ & $n$ \\
\hline$n$ & $n$ & $o$ & $n$ & $n$ \\
\hline$o$ & $n$ & $n$ & $n$ & $o$ \\
\hline
\end{tabular}

Fig. A.1 - Janela 5x5 usado por Ullmann [Ullman, 1974]

Duas regras experimentais são usadas para determinar o valor de limiar de $X$. Tome $n_{X}$ como o nivel de cinza mais alto em $X$. Então, a regra (1) é aplicada se $n_{X} \leq 40 \mathrm{e}$ a regra (2) quando $n_{X}>40$. As duas regras são:

(1) - Rotule $X$ como um ponto de objeto se para algum ponto $n$ em $W, g(X)$ $g(n)<\tau$, onde $g(\cdot)$ significa o nível de cinza de $(\cdot)$ e $\tau$ é algum valor pré-definido de limiar; de outra maneira rotule-o como um ponto de fundo.

(2) - Rotule $X$ como um ponto de objeto se para ao menos um $n$ em $W, g(X)<$ $g(n) / \mu$, onde $\mu$ é alguma constante pré-definida; de outra maneira rotule-o como um ponto de fundo.

Morrin [Morrin, 1974] colocou em um gráfico, nível de cinza versus valor de gradiente para converter imagens em escala de cinza com resolução e contraste superiores para limiarização.

\section{A.4. LIMIARIZAÇÃO LOCAL.}

Em limiarização local, a imagem original é particionada em pequenas subimagens e um valor de limiar é determinado para cada sub-imagem. Isto fornece uma imagem após limiar com descontinuidades em níveis de cinza nas fronteiras de duas diferentes sub-imagens. $\mathrm{O}$ valor de limiar de uma região pode ser determinado pelo método de dependência de ponto ou pelo método de dependência de região. Uma técnica de suavização é então aplicada para eliminar as descontinuidades.

Chow e Kaneko [Chow, 1972] sugeriram o uso de uma janela $7 \times 7$ para limiarização local. Em seu método, a imagem original é dividida em sub-imagens de tamanho $7 \mathrm{x} 7$ e um valor de limiar é computado para cada sub-imagem. Entretanto, para sub-imagens com histograma de níveis de cinza unimodal, não é possível aplicar qualquer valor de limiar com sucesso total. Os valores de limiar para estas sub-imagens são encontrados através de interpolação dos valores das sub-imagens vizinhas. Para uma sub-imagem bimodal, o valor de limiar é computado como segue. Primeiro o histograma de níveis de cinza de uma sub-imagem é aproximado por uma soma de duas distribuições Gaussianas, então o valor de limiar é obtido através da minimização do erro de classificação com respeito ao valor de limiar.

\section{A.5. MÉTODOS DE MULTI-LIMIARIZAÇÃO}

Muitos métodos de limiarização global, como Otsu [Otsu, 1979], Pun [Pun, 1980], [Pun, 1981], Kapur et al. [Kapur, 1985], preservação de momento [Tsai,1985] e 
erro mínimo [Kittler, 1986] podem ser estendidos para o caso de multi-limiarização. Nesta seção serão discutidos métodos de multi-limiarização os quais não estão incluídos nas seções anteriores.

\section{A.5.1. Método de segmentação de amplitude}

Este método foi proposto por Boukharouba et al. [Boukharouba, 1985] e usa as propriedades intrínsecas da função distribuição acumulativa de uma imagem, a ser submetida a um valor de limiar. Neste método, a curvatura da função distribuição é examinada para obter informações considerando os valores de limiar. A função distribuição $\mathrm{F}(\mathrm{k})$ no ponto $\mathrm{k}$ é dada por:

$$
F(k)=\frac{\sum_{g=0}^{k} h(g)}{\sum_{g=0}^{l-1} h(g)}
$$

A curvatura de F é então definida por:

$$
C(x)=F^{\prime \prime}(x)\left[1+\left(F^{\prime}(x)\right)^{2}\right]^{-3 / 2}
$$

onde $F^{\prime}$ e $F^{\prime \prime}$ são a primeira e segunda derivadas de $F$, respectivamente. É colocado em [Boukharouba, 1985] que $C(x)$ é ruidosa e oscilatória e deve ser suavizada e aproximada para uso em limiarização. Os zeros da curvatura determinam os valores de limiar assim como o nível de cinza para cada classe.

\section{A.5.2. Método de Wang e Haralick}

Esta é uma técnica recursiva [Wang, 1984] para seleção de múltiplos valores de limiar. Neste método, os "pixels" são primeiro classificados como "pixels" de borda e "pixels" não pertencentes à borda. Os "pixels" de borda são então classificados, baseado em sua vizinhança, como sendo relativamente escuros ou relativamente claros. Um histograma de níveis de cinza é obtido dos "pixels" os quais são "pixels" de borda e relativamente escuros, e outro histograma é obtido daqueles "pixels" os quais não são "pixels" de borda e relativamente claros. Um limiar é selecionado baseado nos valores de intensidade de níveis de cinza correspondendo a um dos picos mais altos dos dois histogramas. Para obter múltiplos limiares, o procedimento é recursivamente aplicado utilizando primeiro apenas aqueles "pixels" cujas intensidades são menores que o limiar e depois utilizando somente aqueles "pixels" cujas intensidades são maiores que o limiar.

\section{A.5.3. Método do contraste uniforme}

Este é um método recursivo de seleção de limiar proposto por Kohler [Kohler, 1981]. O método é baseado na seguinte idéia. O limiar ótimo para segmentação da 
imagem é aquele que detecta mais bordas de alto contraste e poucas bordas de baixo contraste que qualquer outro limiar. Neste método, é criado um histograma do contraste médio $\mu(t)$ para cada possível limiar $t$ e o mais alto pico no histograma corresponde ao limiar ótimo. $O$ contraste médio $\mu(t)$ é calculado da relação:

$$
\mu(t)=\frac{C(t)}{N(t)}
$$

com $\mu(t)=0$ se $N(t)=0, C(t)$ sendo o contraste total detectado pelo limiar $t$, e $N(t)$ sendo o número de bordas encontradas por $t$. Para multi-limiarização é selecionado qualquer limiar inicial e então um novo histograma de $\mu(t)$ é computado removendo-se a contribuição de todas as bordas já detectadas pelo limiar inicial. Este procedimento é continuado até que o máximo contraste médio para qualquer limiar caia abaixo de algum mínimo critério de contraste médio $\theta>1$.

\section{A.5.4. Método utilizando a máxima correlação}

Este método [Yen, 1995] é proposto para seleção de valores de limiar em multiníveis. Dois fatores são considerados: a discrepância entre as imagens original e após limiarização, e o número de bits necessários para representar a imagem após limiarização. Baseados no critério de máxima correlação para limiarização em dois níveis, os autores definem a discrepância e então é proposta uma função-custo que leva em consideração os dois fatores citados, função esta que deverá ser minimizada para determinação automática dos valores para limiarização em multi-níveis.

Adotando $X$ como uma variável aleatória discreta com faixa finita $R=\left\{x_{0}, x_{1}\right.$, $\left.x_{2}, \ldots\right\}$ e $p_{i}$ denotando $\operatorname{Prob}\left\{X=x_{i}\right\}$. A correlação de $X$ é definida como:

$$
C(X)=-\ln \sum_{i \geq 0} p_{i}^{2}
$$

Os autores defendem o uso da correlação em lugar da entropia, pois a complexidade computacional envolvida é muito menor.

Desenvolvida então a equação que determina o valor de limiar $s$ através da correlação, chega-se a:

$$
\begin{aligned}
T C(s) & =C_{A}(s)+C_{B}(s) \\
& =-\ln \left[G(s) \times G^{\prime}(s)\right]+2 \ln [P(s) \times(1-P(s))]
\end{aligned}
$$

onde

$$
G(s)=\sum_{i=0}^{s-1} p_{i}^{2} \quad \text { e } \quad G^{\prime}(s)=\sum_{i=s}^{m-1} p_{i}^{2}
$$

com $m$ representando o número de níveis de cinza utilizados na imagem. $\operatorname{de} s^{*}:$

O critério da máxima correlação é então maximizado de maneira a obter o valor

$$
T C\left(s^{*}\right)=\max _{s \in G_{m}} T C(s)
$$

Sabe-se que a imagem após limiarização torna-se mais similar à imagem original conforme cresce o "número de classificação" que os níveis de cinza podem ser classificados. Consequentemente, a discrepância entre as imagens original e após limiarização, diminui conforme o número de classificação cresce. Entretanto, o número total de bits necessários para representar a imagem após limiarização cresce conforme o 
número de classes também cresce. Portanto deve existir um compromisso entre estes dois fatores.

Sendo $k$ o número de classificação e $D i s(k)$ a discrepância entre as imagens original e após limiarização, a função custo $C(\bullet)$ que considera ambos os fatores, é proposta como:

$$
C(k)=\rho(\operatorname{Dis}(k))^{1 / 2}+(\ln (k))^{1 / 2}
$$

onde $\rho$ é uma constante de peso. O primeiro termo de $C(k)$ mede o custo devido à discrepância entre as imagens original e após limiarização, e o segundo termo mede o custo resultado do número de bits utilizados para representar a imagem após limiarização.

Com base na função custo $C(k)$, o critério de limiarização automático é então proposto para determinar o número ótimo de classificação $k^{*}$ tal que:

$$
C\left(k^{*}\right)=\min _{k \in G_{m}^{+}} C(k)
$$

onde $G_{m}^{+} \equiv\{1,2, \ldots, m\}$.

A discrepância entre as imagens original e após limiarização é:

$$
\begin{aligned}
\operatorname{Dis}(k) & =\sum_{j=1}^{k} \operatorname{Pr} o b\left(C_{k, j}\right) \times \sigma_{k, j}^{2} \\
& =\sum_{i=0}^{s_{k, 1}-1}\left(i-\mu_{k, 1}\right)^{2} \times p_{i}+\sum_{i=s_{k, 1}}^{s_{k, 2}-1}\left(i-\mu_{k, 2}\right)^{2} \times p_{i}+\ldots+\sum_{i=s_{k, k-1}}^{m-1}\left(i-\mu_{k, k}\right)^{2} \times p_{i}
\end{aligned}
$$

onde

$k$ número de classificação que os níveis de cinza são classificados,

$s_{k, i} \quad$ o i-ésimo limiar não zero quando os níveis de cinza são classificados em $k$ classes,

$C_{k, i}$ a i-ésima classe entre as $k$ classes com níveis de cinza de $s_{k, i-1}$ a $\left(s_{k, i}-1\right)$,

$\omega_{k, i}$ a probabilidade da classe $C_{k, i}$,

$P_{k, i} \quad$ a distribuição derivada de $C_{k, i}$ depois de normalizada por $\omega_{k, i}$,

$\mu_{k, i}$ a média de $P_{k, i}$,

$\sigma_{k, i}^{2} \quad$ a variância de $P_{k, i}$

Consequentemente, para uma dada distribuição $P \equiv\left\{p_{i} \mid i \in G_{m}\right\}$, as seguintes relações podem ser obtidas:

$$
\begin{array}{rlrl}
\omega_{k, i}=\operatorname{Pr} o b\left(C_{k, i}\right)=\sum_{j=s_{k, j-1}}^{s_{k, j}-1} p_{j} & P_{k, i} & =\left\{p_{j} / \omega_{k, i} \mid j \in G_{s_{k, j}}\right. \\
\mu_{k, i}=\sum_{j=s_{k, j-1}}^{s_{k, j}-1} j \times \operatorname{Pr} o b\left(j \mid C_{k, i}\right) & =\sum_{j=s_{k, t-1}}^{s_{k, j}-1}\left(j-\mu_{k, i}\right)^{2} \times \operatorname{Pr} o b\left(j \mid C_{k, i}\right) \\
& =\sum_{j=s_{k, j-1}}^{s_{k, j}-1}\left(j-\mu_{k, i}\right)^{2} \times p_{j} / \omega_{k, i}
\end{array}
$$

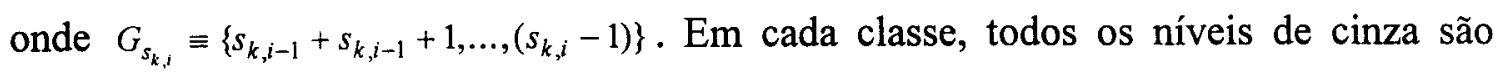
relacionados ao valor médio de níveis de cinza daquela classe.

No artigo, são apresentados resultados comparativos aos resultados do método utilizando o critério da máxima entropia, ressaltando o bom desempenho do método proposto, sobretudo relativo à redução de operações matemáticas e conseqüente redução no tempo de computação. 


\section{A.5.5. Método utilizando a variância de inter-classes}

Um método rápido de busca é apresentado [Reddi, 1984] para encontrar limiares (k) simples e múltiplos que maximizam a variância de inter-classe entre regiões escuras e claras. A formulação original do problema feita por Otsu [Otsu, 1979], sugere uma busca exaustiva. Segundo os autores, este procedimento possui taxas de convergência muito rápidas e requer de 6 a 20 interações para encontrar os limiares ótimos para a maioria dos casos.

A variância de inter-classes entre as regiões pode ser reduzida a: $\sigma^{2}(k)=p_{D} m_{D}^{2}+p_{B} m_{B}^{2}-m_{0}^{2}$

$\mathrm{O}$ limiar ótimo $\mathrm{k}^{*}$ é selecionado pela maximização de $\sigma^{2}(\mathrm{k})$, onde

$$
\begin{array}{ll}
p_{D}=\int_{0}^{k} p(x) d x & p_{B}=\int_{k}^{\infty} p(x) d x \\
p_{D} m_{D}=\int_{b}^{k} x p(x) d x & p_{B} m_{B}=\int_{k}^{\infty} x p(x) d x \\
m_{0}=p_{D} m_{D}+p_{B} m_{B} &
\end{array}
$$

$\mathrm{P}_{\mathrm{D}} \quad$ Probabilidade de "pixel" escuro cujo valor é menor que $\mathrm{k}$.

$\mathrm{P}_{\mathrm{B}} \quad$ Probabilidade de "pixel" claro cujo valor é maior que $\mathrm{k}$.

$\mathrm{m}_{\mathrm{D}}$ Média dos "pixels" escuros.

$\mathrm{m}_{\mathrm{B}} \quad$ Média dos "pixels" claros.

$\mathrm{m}_{0} \quad$ Média total.

$\sigma^{2}(\mathrm{k})$ Variância de inter-classe para $\mathrm{k}$.

\section{A.6. MÉTODOS ENTRÓPICOS}

\section{A.6.1. Métodos de Pun}

Nesta subseção, serão discutidos dois algoritmos desenvolvidos por Thierry Pun [Pun, 1980] e [Pun, 1981].

Tomemos $t$ como o valor de limiar e definindo duas entropias a posteriori :

$$
\begin{aligned}
& H_{b}^{\prime}=-\sum_{i=0}^{t} p_{i} \log _{e} p_{i} \\
& H_{w}^{\prime}=-\sum_{i=t+1}^{l-1} p_{i} \log _{e} p_{i}
\end{aligned}
$$

onde $H_{b}^{\prime}$ e $H_{w}^{\prime}$ podem ser consideradas, respectivamente, como medidas de uma informação a posteriori associada aos "pixels" brancos $(w)$ e pretos $(b)$ depois de limiarização.

Conhecendo a entropia a priori do histograma de níveis de cinza, Pun [Pun, 1980] propôs um algoritmo para determinar o valor de limiar ótimo através da maximização da entropia a posteriori. 


$$
H^{\prime}=H_{b}^{\prime}+H_{w}^{\prime}
$$

Pun [Pun, 1980] mostrou que a maximização de $H^{\prime}$ é equivalente à maximização da função de avaliação $f(t)$ com relação a $t$ :

$$
f(t)=\frac{H_{t}}{H_{T}} \frac{\log _{e} P_{t}}{\log _{e} \max \left\{p_{0}, \ldots, p_{t}\right\}}+\left[1-\frac{H_{t}}{H_{T}}\right] \frac{\log _{e}\left(1-P_{t}\right)}{\log _{e} \max \left\{p_{t+1}, \ldots, p_{l-1}\right\}}
$$

onde,

$$
\begin{aligned}
& H_{t}=-\sum_{i=0}^{t} p_{i} \log _{e} p_{i} \\
& H_{T}=-\sum_{i=0}^{l-1} p_{i} \log _{e} p_{i} \\
& P_{t}=\sum_{i=0}^{t} p_{i}
\end{aligned}
$$

Em seu segundo algoritmo, Pun [Pun, 1981] propôs o uso de um coeficiente anisotrópico, $\alpha$, em limiarização, onde

e $m$ é o menor inteiro tal que :

$$
\alpha=\frac{\sum_{i=0}^{m} p_{i} \log _{e} p_{i}}{\sum_{i=0}^{l-1} p_{i} \log _{e} p_{i}}
$$

$$
\sum_{i=0}^{m} p_{i} \geq 0.5
$$

O valor de limiar ótimo $t^{*}$ é escolhido de maneira que:

$$
\sum_{i=0}^{t} p_{i}= \begin{cases}1-\alpha & \text { se } \alpha \leq 0.5 \\ \alpha & \text { se } \alpha>0.5\end{cases}
$$

Entretanto, Kapur et al. [Kapur, 1985] mostraram que este algoritmo sempre aplicará valores de limiar com $t^{*} \geq m$ em uma imagem, portanto introduzindo um desvio desnecessário.

\section{A.6.2. Método de Kapur, Sahoo e Wong}

Neste método [Kapur, 1985], duas distribuições de probabilidade ( distribuição do objeto e do fundo) são derivadas da distribuição original de níveis de cinza da imagem como segue:

$$
\frac{p_{0}}{P_{t}}, \frac{p_{1}}{P_{t}}, \ldots, \frac{p_{t}}{P_{t}}
$$

e

$$
\frac{p_{t+1}}{1-P_{t}}, \frac{p_{t+2}}{1-P_{t}}, \ldots, \frac{p_{l-1}}{1-P_{t}}
$$


onde t é o valor de limiar e $P_{t}=\sum_{i=0}^{t} p_{i}$, definem:

$$
\begin{aligned}
& H_{b}(t)=-\sum_{i=0}^{t} \frac{p_{i}}{P_{t}} \log _{e}\left(\frac{p_{i}}{P_{t}}\right), \\
& H_{w}(t)=-\sum_{i=t+1}^{l-1} \frac{p_{i}}{1-P_{t}} \log _{e}\left(\frac{p_{i}}{1-P_{t}}\right) .
\end{aligned}
$$

Então o limiar ótimo $t^{*}$ é definido como o nível de cinza o qual maximiza $H_{b}(t)+H_{w}(t)$, isto é:

$$
t^{*}=\arg \underset{t \in G}{\operatorname{Max}}\left\{H_{b}(t)+H_{w}(t)\right\}
$$

\section{A.6.3. Método de Johannsen e Bille}

O método de Johannsen \& Bille apud [Kapur, 1985] utiliza a entropia do histograma de níveis de cinza da imagem digital. Essencialmente, divide o conjunto de níveis de cinza em duas partes de maneira a minimizar a interdependência (no sentido teórico de informação) entre os mesmos. O valor de limiar $t^{*}$ é escolhido da relação:

$$
t^{*}=\arg \underset{t \in G}{\operatorname{Min}}\{S(t)+\bar{S}(t)\}
$$

onde

$$
S(t)=\log _{e}\left(\sum_{i=0}^{t} p_{i}\right)-\frac{1}{\sum_{i=0}^{t} p_{i}}\left[p_{t} \log _{e} p_{t}+\left(\sum_{i=0}^{t-1} p_{i}\right) \log _{e}\left(\sum_{i=0}^{t-1} p_{i}\right)\right]
$$

e

$$
\bar{S}(t)=\log _{e}\left(\sum_{i=t}^{l-1} p_{i}\right)-\frac{1}{\sum_{i=t}^{l-1} p_{i}}\left[p_{t} \log _{e} p_{t}+\left(\sum_{i=t+1}^{l-1} p_{i}\right) \log _{e}\left(\sum_{i=t+1}^{l-1} p_{i}\right)\right]
$$

\section{A.6.4. Método de Nikhil R. Pal e Sankar K. Pal}

Neste método [Pal, 1989], os autores definem a entropia de ordem $q$ (depende da informação contida em uma seqüência de níveis de cinza de comprimento $q$ ) e a entropia condicional de uma imagem. Sabendo que em uma imagem os "pixels" não são independentes uns dos outros, esta dependência pode ser incorporada considerando a seqüência $\left(s_{i}\right)$ de "pixels" para estimar a entropia.

$$
H^{(q)}=-\frac{1}{q} \sum_{i} p\left(s_{i}\right) \log _{e} p\left(s_{i}\right)
$$

A entropia local de primeira ordem corresponde à entropia global, como assumido por Pun [Pun, 1980], [Pun, 1981] e por Kapur et al. [Kapur, 1985]. Quando $q$ $\geq 2, H^{(q)}$ pode ser chamada de entropia local de ordem $q$ de uma imagem.

Definem também a entropia condicional do objeto $X$ dado o fundo $Y$, isto é, a quantidade média de informação que pode ser obtida de $X$ dado que tenha-se o conhecimento a respeito do fundo $Y$ : 


$$
H(X / Y)=-\sum_{x_{i} \in X} \sum_{y_{j} \in Y} p\left(x_{i} / y_{j}\right) \log _{e} p\left(x_{i} / y_{j}\right)
$$

Similarmente, a entropia condicional do fundo $Y$ dado o objeto $X$ :

$$
H(Y / X)=-\sum_{y_{j} \in Y} \sum_{x_{i} \in X} p\left(y_{i} / x_{j}\right) \log _{e} p\left(y_{i} / x_{j}\right)
$$

Daí a entropia condicional da imagem, pode ser definida como:

$$
H^{(C)}=(H(X / Y)+H(Y / X)) / 2
$$

Usando estas definições, são formulados e implementados dois algoritmos para limiarização de imagem (classificação de objeto-fundo) com o auxílio de sua matriz de co-ocorrência.

O algoritmo proposto pode ser estendido para o problema de "multilimiarização" usando o conceito da entropia condicional para mais de duas classes. Por exemplo, se $S_{R}=\left\{s_{1}, s_{2}, \ldots, s_{R}\right\}$ denota $R$ valores de limiares em uma imagem com $(R+1)$ regiões, então $S_{R}$ particiona a matriz de co-ocorrência da imagem em $(R+1) x$ $(\mathrm{R}+1)$ blocos.

\section{A.6.5. Método de Andrew K. C. Wong e P. K. Sahoo}

Este método [Wong, 1989] de seleção de limiar de nível de cinza é baseado no princípio da máxima entropia. Aplicando-se um valor de limiar $t$ em uma imagem, obtém-se uma imagem em dois níveis. A probabilidade a posteriori dos "pixels" com valores de cinza menores que $t$ é dada por:

$$
F(t)=\sum_{i=0}^{t} p_{i}
$$

Similarmente, a probabilidade a posteriori de todos os "pixels" com valores maiores ou iguais a $t$ é $1-F(t)$. Daí a entropia de Shannon de uma imagem em dois níveis é :

$$
H(F(T))=-F(T) \log _{2} F(T)-(1-F(T)) \log _{2}(1-F(T))
$$

O valor ótimo de limiar é determinado pela maximização da entropia $a$ posteriori sujeita a restrições de uniformidade e forma de regiões na imagem. Para este propósito, os autores usam a distribuição de níveis de cinza e a informação espacial da imagem:

- Uniformidade

$$
U(t)=1-\frac{\sigma_{1}^{2}+\sigma_{2}^{2}}{C_{1}}
$$

onde, $C_{l}$ é uma constante de normalização, daí,

$$
t_{1}=\arg \max _{t \in Z^{+},} U(t)
$$

- Forma, fornece informações considerando por exemplo as hordas de um objeto, pode ser construída da seguinte maneira:

- atribua um valor gradiente generalizado $\Delta(x, y)$ para todo "pixel" (x,y); 
- se o "pixel" (x,y) possui um valor de cinza maior que a média de seus vizinhos, então atribua o sinal de mais $(+)$ ao valor gradiente generalizado $\Delta(x, y)$, se não, atribua o valor menos;

- calcule a medida de forma $S$ utilizando a fórmula:

$S(t)=\frac{\sum_{(x, y)} \operatorname{sgn}\left(h(x, y)-\overline{h_{N(x, y)}}\right) \Delta(x, y) \operatorname{sgn}(h(x, y)-t)}{C_{2}}$

onde $\overline{h_{Y(x, y)}}$ é a média dos valores de cinza na vizinhança $N(x, y), t$ é o valor de threshold da imagem, $C_{2}$ é um fator positivo de normalização, e

$\operatorname{sgn}(x)=\left\{\begin{array}{rr}1, & \text { se } x>0 \\ -1, & \text { se } x<0\end{array}\right.$

O valor gradiente generalizado $\Delta(x, y)$ do "pixel" ( $\mathrm{x}, \mathrm{y})$ é calculado por:

$\Delta(x, y)=\left[\sum_{k=1}^{4} D_{k}^{2}+\sqrt{2} D_{1}\left(D_{3}+D_{4}\right)-\sqrt{2} D_{1}\left(D_{3}-D_{4}\right)\right]^{1 / 2}$

onde

$$
\begin{aligned}
& D_{1}=h(x+1, y)-h(x-1, y) \\
& D_{2}=h(x, y-1)-h(x, y+1) \\
& D_{3}=h(x+1, y+1)-h(x-1, y-1) \\
& D_{4}=h(x+1, y-1)-h(x-1, y+1)
\end{aligned}
$$

De acordo com a medida de forma $S$, se a imagem é segmentada ao nível de cinza $t_{2}$, tal que:

$$
t_{2}=\arg \max _{t \in Z^{+}} S(t)
$$

então a imagem obtida após limiarização, irá reter a quantidade máxima de informação considerando as bordas, pois a medida $S$ encoraja a segmentação dos "pixels" com alto valor de gradiente.

A combinação dessas duas medidas obedece o seguinte:

$$
\min \left(t_{1}, t_{2}\right) \leq t \leq \max \left(t_{1}, t_{2}\right)
$$

Depois de algumas considerações e de uma análise gráfica do comportamento da entropia contra a probabilidade $F(t)$, o limiar ótimo entrópico máximo $t^{*}$ pode ser obtido da seguinte equação:

$$
t^{*}= \begin{cases}\max \left(t_{1}, t_{2}\right), & \text { se } F\left(t_{1}\right), F\left(t_{2}\right) \in[0,0.5] \\ \min \left(t_{1}, t_{2}\right), & \text { se } F\left(t_{1}\right), F\left(t_{2}\right) \in[0.5,1] \\ t, & \text { se } F\left(t_{1}\right) \in[0,0.5], F\left(t_{2}\right) \in[0.5,1] \\ t, & \text { se } F\left(t_{2}\right) \in[0,0.5], F\left(t_{1}\right) \in[0.5,1]\end{cases}
$$

onde $t$ é um nível de cinza tal que $F(t)=0.5$.

Também propõem uma extensão deste método para imagens cromáticas.

\section{A.6.6. Método de Liang-Kai Huang e Mao-Jiun J. Wang}

Este método [Huang, 1995] é baseado no conceito de conjuntos "fuzzy", onde dado um certo valor de limiar, a função de pertinência de um "pixel" é definida pela 
diferença absoluta entre o nível de cinza e a média dos níveis de cinza da região a que o mesmo pertence.

$$
\begin{aligned}
\mu_{X}\left(x_{m n}\right) & =\frac{1}{1+\left|x_{m n}-\mu_{0}\right| / C} & & \text { se } x_{m n} \leq t \\
& =\frac{1}{1+\mid x_{m n}-\mu_{1} / C} & & \text { se } x_{m n}>t
\end{aligned}
$$

onde $X$ representa um conjunto imagem de tamanho $M x N$ com $L$ níveis, $x_{m n}$ é o nível de cinza de um "pixel" $(m, n)$ em $X, \mathrm{C}$ é um valor constante tal que $1 / 2 \leq \mu_{X}\left(x_{m n}\right) \leq 1, \mu_{0}$ indica a média dos níveis de cinza do fundo, $\mu_{l}$ a média dos níveis de cinza do objeto e $t$ o valor de limiar.

Também são propostas duas medidas de "fuzzyness" para indicar a "fuzzyness" de uma imagem, sendo que a medida de entropia usa a função de Shannon [Shannon, 1948] e a medida proposta por Yager que utiliza a distância entre um conjunto "fuzzy" e seu complemento. A entropia utilizada como uma medida de "fuzzyness" é análoga à entropia da teoria de informação:

$$
E(X)=\frac{1}{M N \ln 2} \sum_{g} S\left(\mu_{X}(g)\right) H(g),
$$

onde $g$ representa o nível de cinza de uma imagem de entrada com $g=0,1, \ldots, L-1$.

A medida proposta por Yager, é aquela que representa a distância entre um conjunto de imagem "fuzzy" $X$ e seu complemento $\bar{X}$ :

$$
D_{p}(X, \bar{X})=\left[\sum_{g}\left|\mu_{X}(g)-\mu_{\bar{X}}(g)\right|^{p}\right]^{1 / p} h(g), \quad p=1,2,3, \ldots
$$

onde $\mu_{\bar{X}}(g)=1-\mu_{X}(g)$ e a medida de "fuzzyness" de X é dada por:

$$
\eta_{p}(X)=1-\frac{D_{p}(X, \bar{X})}{|X|^{1 / p}}=1-\frac{D_{p}(X, \bar{X})}{(M N)^{1 / p}} .
$$
uma imagem.

O valor de limiar ótimo é determinado minimizando a medida de "fuzzyness" de multi-níveis.

No artigo é proposta também uma extensão do método para limiarização em

\section{A.6.7. Método de Ahmed S. Abutaleb}

Este método [Abutaleb, 1989] estende o algoritmo de limiarização baseado na entropia uni-dimensional, para a análise de um histograma bi-dimensional, considerando tanto o nível de cinza do "pixel" em questão quanto de sua vizinhança para gerar uma superficie de entropia. O pico determina o nível de cinza e a média dos níveis de cinza da vizinhança do valor de limiar. O vetor que maximiza a entropia bi-dimensional é utilizado como o limiar bi-dimensional. A função baseada na entropia é:

$$
\psi(s, t)=\ln \left[P_{s t}\left(1-P_{s t}\right)\right]+H_{s t} / P_{s t}+\left(H_{m m}-H_{s t}\right) /\left(1-P_{s t}\right)
$$

onde

$$
P_{s t}=-\sum_{i=1}^{s} \sum_{j=1}^{t} p_{i j} \quad p_{i j}=\frac{f_{i j}}{N^{2}} \quad i \text { e } j=1, \ldots, m
$$




$$
H_{s t}=-\sum_{i=1}^{s} \sum_{j=1}^{t} p_{i j} \ln \left(p_{i j}\right) \quad H_{m m}=-\sum_{i=1}^{m} \sum_{j=1}^{m t} p_{i j} \ln \left(p_{i j}\right)
$$

com $m$ valores de níveis de cinza, freqüência do par $(i, j) f_{i j}$ e o número total de "pixels" $N^{2}$. Dessa maneira, o algoritmo procura pelo para de valores $(s, t)$, os quais maximizando a função $\psi(s, t)$, permitem a localização do valor de limiar ótimo.

\section{A.6.8. Método de Ian Hannah, Devesh Patel e Roy Davies}

Este método [Hannah, 1995] foi aplicado como parte de um projeto de reconhecimento automático de objetos estranhos (vidro, madeira, borracha, metal, etc..) em imagens de produtos alimentícios. Os autores comparam os resultados com os métodos propostos por Otsu [Otsu, 1979] e também os propostos por Kapur et al. [Kapur, 1985].

Na verdade, o método proposto é uma modificação de interpretação do método de Kapur et al. [Kapur, 1985], e processa valores de limiar simples ou duplos, dependendo da informação caracterizada pela medida de entropia. Analisando apenas o histograma das imagens, não é possivel identificar se existem ou não objetos estranhos na mesma, pois a contribuição desses no histograma é desprezível. Como a medida de entropia tem seu comportamento conhecido, analisando seu gráfico, os autores perceberam claramente que a presença de objetos estranhos produz picos alternativos no gráfico de medida de entropia, os quais podem ser detectados adequadamente. Propuseram então um algoritmo para busca destes picos alternativos, dependentes de dois fatores: a largura do pico e a altura do mesmo comparada com valores adjacentes.

\section{A.6.9. Método de M. Fleury. L. Hayat e A. F. Clarck}

Neste método [Fleury, 1996] é aplicado um algoritmo de limiarização multinível, o qual utiliza a função de entropia-"fuzzy" do histograma da imagem combinada com outras técnicas para obtenção de um padrão de limiar. Este método entrópico é dividido em três partes: busca de pico, lógica "fuzzy" e busca da entropia-"fuzzy" mínima. Para uma dada largura de banda "fuzzy", os níveis de cinza da imagem são transladados em saídas "fuzzy" depois da aplicação de uma transformação não linear. A entropia das saídas "fuzzy" é computada através da entropia de Shannon [Shannon, 1948], compondo assim a medida de entropia-"fuzzy", que é dada por:

$$
H_{f u z z y}(H)=\frac{1}{n \ln 2} \sum_{i=1}^{n} \operatorname{Sn}\left(\mu_{H}\left(g_{i}\right)\right) h_{i}
$$

onde $\operatorname{Sn}(x)$ é a função de Shannon, $H$ é o histograma da imagem, com $n$ níveis de cinza dentro de uma região $g_{i}$ e com $h_{i}$ "pixels" no $i$-ésimo vale do histograma, com:

$$
\mu(x)=S(x, a, b, c)=\left\{\begin{array}{cl}
0, & x \leq a \\
k\left(\frac{x-a}{c-a}\right)^{2}, & a \leq x \leq b, k=\frac{c-a}{b-a} \\
1-k\left(\frac{x-a}{c-a}\right)^{2}, & b \leq x \leq c, k=\frac{c-a}{c-b} \\
1, & x \geq c
\end{array}\right.
$$


Os autores implementaram o método em máquinas paralelas, onde puderam também implementá-lo em um algoritmo paralelo. Simplificadamente, a idéia é dividir a imagem em tiras iguais e distribui-las para $t$ tarefas. Cada tarefa realiza um histograma local de níveis de cinza, os quais são apropriadamente transferidos e combinados entre as tarefas, seguindo uma topologia pré-definida tanto para troca de resultados quanto para extração dos mesmos. Para avaliação dos resultados, são utilizadas medidas de uniformidade e forma. Nas próprias conclusões dos autores, fica claro que trata-se de um algoritmo com tempo computacional elevado para máquinas seqüenciais, pois o método é composto por procedimentos como suavização de histograma, método de corte de picos pouco expressivos, busca de pico e método de seleção de uma largura de banda adequada, os quais consomem considerável tempo de computação em função do tamanho das imagens.

\section{A.6.10. Métodos baseados em "cross-entropy"}

Dentre os métodos que utilizam entropia para determinação de valores de limiar, um deles é o que utiliza a medida de divergência simétrica de Kullback [Kullback, 1959], também referenciada como "cross-entropy". É uma medida não métrica que tem sido implementada nos últimos anos por diferentes autores para obtenção de limiar ótimo, sob certas restrições. Nikhil R. Pal [Pal, 1996] contesta o desenvolvimento conceitual realizado por Li \& Lee [Li, 1993], e propõe um método de minimização da "cross-entropy" baseado em um modelo de distribuição de Poisson. Enquanto Brink \& Pendock [Brink, 1996], constroem suas restrições baseados em médias de níveis de cinza das regiões abaixo e acima de um valor de limiar.

\section{A.6.10.1. Método de Nikhil R. Pal}

Li \& Lee [Li, 1993] propuseram usar a divergência dirigida ("cross-entropy) de Kullback [Kullback, 1959] para seleção de limiar. Embora eles tenham usado uma expressão similar em estrutura à "cross-entropy" de Kullback, a função objetivo utilizada por [Li, 1993], não pode ser chamada de divergência. São propostos alguns métodos [Pal, 1996] baseados na verdadeira divergência simétrica ou "cross-entropy".

Kullback [Kullback, 1959] propôs uma distância teórica de informação $D$ entre duas distribuições de probabilidades. Esta distância teórica de informação é conhecida como divergência dirigida ou "cross-entropy". Tomemos $P=\left\{p_{l}, p_{2}, \ldots, p_{n}\right\}$ e $Q=\left\{q_{l}\right.$, $\left.q_{2}, \ldots, q_{n}\right\}$ como duas distribuições de probabilidades, então a "cross-entropy", $D(P, Q)$ é definida por;

$$
D(P, Q)=\sum_{i=1}^{n} p_{i} \log \frac{p_{i}}{q_{i}}
$$

Desde que $\sum_{i=1}^{n} p_{i}=\sum_{i=1}^{n} q_{i}=1$, a desigualdade de Gibbs (isto é, $-\sum p_{i} \log p_{i} \leq-\sum p_{i} \log q_{i}$ ) assecrura que $D(P, Q) \geq 0$ e a igualdade mantém-se somente se $p_{i}=q_{i} \forall_{\mathrm{i}}=1,2, \ldots, \mathrm{n}$. Claramente $D(P, Q)$ não é simétrica, ou seja, $D(P, Q) \neq D(Q, P)$.

Uma versão simétrica pode ser escrita como:

$$
D_{s}(P, Q)=D(P, Q)+D(Q, P)
$$


Tome $F=[f(x, y)]_{M x N}$ como uma imagem digital com $L$ níveis, $f(x, y) \in\{1,2, \ldots, L\}-$ o conjunto de níveis de cinza. Tome $h_{i}$ como a freqüência do nível de cinza $i$ e $p_{i}=h_{i} /$ $(\mathrm{MxN})$ como a probabilidade de ocorrência do nível de cinza $i$.

Suponha $s$ um assumido valor de limiar. O valor $s$ particiona a imagem em duas regiões, objeto e fundo. Nós assumimos valores de cinza em $[0-s]$ constituindo a região de objeto, enquanto aqueles em [ $(s+1)-\mathrm{L}]$ constituindo o fundo. Li \& Lee [Li, 1993] consideraram $[0-(s-1)]$ para região de objeto, enquanto $[s-L]$ como a região de fundo, mas isso realmente não importa. Li \& Lee [Li, 1993] definiram a "cross-entropy" de uma imagem segmentada com limiar $s$ como:

onde

$$
\eta(s)=\sum_{j=1}^{s} j h_{j} \log \left(\frac{j}{\mu_{1}(s)}\right)+\sum_{j=s+1}^{L} j h_{j} \log \left(\frac{j}{\mu_{2}(s)}\right),
$$

$$
\mu_{1}(s)=\sum_{j=1}^{s}\left(j h_{j}\right) / \sum_{j=1}^{s} h_{j} \quad \text { e } \quad \mu_{2}(s)=\sum_{j=s+1}^{L}\left(j h_{j}\right) / \sum_{j=s+1}^{L} h_{j}
$$

Eles enfatizaram a restrição de conservação de intensidade, ou seja, a soma dos níveis de cinza na imagem original deve ser igual à soma dos valores de cinza na partição correspondente da imagem segmentada. Esta restrição não parece ser importante para um algoritmo de segmentação. Isto pode somente ajudar na comparação visual da saída segmentada com a imagem original. Para propósito de segmentação, realmente não importa como as regiões segmentadas estão coloridas. Ainda, a equação (A3) não pode ser chamada de "cross-entropy".

A razão é que nem $P=\{1,2, \ldots s\}$ nem $Q=\left\{\mu_{1}(s), \mu_{l}(s), \ldots, \mu_{l}(s)\right\}$ podem ser chamadas ou interpretadas como uma distribuição de probabilidades.

Conceitualmente $P=\{1,2, \ldots s\}$ não pode ter uma interpretação probabilística pois é uma coleção de valores de cinza. Matematicamente, também ela não pode ser chamada de uma distribuição de probabilidades, exceto para o primeiro, pois todos os outros valores são maiores que a unidade. "Cross-entropy" (também conhecida como divergência) é um tipo de distância teórica de informação entre duas distribuições de probabilidades.

Portanto, o método proposto por Li \& Lee [Li, 1993] não pode ser chamado de "minimum cross-entropy thresholding". Entretanto, isto não significa que a equação (A3) não seja um bom critério para limiarização. De fato, ele é na verdade um critério razoável de segmentação.

A equação (A1) é assimétrica; usaremos a versão simétrica:

$$
D_{s}(P, Q)=\sum_{i=1} p_{i} \log \frac{p_{i}}{q_{i}}+\sum_{i=1} q_{i} \log \frac{q_{i}}{p_{i}}
$$

Tomemos $s$ como o valor de limiar para segmentação. Então a distribuição de probabilidade observada de um nível de cinza na região de objeto pode ser definida como: onde

$$
P_{O}=\left\{p_{1}^{o}, p_{2}^{o}, \ldots, p_{s}^{o}\right\} \text { e aquela da região de fundo como, } P_{B}=\left\{p_{s+1}^{B}, p_{s+2}^{B}, \ldots, p_{L}^{B}\right\},
$$

$$
\begin{aligned}
& p_{i}^{o}=\frac{h_{i}}{P_{s}}, \quad i=1,2, \ldots, s ; \quad P_{s}=\sum_{i=1}^{s} h_{i} ; \\
& p_{i}^{B}=\frac{h_{i}}{M N-P_{s}}, \quad i=s+1, s+2, \ldots, L
\end{aligned}
$$


Note que $\sum_{i=1}^{s} p_{i}^{o}=\sum_{i=s+1}^{L} p_{i}^{B}=1$.

Tomemos $Q_{O}$ e $Q_{B}$ como as distribuições de probabilidades das regiões de objeto e fundo, respectivamente, baseado em algum modelo. Em outras palavras. $Q_{O}=\left\{q_{1}^{o}, q_{2}^{o}, \ldots, q_{s}^{o}\right\}$ e $Q_{B}=\left\{q_{s+1}^{B}, q_{s+2}^{B}, \ldots, q_{L}^{B}\right\}$ são as distribuições de probabilidades estimadas baseadas em algum modelo.

Agora a "cross-entropy" da região de objeto é $D_{O}(s)=D_{s}\left(P_{o}, Q_{o}\right)$ e que da região de fundo é $D_{B}(s)=D_{s}\left(P_{B}, Q_{B}\right)$. A "cross-entropy" total da imagem segmentada pode então ser escrita como:

$$
D(s)=D_{O}(s)+D_{B}(s)=\sum_{i=1}^{s} p_{i}^{o} \log \left(\frac{p_{i}^{o}}{q_{i}^{o}}\right)+\sum_{i=1}^{s} q_{i}^{o} \log \left(\frac{q_{i}^{o}}{p_{i}^{o}}\right)+\sum_{i=s+1}^{L} p_{i}^{B} \log \left(\frac{p_{i}^{B}}{q_{i}^{B}}\right)+\sum_{i=s+1}^{L} q_{i}^{B} \log \left(\frac{q_{i}^{B}}{p_{i}^{B}}\right) \text { (A7) }
$$

De maneira a segmentar uma imagem, minimiza-se $D(s)$ com relação à $s$. Entretanto, para usar a equação (A7) é necessário obter $Q_{O}$ e $Q_{B}$.

O histograma de nível de cinza freqüentemente é modelado como uma mistura de distribuições normais. Recentemente estabeleceu-se que histogramas de imagens são mais apropriadamente modelados por uma mistura de distribuição de Poisson. O modelamento de histogramas em níveis de cinza por uma mistura de Poisson, foi derivado da teoria de formação de imagens. Considera-se aqui o modelo de Poisson para estimar $Q_{O}$ e $Q_{B}$. Assume-se que o valor de cinza na região de objeto segue a distribuição de Poisson com o parâmetro $\lambda_{O}$ e o nível de cinza na região de fundo segue a distribuição de Poisson com o parâmetro $\lambda_{B}$. Daí:

$$
q_{i}^{o}=\frac{e^{-\lambda_{o}} \lambda_{O}^{i}}{i !}, \quad \mathrm{i}=1,2, \ldots \mathrm{s}
$$

e

$$
q_{i}^{B}=\frac{e^{-\lambda_{B}} \lambda_{B}^{i}}{i !}, \quad \mathrm{i}=\mathrm{s}+1, \mathrm{~s}+2, \ldots \mathrm{L} ;
$$

onde $\lambda_{O}$ e $\lambda_{B}$ podem ser estimados como:

$$
\lambda_{O}=\frac{\sum_{i=1}^{s} i h_{i}}{\sum_{i=1}^{s} h_{i}}, \quad(\mathbf{A 1 0}), \mathrm{e} \quad \lambda_{B}=\frac{\sum_{i=s+1}^{L} i h_{i}}{\sum_{i=s+1}^{L} h_{i}}
$$

Portanto os algoritmos para limiarização tornam-se:

\section{Algoritmo 1}

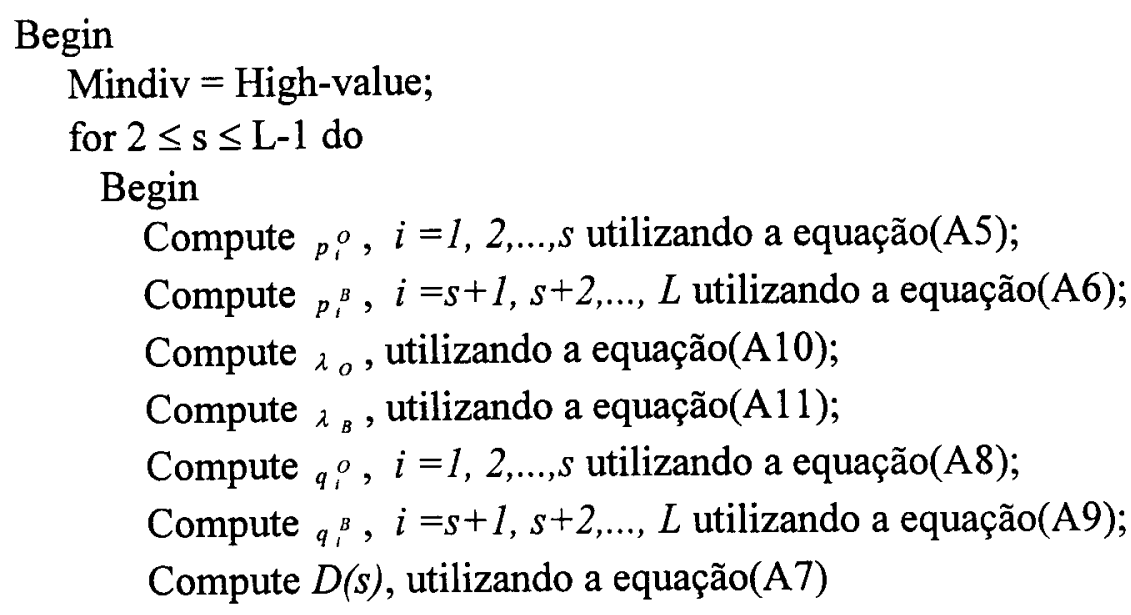




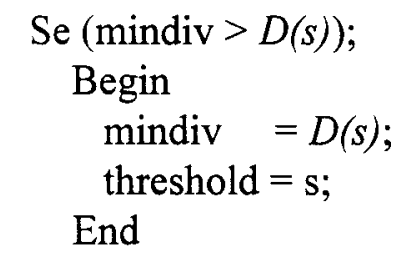

End

End.

No algoritmo 1, a desigualdade de Gibbs pode não ser satisfeita por $Q_{O}$ e $Q_{B}$, isto é, pode não ser verdade que $\sum_{i=1}^{s} q_{i}^{o}=\sum_{i=s+1}^{L} q_{i}^{B}=1$. De maneira a satisfazer a desigualdade de Gibbs, normaliza-se $Q_{O}$ e $Q_{B}$. $\mathrm{O}$ algoritmo revisado pode ser escrito como:

\section{Algoritmo 2}

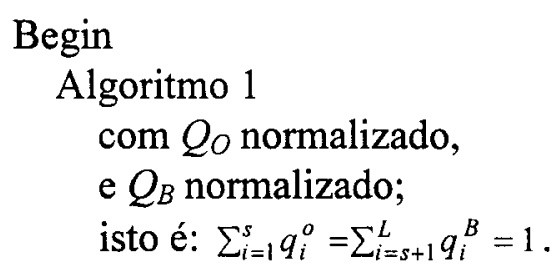

End.

Baseados na "cross-entropy" de Kullback [Kullback, 1959], Li \& Lee [Li, 1993] propuseram um método de limiarização o qual chamaram de "minimum cross-entropy limiarização". Foi mostrado porque tal método não pode ser chamado assim. Os autores reconhecem que o critério usado por Li \& Lee é razoável para segmentação. Foram propostos dois algoritmos baseados na "cross-entropy" (ou divergência simétrica de Kullback), os quais foram testados com sucesso.

\section{A.6.10.2. Método de A. D. Brink e N. E. Pendock}

O método utilizando a "cross-entropy" proposto pelos autores [Brink, 1996], é comparado com duas outras medidas, o coeficiente de correlação e a medida de Pearson $\chi^{2}$, que também são usadas para seleção automática de limiar.

A distância de "cross-entropy", sujeita a consistência de dados, entre uma distribuição de probabilidade a posteriori $q(x)$ e uma distribuição a priori $p(x)$ é definida como:

$$
H_{C E}(q, p)=\int q(x) \log \frac{q(x)}{p(x)} d x
$$

$H_{C E}$ é também algumas vezes referenciada como entropia relativa, número de KullbackLeibler, informação de discriminação ou divergência dirigida.

Para distribuição de probabilidade discreta (digital), substitui-se a integral por um somatório. A distância de a "cross-entropy" discreta entre $q_{x}$ e sua prévia $p_{x}$ é dada por:

$$
H_{C E}(q, p)=\sum_{x=1}^{N} q_{x} \log \frac{q_{x}}{p_{x}}
$$


sujeita a

$$
\sum_{x=1}^{N} p_{x}=\sum_{x=1}^{N} q_{x} \quad(=1)
$$

onde $N$ é o número de células discretas na distribuição. Como a equação (A13) é nãosimétrica, isto é, $H_{C E}(q, p) \neq H_{C E}(p, q)$, ela não é uma medida de distância métrica. Entretanto, a simetria pode ser imposta somando-as, resultando em uma medida de distância métrica:

$$
\begin{aligned}
H_{m}(p, q) & =H_{C E}(q, p)+H_{C E}(p, q) \\
& =\sum_{x=1}^{N} q_{x} \log \frac{q_{x}}{p_{x}}+\sum_{x=1}^{N} p_{x} \log \frac{p_{x}}{q_{x}}
\end{aligned}
$$

Em aplicações como reconstrução, filtragem, reconhecimento de padrões e segmentação, a chamada distribuição prévia, $p$, representa tal conhecimento quanto pode-se ser considerada a solução correta, podendo ser a imagem suavizada ou mesmo a original (no caso de segmentação). A distribuição posterior, $q$, é o resultado do processamento de dados. Simplesmente dito, o princípio da "cross-entropy" mínima, como com qualquer medida de discrepância, é aquele com que espera-se encontrar a solução mais próxima do resultado desejado ou esperado, através da minimização da diferença ("cross-entropy") entre eles. Isto é em muitos casos equivalente ao princípio da máxima entropia, onde tenta-se maximizar o negativo da equação (A12):

$$
H=-\sum_{x=1}^{N} q_{x} \log \frac{q_{x}}{p_{x}}
$$

a qual é a definição usual da entropia teórica de informação.

Para propósitos de seleção de limiar, pode-se considerar a imagem original em escala de cinza a distribuição prévia com cada nível de cinza $g$ representando uma freqüência (ou probabilidade se os níveis são normalizados). A média de limiar abaixo $\mu_{0}(T)$ e a média de limiar acima do valor de limiar da imagem $\mu_{1}(T)$, podem ser usadas como os dois níveis de cinza da imagem binária após limiar. Estes níveis são dados por:

$$
\mu_{0}(T)=\sum_{g=a}^{T} g p_{g} \quad \mu_{1}(T)=\sum_{g=T+1}^{b} g p_{g}
$$

onde $a$ e $b$ são, respectivamente, o menor e o maior nível de cinza presentes na imagem original, $T$ é o nível de limiar e $p_{g}$ é a probabilidade do nível de cinza $g$, dado por:

$$
p_{g}=\frac{f_{g}}{N}
$$

sendo que $f_{g}$ é o número de "pixels" que possuem nível de cinza $g$, e $N$ o número total de "pixels" da imagem. Utilizando as médias da equação (A15) para representar a imagem binária, efetivamente está satisfeita a condição para a equação (A13), que é:

$$
\sum_{i=1}^{N} g_{i}=\left[\sum_{i=1}^{N} \mu_{0}(T)\right]_{g \leq T}+\left[\sum_{i=1}^{N} \mu_{1}(T)\right]_{g>T}
$$


Tanto a verdadeira medida (não métrica) de "cross-entropy" (equação (A13)) quanto a medida métrica (equação (A3)), foram implementadas. Para imagens digitais a equação (A13) pode ser reescrita:

$$
H_{C E}(T)=\left[\sum_{i=1}^{N} \mu_{0}(T) \log \frac{\mu_{0}(T)}{g_{i}}\right]_{g \leq T}+\left[\sum_{i=1}^{N} \mu_{1}(T) \log \frac{\mu_{1}(T)}{g_{i}}\right]_{g>T}
$$

e a equação (A14) pode ser similarmente reescrita.

Como as imagens digitais possuem grande número de "pixels", o cálculo da equação (A16) e a correspondente versão da equação (A14), para qualquer dado nível de limiar, podem consumir tempo considerável, particularmente para imagens muito grandes. O histograma da freqüência de níveis de cinza pode ser utilizado para melhorar a eficiência computacional. Usando esta equação (A16), chegamos a:

$$
H_{C E}(T)=\sum_{g=a}^{T} f_{g} \mu_{0}(T) \log \frac{\mu_{0}(T)}{g}+\sum_{g=T+1}^{b} f_{g} \mu_{1}(T) \log \frac{\mu_{1}(T)}{g}
$$

e a equação (A14) pode ser reescrita:

$$
\begin{aligned}
H_{m}(T) & =\sum_{g=a}^{T} f_{g}\left[\mu_{0}(T) \log \frac{\mu_{0}(T)}{g}+g \log \frac{g}{\mu_{0}(T)}\right] \\
& +\sum_{g=T+1}^{b} f_{g}\left[\mu_{1}(T) \log \frac{\mu_{1}(T)}{g}+g \log \frac{g}{\mu_{4}(T)}\right]
\end{aligned}
$$

onde, como acima, $a$ e $b$ são os níveis de cinza mínimo e máximo na imagem e $\mu_{0}(T)$ e $\mu_{1}(T)$ são as médias de limiar abaixo e acima de um valor de limiar, respectivamente (equação (A15)).

O esquema mais simples e direto para seleção do limiar, seria fazer a iteração através de todos os valores possíveis de $T$, e selecionar o limiar, $\tau$, correspondendo ao mínimo da "cross-entropy", equação (A17) ou (A18), isto é:

$$
\begin{aligned}
& \tau_{C E}=\arg \left(\min _{a \leq T \leq b}\left\{H_{C E}(T)\right\}\right) \\
& \tau_{m}=\arg \left(\min _{a \leq T \leq b}\left\{H_{m}(T)\right\}\right)
\end{aligned}
$$

Para comparação dos resultados, foram implementados o método de Otsu [Otsu, 1979] e o método que usa a medida de discrepância $\chi^{2}$. Brevemente, a distância $\chi^{2}$ entre a imagem original e aquela após limiar pode ser determinada por:

$$
\begin{aligned}
\chi^{2}(T) & =\left[\sum_{i=1}^{N} \frac{\left(\mu_{0}(T)-g_{i}\right)^{2}}{g_{i}}\right]_{g_{1} \leq T}+\left[\sum_{i=1}^{N} \frac{\left(\mu_{1}(T)-g_{i}\right)^{2}}{g_{i}}\right]_{\left.g_{1}\right) T} \\
& =\sum_{g=a}^{T} f_{g} \frac{\left(\mu_{0}(T)-g\right)^{2}}{g}+\sum_{g=T+1}^{b} f_{g} \frac{\left(\mu_{1}(T)-g\right)^{2}}{g}
\end{aligned}
$$

Esta é minimizada para todos os valores possíveis de limiar, de maneira a determinar o limiar ótimo.

É feita uma análise dos resultados obtidos em figuras diferentes, concluindo-se que a "cross-entropy" mínima funciona muito bem como seletor de limiar (melhor ou no mínimo igual aos outros métodos). 
Depois é feito um comentário a respeito de imagens não tão simples, como as utilizadas pelos autores e que necessitariam de "multi-limiarização". Concluem que o tempo computacional seria extremamente elevado (dão até uma fórmula para estimá-lo) e aconselha outros métodos para a solução do problema com imagens mais complexas.

Discute a respeito de métodos de avaliação para o esquema de limiar proposto e para os testados também. Descreve um método proposto por Albregtsen, o qual avalia a precisão dos métodos através da utilização de histogramas, construídos sinteticamente por funções propostas pelo autor e por uma equação de erro. Nesta análise, chega-se que o método da correlação apresenta o melhor desempenho. Mas é rebatido da seguinte forma: "isto é facilmente explicável através da seção 2.1 do artigo, onde é necessário assumir uma distribuição normal de probabilidade para que se possa traçar um paralelo entre a correlação e a "cross-entropy". O método da correlação é feito na medida para este método de avaliação". Mesmo assim os dois métodos de "crossentropy" são superiores ao método que utiliza $X^{2}$.

\section{A.7-CONSIDERAÇÕES FINAIS}

Em suma, apresentou-se um levantamento de vários métodos de limiarização, alguns locais e outros globais os quais são automáticos por natureza. Todos os métodos descritos aqui otimizam alguma função critério e fornecem justificações para tal otimização.

É importante salientar que com o passar dos anos, as técnicas de limiarização vem evoluindo com a introdução de novas interpretações e novos equacionamentos. Mesmo que ainda a maioria dos métodos estejam direcionados para análise de imagens simples, normalmente contendo objeto e fundo apenas, para alguns métodos o conceito de limiarização não está limitado em apenas binarizar uma imagem. Em muitos casos, limiarização significa apenas uma etapa em processos, como por exemplo segmentação. Os métodos para multi-limiarização, são na verdade, métodos completos de segmentação, pois uma imagem em níveis de cinza processada por esses métodos, é segmentada em diversos níveis compondo regiões homogêneas e portanto, em muitos casos, apresentando resultados com informações suficientes para tomadas de decisões.

A grande maioria dos métodos mais recentes, são propostos de modo a encontrar o valor, ou os valores, de limiar automaticamente, e para isso adotam métodos com os quais extraem-se características que possam descrever as imagens, como quantidades estatísticas (diferença de médias, variâncias, etc...) ou como quantidade de informação (usando a definição de entropia de Shannon).

Embora trate-se de um conceito simples, os resultados alcançados com os métodos de limiarização ainda não são definitivos, ou seja, não existe um método geral que atenda a todos os problemas, pois ainda não foi possível "equacionar" uma imagem de modo a conseguir informações suficientes para tomada de decisões completas. 


\section{Anexo B}

\section{TABELA DE CLASSIFICAÇÃO DO CONJUNTO DE}

\section{PLACAS}

Apresentam-se neste apêndice as classificações realizadas pelos três inspetores e pelos dois métodos de classificação final (método de redução de informações baseada em regras de combinações e método baseado em matriz de co-ocorrência).

Tabela B.1 - Classificação realizada no conjunto de 199 placas pelos inspetores e pelos métodos

\begin{tabular}{|c|c|c|c|c|c|c|c|c|}
\hline Placa & Inspetor 1 & $\begin{array}{c}\text { Alternativa } \\
\text { Inspetor } 1\end{array}$ & Inspetor 2 & $\begin{array}{l}\text { Alternativa } \\
\text { Inspetor } 2\end{array}$ & Inspetor 3 & $\begin{array}{l}\text { Alternativa } \\
\text { Inspetor } 3\end{array}$ & $\begin{array}{c}\text { Co- } \\
\text { ocorrência } \\
\end{array}$ & Redução \\
\hline 1 & $\mathrm{~B}$ & - & $B$ & $C$ & B & - & B & B \\
\hline 2 & $\mathrm{C}$ & $B$ & $\mathrm{C}$ & - & $\mathrm{C}$ & - & $\bar{B}$ & B \\
\hline 3 & $\mathrm{~A}$ & - & $\mathrm{A}$ & - & $\mathrm{B}$ & $A$ & $\mathrm{~B}$ & $\mathrm{~B}$ \\
\hline 4 & $\mathrm{C}$ & $B$ & $\mathrm{~B}$ & - & $\mathrm{B}$ & $C$ & $\mathrm{~B}$ & $\mathrm{~B}$ \\
\hline 5 & $\mathrm{~A}$ & - & $\mathrm{A}$ & - & $\mathrm{A}$ & - & $\mathrm{A}$ & $\mathrm{A}$ \\
\hline 6 & $\mathrm{C}$ & - & $\mathrm{B}$ & - & $B$ & - & $\mathrm{C}$ & $\mathrm{C}$ \\
\hline 7 & $\mathrm{~A}$ & $A$ & $\mathrm{~A}$ & - & A & - & $\mathrm{A}$ & $\mathrm{B}$ \\
\hline 8 & $\mathrm{D}$ & $C$ & D & - & $\mathrm{C}$ & $D$ & $\mathrm{D}$ & $\mathrm{B}$ \\
\hline 9 & $\mathrm{~B}$ & - & $\mathrm{B}$ & $C$ & $\mathrm{~B}$ & - & B & $\mathrm{B}$ \\
\hline 10 & $\mathrm{~B}$ & - & $\mathrm{A}$ & $B$ & $\mathrm{~B}$ & $A$ & $\mathrm{~B}$ & $\mathrm{~B}$ \\
\hline 11 & $\mathrm{C}$ & $A$ & $\mathrm{~B}$ & $C$ & $\mathrm{~B}$ & - & $\mathrm{A}$ & $\mathrm{A}$ \\
\hline 12 & $\mathrm{~A}$ & - & $\mathrm{A}$ & - & $\mathrm{A}$ & - & $\mathrm{A}$ & $\bar{A}$ \\
\hline 13 & B & - & $\mathrm{B}$ & $A$ & $\mathrm{~B}$ & $A$ & $\mathrm{~B}$ & $B$ \\
\hline 14 & $\mathrm{~A}$ & - & $\mathrm{A}$ & - & $\mathrm{A}$ & - & $\mathrm{B}$ & $\mathrm{A}$ \\
\hline 15 & $\mathrm{C}$ & - & B & - & B & - & $\mathrm{C}$ & $\mathrm{C}$ \\
\hline 16 & $\mathrm{C}$ & $D$ & $\mathrm{C}$ & - & $\mathrm{C}$ & - & $\mathrm{C}$ & $\mathrm{C}$ \\
\hline 17 & $\mathrm{~A}$ & $B$ & $\mathrm{~A}$ & - & $\mathrm{A}$ & - & $\mathrm{A}$ & $\mathrm{A}$ \\
\hline 18 & B & - & $\mathrm{A}$ & - & $\mathrm{A}$ & - & B & B \\
\hline 19 & D & $C$ & $\mathrm{C}$ & $D$ & $\mathrm{C}$ & $D$ & C & C \\
\hline 20 & $\mathrm{~B}$ & - & $\mathrm{B}$ & $B$ & B & - & $\mathrm{B}$ & $B$ \\
\hline
\end{tabular}


Tabela B.1 - Classificação realizada no conjunto de 199 placas pelos inspetores e pelos métodos

\begin{tabular}{|c|c|c|c|c|c|c|c|c|}
\hline Placa & Inspetor 1 & $\begin{array}{l}\text { Alternativa } \\
\text { Inspetor } 1\end{array}$ & Inspetor 2 & $\begin{array}{l}\text { Alternativa } \\
\text { Inspetor } 2 \\
\end{array}$ & Inspetor 3 & $\begin{array}{l}\text { Alternativa } \\
\text { Inspetor } 3 \\
\end{array}$ & $\begin{array}{c}\text { Co- } \\
\text { ocorrência }\end{array}$ & Redução \\
\hline$\overline{2121}$ & $\overline{\bar{B}}$ & $\begin{array}{ll}C \\
\end{array}$ & $B$ & - & $\bar{B}$ & $\dot{-}$ & $\mathrm{B}$ & $\overline{\bar{C}}$ \\
\hline 22 & $\mathrm{C}$ & & $\mathrm{C}$ & $D$ & C & - & $\mathrm{C}$ & $C$ \\
\hline 23 & $\mathrm{C}$ & $B$ & $\mathrm{C}$ & $B$ & $\mathrm{~B}$ & $C$ & $\mathrm{~B}$ & $\mathrm{~B}$ \\
\hline 24 & C & - & $\mathrm{C}$ & - & $\mathrm{C}$ & $B$ & $\mathrm{C}$ & $B$ \\
\hline 25 & $\mathrm{~B}$ & $B$ & A & - & $B$ & - & $\mathrm{A}$ & $B$ \\
\hline 26 & B & $C$ & $B$ & $C$ & $\mathrm{C}$ & - & $B$ & $B$ \\
\hline 27 & $B$ & $C$ & $B$ & - & $\mathrm{C}$ & - & $\mathrm{C}$ & $\mathrm{C}$ \\
\hline 28 & $B$ & - & $\mathrm{A}$ & - & $\mathrm{A}$ & - & $\mathrm{A}$ & $B$ \\
\hline 29 & $B$ & $A$ & $\mathrm{~A}$ & - & $\mathrm{A}$ & $B$ & $B$ & $\mathrm{~B}$ \\
\hline 30 & $\mathrm{~B}$ & $A$ & $\mathrm{~A}$ & - & $\mathrm{A}$ & - & $\mathrm{A}$ & $\mathrm{A}$ \\
\hline 31 & $\mathrm{~A}$ & - & $\mathrm{A}$ & $B$ & $\mathrm{~A}$ & - & $A$ & $\mathrm{~A}$ \\
\hline 32 & $\mathrm{~A}$ & - & $\mathrm{B}$ & - & B & - & $\mathrm{B}$ & $\mathrm{B}$ \\
\hline 33 & $\mathrm{X}$ & $X$ & $\mathrm{D}$ & $X$ & $\mathrm{D}$ & - & $D$ & $\mathrm{D}$ \\
\hline 34 & $\mathrm{C}$ & $D$ & $\mathrm{C}$ & - & $\mathrm{C}$ & - & $\mathrm{D}$ & $\mathrm{C}$ \\
\hline 35 & $D$ & $X$ & $\mathrm{D}$ & $C$ & $\mathrm{D}$ & $X$ & $\mathrm{D}$ & $\mathrm{D}$ \\
\hline 36 & $\mathrm{X}$ & $D$ & $\mathrm{D}$ & $X$ & $\mathrm{D}$ & - & $\mathrm{X}$ & $\mathrm{D}$ \\
\hline 37 & $\mathrm{X}$ & $C$ & $\mathrm{C}$ & $D$ & $\mathrm{D}$ & - & $\mathrm{C}$ & $\mathrm{C}$ \\
\hline 38 & $\mathrm{X}$ & - & $\mathrm{X}$ & - & $\mathrm{X}$ & - & $\mathrm{C}$ & $\mathrm{C}$ \\
\hline 39 & $\mathrm{D}$ & $X$ & $\mathrm{D}$ & $X$ & $\mathrm{D}$ & - & $\mathrm{D}$ & $\mathrm{D}$ \\
\hline 40 & $\mathrm{X}$ & - & $\mathrm{X}$ & - & $\mathrm{X}$ & 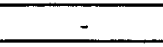 & $\mathrm{X}$ & $X$ \\
\hline 41 & $B$ & $\cdot$ & $B$ & - & $\mathrm{B}$ & - & $B$ & $B$ \\
\hline 42 & $B$ & $A$ & $\mathrm{~B}$ & $C$ & $\mathrm{C}$ & - & $B$ & $B$ \\
\hline 43 & $B$ & - & B & - & $\mathrm{B}$ & - & $B$ & $B$ \\
\hline 44 & $\mathrm{C}$ & - & $\mathrm{C}$ & $\cdot$ & $\mathrm{C}$ & - & $\mathrm{B}$ & $\mathrm{B}$ \\
\hline 45 & $\mathrm{C}$ & - & $\mathrm{C}$ & - & $\mathrm{C}$ & - & $\mathrm{D}$ & $\mathrm{C}$ \\
\hline 46 & $\mathrm{C}$ & $B$ & $\mathrm{C}$ & - & $\mathrm{C}$ & $C$ & $\mathrm{C}$ & $\bar{C}$ \\
\hline 47 & $\mathrm{C}$ & $D$ & $\mathrm{C}$ & $D$ & $\mathrm{C}$ & $D$ & $\mathrm{D}$ & $\mathrm{C}$ \\
\hline 48 & $\mathrm{C}$ & - & $\mathrm{C}$ & $D$ & $C$ & G & $D$ & $\mathrm{C}$ \\
\hline 49 & $B$ & $A$ & $\mathrm{C}$ & - & $\mathrm{B}$ & - & $\mathrm{B}$ & $\mathrm{A}$ \\
\hline 50 & $\mathrm{X}$ & - & $\mathrm{D}$ & - & $\mathrm{D}$ & $X$ & $\mathrm{D}$ & $\mathrm{D}$ \\
\hline 51 & $\mathrm{~B}$ & - & $\mathrm{A}$ & - & $\mathrm{A}$ & $\dot{-}$ & $A$ & $\mathrm{~A}$ \\
\hline 52 & $\mathrm{~B}$ & - & B & - & $\mathrm{B}$ & - & $B$ & $B$ \\
\hline 53 & $\mathrm{C}$ & $B$ & $\mathrm{C}$ & - & $\mathrm{C}$ & $B$ & $\mathrm{C}$ & $\mathrm{D}$ \\
\hline 54 & $\mathrm{C}$ & - & $\mathrm{C}$ & - & $\mathrm{C}$ & $B$ & $\mathrm{C}$ & $\mathrm{C}$ \\
\hline 55 & $\mathrm{D}$ & $C$ & $\mathrm{D}$ & - & $\mathrm{C}$ & $D$ & $\mathrm{C}$ & $\mathrm{C}$ \\
\hline 56 & $\mathrm{D}$ & - & $\mathrm{C}$ & $D$ & $\mathrm{C}$ & - & $\mathrm{D}$ & $\mathrm{C}$ \\
\hline 57 & $\mathrm{C}$ & $D$ & $\mathrm{D}$ & $C$ & $\mathrm{D}$ & 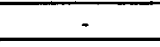 & $D$ & $\mathrm{C}$ \\
\hline 58 & $\mathrm{C}$ & - & $\mathrm{C}$ & $\cdot$ & $\bar{C}$ & - & $\mathrm{C}$ & $\mathrm{C}$ \\
\hline 59 & $\mathrm{C}$ & $B$ & $B$ & $B$ & B & - & $\mathrm{C}$ & $B$ \\
\hline 60 & $\mathrm{C}$ & $B$ & $\mathrm{C}$ & - & $\mathrm{C}$ & $B$ & $\mathrm{C}$ & $\mathrm{C}$ \\
\hline 61 & $\mathrm{C}$ & - & $\mathrm{C}$ & $D$ & $\mathrm{C}$ & $D$ & $\mathrm{C}$ & $\mathrm{C}$ \\
\hline 62 & $\mathrm{~B}$ & $C$ & B & - & B & - & $\mathrm{A}$ & $\mathrm{A}$ \\
\hline 63 & $\mathrm{~A}$ & $B$ & $\mathrm{~B}$ & - & $B$ & $A$ & $\mathrm{~B}$ & $B$ \\
\hline 64 & $\mathrm{D}$ & $C$ & $D$ & $X$ & $\mathrm{D}$ & $X$ & $\mathrm{D}$ & $\mathrm{D}$ \\
\hline 65 & $\mathrm{C}$ & - & $\mathrm{C}$ & $D$ & $\mathrm{C}$ & - & $\mathrm{C}$ & $\mathrm{C}$ \\
\hline 66 & $B$ & $C$ & $\mathrm{D}$ & $C$ & $\mathrm{C}$ & - & $B$ & B \\
\hline 67 & $\mathrm{~A}$ & $B$ & $\mathrm{~B}$ & - & B & $A$ & $\mathrm{~B}$ & B \\
\hline 68 & $C$ & - & $\mathrm{C}$ & - & $B$ & - & $\mathrm{B}$ & $\mathrm{C}$ \\
\hline 69 & B & $C$ & $\mathrm{C}$ & - & B & $C$ & $B$ & $B$ \\
\hline 70 & $\mathrm{C}$ & $B$ & B & - & $\mathrm{B}$ & $C$ & $\mathrm{C}$ & $B$ \\
\hline 71 & $\mathrm{C}$ & $B$ & $\mathrm{C}$ & $D$ & B & $A$ & B & $\mathrm{B}$ \\
\hline 72 & $\mathrm{~B}$ & $C$ & $\mathrm{~A}$ & $B$ & $\mathrm{~A}$ & - & $\mathrm{B}$ & $\mathrm{B}$ \\
\hline 73 & $\mathrm{C}$ & - & $\mathrm{B}$ & $C$ & $B$ & - & $\mathrm{C}$ & $B$ \\
\hline 74 & $\mathrm{C}$ & $D$ & B & $C$ & $\mathrm{C}$ & - & $\mathrm{C}$ & $\mathrm{C}$ \\
\hline 75 & $\mathrm{C}$ & $D$ & $\mathrm{D}$ & $C$ & $\mathrm{D}$ & - & $\mathrm{C}$ & $\mathrm{C}$ \\
\hline 76 & $\mathrm{C}$ & $D$ & $\mathrm{C}$ & $D$ & $\mathrm{C}$ & - & $\mathrm{C}$ & $\mathrm{C}$ \\
\hline 77 & B & $A$ & $\mathrm{~A}$ & - & $\mathrm{B}$ & $A$ & $\mathrm{~A}$ & $\mathrm{~A}$ \\
\hline 78 & $\mathrm{D}$ & $X$ & $\mathrm{D}$ & $C$ & $\mathrm{C}$ & - & $\mathrm{C}$ & $\mathrm{C}$ \\
\hline 79 & $\mathrm{D}$ & $X$ & $D$ & - & $\mathrm{D}$ & $X$ & $\mathrm{D}$ & $\mathrm{D}$ \\
\hline 80 & $B$ & $C$ & $B$ & - & $\mathrm{B}$ & - & $\mathrm{C}$ & $B$ \\
\hline
\end{tabular}


Tabela B.1 - Classificaçăo realizada no conjunto de 199 placas pelos inspetores e pelos métodos

\begin{tabular}{|c|c|c|c|c|c|c|c|c|}
\hline Placa & Inspetor 1 & $\begin{array}{l}\text { Alternativa } \\
\text { Inspetor I }\end{array}$ & Inspetor 2 & $\begin{array}{c}\text { Alternativa } \\
\text { Inspetor } 2 \\
\end{array}$ & Inspetor 3 & $\begin{array}{c}\text { Alternativa } \\
\text { Inspetor } 3 \\
\end{array}$ & $\begin{array}{c}\text { Co- } \\
\text { ocorrência }\end{array}$ & Redução \\
\hline 81 & $\mathrm{~A}$ & - & $\mathrm{B}$ & - & $\mathrm{A}$ & - & $\mathrm{A}$ & $\mathrm{A}$ \\
\hline 82 & $\bar{A}$ & - & $\mathrm{B}$ & - & $\mathrm{A}$ & - & $\mathrm{A}$ & $\bar{A}$ \\
\hline 83 & $\mathrm{~B}$ & $C$ & $\mathrm{C}$ & - & $\mathrm{B}$ & - & $\mathrm{B}$ & $B$ \\
\hline 84 & $\mathrm{~B}$ & $C$ & $\bar{C}$ & - & $\mathrm{B}$ & - & $\mathrm{B}$ & $\mathrm{B}$ \\
\hline 85 & $\mathrm{~B}$ & $A$ & $\mathrm{C}$ & $B$ & $\mathrm{~B}$ & $B$ & $\mathrm{~B}$ & $\mathrm{~B}$ \\
\hline 86 & $\mathrm{~B}$ & - & $\mathrm{C}$ & $B$ & $B$ & $C$ & $\mathrm{~B}$ & $\mathrm{~B}$ \\
\hline 87 & $\mathrm{C}$ & $B$ & $\mathrm{C}$ & - & $B$ & - & $\mathrm{B}$ & $\mathrm{C}$ \\
\hline 88 & $\mathrm{~B}$ & - & $B$ & $A$ & $\mathrm{~B}$ & - & $B$ & $\mathrm{~B}$ \\
\hline 89 & $\mathrm{~B}$ & - & $B$ & - & $\mathrm{B}$ & - & $\mathrm{A}$ & $A$ \\
\hline 90 & $\bar{D}$ & $\bar{X}$ & $\mathrm{D}$ & $X$ & $\mathrm{D}$ & - & $\mathrm{D}$ & $\mathrm{D}$ \\
\hline 91 & $\mathrm{D}$ & - & $\mathrm{x}$ & - & $\mathrm{D}$ & $\bar{X}$ & $\bar{x}$ & $\mathrm{X}$ \\
\hline 92 & $\bar{X}$ & - & $\mathrm{D}$ & - & $\mathrm{X}$ & - & $\mathrm{X}$ & $\mathrm{D}$ \\
\hline 93 & $\mathrm{D}$ & - & $\mathrm{C}$ & $D$ & $\mathrm{D}$ & $X$ & $x$ & $\mathrm{D}$ \\
\hline 94 & $\mathrm{C}$ & $B$ & $\mathrm{C}$ & $\bar{D}$ & $\mathrm{C}$ & $B$ & $\mathrm{C}$ & $\mathrm{D}$ \\
\hline 95 & $\mathrm{C}$ & $D$ & $\mathrm{C}$ & - & $\mathrm{D}$ & - & $\mathrm{C}$ & $\mathrm{C}$ \\
\hline 96 & $\mathrm{D}$ & $C$ & $\mathrm{C}$ & $D$ & $\mathrm{C}$ & $\bar{D}$ & $\mathrm{C}$ & $\mathrm{C}$ \\
\hline 97 & $\mathrm{C}$ & $\bar{L}$ & $\mathrm{C}$ & $C$ & $\mathrm{C}$ & $\bar{D}$ & $\mathrm{C}$ & $\mathrm{B}$ \\
\hline 98 & D & $X$ & $\mathrm{D}$ & - & $\mathrm{D}$ & - & $\mathrm{C}$ & $\mathrm{D}$ \\
\hline 99 & $\mathrm{D}$ & $x$ & $\mathrm{D}$ & - & $\mathrm{D}$ & - & $\mathrm{D}$ & $X$ \\
\hline 100 & $\mathrm{X}$ & - & $\mathrm{X}$ & - & $\mathrm{X}$ & - & $\mathrm{D}$ & $\mathrm{D}$ \\
\hline 101 & $\mathrm{C}$ & $D$ & $\mathrm{C}$ & $D$ & $\mathrm{C}$ & - & $\mathrm{C}$ & $\mathrm{C}$ \\
\hline 102 & $\mathrm{D}$ & - & C & $D$ & $\mathrm{D}$ & - & $\mathrm{C}$ & $\mathrm{C}$ \\
\hline 103 & $\bar{X}$ & - & $\mathrm{X}$ & - & $\mathrm{X}$ & - & $\mathrm{C}$ & $\mathrm{C}$ \\
\hline 104 & $\mathrm{X}$ & - & $\mathrm{X}$ & - & $\mathrm{X}$ & - & $\mathrm{X}$ & $x$ \\
\hline 105 & $\bar{x}$ & - & $\mathrm{X}$ & - & $\mathrm{X}$ & - & $\mathrm{D}$ & $\mathrm{D}$ \\
\hline 106 & $x$ & - & $x$ & $D$ & $\mathrm{D}$ & $X$ & $\bar{x}$ & $\mathrm{X}$ \\
\hline 107 & $D$ & - & $\mathrm{D}$ & - & $\mathrm{D}$ & $X$ & $\mathrm{D}$ & $\mathrm{D}$ \\
\hline 108 & $\mathrm{X}$ & - & $\mathrm{X}$ & $D$ & $\mathrm{D}$ & - & $\mathrm{D}$ & $\mathrm{D}$ \\
\hline 109 & $\mathrm{C}$ & $B$ & $\mathrm{C}$ & - & $\mathrm{C}$ & $D$ & $\mathrm{C}$ & $\mathrm{C}$ \\
\hline 110 & $D$ & - & $\mathrm{D}$ & - & $\mathrm{D}$ & - & $\bar{C}$ & $\mathrm{C}$ \\
\hline 111 & $C$ & $=$ & $\mathrm{C}$ & $D$ & $\mathrm{C}$ & - & $\bar{C}$ & $\mathrm{C}$ \\
\hline 112 & $D$ & $X$ & $\mathrm{D}$ & $C$ & $\mathrm{D}$ & - & $\mathrm{D}$ & $D$ \\
\hline 113 & $\mathrm{X}$ & - & $\mathrm{X}$ & - & $\mathrm{X}$ & - & $\mathrm{D}$ & $\mathrm{D}$ \\
\hline 114 & $\mathrm{D}$ & $\bar{C}$ & $\mathrm{D}$ & $X$ & $\mathrm{D}$ & $X$ & $\mathrm{D}$ & $\mathrm{D}$ \\
\hline 115 & $\mathrm{C}$ & $B$ & $\mathrm{C}$ & - & $\mathrm{C}$ & - & $\mathrm{D}$ & $\mathrm{C}$ \\
\hline 116 & $\mathrm{D}$ & $X$ & $\mathrm{D}$ & $X$ & $\bar{D}$ & - & $\mathrm{D}$ & $\mathrm{D}$ \\
\hline 117 & $\mathrm{C}$ & - & $\mathrm{D}$ & - & $\mathrm{D}$ & $x$ & $\mathrm{C}$ & $\mathrm{C}$ \\
\hline 118 & $\mathrm{C}$ & - & $\mathrm{D}$ & $C$ & $C$ & $D$ & $D$ & $\mathrm{C}$ \\
\hline 119 & $\mathrm{C}$ & $\bar{D}$ & $\mathrm{C}$ & $D$ & $\mathrm{C}$ & $D$ & $\mathrm{D}$ & $\mathrm{C}$ \\
\hline 120 & $\mathrm{C}$ & $D$ & $\mathrm{C}$ & $D$ & $\mathrm{D}$ & - & $\mathrm{C}$ & $C$ \\
\hline 121 & $D$ & - & $\mathrm{D}$ & $X$ & $D$ & $X$ & $\mathrm{D}$ & $\mathrm{D}$ \\
\hline 122 & D & - & $\mathrm{C}$ & $D$ & C & $D$ & $\mathrm{C}$ & $\mathrm{D}$ \\
\hline 123 & $\mathrm{D}$ & - & $\mathrm{D}$ & - & $\mathrm{D}$ & - & $\mathrm{D}$ & $\mathrm{D}$ \\
\hline 124 & $\mathrm{C}$ & - & $\mathrm{C}$ & $\bar{D}$ & $\mathrm{D}$ & $C$ & $\mathrm{C}$ & $\mathrm{C}$ \\
\hline 125 & $\mathrm{D}$ & - & $\mathrm{D}$ & $C$ & $\bar{D}$ & - & $\mathrm{D}$ & $\mathrm{C}$ \\
\hline 126 & $\mathrm{C}$ & $B$ & $\mathrm{C}$ & - & $\mathrm{C}$ & $B$ & B & $B$ \\
\hline 127 & D & - & $\mathrm{D}$ & - & D & $C$ & $C$ & $C$ \\
\hline 128 & $\mathrm{C}$ & - & $D$ & $C$ & $\mathrm{C}$ & - & $\mathrm{B}$ & $B$ \\
\hline 129 & $B$ & $\cdot$ & $\mathrm{B}$ & - & $\mathrm{B}$ & 1 & $\bar{D}$ & $\mathrm{C}$ \\
\hline 130 & D & $C$ & $\mathrm{C}$ & - & $\mathrm{D}$ & - & $\mathrm{C}$ & $\mathrm{C}$ \\
\hline 131 & $\mathrm{D}$ & $X$ & $\mathrm{D}$ & $X$ & $\mathrm{D}$ & - & $\mathrm{X}$ & $\mathrm{X}$ \\
\hline 132 & $\bar{X}$ & - & $x$ & - & $\mathrm{X}$ & - & $\mathrm{X}$ & $\mathrm{X}$ \\
\hline 133 & $x$ & - & $\mathrm{X}$ & $\cdot$ & $X$ & - & 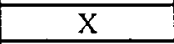 & $X$ \\
\hline 134 & $X$ & $D$ & $\bar{D}$ & $X$ & $x$ & - & $X$ & $\mathrm{D}$ \\
\hline 135 & $\mathrm{D}$ & $X$ & $\mathrm{D}$ & $X$ & $\mathrm{D}$ & $X$ & $\mathrm{C}$ & C \\
\hline 136 & $\mathrm{D}$ & $C$ & $\mathrm{D}$ & - & $\mathrm{D}$ & $X$ & $\mathrm{D}$ & $\mathrm{D}$ \\
\hline 137 & D & $C$ & $D$ & $X$ & $\mathrm{D}$ & - & $\mathrm{C}$ & $\mathrm{C}$ \\
\hline 138 & $\mathrm{C}$ & - & $\mathrm{C}$ & $D$ & D & - & $C$ & $\mathrm{C}$ \\
\hline 139 & B & $C$ & $\mathrm{C}$ & $D$ & $\mathrm{C}$ & - & B & $B$ \\
\hline 140 & $x$ & - & D & $X$ & $\mathrm{X}$ & 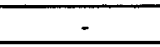 & $x$ & $X$ \\
\hline
\end{tabular}


Tabela B.1 - Classificação realizada no conjunto de 199 placas pelos inspetores e pelos métodos

\begin{tabular}{|c|c|c|c|c|c|c|c|c|}
\hline Placa & Inspetor 1 & $\begin{array}{l}\text { Alternativa } \\
\text { Inspetor } 1\end{array}$ & Inspetor 2 & $\begin{array}{l}\text { Alternativa } \\
\text { Inspetor } 2\end{array}$ & Inspetor 3 & $\begin{array}{l}\text { Alternativa } \\
\text { Inspetor } 3\end{array}$ & $\begin{array}{c}\text { Co- } \\
\text { ocorrência } \\
\end{array}$ & Redução \\
\hline 141 & $\mathrm{X}$ & - & $\mathrm{X}$ & - & $\mathrm{X}$ & - & $\mathrm{X}$ & $X$ \\
\hline 142 & $X$ & - & $\mathrm{X}$ & - & $\mathrm{X}$ & - & $\mathrm{X}$ & $X$ \\
\hline 143 & $\mathrm{X}$ & - & $\mathrm{X}$ & - & $\mathrm{X}$ & - & $\mathrm{X}$ & $\mathrm{X}$ \\
\hline 144 & $X$ & - & $\mathrm{X}$ & - & $X$ & - & $\mathrm{X}$ & $\mathrm{X}$ \\
\hline 145 & $\mathrm{X}$ & - & $X$ & - & $X$ & - & $X$ & $\mathrm{X}$ \\
\hline 146 & $X$ & - & $\mathrm{X}$ & - & $\mathrm{X}$ & - & $\mathrm{X}$ & $\mathrm{X}$ \\
\hline 147 & $X$ & - & $X$ & - & $X$ & - & $\mathrm{X}$ & $X$ \\
\hline 148 & $X$ & $D$ & $\mathrm{X}$ & - & $\mathrm{D}$ & $X$ & $\mathrm{D}$ & $\mathrm{D}$ \\
\hline 149 & $X$ & - & $X$ & - & $X$ & - & $X$ & $\mathrm{D}$ \\
\hline 150 & $\mathrm{C}$ & $B$ & $\mathrm{~B}$ & $C$ & $\mathrm{C}$ & - & $\mathrm{C}$ & $\mathrm{C}$ \\
\hline 151 & $\mathrm{D}$ & - & $\mathrm{D}$ & $X$ & $\mathrm{D}$ & $X$ & $\mathrm{D}$ & $\mathrm{D}$ \\
\hline 152 & $X$ & - & $\mathrm{X}$ & - & $X$ & - & $\mathrm{X}$ & $\mathrm{D}$ \\
\hline 153 & $\mathrm{X}$ & - & $\mathrm{X}$ & - & $\mathrm{X}$ & - & $\mathrm{C}$ & D \\
\hline 154 & $\mathrm{D}$ & $C$ & $\mathrm{D}$ & $X$ & $\mathrm{D}$ & $X$ & D & $\mathrm{D}$ \\
\hline 155 & $\mathrm{X}$ & - & $\mathrm{X}$ & - & $X$ & - & D & $\mathrm{D}$ \\
\hline 156 & $\mathrm{D}$ & - & $\mathrm{X}$ & - & $\mathrm{X}$ & - & $\mathrm{X}$ & $\mathrm{D}$ \\
\hline 157 & D & $X$ & $\mathrm{D}$ & - & $\mathrm{D}$ & $X$ & $\mathrm{X}$ & $\mathrm{D}$ \\
\hline 158 & $\mathrm{X}$ & - & $\mathrm{D}$ & $X$ & $X$ & - & $\mathrm{X}$ & $x$ \\
\hline 159 & $\mathrm{D}$ & $X$ & $\mathrm{D}$ & $X$ & $\mathrm{D}$ & $X$ & $X$ & $\mathrm{X}$ \\
\hline 160 & $X$ & $D$ & $X$ & - & $\mathrm{D}$ & $X$ & D & $x$ \\
\hline 161 & $\mathrm{D}$ & - & $\mathrm{C}$ & $D$ & $\mathrm{D}$ & - & D & $\mathrm{C}$ \\
\hline 162 & $\mathrm{C}$ & $D$ & $\mathrm{C}$ & $D$ & $\mathrm{C}$ & $D$ & $\mathrm{D}$ & $\mathrm{D}$ \\
\hline 163 & $\mathrm{D}$ & $C$ & $\mathrm{D}$ & - & $\mathrm{D}$ & $X$ & $X$ & $\mathrm{D}$ \\
\hline 164 & $X$ & $D$ & $X$ & - & $x$ & - & $\mathrm{D}$ & $X$ \\
\hline 165 & $X$ & $D$ & $X$ & - & $\mathrm{X}$ & - & $\mathrm{D}$ & $X$ \\
\hline 166 & $D$ & $C$ & $\mathrm{C}$ & $D$ & $\mathrm{D}$ & - & $\mathrm{D}$ & $\mathrm{D}$ \\
\hline 167 & $\mathrm{X}$ & - & $X$ & - & $\mathrm{X}$ & - & $\mathrm{X}$ & $\mathrm{X}$ \\
\hline 168 & $\mathrm{X}$ & - & $\mathrm{D}$ & - & $X$ & $D$ & $\mathrm{D}$ & $\mathrm{X}$ \\
\hline 169 & $\mathrm{D}$ & - & $\mathrm{D}$ & - & $\mathrm{X}$ & - & $\mathrm{X}$ & $\mathrm{X}$ \\
\hline 170 & $\mathrm{X}$ & - & $X$ & - & $X$ & - & $x$ & $\mathrm{X}$ \\
\hline 171 & $\mathrm{D}$ & $X$ & $\mathrm{D}$ & - & D & $X$ & $\mathrm{D}$ & $D$ \\
\hline 172 & $X$ & - & $\mathrm{X}$ & - & $X$ & - & $\mathrm{D}$ & $X$ \\
\hline 173 & $X$ & - & $\mathrm{X}$ & - & $\mathrm{X}$ & - & $\mathrm{D}$ & $\mathrm{X}$ \\
\hline 174 & $\mathrm{X}$ & - & $\mathrm{X}$ & $D$ & $\mathrm{X}$ & - & $\mathrm{D}$ & $\mathrm{X}$ \\
\hline 175 & $\mathrm{D}$ & $C$ & $\mathrm{C}$ & $D$ & $\mathrm{D}$ & - & $\mathrm{C}$ & $\mathrm{C}$ \\
\hline 176 & $\mathrm{D}$ & - & $\mathrm{D}$ & $C$ & $\mathrm{D}$ & $C$ & $D$ & $X$ \\
\hline 177 & $\mathrm{D}$ & - & $\mathrm{D}$ & - & $D$ & - & $D$ & $\mathrm{D}$ \\
\hline 178 & $\mathrm{D}$ & - & $\mathrm{D}$ & - & $\mathrm{D}$ & - & $\mathrm{D}$ & $\mathrm{D}$ \\
\hline 179 & $\mathrm{C}$ & $D$ & $\mathrm{D}$ & $C$ & $\mathrm{C}$ & - & $\mathrm{C}$ & $\mathrm{C}$ \\
\hline 180 & $\mathrm{X}$ & - & $\mathrm{X}$ & - & $X$ & - & $\mathrm{X}$ & $\mathrm{X}$ \\
\hline 181 & $\mathrm{X}$ & - & $X$ & - & $X$ & - & $\mathrm{X}$ & $X$ \\
\hline 182 & $\mathrm{X}$ & $=$ & $X$ & - & $\mathrm{X}$ & - & $X$ & $\mathrm{X}$ \\
\hline 183 & $\mathrm{X}$ & - & $X$ & - & $X$ & - & $\mathrm{X}$ & $X$ \\
\hline 184 & $\mathrm{D}$ & - & $\mathrm{D}$ & $X$ & $\mathrm{X}$ & 5 & $\mathrm{D}$ & D \\
\hline 185 & $\mathrm{X}$ & - & $X$ & - & $\mathrm{X}$ & - & $\mathrm{X}$ & $\mathrm{X}$ \\
\hline 186 & $X$ & $\therefore$ & $\mathrm{X}$ & - & $\mathrm{X}$ & - & $X$ & $X$ \\
\hline 187 & $\mathrm{X}$ & - & $X$ & - & $X$ & - & $X$ & $X$ \\
\hline 188 & $\mathrm{X}$ & - & $X$ & - & $\mathrm{X}$ & - & $X$ & $X$ \\
\hline 189 & $\mathrm{X}$ & - & $\mathrm{X}$ & - & $\mathrm{X}$ & - & $\mathrm{x}$ & $\mathrm{D}$ \\
\hline 190 & $\mathrm{X}$ & - & $X$ & $D$ & $\mathrm{D}$ & $X$ & $\mathrm{X}$ & $\mathrm{X}$ \\
\hline 191 & $\mathrm{D}$ & $X$ & $\mathrm{D}$ & - & $\mathrm{D}$ & $X$ & $\mathrm{X}$ & $X$ \\
\hline 192 & $\mathrm{X}$ & - & $\mathrm{X}$ & - & $\mathrm{X}$ & - & $\mathrm{X}$ & $X$ \\
\hline 193 & $\mathrm{X}$ & - & $\mathrm{X}$ & - & $\mathrm{X}$ & - & $\mathrm{D}$ & $\mathrm{D}$ \\
\hline 194 & $\mathrm{D}$ & $X$ & $\mathrm{D}$ & $X$ & $\mathrm{D}$ & $X$ & $X$ & $X$ \\
\hline 195 & $X$ & $D$ & $\mathrm{D}$ & - & $X$ & $D$ & $\mathrm{X}$ & $x$ \\
\hline 196 & $X$ & $D$ & $X$ & - & $X$ & - & $X$ & $X$ \\
\hline 197 & $\mathrm{D}$ & - & $\mathrm{X}$ & - & $X$ & $D$ & $\mathrm{X}$ & $\mathrm{D}$ \\
\hline 198 & $X$ & - & $\mathrm{X}$ & - & $X$ & - & $\mathrm{X}$ & $X$ \\
\hline 199 & $x$ & $D$ & $X$ & - & $\mathrm{X}$ & - & $X$ & $X$ \\
\hline
\end{tabular}




\section{Referências Bibliográficas}

[ABPM, 1985] Associação Brasileira de Produtores de Madeiras - Catalogo de normas de madeira serrada de pinus; Spectrum Comunicação Ltda; Caxias do Sul-RS; $1985 ; 34 \mathrm{p}$

[Abutaleb, 1989] Abutaleb, A.S. - "Automatic thresholding of gray-level pictures using two-dimensional entropy"; Computer Vision, Graphics, and Image Processing; vol. $47 ; 1989 ; 22-32$

[Ahuja, 19978] Ahuja, N. \& Rosenfeld, A. - "A note on the use of second-order gray-level statistics for threshold selection"; IEEE Trans. on Systems, Man, and Cybernetics; vol. SMC-8; 12; dez, 1978; 895-898

[Andersson, 1995] Andersson, C. \& Walter, F. - "Classification of compression wood using digital image analysis"; Forest Products Journal; vol. 45; $\mathrm{n}^{\circ} 11 / 12$; nov./dez. $1995 ; 87-92$

[Andrade, 1998] Andrade, M.G. - Caracterização de placas de madeira para fabricação de lápis, quanto a densidade aparente e o método de desdobro; Dissertação de mestrado a ser defendida no Depto. de Engenharia Elétrica - EESC - USP; maio, 1998

[Andrews, 1972] Andrews, H.C. - "Introduction to mathematical techniques in pattern recognition"; John Wiley \& Sons; New York; 1972; 242p.

[Ballard \& Brown, 1982] Ballard, D.H. \& Brown, C.M. - "Computer vision"; Prentice-Hall Inc., Englewood Cliffs; New Jersey; 1982;

[Batchelor, 1985] Batchelor, B \& Hill, D. - "Automated Visual Inspection"; IFS (Publications) Ltd and North-Holland; Bedford-UK; 1985; 560p. 
[Beghdadi, 1995] Beghdadi, Azeddine; Négrate, Alain Le; e Lesegno, Patrick Viaris de "Entropic thresholding using a block source model"; CVGIP: Graphical Models and Image Processing; vol. 57; ${ }^{\circ} 3$; maio, 1995; 197-205

[Beiguelman, 1996] Beiguelman, B.; Curso prático de bioestatística; Revista Brasileira de Genética; Ribeirão Preto; 1996; 254

[Bhanu, 1982] Bhanu, B. \& Faugeras, O. - "Segmentation of images having unimodal distribuitions"; IEEE Trans. on Pattern Analysis and Machine Intelligence; vol. PAMI-4; 1982; 408-419;

[Blue, 1993] Blue, J.L. - "Evaluation of pattern classifiers for fingerprint and OCR applications"; Technical Report 3162 - Computer Vision Laboratory- Maryland University; 1993

[Bortoletto Jr., 1993] Bortoletto Jr., G. - Indicações para a utilização de madeira de seis espécies e variedades de pinus na construção civil; Dissertação de mestrado apresentada na EESC - USP, junho, 1993

[Boukharouba, 1985] Boukharouba, S.; Rebordao, J. M. e Wendel, P. L. - "An amplitude segmentation method based on the distribuition function of an image"; Computer Vision Graphics Image Processing; vol. 29; 1985; 47-59;

[Brink, 1996] Brink, A.D. - "Using spatial information as an aid to maximum entropy image threshold selection"; Pattern Recognition Letters; vol. 17; 1996; 29-36

[Brink, 1996] Brink, A.D. \& Pendock, N.E. - "Minimum cross-entropy threshold selection; Pattern Recognition"; vol. 29; n 1; 1996; 179-188

[Broman, 1995] Broman, N.O. - "Visual Inspection of Features in scots pines wood surfaces: A qualitative study"; Forest Products Journal; vol. 45; n 3; mar, 1995; 61-66

[Burch, 1983] Burch, S.F.; Gull,S.F. \& Skilling, J. - "Image restoration by a powerful maximum entropy method"; Computer Vision, Graphics, and Image Processing; vol. 23; 1983; 113-128

[Butler, 1993] Butler, D.A.; Funck, J.W. \& Brunner, C.C.; An adaptative image preprocessing algorithm for defect detection in Douglas-fir veneer; Forest Products Journal; vol. 43; $\mathrm{n}^{\circ}$ 5; maio, 1993; 57-60

[Cassens, 1995] Cassens, D.L.; Feist, W.C.; Johnson, B.R. e De Groot, R. .. - "Selection and use of preservative-treated wood; Forest Products Society"; Madison-USA; $1995 ; 104 p$ 
[Castleman, 1979] Castleman,K.R. - "Digital Image Processing", Prentice-Hall, Inc., Englewood Cliffs, New Jersey, 1979.

[Castro, 1995] Castro, J.L. - "Fuzzy logic controllers are universal approximators"; IEEE Trans. on Systems, Man, and Cybernetics; vol. 25; $n^{\circ} 4$; abr, 1995; 629-635

[Chin \& Harlow, 1982] Chin, R.T. \& Harlow, C.A. - "Automated Visual Inspection: A survey"; IEEE Trans. on Pattern Analysis and Machine Intelligence; vol. PAMI-4; nº 6; nov.,1982; 557-573

[Chou, 1997] Chou, P.B.; Rao, A. R.; Sturzenbecker, M.C.; Wu, F.Y. e Brecher, V.H. "Automatic defect classification for semiconductor manufacturing"; Machine Vision and Aplications; vol. 9; ${ }^{\circ} 4 ; 1997 ; 201-214$

- [Chow, 1972] Chow, C. K. \& Kaneko, T. - "Automatic boundary detection of left ventricle from cineangiograms"; Computer Biomedics Research; vol. 5; 1972; 338-410

[Churchland, 1990] Churchland,P.M. \& Churchland,P.S. - "Could a Machine Think?", Scientific American, Vol.262, N¹, January 1990, pp.32-37.

[Clauson, 1991] Clauson, M. L. \& Wilson, J. B. - "Comparison of video and x-ray for scanning wood density"; Forest Products Journal; vol. 41; $\mathrm{n}^{\circ} 3$; mar, 1991; 5862

[Conners, 1980] Conners, R.W.; Harlow, C.A. - "A theoretical comparison of texture algorithms"; IEEE Trans. on Pattern Analysis and Machine Intelligence; PAMIvol. $2 ; n^{0} 3$; maio, 1980; 204-222

[Conners, 1983] Conners, R.W.; McMillin, C.W.; Lin, K. e Vasquez-Espinosa, R.E. "Identifying and locating surface defects in woods: Part of an automated lumber processing system"; IEEE Trans. on Pattern Analysis and Machine Intelligence; vol. PAMI-5; nº 6 nov, 1983; 573-583

[Cover, 1967] Cover, T.M. \& Hart, P.E. - "Nearest neighbor pattern classification"; IEEE Trans. on Information Theory, vol. IT-13, $\mathrm{n}^{\circ} 1$; jan., 1967; 21-27

[Dagli, 1996] Dagli, C.H. \& Tsunekawa, S. - "Automatic PCB inspection algorithmı: A survey"; Computer Vision and Image Understanding; vol. 63; $\mathrm{n}^{\circ} 2$; mar, 1996; 287-313

[Darwish \& Jain, 1988] Darwish, A.M \& Jain, A.K. - "A rule based approach for visual pattern inspection"; IEEE Trans. on Pattern Analysis and Machine Intelligence; vol. 10 ; 1 ; jan., 1988; 56-68

[Davies, 1991] Davies, E.R. - "Computer Vision and Image Processing"; Chapman and Hall; London; 1991; 
[Deravi, 1983] Deravi, F. \& Pal, S. K. - "Gray level thresholdingusing second-order statistics"; Pattern Recognition Letters; vol. 1; 1983; 417-422

[Djouadi, 1997] Djouadi, A. \& Bouktache, E. - "A fast algorithm for the nearest-neighbor classifier"; IEEE Transc. on Pattern Analysis and Machine Intelligence, vol. 19, $\mathrm{n}^{0} 3$, mar., 1997; 277-281

[Duda, 1973] Duda, R.O. \& Hart, P.E. - "Pattern classification and scena analysis"; John Wiley \& Sons; New York; 1973; 482p.

[Edwards, 1971] Edwards, E.; Introdução à teoria de informação; Ed. Cultrix; São Paulo; $1971 ; 151 \mathrm{p}$.

- [Eltoft, 1995] Eltoft, Torbjorn; deFigueiredo, J.P. - "Illumination control as a means of enhancing image features in active vision systems"; IEEE Transactions on Image Processing; vol. $4 ; \mathrm{n}^{\circ} 11$; nov, 1995; 1520-1530

[Ferreira, 1975] Ferreira, A.B.H.; Novo dicionário da língua portuguesa; d. Nova Fronteira; Rio de Janeiro; 1975;

[Findlay, 1975] Findlay, W.P.K. - "Timber: Properties and Uses"; William Clowes \& Sons; London; 1975; 224p

[Fleury, 1996] Fleury, M; Hayat, L.; Clark, A.F. - "Parallel entropic auto-thresholding; Image and Vision Computing"; vol. 14; n 4; Maio, 1996; 247-263

[Fu, 1974] Fu,K.S. - "Syntactic Methods in Pattern Recognition.", Academic Press, New York, 1974.

[Fu, 1976] Fu,K.S. - "Digital Pattern Recognition.", Springer-Verlag, Berlin Heidelberg, 1976.

[Fu, 1981] Fu, K.S. \& Mui, J.K. - "A survey on image segmentation"; Pattern Recognition; vol. $13 ; 1981 ; 3-16$

[Fukunaga, 1990] Fukunaga, K. - "Introduction to statistical pattern recognition"; Academic Piess Inc.; San Diego; 1990; 591p.

[Fukushima, 1988] Fukushima,K. - "A Neural Network for Visual Pattern Recognition.", IEEE Computer, Vol.21, №3, March 1988, pp.65-75.

[Funt, 1987] Funt, B.V \& Bryant, E.C. - "Detection of internal log defects by automatic interpretation of computer tomography images"; Forest Products Journal; vol. $37 ; \mathrm{n}^{\circ} 1$; jan, $1987 ; 56-62$ 
[Gonzaga, 1991] Gonzaga, A. - Tecnologia para o reconhecimento do formato de objetos tri-dimensionais; Tese de doutoramento apresentada ao IFSC - USP; 1991

[Gonzales \& Wintz, 1987] Gonzales, R.C. \& Wintz, P. - "Digital Image Processing"; Addison Wesley Publishing Company; New york; 1987;

[Gonzales \& Woods, 1993] Gonzales, R.C. \& Woods, R.E. - "Digital Image Processing"; Addison-Wesley Publishing Company; USA; 1993; 716p

[Gonzales, 1993] Gonzales, R.C. \& Woods, R.E. - "Digital Image Processing"; AddisonWesley Publishing Company; USA; 1993; 716p

[Gotlieb, 1990] Gotlieb, C.C. \& Kreyszig, H.E. - "Texture descriptors based on cooccurrence matrices"; Computer Vision, Graphics, and Image Processing; vol. $51 ; 1990 ; 71-86$

[Griffin, 1992] Griffin, P.M. \& Villalobos, R. - "Process capability of automated visual inspection systems"; IEEE Trans. on Systems, Man, and Cybernetics; vol. 22; $\mathrm{n}^{\circ} 3$; jun, 1992; 441-448

[Gull, 1984] Gull, S.F. \& Skilling, J. - "Maximum entropy method in image processing"; IEE Proceedings; vol. 131-F; $\mathrm{n}^{\circ} 6$; out, 1984; 646-659

[Han,1989] Han, M.; Jang, D. e Foster, J. - "Inspection of 2-D objects using pattern matching method"; Pattern Recognition; vol. 22; $n^{\circ} 5 ; 1989 ; 567-575$

[Hannah, 1995] Hannah, I.; Patel, D. e Davies, R. - "The use of variance and entropic thresholding methods for image segmentation"; Pattern Recognition; vol. $28 ; \mathrm{n}^{\circ}$ $8 ; 1995 ; 1135-1143$

[Hara, 1998] Hara, Y.; Doi, H.; Karasaki, K. e Iida, T. - "A system for PCB automated inspection using fluorescent light"; IEEE Trans. on Pattern Analysis and Machine Intelligence; vol. 10; 1; 1988; 69-78

[Haralick, 1973] Haralick, R.M.; Shanmugam, K. e Distein, I. - "Textural features for image classification"; IEEE Trans. on Systems, Man, and Cybernetics; vol. SMC-3; n 6; nov, 1973; 610-621

[Hayat, 1996] Hayat, L.; Fleury, M. e Clark, A. F. - "Candidate functions for a parallel multi-level thresholding technique"; Graphical Models and Image Processing; vol. $58 ; n^{\circ} 4$; jul, 1996; 360-381

[Hellmeistre, 1972] Hellmeister, J.C; Sobre a determinação das carłcterísticas físicas da madeira; Tese de doutoramento; São Carlos; dezembro 1972; 
[Hirata, 1983] Hirata, Y. \& Tanaka, H. - "Automatic visual inspection of semicondutor wafer"; Bulletin Japan Soc. of Prec. Engg.; vol. 17; n 3; 1983; 197-198

[Ho, 1994] Ho, T.K.; Hull, J.J. e Srihari, S.N. - "Decision combination in multiple classifier systems"; IEEE Trans. on Pattern Analysis and Machine Intelligence; vol. 16; jan, 1994; 66-75

[Hoag, 1988] Hoag, M. \& McKimmy, M.D. - "Direct scanning x-ray densitometry of thin wood sections"; Forest Products Journal; vol. 23; n² 26; jan, 1988; 23-26

[Horn, 1986] Horn, B.K.P. - "Robot vision"; The MIT Press; Massachusetts; 1986; 509

[Huang, 1995] Huang, L. \& Wang, M. J. - "Image thresholding by minimizing the measures of fuzziness"; Pattern Recognition; vol. 28; $n^{\circ} 1 ; 1995 ; 41-51$

[Jain \& Binford, 1991] Jain, R.C. \& Binford, T.O. - "Ignorance, myopia, and naiveté in computer vision systems"; CVGIP: Image Understanding; vol. 53; $\mathrm{n}^{\circ} 1$; jan, $1991 ; 112-117$

[Jain, 1995] Jain, R.C.; Kasturi, R. e Schunck, B.G. - "Machine Vision"; McGraw-Hill; New York; 1995; 512p.

[Johnson, 1992] Johnson, R.A. \& Bhattacharyya - "Statistics principles and methods"; John Wiley \& Sons; New York; 1992; 686p.

[Jolion, 1994] Jolion, Jean-Michel - "Computer vision methodologies"; CVGIP: Image Understanding; vol. 59; $n^{\circ} 1$; jan, 1994; 53-71

[Kapur, 1985] Kapur, J. N.; Sahoo, P. K. e Wong, A. K. C. - "A new method for gray-level picture thresholding using the entropy of the histogram"; Computer Vision Graphics Image Processing; vol. 29; 1985; 273-285

[Karu, 1996] Karu, K.; Jain, A.K. - "Fingerprint classification"; Pattern Recognition; vol. $29 ; n^{\circ} 3 ;$ mar, 1996; 389-404

[Kittler, 1985] Kittler, J. \& Illingworth, J. - "On threshold selection using clustering criteria"; IEEE Trans. on Systems, Man, and Cybernetics; vol. SMC-15; $\mathrm{n}^{\circ} 5$; out, $1985 ; 652-655$

[Kittler, 1986] Kittler, J, \& Illingworth, J. - "Minimum error thresholding"; Pattern Recognition; vol. $19 ; \mathrm{n}^{\circ} 1 ; 1986 ; 41-47$

[Kohler, 1981] Kohler, R. - "A segmentation system based on thresholding"; Computer Vision Graphics Image Processing; vol. 15; 1981; 319-338 
[Koivo, 1989] Koivo, A.J. \& Kim, C.W. - "Automatic classification of surface defects on red oak boards"; Forest Products Journal; vol. 39; nº 9; set, 1989; 22-30

[Kullback, 1959] Kullback, S.; "Information Theory and statistics"; John Wiley; New York; 1959

[Kung, 1982] Kung, H.T. - "Why systolic architectures?"; Computer; jan.1982; 37-46

[Levine, 1985] Levine, Martin D. - "Vision in Man and Machine"; Mcgraw-Hill, Inc.; New York; 1985;

[Li, 1993] Li, C.H. \& Lee, C.K. - "Minimum cross entropy thresholding"; Pattern Recognition; vol. $26 ; n^{\circ} 4 ; 1993 ; 617-625$

[Lin, 1991] Lin, J. - "Divergence measures based on the Shannon entropy"; IEEE Trans. on Information theory; vol. $37 ; \mathrm{n}^{\circ} 1$; jan, 1991; 145-151

[Low, 1991] Low, A. - "Introdutory computer vision and image processing"; McGraw-Hill; London; 1991;

[Marr, 1982] Marr, D. - "Vision - A computacional investigation into the human representation and processing of visual information"; W.H Freeman and Co.; New York; 1982; -

[McLauchlan, 1973] McLauchlan, T.A.; Norton, J.A. e Kusec, D.J. - "Slope-of-grain indicator"; Forest Products Journal; vol. 23; ${ }^{\circ}$ 5; maio, 1973; 50-551

[McMillin, 1984] McMillin, C.W.; Conners, R.W. e Huber, H.A. - "ALPS - A potential mew automated lumber processing system"; Forest Products Journal; vol. 34; $\mathrm{n}^{\circ}$ 1 ; jan, 1984; 13-20

[Minsky, 1961] Minsky,M. - "Steps toward artificial intelligence.", Proceedings of IRE, Vol.49, 1961, pp.8-30.

[Moganti, 1996] Moganti, M.; Ercal,F.; Dagli, C.H. e Tsunekawa, S. - "Automatic PCB inspection algorithms: a survey"; Computer Vision and Image Understanding; vol. $63 ; \mathrm{n}^{\circ} 2$; mar, $1996 ; 287-313$

[Morii, 1995] Morii, Fujiki - "An image thresholding method using a minimum weighted squared-distortion criterion"; Pattern Recognition; vol. 28; ${ }^{0} 7 ; 1995 ; 1063$ 1071

[Morrin, 1974] Morrin, T. H. - "A black-white representation of a gray scale picture"; IEEE Trans. on Computer; vol. 23; 1974; 184-186 
[Mostaghimi, 1997] Mostaghimi, M. - "Bayesian estimation of a decision using information theory"; IEEE Trans on Syst, Man, and Cyb Part A:Systems and Humans; Vol. $27 ; \mathrm{n}^{\circ} 4$; jul, 1997; 506-517

[Nandhakumar, 1985] Nandhakumar,N. \& Aggarwal,J.K. - "The Artificial Intelligence Approach to Pattern Recognition - A Perspective and an Overview.", Pattern Recognition, Vol.18, No6, 1985, pp.383-389.

[Newman, 1995] Newman, T.S. \& Jain, A.K. - "A survey of automated visual inspection"; Computer Vision and Image Understanding; vol. 61; 2; 1995; 231-262

[Otsu, 1979] Otsu, Nobuyuki - "A threshold selection method from gray-level histograms"; IEEE Trans. on Systems, Man, and Cybernetics; vol. SMC-9; $\mathrm{n}^{\circ} 1$; jan, 1979; $62-66$

[Pal, 1989] Pal, N.R. \& Pal, S.K. - "Entropic thresholding"; Signal Processing; vol. 16; n 2; fev, 1989; 97-108

[Pal, 1991] Pal, N.R. \& Pal, S.K. - "Entropy: A new definition and its applications"; IEEE Trans. on Systems, Man and Cybernetics; vol. 21; n ${ }^{\circ}$ 5; out, 1991; 1260-1270

[Pal, 1993] Pal, N. R. \& Bhandari, D. - "Image thresholding: Some new techniques"; Signal Processing; vol. 33; $\mathrm{n}^{\circ} 2$; ago, 1993; 139-158

[Pal, 1996] Pal, N.R. - "On minimum cross-entropy thresholding"; Pattern Recognition; vol. $29 ; n^{\circ} 4 ; 1996 ; 575-580$

[Papamarkos, 1994] Papamarkos, N. \& Gatos, B. - "A new approach for multilevel threshold selection"; Graphical Models and Image Processing; vol. 56; 1994; $357-370$

[Pavlidis, 1982] Pavlidis, T. - "Algorithms for graphics and image processing"; Computer Science Press, Inc; Rockville, MD, USA; 1982; 413

[Petrucci, 1975] Petrucci, E.G.R.; Materiais de construção; Editora Globo; Porto Alegre; $1975 ; 435 p$

[Pun, 1980] Pun, T. - "A new method for gray level picture thresholding using the entropy of the histogram"; Signal Processing; vol. 2; $\mathrm{n}^{0} 3$; jul, 1980; 223-237

[Pun, 1981] Pun, T. - "Entropic thresholding, a new approach"; Computer Graphics and Image Processing; vol. 16; 1981; 210-239

[Ratha, 1996] Ratha, N.K.; Karu, K.; Chen, S. e Jain, A.K. - "A real-time matching system for large fingerprint databases"; IEEE Trans. on Pattern Analysis and Machine Intelligence, vol. 18, $\mathrm{n}^{\circ}$ 8, ago, 1996, 799-813 
[Reddi, 1984] Reddi, S.S.; Rudin, S.F e Keshavan, H.R. - "An optimal multiple threshold scheme for image segmentation"; IEEE Trans. on Systems, Man and Cybernetics; vol. SMC-14; nº 4; jul/ago 1984; 661-665

[Rhemrev, 1991] Rhemrev, J; Rhemrev, R. \& Lemaster, R. - "Laser scanning for the detection of twist or warp in pencil slats"; Forest Products Journal; vol. 43; $\mathrm{n}^{\circ}$ 2; fev, 1993; 29-36

[Rhemrev, 1994] Rhemrev, J; Rhemrev, R.; Smith, H. \& Waltkin, L. - "The development of a longitudinal moisture gradient meter for pencil slats"; Forest Products Journal; vol. $41 ; \mathrm{n}^{\circ} 4$; abril, 1991; 58-62

[Rodrigues, 1996] Rodrigues, E.L.L. \& Roda, V.O. - Determinação dinâmica de "threshold" por avaliação local de bordas em imagens, implementada em arranjos sistólicos; III Forum Nacional de Ciência e Tecnologia em Saúde; Campos de Jordão, out., 1996.

[Rosenfeld, 1981] Rosenfeld, A. \& Smith, R. C. - "Thresholding using relaxation"; IEEE Trans. on Pattern Analysis and Machine Intelligence; vol. PAMI-3; 1981; 598606

[Rosenfeld, 1983] Rosenfeld, A. e De LA Torre, P. - "Histogram concavity analisys as an aid in threshold selection"; IEEE Trans. on Systems, Man, and Cybernetics; vol. SMC-13; 1983; 231-235

[Russ, 1992] Russ, J.C. - "Computer-Assisted microscopy- the measurement and analysis of images"; Plenum Press; New York; 1992; 453p.

[Russ, 1994] Russ, J.C. - "The image processing handbook - Second edition"; CRC Press; New York; 1994; 674p.

[Sahoo, 1988] Sahoo, P.K.; Soltani, S.; Wong, A.K.C. e Chen, Y.C. - "A survey of thresholding techniques"; Computer Vision, Graphics, and Image Processing; vol. $41 ; 1988 ; 233-260$

[Shannon, 1948] Shannon, C.E. - "A Mathematical Theory of Communication"; The Bell System Technical Journal; vol. 27; $n^{\circ} 3 ; 1948 ; 379-423$

[Siegel 1977] Siegel, S; Estatística não-paramétrica (Para as ciências do comportamento); McGraw-Hill do Brasil Ltda; São Paulo; 1977; 350

[Skilling, 1984] Skilling, J. \& Gull, S.F. - "The entropy of an image"; SIAM-AMS Proceedings; vol. 14; 1984; 167-189 
[Sobey, 1989] Sobey, P.J. \& Semple, E.C. - "Detection and sizing visual features in wood using tonal measures and classification algorithm"; Pattern Recognition; vol. $22 ; \mathrm{n}^{\circ} 4 ; 1989 ; 367-379$

[Sonka, 1993] Sonka, M.; Hlavac, V. e Boyle, R. - "Image processing, analisys and machine vision"; Chapman \& Hall; London; 1993; 555p.

[Sprague, 1991] Sprague, A.P., Donahue, M.J. e Rokhlin, S.I. - "A method for automatic inspetion of printed circuit boards"; CVGIP: Image Understanding; vol. $54 ; \mathrm{n}^{\circ}$ 3; nov, 1991; 401-415

[Steele, 1991] Steele, P.H.; Neal, S.C.; McDonald, K.A \& Cramer, S.M. - "The slope-ofgrain indicator for defect detection in unplaned hardwood lumber"; Forest Products Journal; vol. $41 ; n^{0} 1$; jan, 1991; 15-20

[Szymani, 1981] Szymani, R. \& McDonald, K. A. - "Defect detection in lumber: state of the art"; Forest Products Journal; vol. $31 ; n^{\circ} 11$; nov., 1981; 34-44

[Thomas, 1995] Thomas, A.D.H.; Rodd, M.G.; Holt, J.D. e Neil, C.J. - "Real-time industrial visual inspection: a review"; Real-Time Imaging; vol. 1; 1995; 139158

[Tolba, 1997] Tolba A.S. \& Abu-Rezeq, A.S. - "A self-organizing feature map for automated visual inspection of textile products"; Computers in Industry; vol. $32 ; 1997 ; 319-333$

[Tou, 1974] Tou,J.T. \& Gonzalez,R.C. - "Pattern Recognition Principles", Addison-Wesley Publ. Co., Reading, Massachusetts, 1974.

[Trier, 1996] Trier, O.D.; Jain, A.K. E Taxt, T. - "Feature extraction methods for character recognition - a survey"; Pattern Recognition; vol. 29; n 4; 1996; 641-662

[Tsai, 1995] Tsai, Du-Ming - "A fast thresholding selection procedure for multimodal and unimodal histograms"; Pattern Recognition Letters; vol. 16; jun, 1995; 653-666

[Ullman, 1974] Ullman, J. R. - "Binarization using associative addressing"; Pattern Kecognition; vol. 6; 1974; 127-135

[Venkatesh, 1995] Venkatesh, S. \& Rosin, P.L. - "Dynamic threshold determination by local and global edge evaluation"; Graphical Models and Image Processing; vol. $57 ; \mathrm{n}^{\circ} 2$; mar, $1995 ; 146-160$

[Venkateswarlu, 1995] Venkateswarlu, N.B. \& Boyle, R.D. - "New segmentation techniques for document image analysis"; Image and Vision Computing; vol. $13 ; n^{\circ} 7 ; 1995 ; 573-583$

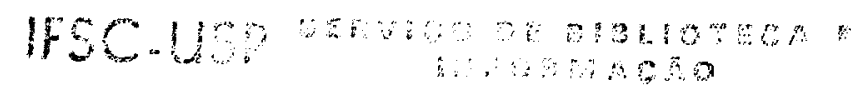


[Wagner, 1991] Wagner, F.G.; Steele, P.H.; Kumar, L. \& Butkovic, D. - "Computer grading of southern pine lumber"; Forest Products Journal; vol. 41; ${ }^{\circ} 2$; 1991; 27-29

[Wang, 1984] Wang, S. \& Haralick, R. M. - "Automatic multithreshold selection"; Computer Vision Graphics Image Processing; vol. 29; 1984; 46-67

[Wang, 1989] Wang, D. \& Shihari, S.N. - "Classification of newspaper image blocks using texture analysis"; Computer Vision, Graphics, and Image Processing; vol. 47; $1989 ; 327-352$

[Wechsler, 1990] Wechsler, H. - "Computational vision"; Academic Press, Inc.; San Diego; 1990; 559

- [Weng, 1994] Weng, J. \& Huang, T.S. - "Performance of computer vision algorithms"; CVGIP: Image Understanding; vol. $60 ; \mathrm{n}^{\circ} 2$; set, 1994; 253-256

[West, 1983] West, P.C. - "Machine vision in practice" - “, IEEE Transactions on Industry applications; IA-19; 5; 1983; 794-801

[Weszka, 1978] Weszka, Joan S. - "A survey of threshold selection techniques"; Computer Graphics and Image Processing; vol. 7; 1978; 259-265

[Weszka, 1978] Weszka, J.S. \& Rosenfeld, A. - "Threshold evaluation techniques"; IEEE Trans. on Systems, Man, and Cybernetics; vol. SMC-8;n 8; ago, 1978; 622629

[Wildes, 1996] Wildes, Richard P.; Asmuth, Jane C.; Green, Gilbert L.; Hsu, Steven "Machine-vision system for iris recognition"; Machine Vision and Applications; vol. 9; $\mathrm{n}^{\circ} 1 ; 1996 ; 1-8$

[Wong, 1989] Wong, A.K.C. \& Sahoo, P.K. - "A grey-level threshold selection method based on maximum entropy principle"; IEEE Trans. on Systems, Man and Cybernetics; vol. SMC-19; $\mathrm{n}^{\circ}$ 4; ago, 1989; 866-871

[Woods, 1997] Woods, K.; Kegelmeyer, W.P. e Bowyer, K. - "Combination of multiple classifiers using local accuracy estimates"; IEEE Trans. on Pattern Analysis and Machine Intelligence; vol. $19 ; \mathrm{n}^{\circ} 4$, abr, 1997; 405-410

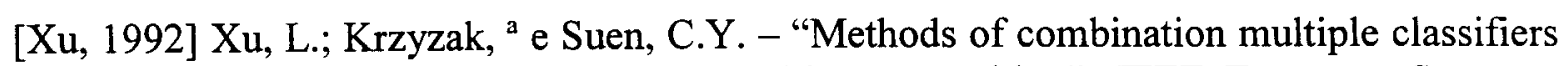
and their applications to handwriting recognition"; IEEE Trans. on Systems, Man and Cybernetics; vol. 22; $n^{\circ} 3 ; 1992 ; 418-435$

[Yang, 1994] Yang, Jeng-Dang; Chen, Yung-Sheng e Hsu, Wen-Hsing - "Adaptive thresholding algorithm and its hardware implementation"; Pattern Recognition Letters; vol. 15; fev, 1994; 141-150 
[Yen, 1995] Yen, J.C.; Chang, F.J. and Chang, S. - "A new criterion for automatic multilevel thresholding"; IEEE Trans. on Image Processing; vol. 4; ${ }^{\circ}$ 3; 1995 ; 370-378

[Young, 1986] Young, T.Y. \& Fu, K.S. - "Handbook of Pattern recognition and image processing"; Academic Press, Inc; San Diego, 1986; 705Pp.

[Zadeh, 1965] Zadeh, L. - "Fuzzy sets"; Information and Control; 8; 1965; 338-353

[Zhang, 1996] Zhang, Y.J - "Survey on evaluation methods for image segmentation"; Pattern Recognition; vol. 29; n ${ }^{\circ}$ 8; 1996; 1335-1346 


\section{Apêndice 1}

\section{COMPONENTES E CARACTERÍSTICAS \\ PRINCIPAIS UTILIZADOS NA AQUISIÇÃO DAS}

\section{IMAGENS DAS PLACAS}

Componentes utilizados:

- Câmera:

Fabricante: Hitachi

Modelo: KP-100

Caracteristicas gerais:

* utiliza dispositivo de imagem em estado sólido com $570 \times 485$ "pixels"

* circuito supressor de branco dinâmico assegura a qualidade da imagem mesmo em imagens com alto contraste

* sem distorção geométrica

- "Frame grabber":

Fabricante: Data Translation

Modelo: DT2858 e DT2851 


\section{Características gerais:}

* (DT2851) "Frame grabber"

- digitaliza um quadro em $1 / 30$ segundos

- converte o sinal de vídeo em 480 linhas com 512 "pixels" por linha e 8 bits por "pixel"

* (DT2858) placa de processamento auxiliar

- possui duas portas assíncronas para transferência de dados com a DT2851

- possui unidade lógica aritmética de16 bits (300 ns por "pixel")

- opera em quadros de imagens de 512x512 "pixels"

- opera com tabelas de conversão (tamanho $=8 \times 256$ com 16 bits)

- além de outras funções como geração de histogramas, "zoom", rolamento horizontal e vertical, etc...

- Microcomputador

- PC-compatível 